This document is downloaded from DR-NTU (https://dr.ntu.edu.sg) Nanyang Technological University, Singapore.

Wear behaviour of NiTi shape memory alloys

Yan, Lina

2016

https://hdl.handle.net/10356/68803

https://doi.org/10.32657/10356/68803 


\section{NANYANG TECHNOLOGICAL UNIVERSITY}

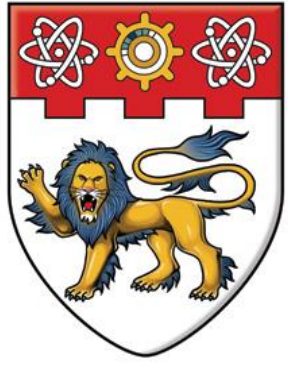

NANYANG TECHNOLOGICAL

UNIVERSITY

WEAR BEHAVIOUR OF NITI SHAPE MEMORY

ALLOYS

by

LINA YAN

Supervisor: Associate professor YONG LIU

A dissertation submitted to Nanyang Technological University in partial fulfillment of the requirements for the degree of DOCTOR OF PHILOSOPHY

SCHOOL OF MECHANICAL AND AEROSPACE ENGINEERING

July 2015 


\section{Preface}

This thesis is submitted for the degree of Doctor of Philosophy in the Nanyang Technological University. The research described herein was conducted by the author under supervision of Associate Professor Yong Liu, in the School of Mechanical and Aerospace Engineering at the Nanyang Technological University, between August 2009 and July 2015.

The author wishes to declare that, except for commonly understood concepts and previous work that with explicit references, all of the contents of this thesis are original. This thesis has not been submitted to any other University or institution for any degree, diploma or any other qualifications.

This thesis contains 202 pages with approximately 45500 words.

\section{LINA YAN \\ NANYANG TECHNOLOGICAL UNIVERISTY}

31 July 2015 


\section{Acknowledgements}

Firstly, the author extends the warmest and heartfelt thanks to her supervisor Associate Professor Yong Liu, for his great patient, inspiration, keen insight, enthusiasm and careful guidance throughout years of studies.

The author likes to thank Associate Professor Erjia Liu, for his great help and support on this study.

The author likes to thank the group members, Dr. Baomin Wang, Dr. Shuiyuan Yang, Dr. Liangliang Gou, Dr. Joanne, Teoh Ee Mei, for their friendship, encouragement and help.

The author likes to thank technicians in the Tribology Lab, Manufacturing Lab and Materials Lab for their generous help.

Finally yet importantly, the author would like to thank her dear friends and family members for their deep love and everlasting support.

The author gratefully acknowledges the financial support from Nanyang Technological University through a research scholarship.

Lina Yan

July 2015 


\section{Abstract}

NiTi shape memory alloys have been widely researched for tribology related applications such as biomedical devices and micro-electro-mechanical system (MEMS) devices. Micro-scale wear is a critical issue in such applications, which may trigger an inflammation of the human body, or result in a malfunction of MEMS devices. Many studies have compared the wear resistance of NiTi SMA with conventional wear resistant materials. However, a systematic study on the wear behaviour of NiTi SMA has rarely being reported. This study aims at understanding the wear behaviour of NiTi SMA, with the hope to provide a guideline for its better use as wear resistant materials. Ball-on-disk sliding wear tests and reciprocating wear tests were conducted, and an alumina $\left(\mathrm{Al}_{2} \mathrm{O}_{3}\right)$ ball was used as counter-body. The effect of major influential factors on the wear behaviour of NiTi SMAs were investigated. Those influential factors including the temperature, applied load, deformation mode, wear cycles, and sliding speed. The deformation mechanisms involved in the wear process were revealed in consideration of the surface wear features, coefficients of friction, stress-strain curves, estimated contact stresses, and microstructures of NiTi SMA. The results can provide guidelines for the effective use of NiTi SMAs as wear resistant materials.

In particular, when the forged ingot $\mathrm{Ni} 48.2 \mathrm{at} \% \mathrm{Ti}$ SMA was studied, three surface degradation stages were identified in the martensitic state, namely, a near-zero wear stage, a transition wear stage and an abrasive wear stage. Those degradation stages are related to the stable evolution of the coefficient of friction and surface wear features. A special wear feature, herein referred to as the "crown-like structure", was observed for the first time. The crown-like structure was produced in the near-zero and transition wear stage. For the flat annealed $\mathrm{Ni} 50.9 \mathrm{at} \% \mathrm{Ti}$ 
SMA, two wear modes were identified in the austenitic state. Mode $I$ is temperature-sensitive and occurred when $A_{\mathrm{f}}<T<M_{\mathrm{d}}$. In this mode, the wear process was dominated by the interplay between the contact stress, critical stress for stress-induced martensitic transformation, and the shape recovery property. Mode II occurs when $T>M_{\mathrm{d}}$. This mode is less temperature-sensitive within the testing range. In this mode, the austenitic NiTi loses its super-elasticity and obeys a conventional deformation sequence. Furthermore, the wear behaviour of the forged ingot $\mathrm{Ni} 48.2$ at\% Ti SMA was studied in three temperature regimes where different phases were present, that is, fully martensitic phase when $T<M_{\mathrm{f}}$, fully austenitic phase when $M_{\mathrm{f}}<T<A_{\mathrm{f}}$, and martensitic phase coexisted with austenitic phase when $T>A_{\mathrm{f}}$. When $T<M_{\mathrm{f}}$, it was observed that the coefficient of friction decreased initially and thereafter stabilized at a lower value with increasing wear cycles. Further decrease was noticed when the temperature approached the $A_{\mathrm{f}}$. When tested above the $A_{\mathrm{f}}$, the coefficient of friction decreased more significantly under higher loads. Different types of wear behaviour originated from different deformation mechanisms involved in the wear process, particularly, the martensite detwinning process, the stress-induced phase transformation process, and the superimposed plastic deformation.

This study can provide a guideline in applications of NiTi SMAs as wear-resistant materials. For example, since mechanical properties of NiTi SMAs are close to those of cortical bones, NiTi SMA based implants such as joint replacements, bone plates, and spine fracture fixations were developed. However, complex wear modes on the surface may cause undesired reactions from neighboring tissues, leading to a serious inflammation of the human body. Based on the fundamental understandings of the wear behaviour of NiTi SMAs, the surface degradation process of the implants can be predicted. This has great potential in improving the service life and safety factors of the NiTi SMA based implants/devices. 
Keywords: NiTi shape memory alloys; shape memory effects; super-elasticity; sliding wear; deformation mechanisms. 


\section{List of publications}

1. Wear behaviour of martensitic NiTi shape memory alloy under ball-on-disk sliding wear tests.

L. Yan, Y. Liu, E. Liu,

Tribology International 66, 219 (May 2013).

2. Effect of temperature on the wear behaviour of NiTi shape memory alloy.

L. Yan, Y. Liu,

Journal of Materials Research 30, 186 (Jan 2015).

3. Wear behaviour of austenitic NiTi shape memory alloy.

L. Yan, Y. Liu,

Shape Memory and Superelasticity 1, 58 (April 2015).

4. Effect of deformation mode on the wear behaviour of NiTi shape memory alloys.

L. Yan, Y. Liu,

Shape Memory and Superelasticity, 1 (May 2016), Special issue: research on biomedical shape memory alloys, invited paper. 


\section{Table of contents}

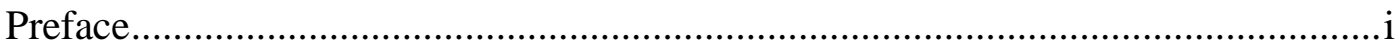

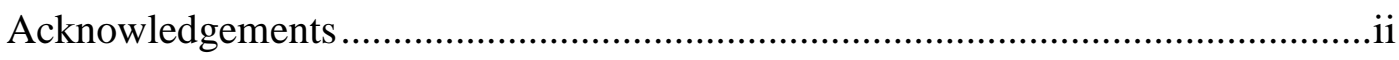

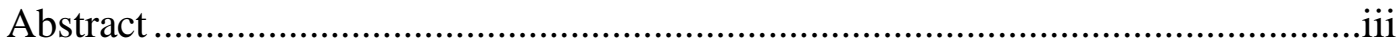

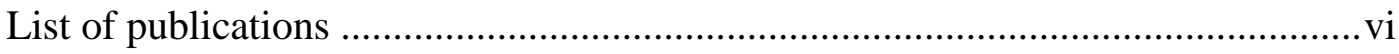

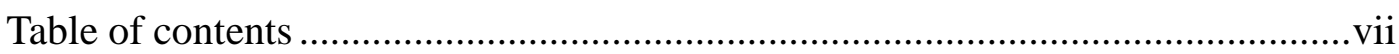

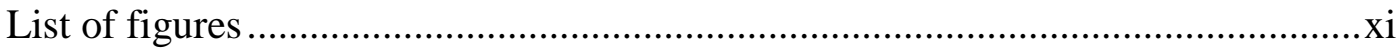

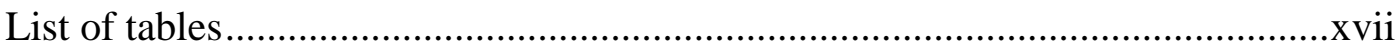

List of Abbreviations and Symbols ...................................................................

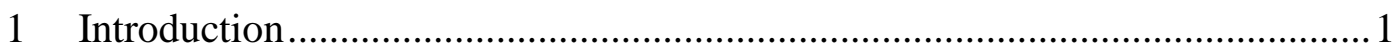

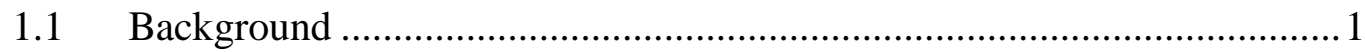

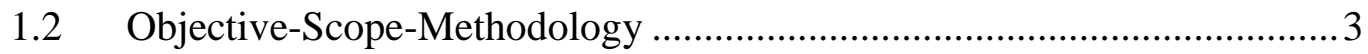

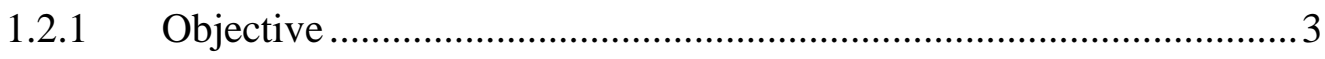

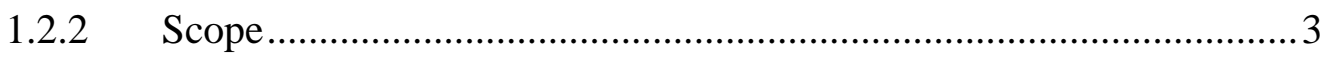

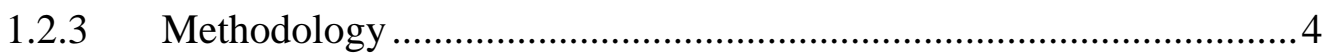

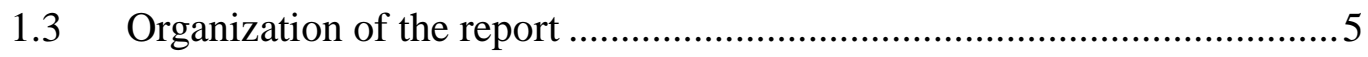

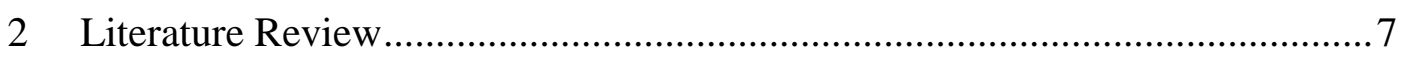

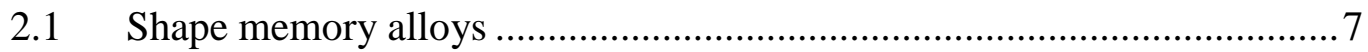

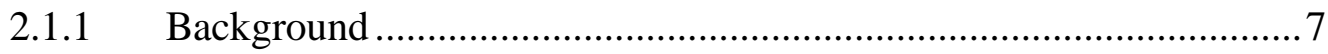

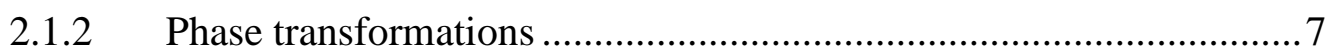

2.1.3 Shape memory effect and super-elasticity .................................. 11

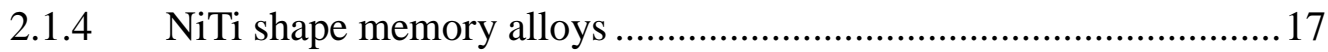

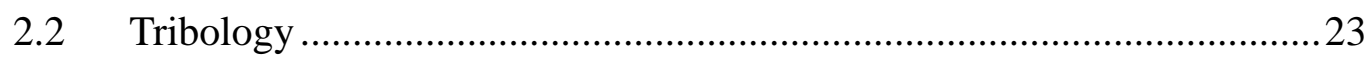

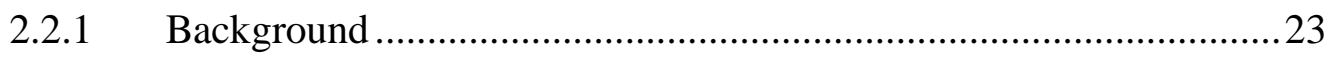

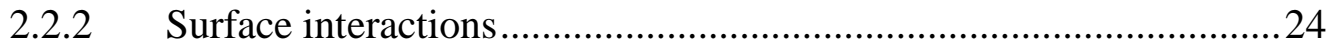

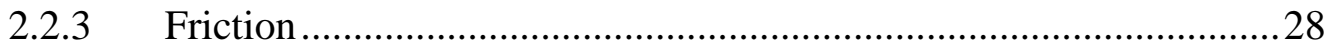

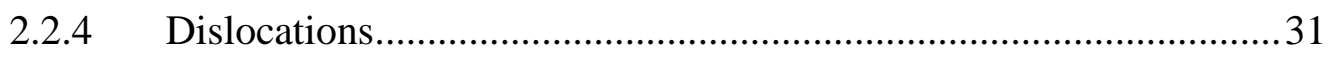

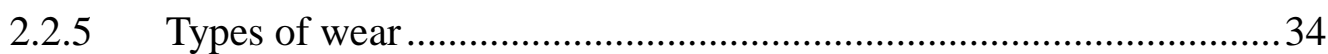




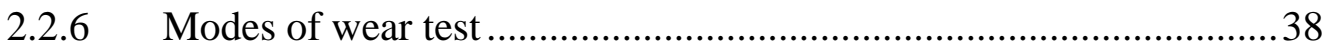

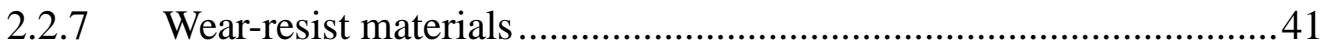

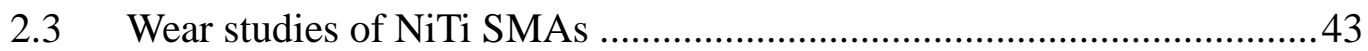

2.3.1 Overview of past and recent progresses on the wear study of NiTi

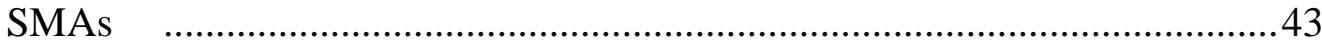

2.3.2 Wear studies on the martensitic NiTi SMAs ....................................44

2.3.3 Wear studies on the austenitic NiTi SMAs ...................................46

2.3.4 Simulation/modeling studies of the wear behaviour of NiTi SMAs.49

2.3.5 Influential factors on the wear behaviour of NiTi SMAs ................51

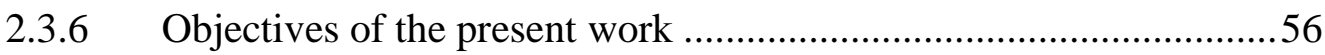

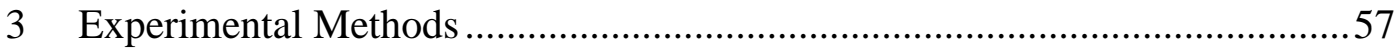

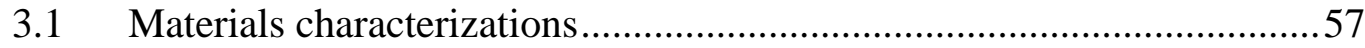

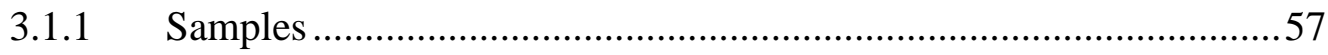

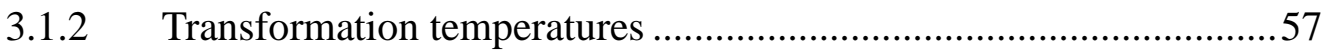

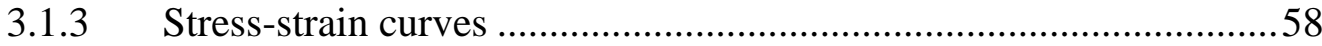

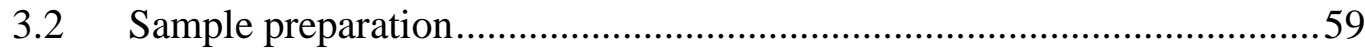

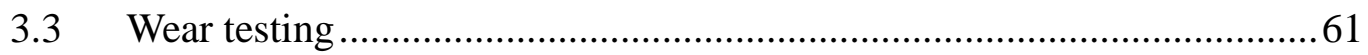

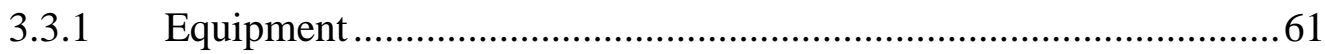

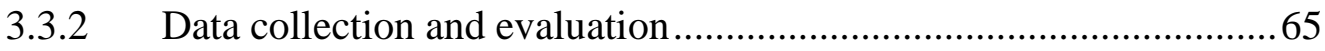

4 Wear Behaviour of Stable Martensitic NiTi SMA ….......................................69

4.1 Wear resistance of forged ingot Ni 48.2 at\% Ti SMA............................69

4.1.1 Under ball-on-disk sliding wear mode ...........................................69

4.1.2 Under ball-on-disk reciprocating wear mode ................................77

4.1.3 Summary on the coefficient of friction and wear volume ................82

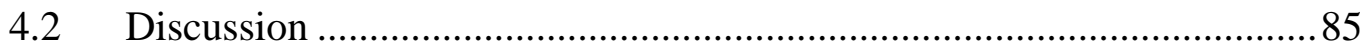

4.2.1 Deformation mechanisms and contact stress distributions ..............85

4.2.2 Degradation stages of martensitic NiTi SMA …............................... 87

4.2.3 Effect of deformation mode on the wear behaviour of martensitic 
NiTi SMA

92

4.3 Summary 94

5 Wear Behaviour of Stable Austenitic NiTi SMA .96

5.1 Wear resistance of flat annealed Ni 50.9 at\% Ti SMA............................ 96

5.1.1 Under ball-on-disk sliding wear mode ............................................ 96

5.1.2 Under ball-on-disk reciprocating wear mode ............................... 102

5.1.3 Summary on the coefficient of friction and wear volume ............. 102

5.2 Wear resistance of austenitic Ni 50.9 at\% Ti SMA when tested at different

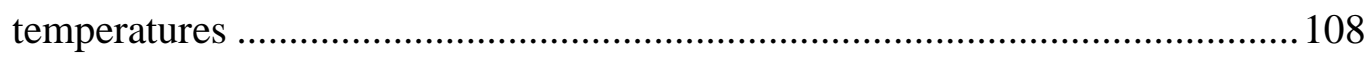

5.2.1 Stress-strain curves at different temperatures .............................. 109

5.2.2 Coefficients of friction .......................................................... 112

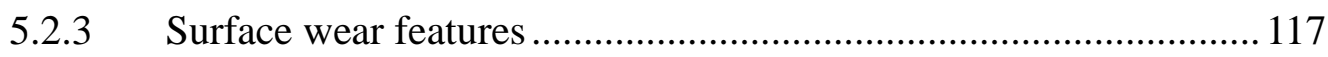

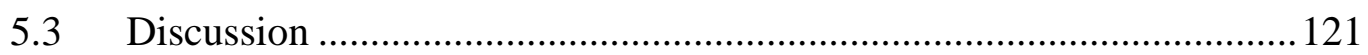

5.3.1 Deformation mechanisms of austenitic NiTi SMA....................... 121

5.3.2 Effect of deformation mode on the wear behaviour of austenitic NiTi SMA 122

5.3.3 Wear behaviour of austenitic NiTi SMA when tested under different

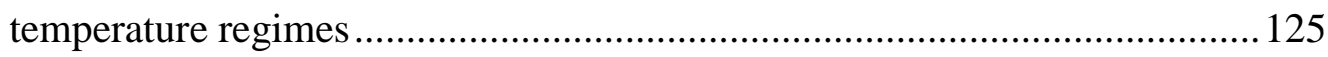

6 Effect of microstructure on the Wear Behaviour of NiTi SMA associated with temperature changes.

6.1 Wear resistance of forged ingot $\mathrm{Ni} 48.2$ at $\%$ Ti SMA when under different

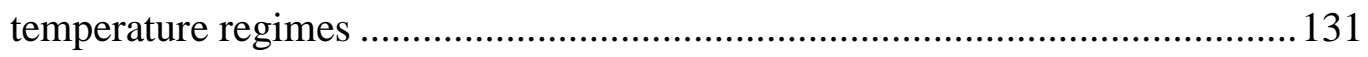

6.1.1 Micro-scale wear behaviour of NiTi SMA ................................. 131

6.1.2 Macro-scale wear behaviour of NiTi SMA.................................. 138

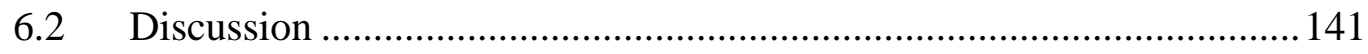

6.2.1 Wear behaviour of NiTi SMA when under different temperature regimes 
6.2.2 Abrasive wear behaviour of NiTi SMA …...................................... 150

7 Wear Behaviour of Single Crystal and Polycrystal NiTi SMAs When

Martensite Coexists with Austenite

7.1 Wear resistance of single crystal Ni 50 at\% Ti SMA and polycrystal Ni 49.4 at $\%$ Ti SMA 151

7.1.1 Phase transformation temperatures ............................................ 151

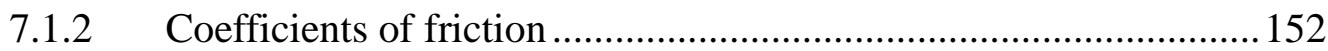

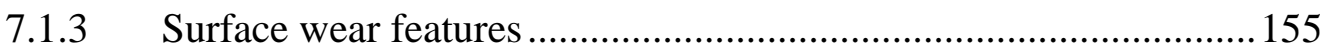

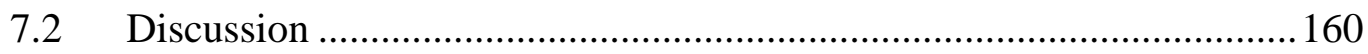

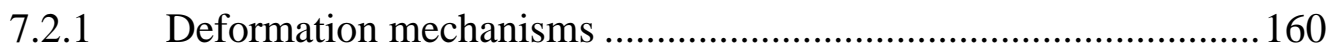

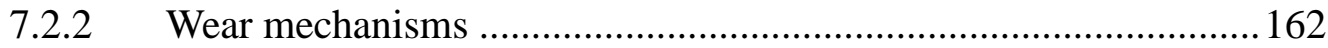

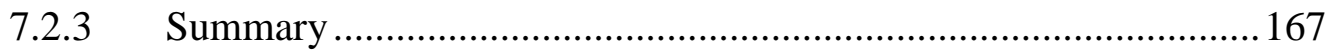

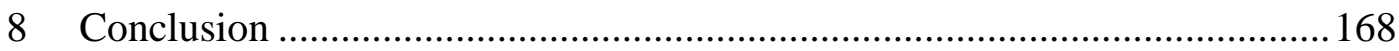

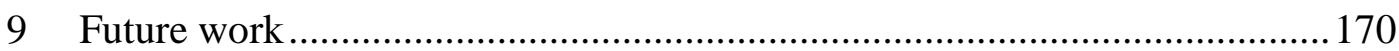

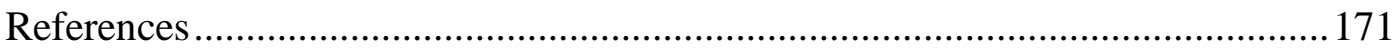




\section{List of figures}

Figure 2-1: Schematic illustration of the chemical Gibbs free energies of austenite.

Figure 2-2: Stress-strain curves of shape memory alloy at different temperatures. 12

Figure 2-3: Stress-strain curve of martensitic shape memory alloy.

Figure 2-4: Stress-strain curve of austenitic shape memory alloy. 16

Figure 2-5: The binary phase diagram of NiTi alloys.

Figure 2-6: Variations in $M_{\mathrm{s}}$ temperature of NiTi SMA with respect to the nickel/ titanium ratio as well as nickel content [18]

Figure 2-7: Schematic representations of the average surface roughness $(R a)$, amplitude of profile $(R t)$ and root mean square $(R q)$ [86]. 25

Figure 2-8: A typical stress-strain curve for a ductile metal [89]. 26

Figure 2-9: (a) Contact model proposed by Hertz, (b) the illustrations on the detailed deformation features and, (c) the simplified Hertzian contact model [91].

Figure 2-10: (a) Dislocation motion in a pure copper studied by the etch-pit method [95]; (b) computer simulation of dislocation motion through a random distribution of point obstacles [98]. 32

Figure 2-11: Schematic illustrations of two types of abrasive wear, (a) the two body abrasive wear and, (b) the three-body abrasive wear [102]. 35

Figure 2-12: Schematic illustration of the adhesive sliding wear process. 37

Figure 2-13: Schematic illustrations of different types of wear testers. (a) A dry sand/rubber-wheel tester; (b) a block-on-drum tester; (c) and, a ball-on-disk tester.

Figure 2-14: Schematic illustrations of a load-displacement curve obtained from the nano-indentation test. 40

Figure 2-15: Schematic representation of the contact mechanism of martensitic NiTi SMAs [12]. 
Figure 2-16: Contact mechanisms of (a) a NiTi/GCr15 pair at $22{ }^{\circ} \mathrm{C}$, (b) a NiTi/GCr15 pair at $200{ }^{\circ} \mathrm{C}$ and, (c) a GCr15/GCr15 pair at $22{ }^{\circ} \mathrm{C}$ and $200{ }^{\circ} \mathrm{C}[114$, $115]$.

Figure 2-17: The FEM model on the plastic strain distribution in a surface asperity [111]. 51

Figure 2-18: Elastic half-space diagram of the indentation of SMA with comparison to a representative tensile loading curve for the martensitic NiTi SMA.

Figure 3-1: DSC curves of four samples with different transformation temperatures shown. (a) The forged ingot NiTi SMA; (b) the flat annealed NiTi SMA; (c) the cold rolled NiTi SMA and (d) the single crystal NiTi SMA 58 Figure 3-2: Tensile stress-strain curves when tested at $20{ }^{\circ} \mathrm{C}$. (a) The forged ingot NiTi SMA sample, and (b) the flat annealed NiTi SMA sample. 59

Figure 3-3: Sample preparation process. (a) Samples were mounted onto an acrylic resin substrate; (b) samples were grinded and polished; (c) the substrate was removed partially.

Figure 3-4: AFM image of a sample surface. 60

Figure 3-5: (a) Typical surface wear features imaged using the confocal microscope; (b) a profile on the cross-section of the wear track. 66

Figure 4-1: When under ball-on-disk sliding wear mode, the coefficients of friction were shown as a function of wear cycles and applied load. (a) With sliding speed of $1.25 \mathrm{~mm} / \mathrm{s}$; (b) with sliding speed of $2.5 \mathrm{~mm} / \mathrm{s}$. 70 Figure 4-2: 3D confocal microscopic images of worn surfaces of the martensitic NiTi SMA, with sliding speed of $1.25 \mathrm{~mm} / \mathrm{s}$ and $2.5 \mathrm{~mm} / \mathrm{s}$. The test conditions were indicated. 72

Figure 4-3: AFM image of a portion of the "crown-like" structure 74 
Figure 4-4: High magnification SEM images of surface wear features. (a) under 50 $\mathrm{mN}$; (b) under $100 \mathrm{mN}$

Figure 4-5: The EDX analysis highlighting the chemical composition of the crown-like structure shown. .75

Figure 4-6: The width of wear tracks with respect to applied loads in ball-on-disk sliding wear tests. (a) At the sliding speed of $1.25 \mathrm{~mm} / \mathrm{s}$, (b) at the sliding speed of $2.5 \mathrm{~mm} / \mathrm{s}$

Figure 4-7: When tested under reciprocating wear mode, the coefficients of friction were shown as a function wear cycles and applied load, (a) with the sliding speed of $1.5 \mathrm{~mm} / \mathrm{s}$; (b) with the sliding speed of $2.5 \mathrm{~mm} / \mathrm{s}$. 78

Figure 4-8: 3D confocal microscopic images of worn surfaces of the martensitic NiTi samples when tested at the sliding speed of $1.5 \mathrm{~mm} / \mathrm{s}$ and $2.5 \mathrm{~mm} / \mathrm{s}$. The applied load and wear cycles were indicated accordingly.

Figure 4-9: When tested under reciprocating wear mode, the width of wear track is shown as a function of applied load. (a) When tested at the sliding speed of 1.5 $\mathrm{mm} / \mathrm{s}$ and, (b) when tested at the sliding speed of $2.5 \mathrm{~mm} / \mathrm{s}$.

Figure 4-10: The coefficients of friction when tested under different applied load, wear mode and sliding speed. (a) When under the sliding wear mode after 100 wear cycles; (b) when under the sliding wear mode after 1000 wear cycles; (c) when under the reciprocating wear mode after 100 wear cycles; and (d) when under the reciprocating wear mode after 1000 wear cycles.

Figure 4-11: The estimated wear volume of the martensitic NiTi SMA when tested under different wear mode, sliding speed and applied load. 84 Figure 4-12: Schematic illustration of the deformation distribution in the vicinity of the contact area in the wear test of the martensitic forged ingot NiTi. 86

Figure 5-1: Coefficients of friction as a function of wear cycles and applied load when tested under sliding wear mode. (a) With sliding speed of $1.25 \mathrm{~mm} / \mathrm{s}$; (b) 
with sliding speed of $2.5 \mathrm{~mm} / \mathrm{s}$.

Figure 5-2: 3D confocal microscopic images of worn surfaces of austenitic NiTi SMA under sliding wear mode and at sliding speed of $1.25 \mathrm{~mm} / \mathrm{s}$ and $2.5 \mathrm{~mm} / \mathrm{s}$. The applied load and number of wear cycles were indicated accordingly. 99

Figure 5-3: High resolution atomic force microscopic image of the surface wear features obtained when tested under $100 \mathrm{mN}$ at $20^{\circ} \mathrm{C}$.

Figure 5-4: Energy dispersive X-ray analysis on the composition of surface asperities obtained when tested under $100 \mathrm{mN}$ at $20^{\circ} \mathrm{C}$

Figure 5-5: The width of wear track with respect to the applied load in ball-on-disk sliding wear test. (a) At sliding speed of $1.25 \mathrm{~mm} / \mathrm{s}$, (b) at sliding speed of 2.5 $\mathrm{mm} / \mathrm{s}$ 102

Figure 5-6: Coefficients of friction as a function of wear cycles and applied load when tested under reciprocating wear mode. (a) At sliding speed of $1.5 \mathrm{~mm} / \mathrm{s}$; (b) at sliding speed of $2.5 \mathrm{~mm} / \mathrm{s}$.

Figure 5-7: 3D confocal microscopic images of worn surfaces of austenitic NiTi SMA when under reciprocating wear mode and at sliding speed of $1.5 \mathrm{~mm} / \mathrm{s}$ and $2.5 \mathrm{~mm} / \mathrm{s}$. The applied loads and number of wear cycles were indicated accordingly.

Figure 5-8: Average widths of wear track with respect to applied load in reciprocating wear tests. (a) At sliding speed of $1.5 \mathrm{~mm} / \mathrm{s}$; (b) at sliding speed of $2.5 \mathrm{~mm} / \mathrm{s}$ 106

Figure 5-9: Summary of coefficients of friction when tested under different applied load, wear mode and sliding speed. (a) When tested under sliding wear mode after 100 wear cycles; (b) when tested under sliding wear mode after 1000 wear cycles; (c) when tested under reciprocating wear mode after 100 wear cycles; (d) when tested under reciprocating wear mode after 1000 wear cycles. 107 Figure 5-10: Estimated wear volume as a function of wear mode, applied load and sliding speed. 108 
Figure 5-11: (a) Transformation temperature of austenitic NiTi SMA obtained by using differential scanning calorimeter (DSC); (b) stress-strain curves of austenitic NiTi SMA obtained at temperatures ranged from 20 to $120{ }^{\circ} \mathrm{C}$ 110

Figure 5-12: Coefficient of friction as a function of applied load and temperature. (a) When tested at $20{ }^{\circ} \mathrm{C}$ under various loads; (b) when tested at $35^{\circ} \mathrm{C}$ under various loads; (c) when tested at $50{ }^{\circ} \mathrm{C}$ under various loads; (d) when tested at 90 ${ }^{\circ} \mathrm{C}$ under various loads and, (e) when tested at $120^{\circ} \mathrm{C}$ under various loads. 113

Figure 5-13: The values of stabilized coefficient of friction when tested under different loads and temperatures shown 116 Figure 5-14: The 3-D confocal microscopic images of the surface wear features when tested at $20^{\circ} \mathrm{C}, 35^{\circ} \mathrm{C}, 50^{\circ} \mathrm{C}, 90^{\circ} \mathrm{C}$, and $120^{\circ} \mathrm{C}$, with the applied loads and wear cycles indicated individually. 118 Figure 5-15: The estimated surface wear volume as a function of load and temperature.

Figure 6-1: The coefficients of friction as a function of temperature, wear cycles and applied load shown. (a) When tested at $20{ }^{\circ} \mathrm{C}$ under various applied loads; (b) when tested at $90{ }^{\circ} \mathrm{C}$ under various applied loads; (c) when tested at $120{ }^{\circ} \mathrm{C}$ under various applied loads. 132

Figure 6-2: The coefficient of friction as a function of applied load and temperature. (a) After 100 wear cycles, and (b) after 1000 wear cycles. 135 Figure 6-3: 3D confocal microscopic images of worn surfaces when tested at $20{ }^{\circ} \mathrm{C}$, $90{ }^{\circ} \mathrm{C}$, and $120^{\circ} \mathrm{C}$, with applied loads and wear cycles indicated individually. ... 137 Figure 6-4: (a) The average width of track as a function of temperature and load; (b) the estimated wear volume as a function of temperature and load. 138 Figure 6-5: (a) The coefficient of friction as a function of wear cycles in test conducted at sliding speed of $30 \mathrm{~mm} / \mathrm{s}$ at $20{ }^{\circ} \mathrm{C}$; (b) the average coefficients of friction obtained when tested at various sliding speeds and temperatures. 139 
Figure 6-6: The surface wear features of martensitic NiTi SMA when tested under $1000 \mathrm{mN}$ at sliding speed of $30 \mathrm{~mm} / \mathrm{s}$, with wear cycles indicated in each image.

Figure 6-7: Summary of the effect of temperature on the wear behaviour of NiTi SMA. 148

Figure 7-1: The schematic illustration of phase transformations in pre-heating and pre-cooling processes. (a) Single crystal NiTi SMA (SC samples), and (b) polycrystal NiTi SMA (PC samples).

Figure 7-2: Coefficients of friction as a function of applied load when tested on, (a) sample SC1; (b) sample SC2; (c) sample PC1, and (d) sample PC2. 153

Figure 7-3: 3D confocal microscopic images of worn surfaces on sample SC1, SC2, $\mathrm{PC} 1$, and PC2, with wear conditions indicated in each image. 156 Figure 7-4: The SEM image of the wear features on the surface of SC1, (a) when tested under $100 \mathrm{mN}$ after 1000 cycles; (b) when tested under $200 \mathrm{mN}$ after 1000 cycles; (c) when tested under $300 \mathrm{mN}$ after 280 cycles. 159 Figure 7-5: The estimated wear volume as a function of applied load, (a) for the SC samples and, (b) for the PC samples. 160

Figure 7-6: The slip plane and slip direction in a single crystal material. 164 Figure 7-7: The schematic representation of dislocation motion in the single crystal and polycrystal materials. 166 


\section{List of tables}

Table 3-1: Summary of transformation temperatures. ..........................................57

Table 3-2: Summary of the detailed parameters used in the wear study. 63

Table 5-1: Summary of the critical stress for stress-induced martensitic transformation, the yield stress of austenite and the recovery ratio at different temperatures. 


\section{List of Abbreviations and Symbols}

\section{Abbreviations}

AFM

$\mathrm{COF}$

DSC

EDX

SEM

SMA

SME

SIMT

\section{Symbols}

$A_{\mathrm{f}}$

$A_{\mathrm{s}}$

$M_{\mathrm{d}}$

$M_{\mathrm{f}}$

$M_{\mathrm{S}}$
Atomic force microscope

Coefficient of friction

Differential scanning calorimetry

Energy dispersive X-ray spectrometry

Scanning electron microscope

Shape memory alloy

Shape memory effect

Stress-induced martensitic transformation

Austenitic transformation finishing temperature

Austenitic transformation starting temperature

Highest temperature for stress-induced martensitic transformation

Martensitic transformation finishing temperature

Martensitic transformation starting temperature 


\section{Introduction}

\subsection{Background}

For the past 60 years, researchers have reported shape memory effect in different alloy systems. For example, NiTi-based alloys, such as NiTi, NiTiPd and TiNiZr; copper-based alloys, such as $\mathrm{CuZnAl}, \mathrm{CuAlNi}$ and $\mathrm{CuAlMn}$; iron-based alloys, such as FeNiCoTi and FeMnSi; and other SMAs, including CoNiAl, NiMnGa [1]. The first most successful application of SMA was the couplings that developed by Raychem Corporation to hydraulic systems of F-14 jet fighter. In addition, actuators and electric connectors were developed in applications such as automobile devices and robotics [2].

Among all those combinations of SMAs, NiTi SMA was mostly researched due to its good shape memory effect, super-elasticity, wear resistance, corrosion resistance, damping capacity and bio-compatibility. It has been widely researched for applications such as actuators, Micro-Electro-Mechanical-System (MEMS) devices, and biomedical devices [3-11]. Various types of biomedical devices have been developed, for example, NiTi marrow needles, NiTi super-elastic arch wire and shape memory attachment for partial denture.

Due to the superior wear resistance of NiTi SMA, it has been proposed as a new candidate material for tribo applications. Various studies have compared the wear resistance of NiTi SMA with conventional wear resistant materials. The NiTi SMAs, which in either martensitic or austenitic state, were reported to show a better wear resistance than conventional wear resistant materials such as AISI 304 stainless steel, GCr15 steel, BS11 rail steel, 2024 aluminum, Co45 alloy, and surface nitride 38 CrMoAIA alloys [12-19]. Good wear resistance of the martensitic NiTi SMA was attributed to deformation strain accommodation through the detwinning process. Meanwhile, good wear resistance of the austenitic NiTi SMA 
was attributed to deformation strain accommodation through the reversible stress-induced martensitic transformation process [20, 21]. In addition, phase-transformational shakedown due to the cancelling out of transformation strain was suggested to further contribute to the wear resistance of NiTi SMA.

It is known that, the NiTi SMA experiences a thermo-elastic phase transformation, and its microstructure is sensitive to temperature changes. The deformation mechanism involved in the wear process is dependent on the phase presents when tested at different temperatures (martensite or austenite). However, the elementary deformation mechanisms which govern the wear of NiTi SMA have rarely been discussed.

In this study, the wear behaviour of NiTi SMA was investigated under different temperature regimes to systematically reveal the deformation mechanisms involved in the wear process. When $T<M_{f}$, the wear behaviour of a stable martensitic NiTi SMA (forged ingot Ni 48.2 at\% Ti) was studied as a function of the applied load and wear cycles (Chapter 4). Therefore, the surface degradation process of the martensitic NiTi SMA was explained on the basis of a deformation mechanism associated with plastic strain accumulation. When $A_{\mathrm{f}}<T<M_{d}$, the wear behaviour of a stable austenitic Ni 50.9 at\% $\mathrm{Ti}$ was studied as a function of the temperature and load (Chapter 5). The deformation mechanism in the austenitic NiTi SMA was closely related to the temperature-dependent stress-strain curves. Furthermore, when $T>M_{d}$, wear resistance of the austenitic NiTi SMA was deteriorate due to severe plastic deformation. In Chapter 6, the effect of microstructure on the wear behaviour of $\mathrm{Ni} 48.2$ at $\%$ Ti SMA was studied. Three temperature regimes were selected, where samples showed martensitic phase $(T<$ $M_{\mathrm{f}}$ ), austenitic phase $\left(A_{\mathrm{f}}<T<M_{\mathrm{d}}\right)$, and martensitic phase coexisted with austenitic phase $\left(M_{\mathrm{f}}<T<A_{\mathrm{f}}\right)$. Moreover, in Chapter 7, a comparison was made between the wear behaviour of a single crystal and a polycrystal NiTi SMA to obtain a better understanding on the surface wear process. 


\subsection{Objective-Scope-Methodology}

\subsubsection{Objective}

Through evaluating effects of several key influential factors on the wear behaviour of NiTi SMAs, we aim at revealing the predominant deformation mechanisms involved in the wear process in consideration of temperature-dependent stress-strain curves and load-dependent contact stresses. Therefore, a guideline can be provided for the better use of NiTi SMAs when the wear resistance is important.

\subsubsection{Scope}

Different types of NiTi SMAs were used in applications such as bio-medical devices and implants. Wear resistance of different types of NiTi SMAs are investigated in the present study to provide a guideline in materials selection. In addition, when different types of NiTi SMAs were used, this study also suggests the optimized applications conditions, and can help in predicting the service life of devices.

(1) Wear behaviour of fully martensitic NiTi shape memory alloy

The wear behaviour of a fully martensitic $\mathrm{Ni} 48.2$ at $\%$ Ti SMA was studied as a function of the applied load and wear cycles in order to reveal the deformation mechanisms involved in the wear process. Tests were conducted under both sliding and reciprocating wear modes.

(2) Wear behaviour of fully austenitic NiTi shape memory alloy

The wear behaviour of a fully austenitic Ni 50.9 at\% Ti SMA was studied as a function of the temperature, applied load, and deformation mode. This study aims 
at revealing the deformation mechanisms involved in the wear process of a austenitic NiTi SMA.

(3) Effect of microstructure on the wear behaviour of NiTi shape memory alloys

Ball-on-disk sliding wear tests were conducted at three temperature regimes, where different phases were present, that is, fully martensitic phase when $T<M_{\mathrm{f}}$, fully austenitic phase when $M_{\mathrm{f}}<T<A_{\mathrm{f}}$, and martensitic phase coexisted with austenitic phase when $T>A_{\mathrm{f}}$. A systematic understanding of the effect of microstructure on the wear behaviour of NiTi SMA is essential in understanding the wear resistance associated with temperature changes.

(4) Wear behaviour of single crystal and polycrystal NiTi SMA when martensite coexisted with austenite

In the wear process, the deformation mechanism can be affected by hardness associated with grain size. The wear behaviour of a single crystal and a polycrystal NiTi SMA was compared to reveal the deformation mechanisms associated with plastic strain accumulation.

\subsubsection{Methodology}

Wear behaviour of NiTi SMA was studied at various temperatures, applied loads, and wear cycles. A micro-scale wear test was selected in order to investigate the deformation mechanisms associated with plastic strain accumulation. Tests were stopped once severe wear occurred. The coefficient of friction was recorded as a function of wear cycles. After each test, the surface wear features were examined using the Atomic Force Microscope (AFM), Scanning Electron Microscope (SEM), and laser confocal microscope. 


\subsection{Organization of the report}

Chapter 1 gives a brief introduction on the background, objective, scope and methodology of the present study.

Chapter 2 provides a literature review, which is composed of three parts. The first part introduces a fundamental understanding of shape memory alloys. The second part introduces wear/tribology related terminologies. The last part summarizes previous wear studies on NiTi SMAs.

Chapter 3 summarizes the experimental aspects in the sequence of: material characterizations, sample preparation, wear testing, data collection and evaluation.

Chapter 4 discusses the wear behaviour of a stable martensitic Ni 48.2 at\% $\mathrm{Ti}$ SMA with respect to the applied load and wear cycles. Through comparing the wear observations, stress-strain curves, and contact stress estimations, we revealed the dominant deformation mechanisms involved in the wear process of the martensitic NiTi SMA.

Chapter 5 aims at understanding the wear behaviour of the austenitic NiTi SMA, with the hope to provide a guideline for a better use in wear resistant applications. Two wear modes were identified. Mode I was temperature-sensitive and occurred when $A_{\mathrm{f}}<T<M_{\mathrm{d}}$. Mode II occurred when $T>M_{\mathrm{d}}$ and it was less temperature-sensitive within the testing range.

Chapter 6 focuses on the effect of microstructure on the wear behaviour of $\mathrm{Ni}$ 48.2 at\% Ti SMA associated with temperature changes. Three temperature regimes were selected, namely, $T<M_{\mathrm{f}}, A_{\mathrm{s}}<T<A_{\mathrm{f}}$ and $T>A_{\mathrm{f}}$, where fully martensite, martensite co-existed with austenite, and fully austenite were present. 
Chapter 7 compares the wear behaviour of a single crystal and a polycrystal NiTi SMA, therefore to reveal the deformation mechanisms associated with plastic strain accumulation.

Chapter 8 concludes the fundamental understandings on the deformation mechanisms involved in the wear process of NiTi SMAs when different phases are present, that is, stable martensite, stable austenite, and when the martensite coexisted with austenite. 


\section{Literature Review}

\subsection{Shape memory alloys}

\subsubsection{Background}

In 1932, the Swedish physicist Arne Ölander observed rubberlike behaviour in the alloy of Cadmium-gold (Au-47.5Cd) [22, 23]. In 1951, the crystallographic explanation on this rubberlike behaviour was given by Chang and Read. The rubberlike behaviour was attributed to the "reorientation" of martensitic twinned lattices, and it was believed to be related to the shape memory effect (SME). After that, scientists have reported the shape memory effect in CuZn and CuAlNi [18]. In 1960, Buehler and his co-workers from the US Naval Ordnance Laboratory (NOL) reported the shape memory effect for a binary NiTi alloy. Since then, the NiTi shape memory alloy was referred to as nitinol $[1,24]$. Further studies on the NiTi SMA reported that this alloy possessed a good combination of properties, including the shape memory effect, super-elasticity, wear resistance, damping capacity, fatigue property, corrosion resistance, and bio-compatibility $[1,25]$. Therefore, NiTi SMAs are widely investigated for applications such as actuators [26-28], MEMS devices [11, 29], and biomedical devices [3].

\subsubsection{Phase transformations}

Shape memory alloys (SMAs) represent a unique class of materials with the ability to recover their original shape after severe deformation, and the shape recovery can be achieved by increasing the temperature to a critical value. Two phases are present in SMAs, which have the same composition but different mechanical properties. The high temperature phase is called austenite, which has a cubic structure. Meanwhile, the low temperature phase is called martensite, which has a tetragonal, orthorhombic or monoclinic structure [18]. 
By decreasing the temperature or applying an external stress, the austenite (parent phase) transforms to the martensite (product phase), this is called martensitic transformation. The martensitic transformation is accomplished by a structural change, which gives rise to an invariant plane strain, through which the parent and product phases are related by a substitutional lattice correspondence, irrational habit plane, and a precise orientation relationship [30]. When under this mode of transformation, the boundary between the transformed and untransformed region is displaced by random and non-cooperative movements of atoms. Therefore, dislocations may be produced by transformation-induced stresses [31, 32].

(1) Thermal-induced martensitic transformations

Gibbs free energy is a kind of chemical potential energy, and the change of Gibbs free energy indicates the processing direction of a chemical reaction [33]. The change of Gibbs free energy from two states is defined as:

$$
\Delta G=G_{\text {final }}-G_{\text {initial }} \quad E q .(2.1)
$$

For change of state in a system to occur spontaneously, $G_{\text {final }}$ must be less than $G_{\text {initial}}$, thus, $\Delta G$ must be negative.

From a thermodynamics point of view, the martensitic transformation occurs when the free energy of the martensitic phase $\left(\alpha^{\prime}\right)$ becomes lower than that of the austenitic phase $(\gamma)$. The change of Gibbs free energy is caused by super-cooling and may be written as:

$$
\Delta G=\Delta G_{c}+\Delta G_{s}+\Delta G_{e}=\Delta G_{c}+\Delta G_{n c}
$$

Here, $\Delta G_{\mathrm{c}}$ is the chemical energy term which drives the transformation and originates from the phase change between austenite and martensite. The $\Delta G_{\mathrm{s}}$ is the 
surface energy term. It is related to the fact that for the formation of a martensite nucleus, and for the movement of interfaces between martensite and parent phase, surface energy has to be provided. The $\Delta G_{\mathrm{e}}$ is an elastic energy term around the martensite. The $\Delta G_{\mathrm{nc}}$ summarizes the two non-chemical energy terms.

Free energy curves for both austenitic and martensitic phases are schematically illustrated as a function of temperature in Fig. 2-1, while the chemical composition is consistent. In the martensitic transformation process, the martensite replaces the austenite when the magnitude of overcooling $(\Delta T)$ reaches the critical value as indicated in Fig. 2-1. In addition, the starting and finishing temperatures of martensitic transformation are denoted $M_{\mathrm{s}}$ and $M_{\mathrm{f}}$; while the starting and finishing temperatures of austenitic transformation are denoted $A_{\mathrm{s}}$ and $A_{\mathrm{f}}$, respectively.

As shown in Fig. 2-1, the martensitic phase and the austenitic phase are in equilibrium at $T_{0}$, hence these two phases coexist. When the temperature falls below the $T_{0}$, the chemical Gibbs free energy of martensite is lower than that of austenite. As a result, a driving force for the martensitic transformation is build up. When the temperature is further decreased to the $M_{s}$, the driving force reaches the energy barrier for martensitic transformation. This energy barrier is related to the surface energy term and the elastic energy term in Eq. 2.2.

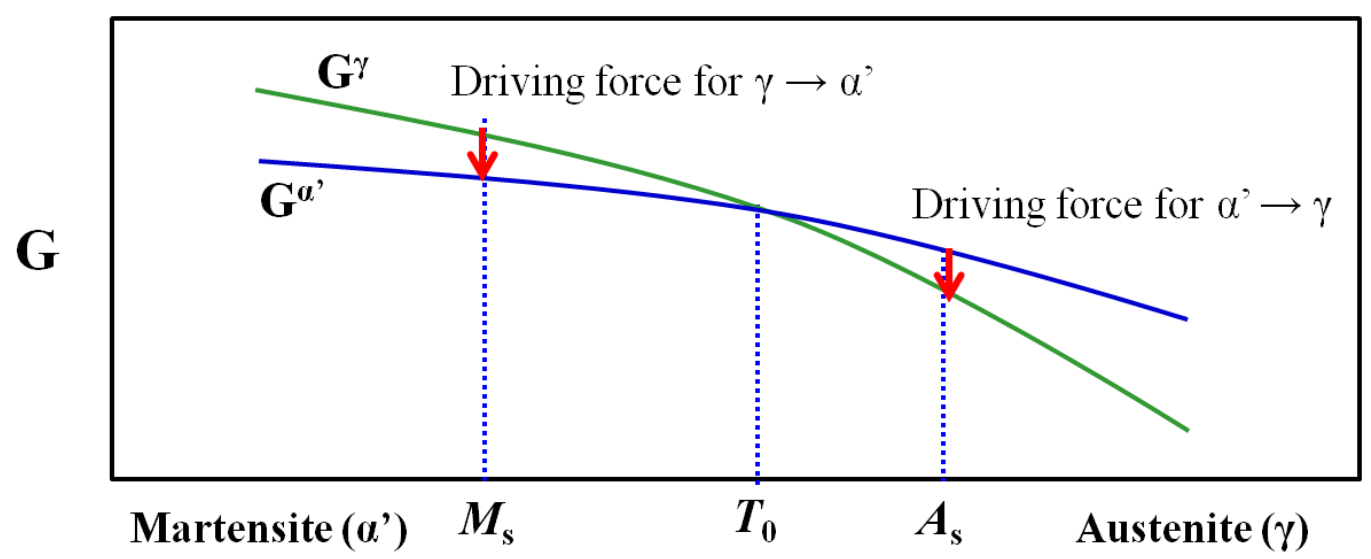

Figure 2-1: Schematic illustration of the chemical Gibbs free energies of austenite. 
The surface energy term $\Delta \mathrm{G}_{\mathrm{s}}$ is further related to the activation free energy for the formation of a critical nucleus, and the energy required to move the interfaces between martensite and parent phase. On the other hand, in martensitic transformation process upon cooling, elastic energy is stored in the newly formed twinned martensite. This energy dissipation process hinders the forward transformation by increasing the energy barrier. However this process assists the reversed transformation upon heating.

Olson-Cohen has derived Eqs. 2.3 and 2.4 to describe the free energy changes when a thin martensite plate is formed completely thermo-elastically within the volume of its parent phase $[34,35]$.

$$
\begin{array}{ll}
\Delta G_{c h}^{A \rightarrow M}+2 \Delta G_{e l}=-V_{m} \tau_{0} \gamma_{T} & \text { on cooling } \\
\Delta G_{c h}^{A \rightarrow M}+2 \Delta G_{e l}=V_{m} \tau_{0} \gamma_{T} & \text { on heating }
\end{array}
$$

Here, $\Delta G_{c h}$ represents the free-energy changes per mole (referred to the martensitic phase); $V_{m}$ is the molar volume; $\tau_{0}$ is the shear stress required to move an interface which accomplishes the transformational shear strain $\gamma_{T}$. The term $\left(V_{m} \tau_{0} \gamma_{T}\right)$ is merely the frictional work that is dissipated in moving the interface through one mole of transformation.

(2) Stress-induced martensitic transformation

When $T>A_{s}$, the austenitic phase is present under zero-loading condition. By applying an external stress which reaches a critical stress, stress-induced martensite forms. This transformation is fully reversible upon unloading. The driving force for the stress-induced martensitic transformation (SIMT) is the mechanical energy. Furthermore, by increasing the strain-rate, the stress-induced martensite tends to nucleate at more sites within the specimen [36]. This originates 
from the interactions between the thermal and mechanical energy, since insufficient latent heat was provided.

According to the first law of thermodynamics, when a system undergoes a process in which it moves from one state to another, the change in the internal energy of the system, $\Delta U$, is given by [37]:

$$
\Delta U=U_{2}-U_{1}=q+w
$$

Where, $q$ is the heat entering or leaving the system, while $w$ is the work done on or done by the system. By convention, heat leaving the system and work done by the system are defined as negative.

The internal energy can be increased when mechanical work is done on the system (external applied stress). Thus, SIMT occurs once the internal energy overcomes the energy barrier. Heat can be released in the SIMT process, this is due to the lower energy state of the martensite as compared to the austenite. In addition, since the free energy of the martensitic phase increases with increasing temperature, the SIMT becomes more difficult at higher temperature. The critical stress for SIMT increases with increasing temperature, which obeys a Clausius-Clapeyron type of equation (this will be explained in the next section). When the temperature exceeds the $M_{d}$, which is the highest temperature for SIMT, yielding of austenite occurs prior to the formation of stress-induced martensite. This can be attributed to the extreme high free energy of the martensitic phase, and the energy barrier for the SIMT exceeded the energy barrier for dislocation motion.

\subsubsection{Shape memory effect and super-elasticity}

For SMAs, different phases are present in different temperature regimes. The deformation sequences of SMAs are schematically illustrated in Fig. 2-2. 


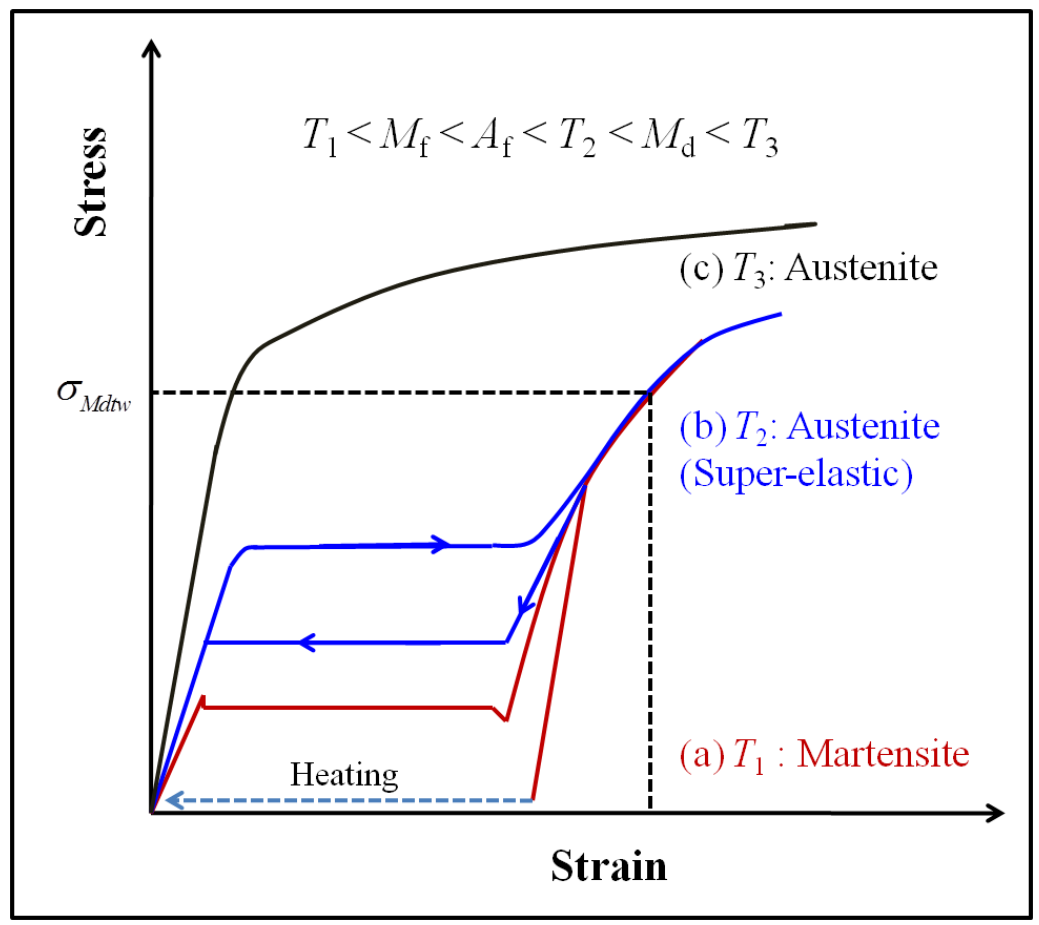

Figure 2-2: Stress-strain curves of shape memory alloy at different temperatures ${ }^{1}$.

When tested at $T_{1}$, below $M_{\mathrm{f}}$, martensite deforms as follows: elastic deformation of martensite; detwinning accompanied with a stress-plateau in the stress-strain curve; elastic deformation of detwinned martensite and finally plastic deformation of detwinned martensite. The deformation associated with detwinning process can be fully recovered when heating to a temperature above the $A_{\mathrm{f}}$, this is the basis of the shape memory effect (Fig. 2-2).

When tested at $T_{2}$ which is above the $A_{\mathrm{f}}$ but below the $M_{\mathrm{d}}$, austenitic SMA deforms in another sequence of: elastic deformation of austenite; stress-induced martensitic transformation accompanied with a stress-plateau in the stress-strain curve; elastic deformation of stress-induced martensite; and finally plastic deformation of stress-induced martensite. The SIMT process is fully reversible upon unloading. The term of "super-elasticity" is used to describe the high percentage of

\footnotetext{
${ }^{1} \sigma_{M d t w}$ is the yield stress of detwinned martensite
} 
recoverable strain of the austenitic SMA. The "elastic" refers to the reversibility as in a normal elastic material behaviour. The "super" refers to the fact that the super-elastic strain can be as high as $13 \%$, which is higher than the $1 \%$ elastic strain which characterizes the normal elastic deformation [38].

When tested at $T_{3}$, above the $M_{\mathrm{d}}$, the critical stress for inducing martensitic transformation becomes extremely high. Plastic deformation occurs prior to the stress-induced martensitic transformation, thus dislocations are generated [39]. At $T_{3}$, austenite has lost super-elasticity, thus the deformation sequences are similar to that of a conventional structural materials, that is, elastic and plastic deformation of austenite.

\section{(1) Shape memory effect}

When an external stress is applied, below $M_{f}$, detwinning occurs which is associated with twin boundary movement. Those twinned martensitic variants in the direction of the stress field will grow in the expense of variants which yield shear strain in other orientations. In a textured polycrystal shape memory alloy, the martensitic phase can accumulate strains for up to about $6 \%$ without significant increase in dislocation density $[40,41]$. However, austenite does not form variants. By increasing the temperature to the $A_{\mathrm{f}}$, both twinned and detwinned martensite variants have to transform back to the one and only austenite lattice. In addition, if martensite is over-deformed, dislocations can be generated. Those dislocations can pin and stabilize the detwinned martensite variants, results in residual strains in repeated deformation cycles.

The stress-strain curve of the martensitic SMA is schematically illustrated in Fig. 2-3. Three deformation regions are defined according to different deformation mechanisms. Region I is the elastic deformation region (Fig. 2-3). The applied stress is below the critical stress for detwinning, hence, fully reversible elastic 
deformation of twinned martensite occurs.

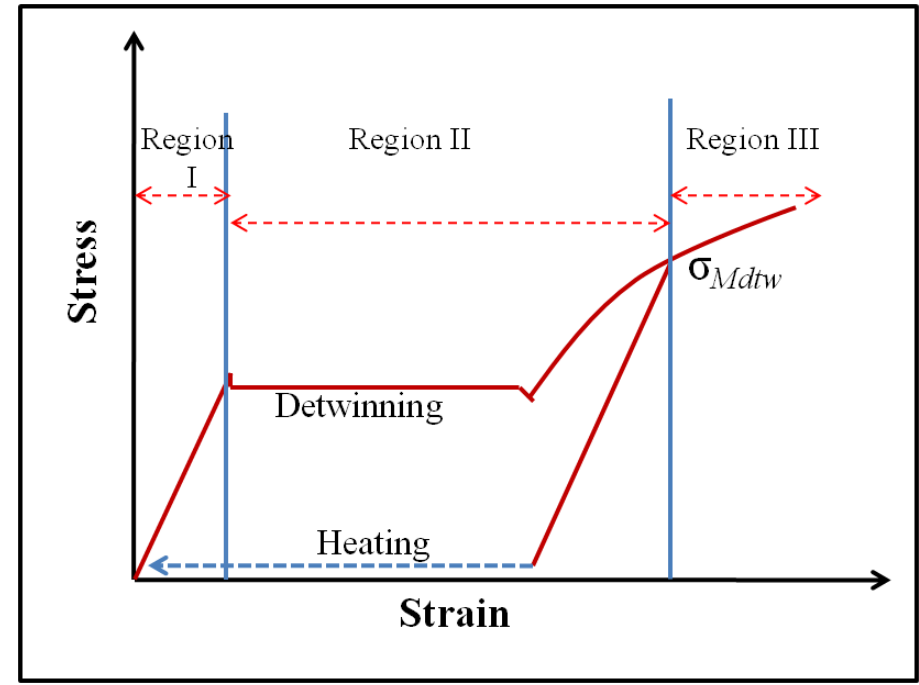

Figure 2-3: Stress-strain curve of martensitic shape memory alloy.

When the stress approaches the critical stress for detwinning, Region II sets in. Two types of detwinning have been suggested by Zheng and Liu [40], namely, domino detwinning and assisted detwinning. The domino detwinning occurs at the beginning of the detwinning process, where self-propagating occurs and a critical driving force is required. Thereby, the assisted detwinning occurs at higher stress levels, which may continue beyond the stress-plateau [41].

When cooling below the $M_{\mathrm{s}}$, martensitic transformation proceeds through formation of a typical triangular morphology consisting of three variants. These three variants are twin-related to each other by three junction planes, including one (011)M Type I twinning plane, and two <011>M Type II twinning planes [42-44]. Furthermore, with an external applied stress, the triangular morphology changes into the most favorable variant in the loading direction through the movement of interfaces. Insignificant dislocation movement is involved in this process, results in perfect shape recovery behaviour.

When the applied stress reaches the yield stress of detwinned martensite, plastic 
deformation occurs and irreversible deformation is introduced (Region III) [45].

After deforming the martensitic SMA within the recoverable limit, the original shape can be fully recovered by heating to a temperature above the $A_{f}$. This behaviour is referred to as the one-way shape memory effect. In addition, a shape memory alloy can exhibit repeatable shape changes when it is subjected to thermal cycles without an external stress. This behaviour is referred to as the two-way shape memory effect (TWSME). The TWSME is caused by defects or permanent deformations that were introduced during a training process [46]. For example, by introducing dislocations into the shape memory alloy when it is in the martensitic state, the deformation can be partially remembered even after heating to a temperature above the $A_{f}[47,48]$. Therefore, the material can change its shape as the temperature changes. There are several ways to train shape memory alloys to help them in remembering the low temperature shape [46]. For example, one can over-deform the shape memory alloy in the martensitic state [49], or conduct shape memory cycling (cool-deform-heat) and super-elastic cycling (load-unload) [50].

\section{(2) Pseudo-elasticity / super-elasticity}

When tested at a temperature above the $A_{f}$ but below the $M_{d}$, three regions with different deformation mechanisms can be distinguished in the stress-strain curve (Fig. 2-4). In Region I, the applied stress is below the critical stress for stress-induced martensitic transformation (SIMT), hence elastic deformation of austenite occurs.

At the beginning of Region II, SIMT occurs and the deformation is proceeded by the formation of stress-induced martensite, or the movement of twin boundaries. By further increasing the deformation strain in Region II, elastic deformation of stress-induced martensite occurs, accompanied with a small amount of dislocation generation. Due to the super-elasticity of an austenitic shape memory alloy, a recoverable strain for up to $13 \%$ can be achieved [51]. 


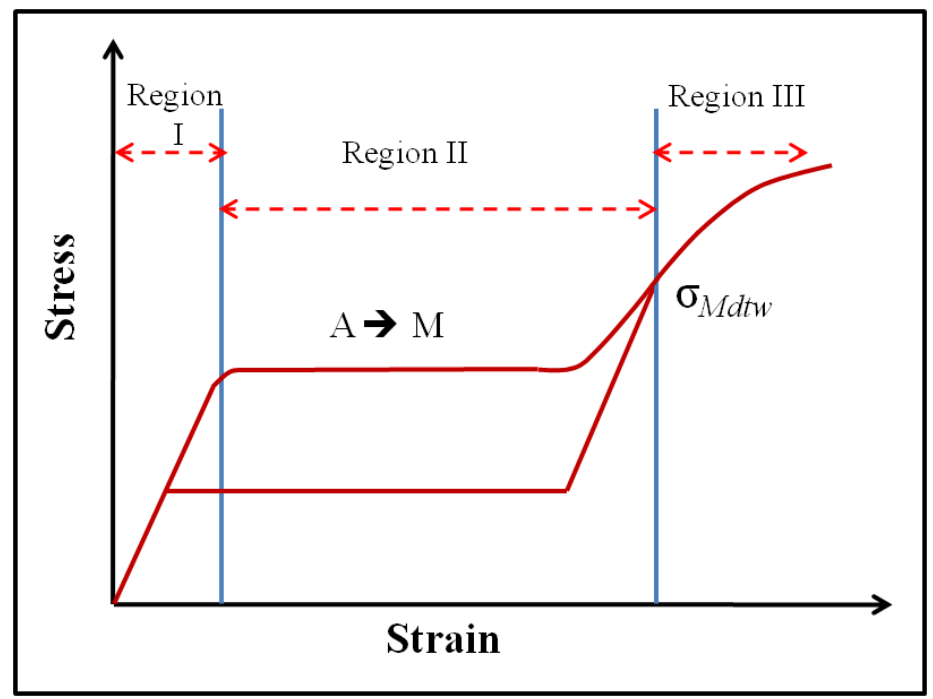

Figure 2-4: Stress-strain curve of austenitic shape memory alloy.

In Region III, plastic deformation occurs, and a significant amount of dislocations are generated. Two processes account for the accumulation of irreversible strain. Firstly, some of the stress-induced martensite variants can be pinned or constrained by strain field that caused by dislocations, which leads to the accumulation of irreversible strain. Secondly, upon unloading, dislocations can be left after a back transformation from the SIM to austenite. This can further contribute to the total irreversible strain $[39,52]$.

In the super-elastic temperature range $\left(A_{\mathrm{f}}<T<M_{\mathrm{d}}\right)$, the critical stress for SIMT increases with increasing temperature, as described by a Clausius-Clapeyron type of equation shown in Eq. 2.6 [20, 21]. The Clausius-Clapeyron equation originated from discontinuous gas / liquid phase transitions, assuming an equilibrium between phase I and II: $d G I=d G I I$. Material scientists then replaced the volume change by a transformation strain, and replaced the pressure by the mechanical stress. The equation still works. But it is a Clausius-Clapeyron type of equation, not the Clausius-Clapeyron equation. 


$$
\frac{d \sigma}{d T}=-\frac{\Delta H}{T \varepsilon_{0}}
$$

Here, $\sigma$ is the applied stress; $\Delta H$ is the transformational latent heat (or enthalpy of the transformation per unit volume); $T$ is the temperature and $\varepsilon_{0}$ is the amount of strain required for the stress-induced martensitic transformation.

The Clausius-Clapeyron type of equation is only applicable under adiabatic conditions. Furthermore, the transformational latent heat is dependent on the crystallography, and thus can be considered as a constant for a specific SMA system.

By further modifying the Clausius-Clapeyron equation, Lexcellent et al [53] has modeled the deformation behaviour of NiTi thin films with Eqs. 2.7 and 2.8.

$$
\begin{gathered}
\frac{d \sigma^{A M}}{d T}=\frac{\rho}{\gamma}\left(\Delta s^{*}-s_{o}\right) \\
\frac{d \sigma^{M A}}{d T}=\frac{\rho}{\gamma}\left(\Delta s^{*}+s_{o}\right)
\end{gathered}
$$

Here, $\sigma^{A M}$ and $\sigma^{M A}$ represent the critical stresses for the forward and reversed phase transformations; $\rho$ is the mass density; $\gamma$ is the total pseudo-elastic uni-axial strain, which is obtained from a tensile test; $\Delta s^{*}$ is the difference in the entropy of the martensite and parent phases; while $s_{o}$ is the entropy when the martensite coexisted with austenite at $T_{o}$. The fitting between the calculated and experimental results were fairly good.

\subsubsection{NiTi shape memory alloys}

There are several types of shape memory alloys, including NiTi-based SMAs, copper-based SMAs, iron-based SMAs, as well as some special SMAs such as 
CoNiAl and NiMnGa. The NiTi SMA has been mostly researched since its characteristic of deformation and transformation pseudo-elasticity are remarkably different from other $\beta$-phase alloys [21]. For example, the NiTi SMA is very ductile, while other SMAs are not. The high ductility in the NiTi SMA originates from the low elastic anisotropy, as well as the low yield stress for slip [54]. Furthermore, the NiTi SMA exhibits strong SME, TWSME and super-elasticity under right conditions $[55,56]$. It was successfully used as tube coupling by Raychem Corporation for the first time [57]. Nevertheless, the NiTi SMA was promised to be a new candidate of metallic bio-material in the orthopedics, dentistry, and cardiovascular devices $[7,9,10,58]$.

\section{(1) Crystal structure of NiTi SMA}

$\mathrm{NiTi}$ alloys have several different crystal structures depending on the percentage of $\mathrm{Ni}$ /Ti. The phase diagram of NiTi binary alloys is shown in Fig. 2-5 [1, 59, 60]. When the atomic percentage of $\mathrm{Ni}$ or $\mathrm{Ti}$ is high, Ni-rich or Ti-rich phases can be formed. When the nickel percentage approaches the titanium percentage, an inter-metallic structure can be formed, which shows the shape memory effect [61, 62]. For the NiTi SMA, the martensitic B19' phase presents at low temperature ( $T$ $\left.<M_{\mathrm{f}}\right)$, while the austenitic B2 phase presents at high temperature $\left(T>A_{\mathrm{f}}\right)$ [63].

By varying the nickel/ titanium ratio in a small range, large variations in the transformation temperature can be achieved (Fig. 2-6) [18]. Conventionally, the super-elastic temperature of the NiTi SMA ranges from about minus $20{ }^{\circ} \mathrm{C}$ to positive $60{ }^{\circ} \mathrm{C}[64,65]$.

For the austenitic NiTi SMA, an excess of nickel reduces the transformation temperature while increases the yield strength $[64,66,67]$. The Ti-rich NiTi SMA is stable until $300{ }^{\circ} \mathrm{C}$, and it usually shows relative poor thermal conductivity. 


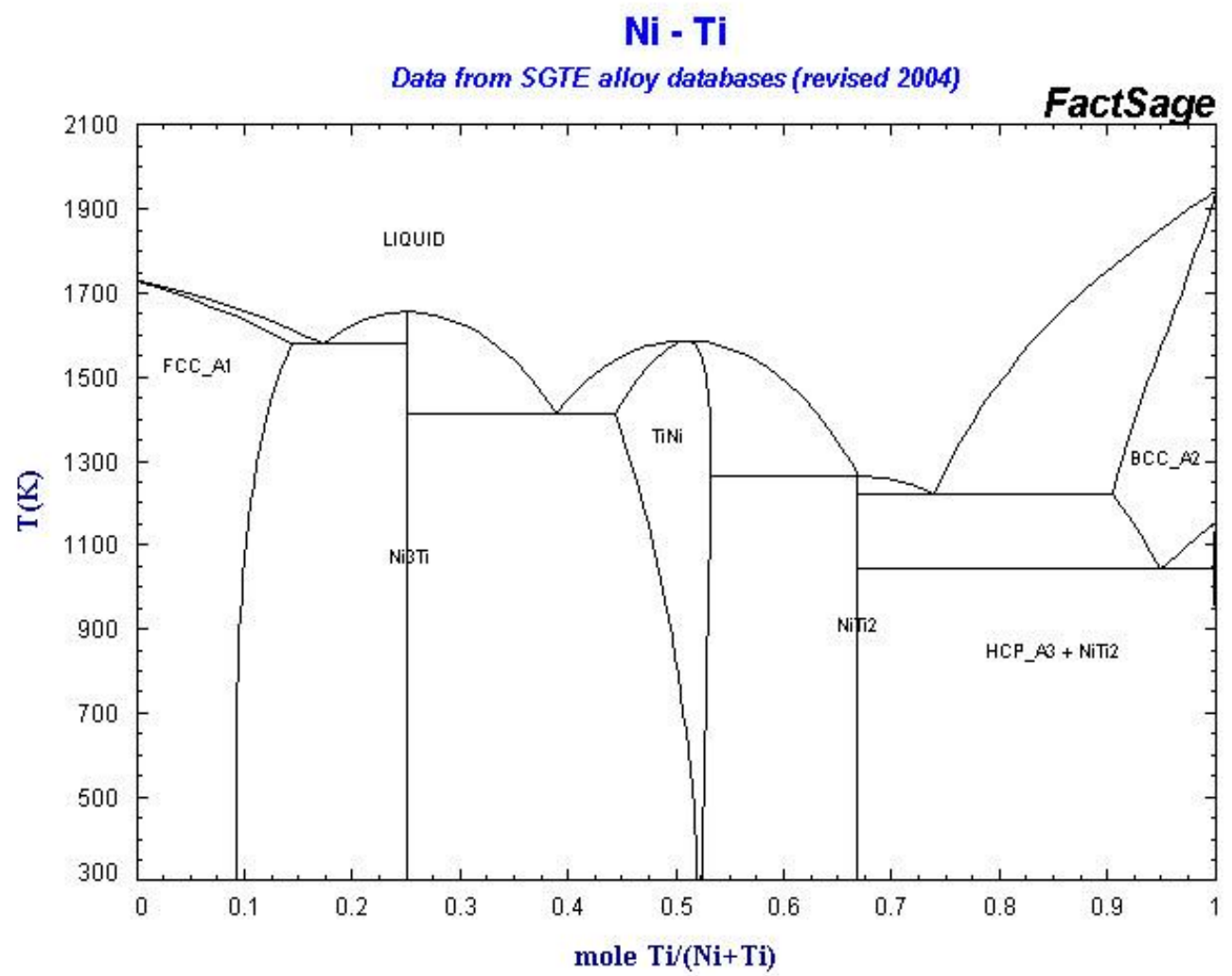

Figure 2-5: The binary phase diagram of NiTi alloys.

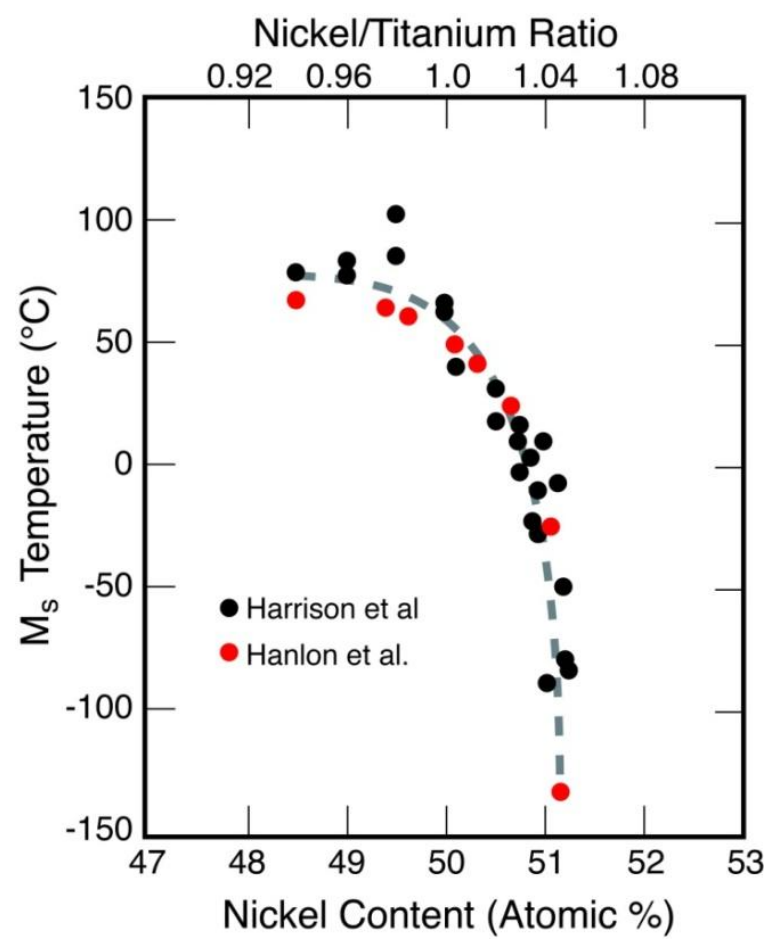

Figure 2-6: Variations in $M_{\mathrm{s}}$ temperature of NiTi SMA with respect to the nickel/ titanium ratio as well as nickel content [18]. 
Mechanical properties of NiTi SMAs are extremely sensitive to the compositions. The most commonly used manufacturing techniques are the vacuum arc re-melting and vacuum induction melting [68].

In addition, due to the super-elasticity of NiTi SMAs, cold working is extremely difficult, while hot working is comparably easier. The processing temperature is an essential factor in controlling the mechanical properties of NiTi SMAs. After the cold/hot working, a critical heat treatment is required to restore the shape memory effect or super-elasticity.

(2) R-phase

When the R-phase presents, NiTi SMA shows a so-called "premartensitic" rhombohedral phase transition prior to the martensitic transformation [69-71]. The generation of the R-phase of NiTi SMA originates from stress fields introduced by dislocations or precipitates $[52,72,73]$. The stress field might be introduced in several ways, for example, substitution of small amount of $\mathrm{Ni}$ with iron or aluminum; precipitation of $\mathrm{Ti}_{3} \mathrm{Ni}_{4}$ in $\mathrm{Ni}$ rich alloys; or by introducing dislocations through cold/hot working. The R-phase possesses smaller shape memory effect as compared to the martensitic and austenitic phases. Therefore, the R-phase transition is very useful in developing temperature-sensitive actuators due to their small temperature hysteresis (around $2{ }^{\circ} \mathrm{C}$ ).

The R-phase transition is accomplished by a lattice change from a cubic structure to a rhombohedral structure, which is achieved by elongating the cubic lattice along $\langle 111\rangle_{\mathrm{B} 2}$ direction. Upon cooling a NiTi SMA, the phases are present in the sequences of: (1) austenitic phase (B2), (2) incommensurate phase (I), (3) commensurate phase (R) at $T_{\mathrm{R}}$, and (4) martensitic phase at the $M_{\mathrm{s}}$. The transition from the austenite to incommensurate phase is a second order phase transition, and no lattice distortion is involved. Meanwhile, the transition from the 
incommensurate phase to $\mathrm{R}$ phase is a first order phase transition, the cubic lattice transits to a rhombohedral lattice. On the other hand, upon heating, up to the $T_{\mathrm{R}}$, most of the shape recovery occurs in the second order manner. When the temperature exceeds the $T_{\mathrm{R}}$, the R-phase transits to austenite phase with a perfect shape recovery [71].

(3) Heat treatment of the NiTi SMA

Transformation temperatures and mechanical properties of NiTi SMA can be modified by changing the temperature and time of annealing [74]. When anneal NiTi SMA below $550^{\circ} \mathrm{C}$, precipitations can be formed [25, 75]. Nishida et al. [76] reported that when a Ni-rich alloy was annealed, meta-stable phases of the $\mathrm{Ti}_{3} \mathrm{Ni}_{4}$ and $\mathrm{Ti}_{2} \mathrm{Ni}_{3}$ were formed. The $\mathrm{Ti}_{3} \mathrm{Ni}_{4}$ appeared as thin plate that dispersed densely in the matrix, which was effective in improving the shape memory characteristics [54]. When annealing a NiTi SMA sample at low temperature (for example, 400 ${ }^{\circ} \mathrm{C}$ ), with increasing the annealing time, $\mathrm{Ti}_{3} \mathrm{Ni}_{4}$ can be formed, followed by $\mathrm{Ti}_{2} \mathrm{Ni}_{3}$, and therefore finally reached a stable phase of $\mathrm{TiNi}_{3}$. Furthermore, annealing tends to increase the transformation temperature, since the local nickel content can be reduced by precipitation of nickel-rich phases [77]. It was reported that the effect of annealing was more prominent in a high nickel-content specimen than that in a low nickel-content one due to the presence of nickel-rich phases [54].

In addition, when NiTi SMA is annealed at temperatures ranging from $300{ }^{\circ} \mathrm{C}$ to $550{ }^{\circ} \mathrm{C}$, dislocations associated with internal residual strain will start moving, so as defects that were introduced in the previous deformations [78].

Temperature between $550{ }^{\circ} \mathrm{C}$ to $600{ }^{\circ} \mathrm{C}$ is the re-crystallization temperature of $\mathrm{NiTi}$ SMAs. However, over heating will cause over-growth of grains, thus change the mechanical properties of the sample. Nevertheless, heat treatments above the recrystallization temperature of the NiTi SMA can be applied to eliminate the 
R-phase [52].

By annealing NiTi SMA at $700{ }^{\circ} \mathrm{C}$, internal strain fields can be released through re-crystallization. Furthermore, dissolution of precipitations and even oxidation occur if heat treatment is carried out in air [79].

On another hand, cooling process can also affect the pseudo-elasticity of NiTi SMAs. A slowly cooled NiTi SMA specimen showed better pseudo-elasticity than those quenched specimens. Furthermore, the $A_{f}$ temperature of NiTi SMA was decreased when the cooling rate was increased [80]. This was attributed to an aging effect during cooling associated with the formation of fine precipitates. The presence of fine precipitates raises the flow stress for dislocation slip, thus favors the stress-induced martensitic transformation.

(4) Mechanical properties of NiTi SMAs

When under tensile stress, martensitic NiTi SMA is insensitive to the strain rate ranging from $0.002 \mathrm{~s}^{-1}$ to $300 \mathrm{~s}^{-1}$ [41]. A martensitic detwinning plateau exists when the strain rate reached $300 \mathrm{~s}^{-1}$, while the critical stress for detwinning increases slightly with increasing the strain rate. For austenitic NiTi SMA, the critical stress for stress-induced martensitic transformation increases with increasing the strain rate. This originated from the restricted heat release process when under high strain rate, which caused local heating [81].

Liu et al $[82,83]$ studied the stress-strain relations of martensitic NiTi SMA when under tension and compression, and different deformation mechanisms were proposed. The deformation mechanisms were further confirmed by observations of the microstructural changes using a transmission electron microscope (TEM). By applying a compressive stress, no flat stress-plateau existed in the stress-strain curve, even through a clear stress-plateau existed when under tensile stress. When 
under compression, the martensitic deformation proceeded through the generation and movement of lattice defects or dislocations. Meanwhile, when under tension, the early stage of martensitic deformation proceeded through the migration of variant interfaces between two adjacent martensitic plates.

In addition, for an anisotropic NiTi SMA, the stress-strain curve is dependent on the texture orientations [84]. For example, for a super-elastic NiTi SMA, the transformation stress and Young's modulus got maximum values in the rolling direction. Nevertheless the recoverable super-elastic transformation strain and hysteresis area reached maximum values when the applied stress was in an angle from the rolling direction [85].

\subsection{Tribology}

\subsubsection{Background}

Wear is a long-term subject of high importance in engineering since it is related to safety issues. Studying of wear becomes a discipline named as tribology. Tribology is a complex and multi-discipline subject, where mechanics, metallurgy, materials science, physics and chemistry are all involved. Wear can be harmful, but it can also be beneficial. For example, wear of moving parts due to friction can cause damage and thus high costs; wear of joints in medical implants can cause an inflammation of the human body. On the other hand, wear is beneficial in removing the un-necessarily deposited parts in the chemical/mechanical planarization of interconnects in electronic chips [86]. In the present study, small-scale wear on the NiTi SMA surface was studied to reveal the fundamental deformation mechanisms involved in the wear process, thereby to provide a guideline in materials selections when NiTi SMAs are used in wear-resistant applications. 


\subsubsection{Surface interactions}

Surface characterization is the first step in wear studies, since the wear performance of a material is dependent on the interaction of surfaces at the nanometer or sub nanometer scales. Furthermore, mechanical interactions of surface determine the deformation mechanisms in the wear process. The surface characterization methods and contact mechanics are introduced in the following section.

\section{(1) Surface characterization}

The crystal structure of a material is an important parameter in determining the surface properties, since some crystal structures are more adhesive or reactive than others. When two surfaces approach each other, the compatibility indicates whether the materials "like" each other or not. The interactions between two rubbing surfaces are strongly dependent on the compatibility of two materials if the contact area is relatively large.

Mechanical and metallurgical properties of surfaces are different from bulk properties due to defects and residual stresses introduced when creating surfaces. Furthermore, many materials can interact with the environment to form surface films such as oxides, which can further change the tribological properties of surfaces. On another hand, effective coatings enhance surface properties without changing the bulk properties. In the present wear study, fresh sample surfaces were prepared by grinding and polishing.

Surface roughness is an important experimental parameter in determining the wear performance. It is a measurement of the surface texture and quantified by the vertical deviations from the mean line value on the surface profile. The surface roughness is commonly defined by parameters including the average surface 
roughness $(R a)$, amplitude of profile $(R t)$, and root mean square $(R q)$ (Fig. 2-7). The amplitude of profile (Rt) represents the total height of the profile.

The Average roughness ( $\mathrm{Ra})$ is the mean deviation of the surface height from the mean line, which is also defined as arithmetical mean deviation of the assessed profile.

$$
R a=\frac{1}{L} \int_{0}^{L}|y(x)| d x
$$

Here, $y(x)$ is the height of the surface above the mean line at a position of $x$.

Root mean square $(R M S$, also abbreviated as $R q)$ is the root mean square deviation of the height from the mean line.

$$
R_{q}^{2}=\frac{1}{L} \int_{0}^{L} y(x)^{2} d x
$$

In general, the $R q$ is more sensitive to the changes in the surface height as compared to the $R a$.

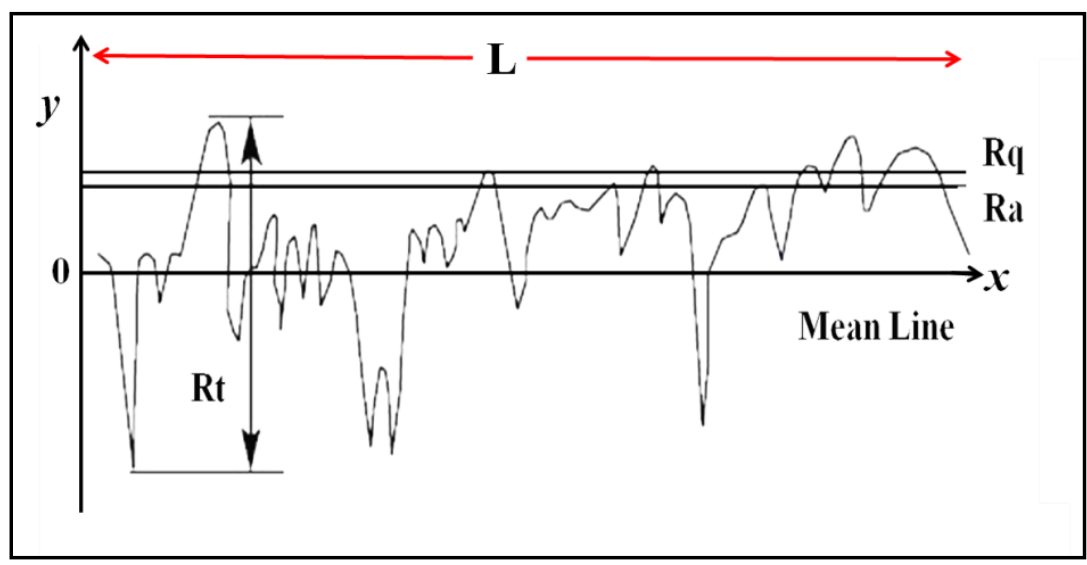

Figure 2-7: Schematic representations of the average surface roughness $(R a)$, amplitude of profile $(R t)$ and root mean square $(R q)$ [86]. 
As proposed by Jin et al [87], the contact between two surfaces is mainly the contact between the highest surface asperities. The contacted asperities will be in relative motion with the surface once plastic deformation dominates the contact area [88]. Furthermore, under the same contact condition, a larger surface asperity will cause higher local plastic deformation. Since the surface roughness is a measurement of the sizes of asperity, it affects the percentage of elastic/plastic deformation when two surfaces are in contact [89]. In this study, in order to minimize the effect of surface roughness on the wear behaviour of NiTi SMAs, samples were prepared with the average surface roughness value below $10 \mathrm{~nm}$.

(2) Mechanical interactions

The fundamental character of wear is the removal of materials from a surface, which is determined by the mechanical interactions between two moving parts. For a conventional material, when the contact stress is below the yield stress, fully reversible elastic deformation occurs. When the contact stress exceeds the yield stress, plastic deformation occurs, which causes a permanent shape change [90]. A typical stress-strain curve of a ductile material is shown in Fig. 2-8. For a brittle material, fracture occurs once the contact stress exceeds the yield stress.

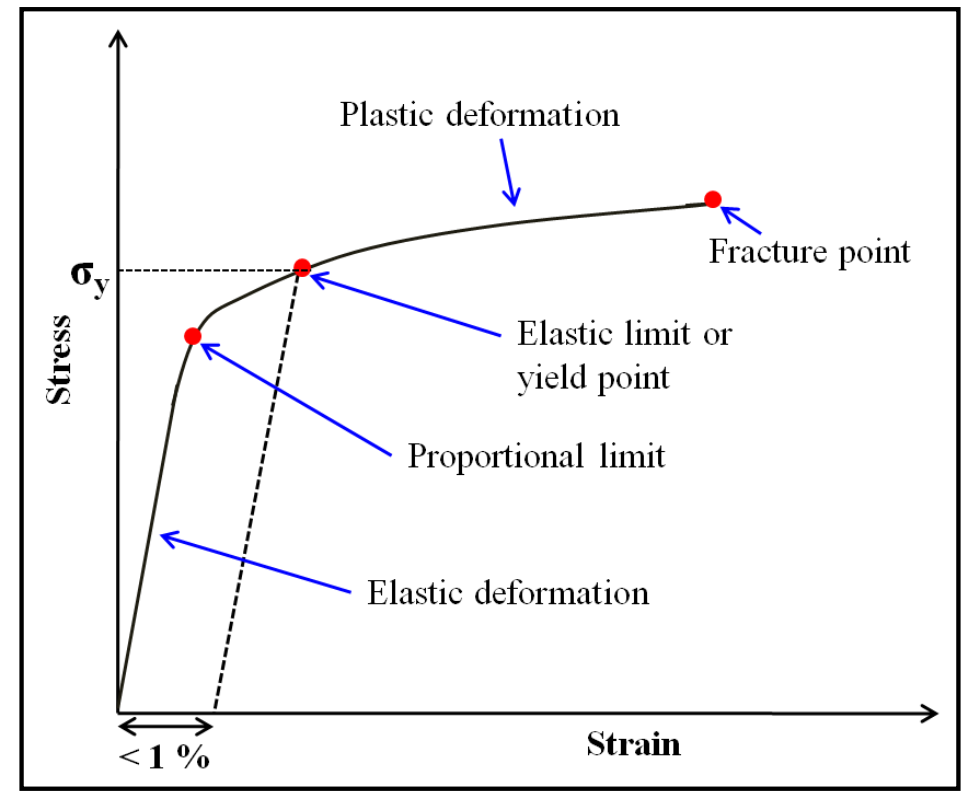

Figure 2-8: A typical stress-strain curve for a ductile metal [89]. 
In 1882, Hertz solved the elastic contact problem and proposed a mathematical model to predict the relation between the applied force and deformations. The relations are illustrated in Eqs. 2.11 and 2.12. An elastic sphere of radius " $R$ " indents an elastic half-space to a depth " $d$ ", and thus creates a contact area of radius " $a$ ", which is also named as the radius of footprint. The schematic illustrations on the contact is shown in Fig. 2-9. In addition, only elastic deformation was assumed on both the sphere and the elastic half-space.

$$
\begin{gathered}
a=\sqrt{R d} \\
A=2.6\left[\left(\frac{R}{E^{*}}\right)^{2 / 3}\right]\left(F^{2 / 3}\right) \\
\frac{1}{E^{*}}=\frac{1-v_{1}^{2}}{E_{1}}+\frac{1-v_{2}^{2}}{E_{2}}
\end{gathered}
$$

Here, $A$ is the contact area; $F$ is the applied force; $E^{*}$ is the combined modulus, which is related to the Young's modulus of the two materials; the $v_{1}$ and $v_{2}$ are the Poisson's ratio of each contact body.

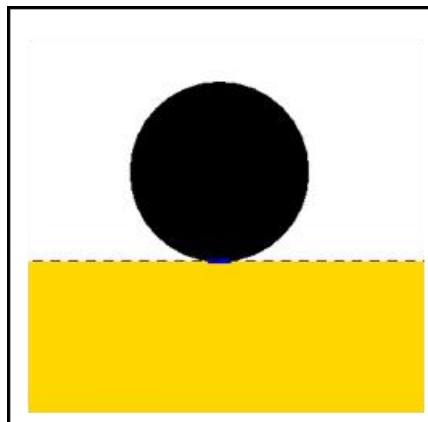

(a)

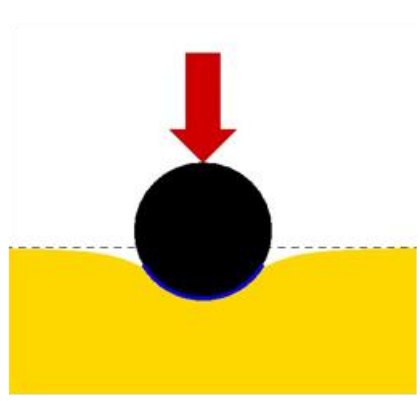

(b)

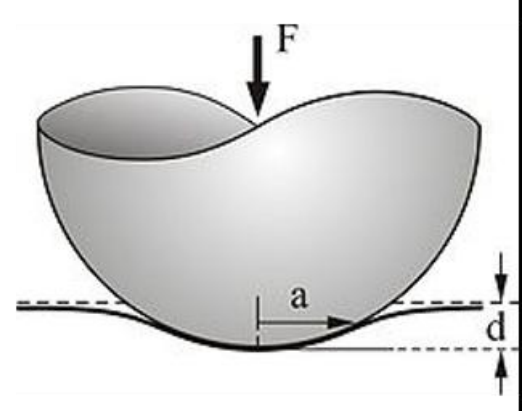

(c)

Figure 2-9: (a) Contact model proposed by Hertz, (b) the illustrations on the detailed deformation features and, (c) the simplified Hertzian contact model [91]. 
Furthermore, the applied force $F$ is related to $E^{*}, R$ and $d$ as shown:

$$
F=\frac{4}{3} E^{*}\left(R^{\frac{1}{2}}\right)\left(d^{\frac{3}{2}}\right)
$$

In the Hertzian elastic contact model, the materials in contact are elastic materials rather than fluid or viscous materials. The equations were further modified to study the elastic contact problems in NiTi SMAs [87, 90, 92].

When plastic deformation occurs, the contact problems become extremely complicated, hence it is difficult to obtain an exact analytical solution [93]. The Finite Element Method (FEM) is usually used to study the plastic contact problems, which is out of the scope in this report.

\subsubsection{Friction}

Wear process is related to the formation and separation of micro-contacts [94]. Friction is the resistance to motion when two bodies in contact move (or attempt to move) tangentially in the opposite directions. The static frictional force is the force that is required to initiate a sliding; while the kinetic frictional force is the force that is required to maintain the sliding. When a wear experiment is carried out in vacuum, clean metal couples have very strong adhesion since there is no surface film and adsorption layer. The presence of friction in a contact strongly affects the tangential force or resistive force for a motion. Thus, the friction strongly affects the wear behaviour of a surface.

\section{(1) General laws of friction}

There are three laws to define the friction force that is involved in a wear process: (I) the friction force $\mathrm{F}$, is proportional to the normal force L; (II) the friction force 
is independent on the apparent area of the contact; and (III) the friction force is independent of the sliding velocity.

These laws only apply in a limited condition. Discrepancy do exists between observations and laws when other range of factors which also affect the wear process are considered. Specifically, law three is applicable in rather limited scenarios since it works in a very narrow speed range [91, 92].

Friction is related to two factors, the adhesion of surfaces in contact, and mechanical inter-lock of surface asperities. The friction force is a sum of adhesion force and deformation force that are needed to remove or plow the asperities in a contact. Furthermore, the adhesion force is time-dependent, it is very small if the contact time is extremely short. Nevertheless, the mechanical inter-lock force increases with increasing the surface roughness.

\section{(2) Coefficient of friction}

Coefficient of friction (COF), or friction coefficient, is labeled by the Greek letter $\mu$. It is a dimensionless scalar value that is defined by the ratio of the friction force $(F)$ between two bodies and the normal force $(L)$ that presses them together.

$$
\mu=F / L
$$

In a wear process, the contact area, adhesion force and metallic inter-lock force can be increased by increasing the normal force. The coefficient of friction is widely used to define the wear process. As stated by Arnell et al [89], if the local coefficient of friction is less than 0.25 , plastic deformation will be limited and the plastic zone will be constrained. However, if the coefficient of friction is greater than 0.25 , the plastic zone will be further developed, thereby a more significant 
amount of plastic work can be done.

Several factors can affect the coefficient of friction, for example, the temperature, chemical and physical properties of the two surfaces in contact, lubricant, linear speed and wear cycles [19]. Many metals can form a thin oxide layer on the surface, which can reduce the coefficient of friction when the metal is worn against other bodies. However, when the oxide layer is removed after repeated wear cycling, the coefficient of friction increases due to debris generation.

\section{(3) Flash temperature}

In a wear process, mechanical energy is mostly dissipated in the form of heat. As a result, a temperature gradient can be introduced in the contact region, and the highest temperature occurs in the mostly deformed region. The term "flash temperature" is used to describe the temperature rise at a short duration on such asperity tips. A high local temperature likely speeds up the surface degradation process, vaporizes lubricants, and sometimes even forms sparks which is very dangerous in mines [92]. Under some extreme conditions, local heating due to a high flash temperature can change the microstructure of an alloy or even cause oxidation and melting. The local temperature rise can be estimated theoretically using Eq. 2.16:

$$
\Delta T=\frac{\mu \Delta L v}{4 J r\left(k_{1}+k_{2}\right)}
$$

Here, $\Delta T$ is the temperature rise at the junction of the contact in the wear process; $\mu$ is the coefficient of friction; $\Delta L$ is the load that carried by single junction; $v$ is the sliding speed; $J$ is the mechanical equivalent of heat; $k_{1}$ and $k_{2}$ are the thermal conductivity of materials in contact. 
Parameters in this equation have large variations when tested under different experimental conditions. Discrepancies exist between the calculated flash temperature and the real values $[91,92]$. Since temperature governs the presence of phase in NiTi SMAs, in this study, we have selected small-scale wear tests to minimize the flash temperature.

\subsubsection{Dislocations}

Macro-scale wear is related to debris generation. While micro-scale wear is related to local plastic strain accumulation, which is associated with the details of dislocation generation.

The energy barrier for the dislocation generation is proportional to the atomic bonding strength. Theoretically, the strength for bond breaking $\left(\tau_{\max }\right)$ is related to the shear modulus $(G)$, this relation is illustrated in Eq. 2.17. Furthermore, the elastic energy ( $\mathrm{J} /$ unit length) of a dislocation is proportional to the lattice distortion $b^{2}$ as shown in Eq. 2.18.

$$
\begin{aligned}
& \tau_{\max } \approx \frac{G}{\sqrt{3} \pi} \approx \frac{G}{5} \\
& U=\frac{K b^{2}}{4 \pi} \ln \frac{R}{r_{0}}=\alpha G b^{2}
\end{aligned}
$$

Here, $K$ is a constant called energy factor; $b$ is the Burgers vector which represents the magnitude and direction of the lattice distortion; $R$ and $r$ are the outer and inner cutoff radii, and represent angular distances from the dislocation; while $\alpha$ is a geometrical factor between 0.5 and 1.0, respectively.

In a perfect crystal, a permanent deformation may be caused by simultaneous break of all atomic bonds along a particular crystal plane. However, real crystals 
are not perfect. There are several types of defects present, for example, vacancies, dislocations and inclusions. Hence, the theoretical bond-breaking stress is normally greater than the measured value due to the presence of lattice imperfections.

Dislocations propagate along a lattice plane when under a shear stress, and the translation motion is called glide motion. On another hand, interfaces and grain boundaries in crystals usually act as strong barriers to dislocation gliding. For example, when a copper was loaded by pulsed stresses, dislocations were clearly obstructed by strong barriers (Fig. 2-10) [95]. If dislocations are interacting with obstacles such as inclusions or grain boundaries, internal stress fields can be introduced $[96,97]$.

In general, a dislocation tends to be oriented in a low-index direction on the glide plane in order to lower the free energy. The potential energy of a dislocation fluctuates with the period of lattice spacing, this is called the Peierls potential.

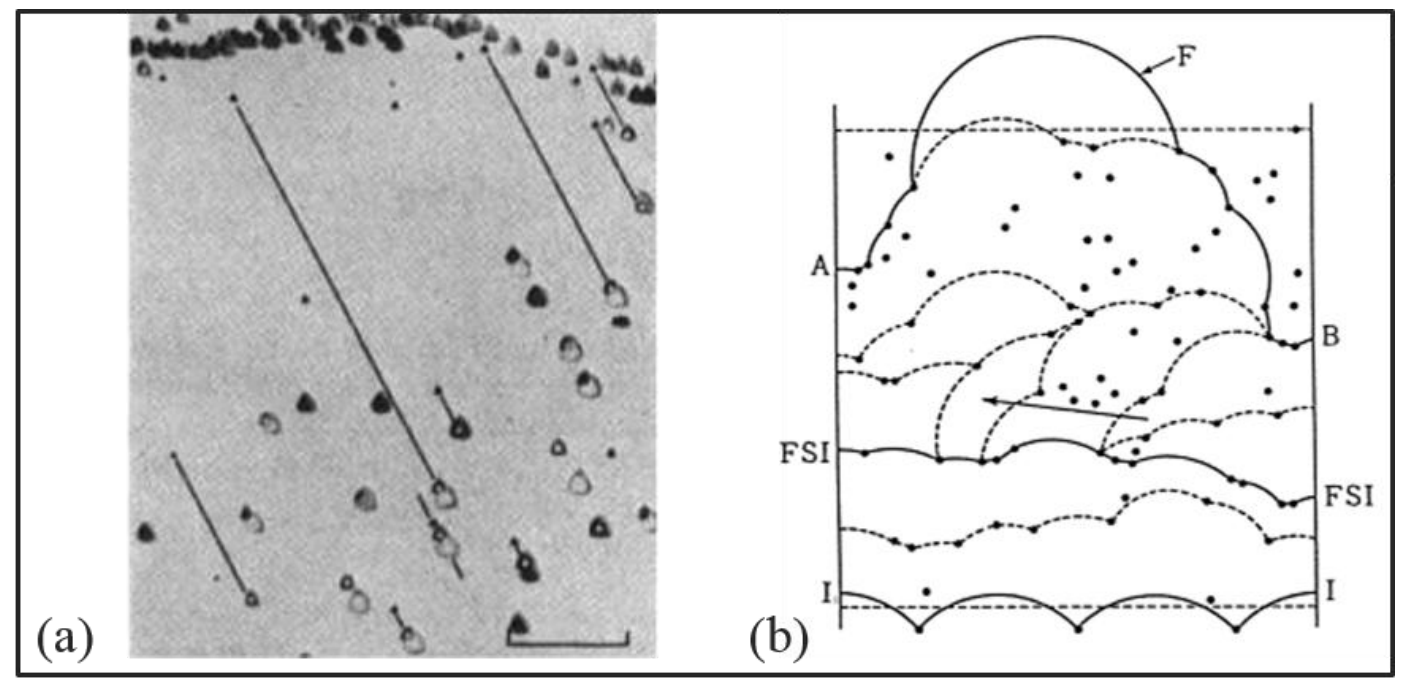

Figure 2-10: (a) Dislocation motion in a pure copper studied by the etch-pit method [95]; (b) computer simulation of dislocation motion through a random distribution of point obstacles [98]. 
The most popular form of the potential used for a quantitative description of the Peierls-Nabarro relief is a harmonic potential [99]:

$$
U_{0}(y)=\frac{\sigma_{P-N} a b}{2 \pi}\left[1-\cos \left(\frac{2 \pi y}{a}\right)\right]
$$

Here, $y$ is the dislocation displacement in a slip plane; $a$ represents lattice parameter; $b$ is the Burgers vector of a dislocation, which represents the magnitude and direction of the lattice distortion; $\sigma_{P-N}$ is the Peierls stress, which represents the force required for moving a dislocation within an atomic plane of atoms in the unit cell.

Dislocations may be pinned by imperfections of the crystal structure such as impurities and precipitates [100]. Intrinsic barriers for dislocation motion exist even in the most perfect crystal lattice, and these barriers were named as Peierls-Nabarro barriers. Their magnitudes can be characterized by the stress of pinning, or Peierls stress. Since the Peierls-Nabarro barrier affects the dislocation mobility, the mechanical properties of materials depend on the fundamental characteristics such as the type of crystal structure and the character of chemical bonds. The resolved shear stress that required to move an edge dislocation at $0 \mathrm{~K}$ is given by Eqs. 2.20 and 2.21 [101]:

$$
\begin{gathered}
\tau_{P-N}=G e^{-2 \pi W / b} \\
W=\frac{a}{1-\vartheta}
\end{gathered}
$$

Here, $W$ is the dislocation width; $G$ is the shear modulus; and $a$ is the lattice spacing of the glide plane. The magnitude of Peierls stress varies periodically as a dislocation moves within planes. The dislocation width $(W)$ is dependent on the bonding characteristics; while the magnitude of Burgers vector $(b)$ is dependent on 
the crystal structure. The Peierls model is an extremely simplified one, hence the result is not strictly applicable in the real crystals. However, the equation signifies an important fact, namely, the Peierls stress, which is very sensitive to the value of $(a / b)$ or $(W / b)$. Metallic crystals generally have large $(a / b)$ values because of their close-packed structure, which is inherent of the metallic bonds.

\subsubsection{Types of wear}

Materials show different wear behaviour when tested under different wear modes. Understanding of wear modes and the corresponding deformation mechanisms are of critical importance in determining the surface degradation process of materials. In the following part, different wear modes are introduced, including abrasive wear, adhesive wear, and fatigue wear.

\section{(1) Abrasive wear}

Abrasive wear is defined as the loss of material due to hard particles or hard protuberances that were forced against thereby moved along a solid surface [102]. There are two types of abrasive wear, two-body and three-body abrasive wear. As shown in Fig. 2-11a, the two-body abrasive wear occurs when a rough and hard surface is sliding against a soft surface. As a result, materials on the soft surface can be removed. For the three-body abrasive wear, particles are present in the contact before wear test. Schematic illustrations of this two types of abrasive wear are shown in Fig. 2-11a and 2-11b, respectively.

The size of the abrasive particles is also an important factor in the three-body abrasive wear. Large particles can introduce stress concentration in the contact area, which likely cause plastic deformation. Furthermore, when the size of the abrasive particles reaches a critical value, the wear rate can be stabilized due to the clogging of abrasive particles. 


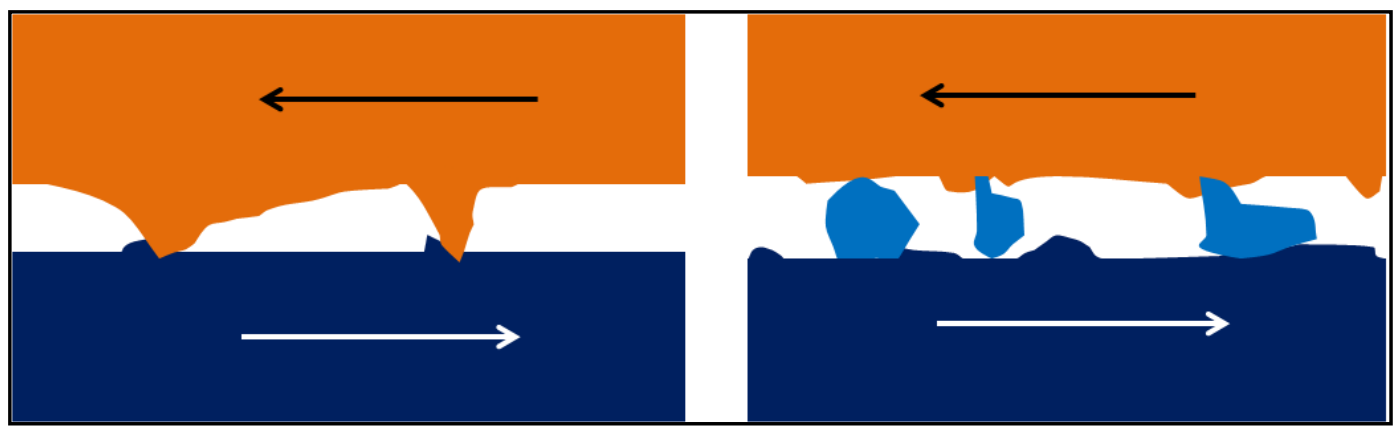

(a)

(b)

Figure 2-11: Schematic illustrations of two types of abrasive wear, (a) the two body abrasive wear and, (b) the three-body abrasive wear [102].

In the present study, ball-on-disk sliding wear tests and reciprocating wear tests were conducted. An alumina ball was pressed against a NiTi surface, hence the two-body abrasive wear occurred at the beginning of the wear process. The three-body abrasive wear may set in after repeated wear cycles due to the formation of debris.

The abrasive wear causes cutting and plowing of a ductile material, meanwhile it causes fracture and delaminating of a brittle material. The Archard's equation is commonly used to estimate the volume loss of a ductile materials due to abrasive wear [92]:

$$
V=K \frac{L}{H} l
$$

Here, $V$ is the volume loss in the wear process; $K$ is the abrasive wear coefficient; $L$ is the total force applied; $H$ is the hardness of the softer material when two surfaces are in contact; and $l$ is the sliding distance. This equation agrees with some experimental observations, but it is not working for materials such as NiTi SMAs which possess high levels of elasticity.

On the other hand, for a brittle material, the fracture toughness $\left(k_{c}\right)$ is considered 
when estimating the wear loss.

$$
V=K^{\prime} \frac{(E / H) L^{9 / 8}}{K_{C}^{1 / 2} H^{5 / 8}} l
$$

Here, the $K^{\prime}$ is the wear coefficient; $E$ is the Young's modulus; $H$ is the hardness of the material, and $l$ is the sliding distance. This equation can only be used as a point of reference since several types of wear may cooperate in a wear process.

\section{(2) Adhesive wear}

The adhesive wear is defined as the loss of material due to the action of one material sliding over another associated with welding (adhesive) at the localized contact region. In the beginning of adhesive wear process, a normal force $(F)$ is applied when two materials get in contact. Cold welds form at the contact asperities as shown in Fig. 2-12, and those welds are sheared during sliding. When shear occurs at the original interfaces, no adhesive wear occurs. However, shear occurs in the relative softer material when the interfacial bonding strength exceeds the shear strength of the softer material. As a result, wear fragments form from the softer material, indicates the starting of adhesive wear. With subsequent rubbing in sliding, some of the adhered materials become detached, thus lead to the formation of debris. In this case, the adhesive wear transits into the abrasive wear.

The adhesive wear may occur between metallic materials, ceramics, polymers or their combinations. The adhesive wear resistance of a material is dependent on the adhesion or compatibility of the pair of materials in contact. Surface films like the oxides or lubricants have strong effects on the adhesive wear resistance, since they can modify the surface properties. 


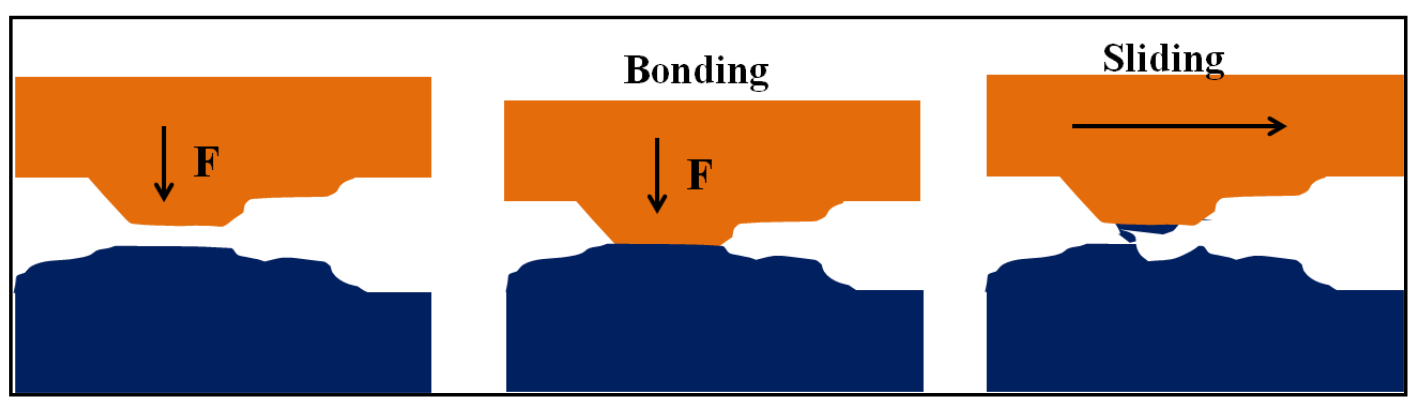

Figure 2-12: Schematic illustration of the adhesive sliding wear process.

The adhesion between ceramic materials is negligible, even if the surface roughness is as low as a few atomic spacings. This is due to the strong ionic bonds in ceramic materials. For other materials, when the distance between two surfaces is less than $1 \mathrm{~nm}$, short range bonds can be formed, for example, the metallic bonds, molecular bonds, and Van Der Waal's bonds. The types of bond formed depend on the chemical properties of the surfaces. Furthermore, in the adhesive wear process, materials transfer in between the counter-body, and the volume obeys the Archard's equation [91]. The volume loss of materials increases with an increase in the sliding distance, or a decrease in the hardness.

The compatibility of the counter-body affects the adhesive wear process of materials. With an increase in the compatibility, materials tend to bond with each other, thus adhesive wear can be enhanced. In addition, materials with higher hardness show better adhesive wear resistance. Nevertheless, an effective lubrication can reduce the adhesion of two surfaces, thus can further reduce the adhesive wear. The Energy Dispersive Spectroscope (EDS) is used to analyze the materials that adhered to the surface, and this is also used to distinguish the adhesive and abrasive wear. The adhesive wear can be minimized when a counter-body having high hardness and low compatibility is used. This is the reason to select the high hardness alumina $\left(\mathrm{Al}_{2} \mathrm{O}_{3}\right)$ counter-ball in the present wear study. 
(3) Fatigue wear

Fatigue wear is defined as the loss of material due to repeated cyclic loading. Crack initiation and propagation are involved in the fatigue wear process, and failure occurs with further crack development. Under cyclic stresses, dislocations pile up at grain boundaries thus cause local stress concentration. As a result, cracks can be initiated at those regions. By increasing the wear cycles, cracks propagate and finally lead to the failure of the material.

For the fatigue wear, when the contact stress is below the stress limit, no failure occurs even after a large number of wear cycles. This is true when there are no defects, voids or pores present in the material. When the contact stress exceeds the fracture stress of the material, fracture or failure occurs immediately. When under an intermediate stress, plastic strain accumulates in repeated wear cycles, therefore, cracks can be initiated and propagated [86].

Fretting wear is a special case of fatigue wear, which occurs when the contact length is higher than the amplitude of the reciprocating motion. Hence, the surface is partially exposed. Generally speaking, the fretting wear can be avoided through changing the displacements and contact stresses in a design [96].

\subsubsection{Modes of wear test}

(1) Abrasive wear test

The dry sand/ rubber-wheel abrasion tester illustrated in Fig. 2-13a is designed for abrasive wear studies. Abrasive particles are applied in between the two wearing bodies. The rubber wheel is used at low-stress abrasion conditions, while the steel wheel is used at high speed abrasion conditions. 


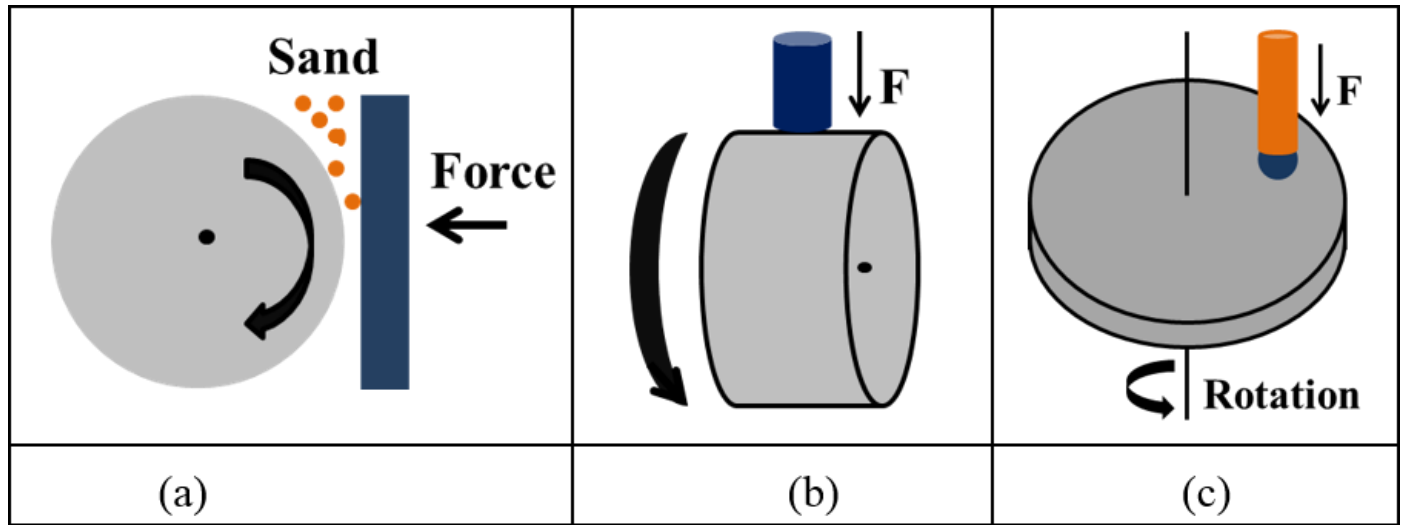

Figure 2-13: Schematic illustrations of different types of wear testers. (a) A dry sand/rubber-wheel tester; (b) a block-on-drum tester; (c) and, a ball-on-disk tester.

The block-on-drum tester (Fig. 2-13b) is suitable for abrasive wear studies when under high speeds and high wear rates. Another type of tester is called the block-on-ring tester, which is similar to the block-on-drum tester. The only difference is the thickness of the drum used.

The settings of the pin-on-disk and ball-on-disk tester are similar. The only difference is the shape of the counter-body used. This setting is commonly used in abrasive wear and adhesive wear studies. In the present study, wear tests were conducted on the ball-on-disk tester.

Flash temperature is the temperature at the tip of individually contacted asperities in the wear process, and the bulk temperature appears a few tens of microns below the actual contacted surface [103]. Furthermore, the flash temperature in the wear track region is related to the sliding speed $(v)$, applied force $(F)$, contact area $\left(A_{r}\right)$ and the coefficient of friction $(\mu)$. The flash temperature $\left(T_{\mathrm{f}}\right)$ and the bulk temperature $\left(T_{\mathrm{b}}\right)$ are related by Archard's formula shown below [104]:

$$
T_{f}=T_{b}+\frac{\mu F v}{A_{r}}\left(\frac{1}{k_{1} / l_{1 f}+{ }^{k_{2}} / l_{2 f}}\right)
$$


Here, $T_{b}$ is the bulk surface temperature in a steady state; $k_{1}$ and $k_{2}$ are the thermal conductivity of two surfaces in contact; $l_{l f}$ and $l_{2 f}$ are the equivalent linear heat-diffusion distances of the pin and disk. The values of the $l_{l f}$ and $l_{2 f}$ are determined by several factors, for example, the radius of asperities, real contact area, thermal diffusivity of the disk, and some correction factors.

(2) Nano-indentation and nano-scratching tests

The Nano-indentation and Nano-scratching tests are used to study the micro-scale wear performances of materials. Three types of probes are used, namely, a three-sided pyramidal probe (also known as the Berkovich probe), a cono-spherical probe, and a specialty probe. The load-displacement curves can be obtained from the nano-indentation test. Hence, the hardness and Young's modulus of materials can be estimated. Fig. 2-14 shows a typical load-displacement curve, here, $h_{\text {end }}$ is the maximum displacement achieved; $P_{\max }$ is the maximum force applied; and $h_{r}$ is the remained displacement after unloading.

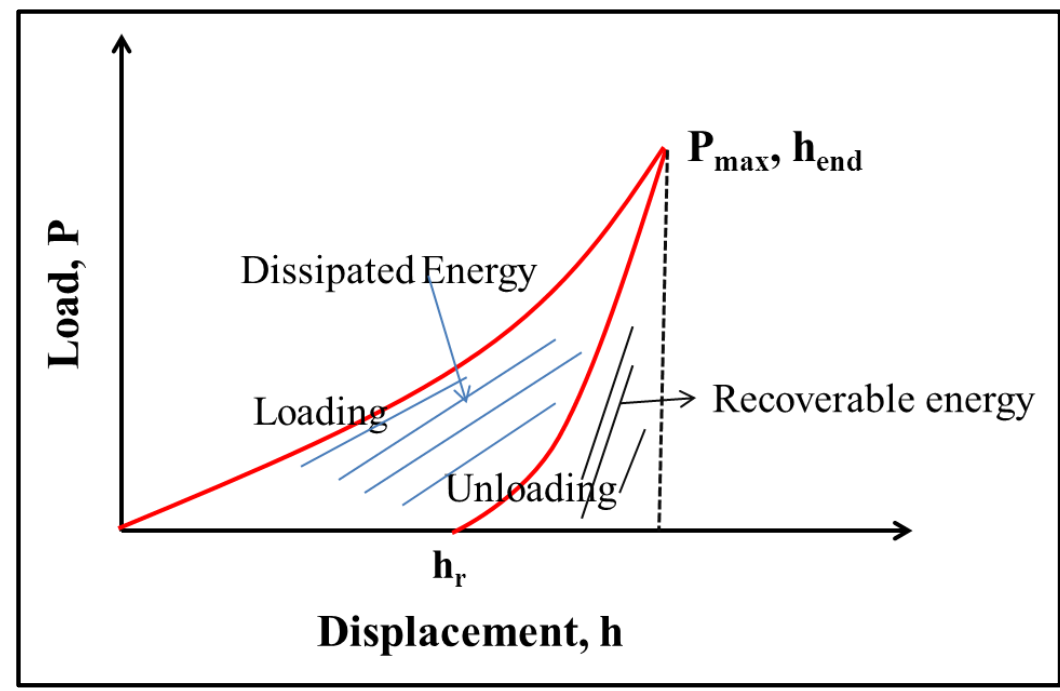

Figure 2-14: Schematic illustrations of a load-displacement curve obtained from the nano-indentation test. 
The amount of dissipated energy and recoverable energy after an indentation is dependent on materials mechanical properties. The relations are shown below.

$$
\begin{gathered}
W_{t}(\text { Total energy })=\int_{0}^{h_{\text {end }}} p d h \\
W_{r}(\text { recoverable energy })=\int_{h_{r}}^{h_{\text {end }}} p d h \\
\text { Energy dissipation ratio }=\frac{W_{t}-W_{r}}{W t}
\end{gathered}
$$

The hardness of a material $(H)$ can be calculated using Oliver Pharr method [92]:

$$
H=\frac{P_{\max }}{A(h)}
$$

In this equation, $A$ is the contact area as a function of the displacement $h$. The value of $h$ is dependent on several factors as shown in Eq. 2.29.

$$
h_{c}=h_{\text {end }}-\theta \frac{p_{\max }}{s}
$$

Here, $h_{c}$ is the recovered displacement; $S$ is the contact stiffness, which is the slope of the unloading curve at $P_{\max }$. The value of $\theta$ is dependent on the tip geometry, which is $0.72,0.75$ and 1 , for cone-, sphere-, and flat-punch-geometry, respectively.

\subsubsection{Wear-resist materials}

(1) Metallic materials

Steels are widely used as tribo-materials due to their high availability and relative 
good wear resistance. Mechanical properties of steels are strongly dependent on their microstructure, which can be modified by heat treatment and work hardening. The martensitic steel is the hardest steel but it is brittle, it shows high resistance to the low-stress wear. However, the martensitic steel is not suitable for high-temperature applications where martensite is not stable. Nevertheless, the austenitic steel is commonly used at high temperatures, which shows high impact resistance. In addition, the wear resistance of a steel can be improved by inclusions, since its hardness can be improved by solid solution strengthening or second phase strengthening. Applications of steel for wear-resistant purpose are in such a wide range that we can find them everywhere in life.

Copper based alloys are important wear resistant materials due to their good electrical conductivity, thermal conductivity, corrosion wear resistance, and high strength. They are widely used in the underground mines, hydroelectric facilities and bearings.

Aluminum-silicon alloys possess comparable strength, high corrosive wear resistance, and good thermal conductivity. Furthermore, aluminum-silicon alloys are lighter than the stainless steel and copper based alloys.

Super-alloys have high oxidation resistance and high strength at high temperatures, so they are capable of high temperature applications. For example, in Ni based alloys, an oxidized layer can be formed which can reduce the adhesion during sliding when the temperature is high. High entropy alloy of $\mathrm{Al}_{\mathrm{x}} \mathrm{Co}_{1.5} \mathrm{CrFeNi}_{1.5} \mathrm{Ti}_{\mathrm{y}}$ was reported with good wear resistance [105]. The cobalt based alloys possess high strength at high temperature, and they also have high corrosion resistance and high impact resistance. In addition, the shape memory alloy of Fe-Mn-Si-Cr-Ni showed better wear resistance than the Cr-18Ni-9Ti stainless steel [106]. The super-elastic NiTi shape memory alloy possesses an excellent wear resistance, which is benefited from their super-elasticity $[107,108]$. 
(2) Ceramic materials

Ceramic materials have high strength and are very stable at high temperatures. They also show high resistance to the corrosion and oxidation due to their stable ionic bonds or covalent bonds. Ceramic materials show low thermal conductivity and low chemical reactivity. Therefore, they are commonly used in areas such as the engine components, rolling bearings and bio-medical implantations. On another hand, ceramic materials are brittle and have low toughness, thus the crack initiation is difficult while the propagation is easy. Catastrophic failure occurs in ceramic materials without much warning, thus they are rarely used for structural applications. The alumina $\left(\mathrm{Al}_{2} \mathrm{O}_{3}\right)$ ceramic counter-ball was selected in the present wear study due to their high hardness and good wear resistance.

\section{(3) Polymer materials}

Polymer materials have advantages of light weight, high corrosion resistance, ease of manufacturing, good bio-compatibility and low modulus. However, for a polymer material, the strength is relatively low as compared to the metallic and ceramic materials. Furthermore, the wear resistance of a polymer material is strongly temperature-dependent. The polymer materials that used in the wear-resistant applications are usually specially designed, thus the cost is very high as compared to the metallic and ceramic materials.

\subsection{Wear studies of NiTi SMAs}

\subsubsection{Overview of past and recent progresses on the wear study of NiTi SMAs}

NiTi SMA has been reported with superior wear resistance as compared to the conventional wear resistant materials. It has also been suggested as a new candidate material for bio-medical devices and Micro-Electro-Mechanical-System 
(MEMS) devices. Significant amount of work have been published by Qian et al [109] to discuss the relationship between the mechanical properties and wear behaviour of NiTi SMAs. Furthermore, the indentation behaviour of NiTi SMAs has been studied to further understand the contact stresses involved in the wear process $[79,110]$. Researchers have also compared the wear resistance of NiTi SMAs with conventional wear resistant materials, for example, the stainless steel and nitrided 38CrMoA1A alloy steel $[14,15]$. The super-elasticity of NiTi SMAs associated with a high percentage of recoverable strain has been suggested as the main contribution factor for their superior wear resistance. Furthermore, Yan and $\mathrm{Li}[90,111]$ have reported simulation/modeling works on the wear behaviour of NiTi SMAs, which further provides numerical evidences on the contribution of pseudo-elasticity on the wear resistance of NiTi SMAs.

A large number of wear studies were reported, and different parameters were used in the wear tests, for example, the applied loads, temperatures, and sliding speeds. When tested under different wear conditions, NiTi SMAs deform differently thus caused different paces of surface damage. Understanding of the deformation mechanisms involved in the wear process is essential in understanding the surface degradation processes when NiTi SMAs are used for wear-bearing devices. However, such understanding is missing. Therefore, a systematic work on evaluating the wear resistance of NiTi SMAs is needed.

This section gives a general review on the wear studies on NiTi SMAs in both experimental and simulation/modeling works.

\subsubsection{Wear studies on the martensitic NiTi SMAs}

Compared to several conventional wear resistant materials, the martensitic NiTi SMA showed better wear resistance when tested under different wear conditions. For example, the martensitic NiTi and the GCr15 steel have been worn against a 
GCr15 steel ball. Lower coefficient of friction as well as smaller wear scar were observed on the martenstic NiTi SMA as compared to the GCr15 steel [12]. In a similar study, the martensitic NiTi SMA has been worn against a BS11 rail steel when under the pin-on-disk sliding wear mode. Under a high contact pressure, the combined wear rate of the NiTi sample against the BS11 steel was lower than that of a steel-on-steel pair [15]. Since the hardness of the martensitic NiTi is much lower than the GCr 15 steel and the BS11 rail steel, the detwinning process of the martensitic NiTi SMA has been suggested as the main contribution factor for its better wear resistance.

The contact model for the martensitic NiTi SMA that proposed by Qian et al [12] is shown Fig. 2-15. Only elastic deformation was assumed.

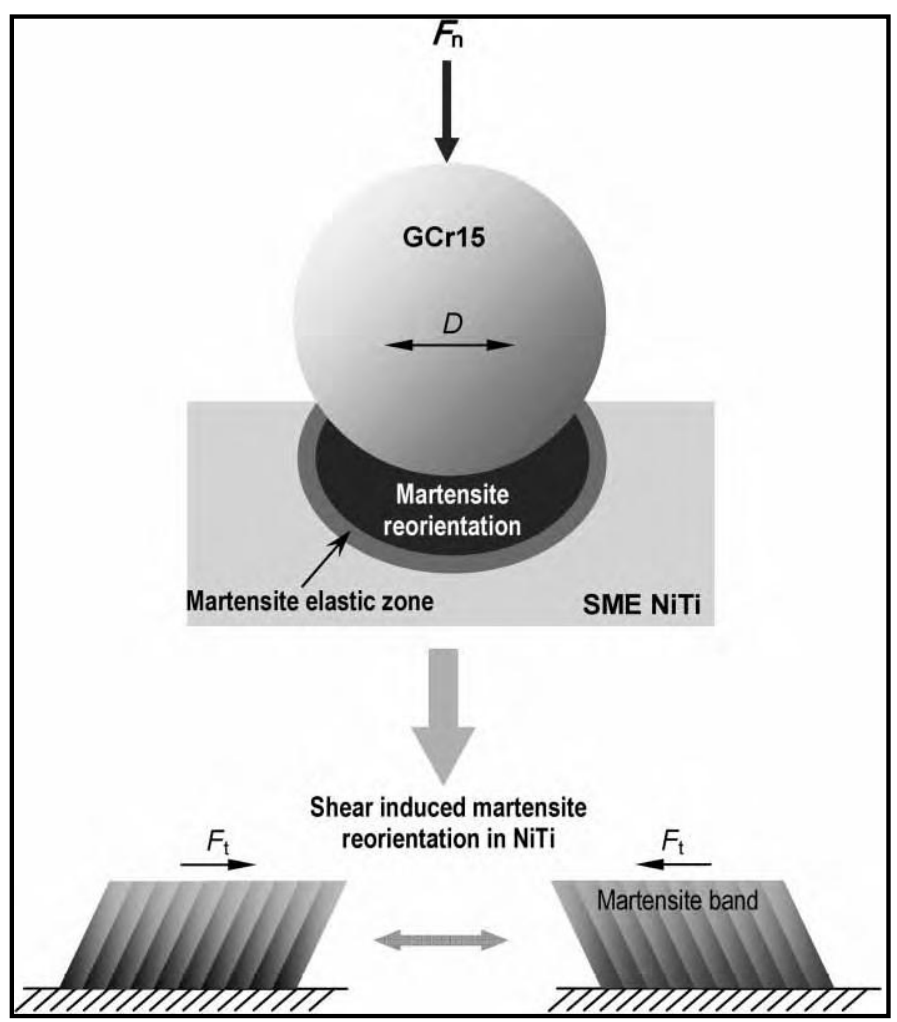

Figure 2-15: Schematic representation of the contact mechanism of martensitic NiTi SMAs [12]. 
Under a normal applied load, the contact area consists of a martensitic reorientation zone and an elastic deformation zone. When the contact stress is below the yield stress of the detwinned martensite, deformations can be accommodated through the martensite variants reorientation process. As a result, the plastic strain accumulation can be retarded thus wear can be reduced. This explains better wear resistance of the martensitic NiTi SMA than the GCr15 steel and the BS11 rail steel, since the elastic accommodation ability of steels is poor.

Furthermore, the martensitic NiTi SMA is capable of cyclic hardening under high strain conditions, which is likely to further contribute to the wear resistance [112]. However, once permanent damage is done, wear loss occurs and the recoverability of NiTi SMAs no longer contributes to the wear resistance. For example, when tested under a load of $80 \mathrm{~N}$, under pin-on-disk and three-point bending test mode, the amount of recoverable deformation was studied on martensitic NiTi samples with/without wear loss. Higher recovery ratio was observed in the bending test as compared to the wear test, since wear loss and frictional heating occurred in the wear test [112].

In addition, the facility or difficulty of re-transforming/re-orienting the existed martensite plates also affect the wear resistance of martensitic NiTi SMA. The weight loss of a martensitic NiTi SMA was reported to increase with an increase in the $M_{s}$ temperature [113].

\subsubsection{Wear studies on the austenitic NiTi SMAs}

A large number of wear studies were reported on comparing the wear resistance of the austenitic NiTi SMA and conventional wear resistant materials. When tested under an extreme low load, nano-indentation and scratching tests were conducted to study the micro-scale wear behaviour of the austenitic NiTi SMA. When under applied loads ranging from $20 \mu \mathrm{N}$ to $100 \mu \mathrm{N}$, the austenitic NiTi SMA showed 
better wear resistance than the AISI304 stainless steel [114]. When under applied loads ranging from $1 \mathrm{mN}$ to $10 \mathrm{mN}$, the NiTi/diamond-tip pair showed low coefficient of friction (that is, in between 0.09 to 0.12 ) and insignificant surface damage [110]. In addition, the austenitic NiTi SMA has shown better wear resistance than the GCr15 steel.

When under an extreme high load, materials loss due to abrasive or adhesive wear occurs. For example, under applied loads ranging from $4 \mathrm{~N}$ to $30 \mathrm{~N}$, the austenitic NiTi SMA showed better wear resistance than the commercial wear resistant materials including the Co45 alloy, surface nitrided 38CrMo-AIA alloys, aluminum (2024Al), and stainless steel (Ni-hard-4) [13]. When tested under an applied load of $100 \mathrm{~N}$, the austenitic NiTi SMA showed better fretting wear resistance than the GCr15 steel $[109,115]$.

The superior wear resistance of the austenitic NiTi SMA originated from deformation accommodations through the fully reversible stress-induced martensitic transformation process. For a conventional wear resistant material, three stages of wear occur, namely, the plastic strain accumulation stage, the crack initiation and propagation stage, and the debris formation stage [90]. However, for the austenitic NiTi SMA, the plastic strain accumulation stage can be retarded due to the effective deformation accommodation through the SIMT process [111]. As a result, the wear process can be retarded. In addition, the super-elasticity of the austenitic NiTi SMA reduces the stress concentration in the contact area, thus further retards the crack initiation stage. Nevertheless, the super-elastic deformation is fully reversible upon unloading, this further retards the plastic strain accumulation thereby suppresses the crack formation and propagation.

A contact model was reported by Qian et al when an austenitic NiTi SMA sample worn against a GCr15 steel counter-ball, the model is shown in Fig. 2-16 [114, $115]$. 


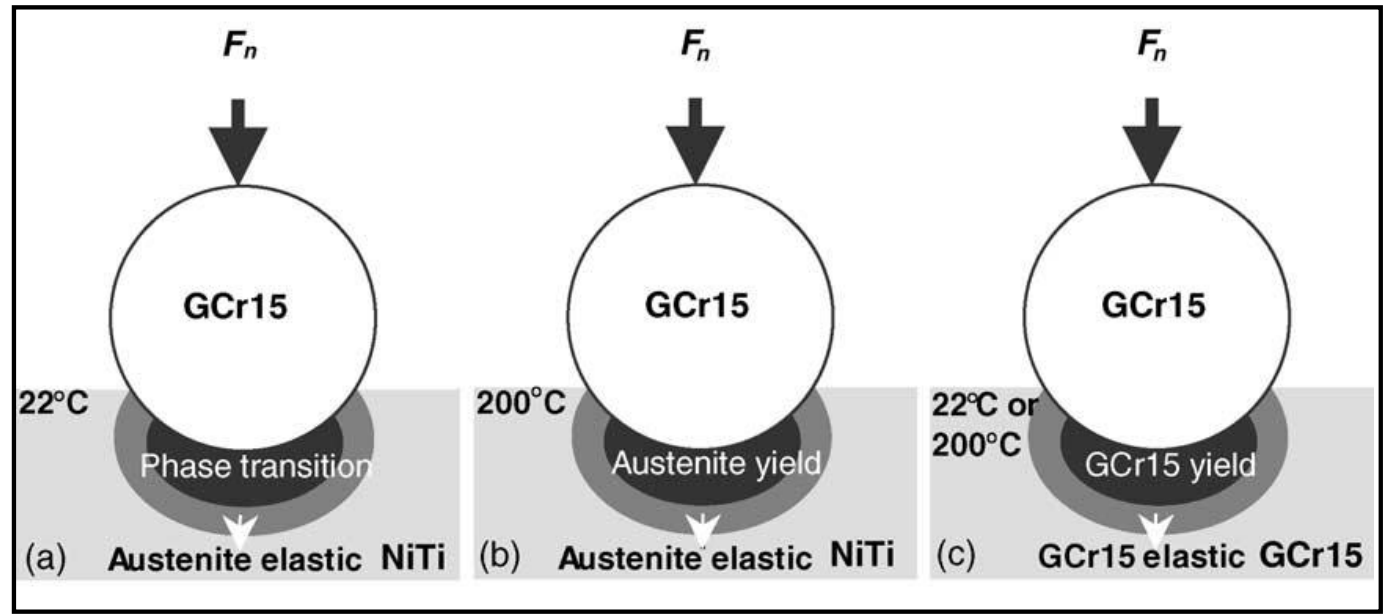

Figure 2-16: Contact mechanisms of (a) a NiTi/GCr15 pair at $22{ }^{\circ} \mathrm{C}$, (b) a NiTi/GCr15 pair at $200{ }^{\circ} \mathrm{C}$ and, (c) a GCr15/GCr15 pair at $22^{\circ} \mathrm{C}$ and $200{ }^{\circ} \mathrm{C}[114$, $115]$.

At $22{ }^{\circ} \mathrm{C}$, the contact region of the austenitic NiTi SMA consisted of an elastic deformation zone at the edge, and a phase transition zone in the center. While at $200{ }^{\circ} \mathrm{C}$, due to the loss of super-elasticity, the contact region consisted of an elastic deformation zone and a yield zone. On a contrary, for the GCr15 steel, the contact region consisted of an elastic deformation zone and a yield zone at 22 and $200{ }^{\circ} \mathrm{C}$. Better wear resistance of the austenitic NiTi than the GCr15 steel was attributed to the larger elastic deformation zone on the NiTi SMA surface. Furthermore, the wear resistance of the austenitic NiTi SMA degraded when the temperature was extremely high.

Nevertheless, Feng et al [116] introduced the concept of phase transformation shakedown to explain the superior wear resistance of the austenitic NiTi SMA. In this concept, an alternated transformation strain in the repeated wear cycles stabilized the deformation strain. Hence, no additional net deformation strain was accumulated in the wear process, which caused better wear resistance.

In addition, the experimental test condition affects the wear resistance of the 
austenitic NiTi SMA. Imbeni et al [117] studied the abrasive wear behaviour of the austenitic NiTi SMA when three types of abrasive particles were used, that is, the silicon carbide, alumina and crushed soda lime glass. They found that the angular particles (small and round) caused higher materials removal rate on a smooth surface than the non-angular particles. Furthermore, the roughness of the worn surfaces was increased with an increase in the particle size, or an decrease in the particle roundness factor.

\subsubsection{Simulation/modeling studies of the wear behaviour of NiTi SMAs}

Wear of materials originates from plastic deformation due to sliding or particle impulsion when under a cyclic-mechanical contact. In a wear process, surface damage accumulation causes the crack formation and propagation, which further leads to the delaminating wear in ductile materials. A damage gradient exists beneath the contact surface, which is dependent on the plastic strain and hydrostatic pressure gradients [118]. The wear resistance of a ductile material can be evaluated by its capacity of deformation accommodation under a contact stress [119]. A material is expected to possess high wear resistance if their plastic deformation is retarded. When tested on a self-mated alumina under the ball-on-disk contact model, the wear coefficient was reduced as the apparent area of contact was increased [118].

Due to the super-elasticity of NiTi SMAs, the contact problem becomes extremely complicated. Some wear studies assumed an elastic deformation, hence Hertzian elastic contact model was applied in stress-strain analysis [120]. For plastic contact problems, the Finite Element Method (FEM) was used to study the stress-strain behaviour [110]. Nevertheless, solid mechanics was also applied to analyze the contact problems, and the theoretical framework is based on the simplified phenomenological constitutive model [121]. 
Yan [90] analyzed the plastic strain accumulation of the NiTi SMA using the FEM. The total strain rate of the super-elastic NiTi SMA composed of three parts:

$$
\dot{\varepsilon}=\dot{\varepsilon}^{e l}+\dot{\varepsilon}^{t r}+\dot{\varepsilon}^{p l}
$$

Here, $\dot{\varepsilon}^{e l}$ is the elastic strain rate that is described by the isotropic Hooke's law; $\dot{\varepsilon}^{\text {tr }}$ is the transformation strain rate, which is proportional to the volume fraction of the martensite in the matrix; $\dot{\varepsilon}^{p l}$ is the plastic strain rate due to dislocation movements, which can be determined using the isotropic hardening theory based on von Mises yield condition.

By using multi-scale micromechanics approaches, the maximum number of sliding cycles at each individual asperity was correlated with the macroscopic maximum number of stamping operations that required to remove the coating [122].

Comparing to the stainless steel, lower Young's modulus of the NiTi SMA caused lower contact pressure. Meanwhile, the transformation stress of the NiTi SMA is lower than the yield stress of the stainless steel, this further reduced the contact pressure [122]. Therefore, the plastic deformation was retarded. The numerical results also revealed that the occurrence of plastic deformation was hindered by high plastic yield stress of the stress-induced/detwinned martensite.

When two surfaces get into contact, the asperties that existed on surfaces are deformed thus the subsequent wear behaviour is dependent on the deformation mechanisms of the asperities. Such contact is treated as a two-dimensional plane strain problem. The FEM analysis on the interfacial interactions in the wear process of the NiTi SMA was reported by Li and Liu [111]. The contribution of pseudo-elasticity on the superior wear resistance of the NiTi SMA was demonstrated using Fig. 2-17. 


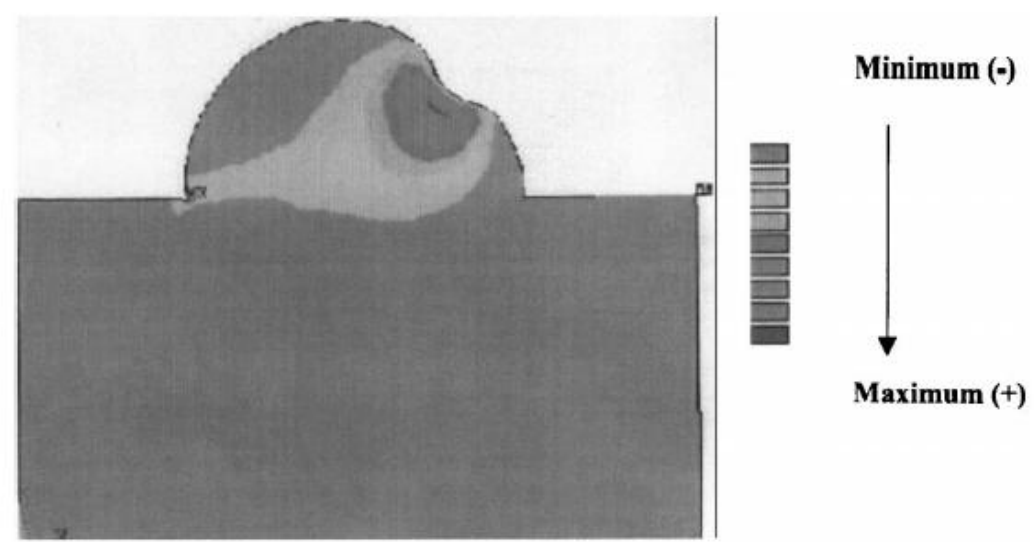

Figure 2-17: The FEM model on the plastic strain distribution in a surface asperity [111].

The results illustrated that the maximum plastic strain occurred beneath the contact surface $[88,111]$. When a significant amount of plastic strain is accumulated thus reaches the fracture strain of the surface, cracks nucleate at the mostly deformed region. Further wear cycles resulted in delamination of the deformed materials. The pseudo-elastic deformation of the NiTi SMA enlarges the contact area, therefore reduces the stress concentration. This results in less plastic strain accumulation in the NiTi SMA as compared to the conventional metals.

\subsubsection{Influential factors on the wear behaviour of NiTi SMAs}

(1) Microstructure

The deformation mechanism of NiTi SMAs is dependent on the phases present. For the martensitic NiTi SMA, strain accommodation through the detwinning process can retard the plastic strain accumulation therefore improve the wear resistance. For the austenitic NiTi SMA, strain accommodation through the stress-induced martensitic transformation process is the main contribution factor for their good wear resistance. 
When under different applied loads, different deformation mechanisms are involved in the wear process, which correspond to different deformation stages in the stress-strain curve [16]. In the micro-scale wear test, the austenitic NiTi SMA shows better wear resistance than the martensitic NiTi SMA. For example, when tested at $22^{\circ} \mathrm{C}$, scratched tracks were observed on the martensitic NiTi SMA [116]. By increasing the temperature to $60{ }^{\circ} \mathrm{C}$ and $120^{\circ} \mathrm{C}$, the fully austenitic phase was present, and no scratching track was observed when tested under the same magnitude of load.

When tested under a high load, at higher temperatures, NiTi SMAs show better wear resistance $[16,123]$. For example, in the pin-on-disk wear test conducted under an applied load of $80 \mathrm{~N}$, the austenitic NiTi SMA showed lower coefficient of friction than the martensitic NiTi SMA. This was attributed to better strain accommodation though the reversible stress-induced martensitic transformation process than the detwinning process [18].

On another hand, in a pin-on-disk sliding wear test, no significant difference was observed when the samples possessed different critical stresses for the SIMT [19]. Since the applied load was ranged from $50 \mathrm{~N}$ to $150 \mathrm{~N}$, the extreme high contact stresses likely resulted in severe plastic deformation. Furthermore, the wear resistance of the NiTi SMA and TiC-TiNi composite degraded when the applied load was increased. The volume loss in the NiTi SMA was still lower than that in the 304 steel under both dry and oil-lubricated sliding conditions [19].

Amini et al [124] studied the effect of loading rate on the indentation depth, and the loading rate was ranged from $200 \mu \mathrm{N} / \mathrm{sec}$ to $20000 \mu \mathrm{N} / \mathrm{sec}$. By increasing the loading rate, the indentation depth decreased under the same magnitude of indentation load. This was attributed to the local temperature raise, which resulted in higher hardness and higher critical stress for the SIMT. Nevertheless, the transformation hardness of the NiTi SMA increased when the indentation depth 
was decreased [125].

Furthermore, the formation of precipitations in heat treatments may change the wear behaviour of NiTi SMAs. For example, the formation of fine and coherent $\mathrm{Ti}_{11} \mathrm{Ni}_{14}$ precipitations in a heat treatment enhanced the wear resistance. However, overheating caused earlier surface degradation [126].

\section{(2) Thin film}

The wear performance of a thin film is likely different from the bulk materials. The mechanical properties of thin film changes with the deposition condition and heat treatment. In the following part, the mechanical properties and wear performance of the NiTi thin film will be introduced.

Huang et al [127] studied the indentation behaviour of the NiTi thin films. The martensitic thin film dissipated higher energy than the austenitic thin film in the indentation test. The deformation model proposed in their study is shown in Fig. $2-18[127,128]$.

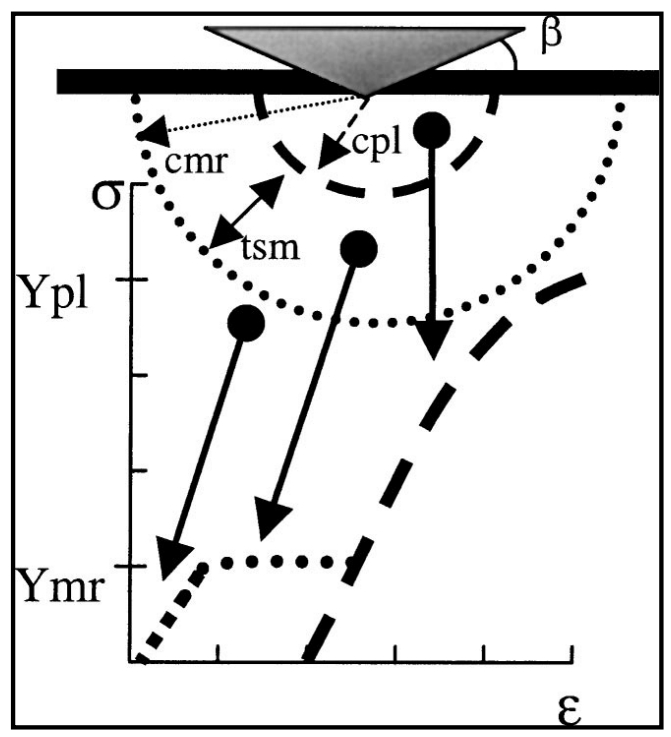

Figure 2-18: Elastic half-space diagram of the indentation of SMA with comparison to a representative tensile loading curve for the martensitic NiTi SMA. 
In Fig. 2-18, $\mathrm{c}_{\mathrm{mr}}$ represents the boundary between the elastic deformation and martensitic reorientation; $\mathrm{c}_{\mathrm{pl}}$ is the boundary between martensitic reorientation and plastic deformation; $t_{\mathrm{sm}}$ is the strain that accommodated through the martensitic rearrangement, which is recoverable upon heating; $\mathrm{Y}_{\mathrm{pl}}$ is the yield stress, while $\mathrm{Y}_{\mathrm{mr}}$ is the critical stress for the martensitic reorientation.

Three contact areas were divided in Fig. 2-18. Fully reversible elastic deformation occurs in the region that is farthest from the point of contact. Meanwhile, plastic deformation occurs in the point of contact. Detwinning occurs in the region that is in between, and this deformation is recoverable after heating. Furthermore, the thin film NiTi SMA was reported with the similar deformation behaviour as the bulk $[127,128]$.

Recent publications on the wear behaviour of NiTi thin films further confirmed the contribution of super-elasticity on the wear resistance [129]. For example, a NiTi thin film was deposited on a plasma nitrided hot work tool steel substrate by means of an industrial magnetron sputtering device. When tested under ball-on-disk contact mode, under $1 \mathrm{~N}$, the near equiatomic NiTi thin film showed much better wear resistance than the Ti-rich NiTi coating. This was attributed to the high volume fraction of the austenitic phase in the near equiatomic NiTi thin film. Furthermore, the poor wear resistance of the Ti-rich NiTi thin film was further attributed to their multiphase microstructure, where the austenite, the martensite, and the $\mathrm{Ti}_{2} \mathrm{Ni}$ precipitations were coexisted.

Scratching wear behaviour of the NiTi thin film was further studied by deposition of NiTi thin films on a silicon substrate. When tested under loads ranging from 20 $\mu \mathrm{N}$ to $200 \mu \mathrm{N}$, by increasing the temperature, the wear resistance of the thin film deteriorated even though the hardness was increased [130].

Furthermore, the wear resistance of NiTi thin film was compared with some 
conventional hard coatings such as the $\mathrm{CrN}$ and TiN. Different results were reported since the mechanical properties of coatings were strongly dependent on the bias-voltage parameters [131-134].

Nevertheless, a NiTi coating can be used as an interlayer to improve the wear resistance of hard coatings [135]. Wear performances of NiTi thin films can be strongly affected by factors such as the film thickness, thermal mismatching of film and substrate, and compression or tension strain within films.

Gas nitriding and ion nitriding are the most commonly used methods in improving the wear resistance of the conventional wear resistant materials. Different surface properties present due to different nitriding temperatures, time, surface morphology and the reactions involved in the nitriding process [136, 137]. Surface modifications on NiTi SMAs were studied to further improve their wear resistance. Wear performances of NiTi surfaces with and without modifications were compared, and different conclusions were given by different studies. For example, the gas nitrided and ion nitrided NiTi surfaces showed better wear resistance than the pure NiTi surface $[136,137]$. Furthermore, the coefficient of friction and weight loss of the NiTi SMA increased drastically after wearing out of the modified layer [138].

Several research groups studied the effect of ion implantation on the wear resistance of NiTi SMAs. The modified surfaces showed better wear resistance than the original surface [139-141]. However, some study also reported that there was no improvement in the wear resistance of a NiTi surface after ion implantation $[142,143]$. Surface modifications of NiTi SMAs are complex and processing-dependent, thus, a precise control of the processing parameter is essential.

In addition, by adding TiC particles to the NiTi SMA, the wear resistance was 
improved when an optimal fraction of $60 \%$ was used $[144,145]$. The composite coating not only improved the wear resistance, but also enhanced the bio-compatibility of NiTi SMAs [146, 147]. Nevertheless, it was reported that, grain size refinements also improved the strength of NiTi SMAs, and therefore improved the wear resistance [148].

\subsubsection{Objectives of the present work}

In the present work, we aim at evaluating the wear resistance of different types NiTi SMAs through investigating the effects of several key influential factors on the wear behaviour of NiTi SMAs, for example, the temperature, deformation mode, sliding speed and applied load. The deformation mechanisms involved in the wear process can be revealed through taking into consideration the microstructure, stress-strain curves, contact stress estimations, coefficients of friction and surface wear features. Therefore, a fundamental understanding on the wear behaviour of NiTi SMAs can be provided. This understanding can guide the materials selection when NiTi SMAs are used in wear-resistant applications. Furthermore, this study might help to guide further study on the prediction of wear process of NiTi SMAs in applications such as bone plates and spine fracture fixation, which involve complex stress conditions and uneven distribution of wear damages. 


\section{Experimental Methods}

\subsection{Materials characterizations}

\subsubsection{Samples}

For NiTi SMAs, the deformation mechanisms involved in the wear process are dependent on their microstructures. To systematically reveal the effect of microstructure on the wear behavior, four types of commercial NiTi SMAs were studied, namely, the forged ingot $\mathrm{Ni} 48.2$ at\% Ti SMA, cold rolled $\mathrm{Ni} 49.4$ at\% $\mathrm{Ti}$ SMA, single crystal Ni 50 at\% Ti SMA, and flat annealed Ni 50.9 at\% Ti SMA. An Energy Dispersive X-ray (EDX) spectroscope, which is attached to a JEOL JSM-5600LV Scanning Electron Microscope (SEM), was used to analyze the compositions.

\subsubsection{Transformation temperatures}

The as-received samples were heat treated at $600{ }^{\circ} \mathrm{C}$ for 30 minutes and followed by air cooling. The transformation temperatures were determined using a Q200 Differential Scanning Calorimeter (DSC), which is from TA instruments. With reference to a standard cell materials, the phase transformation was indicated by endothermic/exothermic peaks in the heating/cooling process. The DSC curves are shown in Fig. 3-1, and the transformation temperatures are indicated.

Table 3-1: Summary of transformation temperatures.

\begin{tabular}{lllll}
\hline Samples & $\boldsymbol{M}_{\mathrm{s}}\left({ }^{\circ} \mathrm{C}\right)$ & $\boldsymbol{M}_{\mathrm{f}}\left({ }^{\circ} \mathrm{C}\right)$ & $\boldsymbol{A}_{\mathrm{s}}\left({ }^{\circ} \mathrm{C}\right)$ & $\boldsymbol{A}_{\mathrm{f}}\left({ }^{\circ} \mathrm{C}\right)$ \\
\hline Forged ingot & 57.7 & 35.8 & 65.8 & 91.5 \\
Flat annealed & -18.3 & -43.9 & -16.3 & 5.9 \\
\hline Cold rolled & 27.6 & 17.5 & 38.6 & 53.4 \\
\hline Single crystal & 22.3 & -20.2 & 18.1 & 44.5 \\
\hline
\end{tabular}


In table 3-1, the $M_{s}$ and $M_{f}$ represent the starting and finishing temperatures of the martensitic transformation; meanwhile, the $A_{s}$ and $A_{f}$ represent the starting and finishing temperatures of the austenitic transformation, respectively.

\subsubsection{Stress-strain curves}

To obtain the stress-strain curves, tensile tests were conducted on the Instron 8846 from Instron corporation. The strain rate was at $1 \times 10^{-4} \mathrm{~s}^{-1}$. At $20{ }^{\circ} \mathrm{C}$, the forged ingot Ni 48.2 at\% Ti SMA was in the stable martensitic phase. A stress-plateau associated with the detwinning was found in the stress-strain curve (Fig. 3-2a). The critical stress for detwinning was at $157 \mathrm{MPa}$, this is comparable to those reported values. In addition, the $4 \%$ deformation strain was fully recovered by heating to a temperature above the $A_{\mathrm{f}}$ (that is, at $100^{\circ} \mathrm{C}$ ).
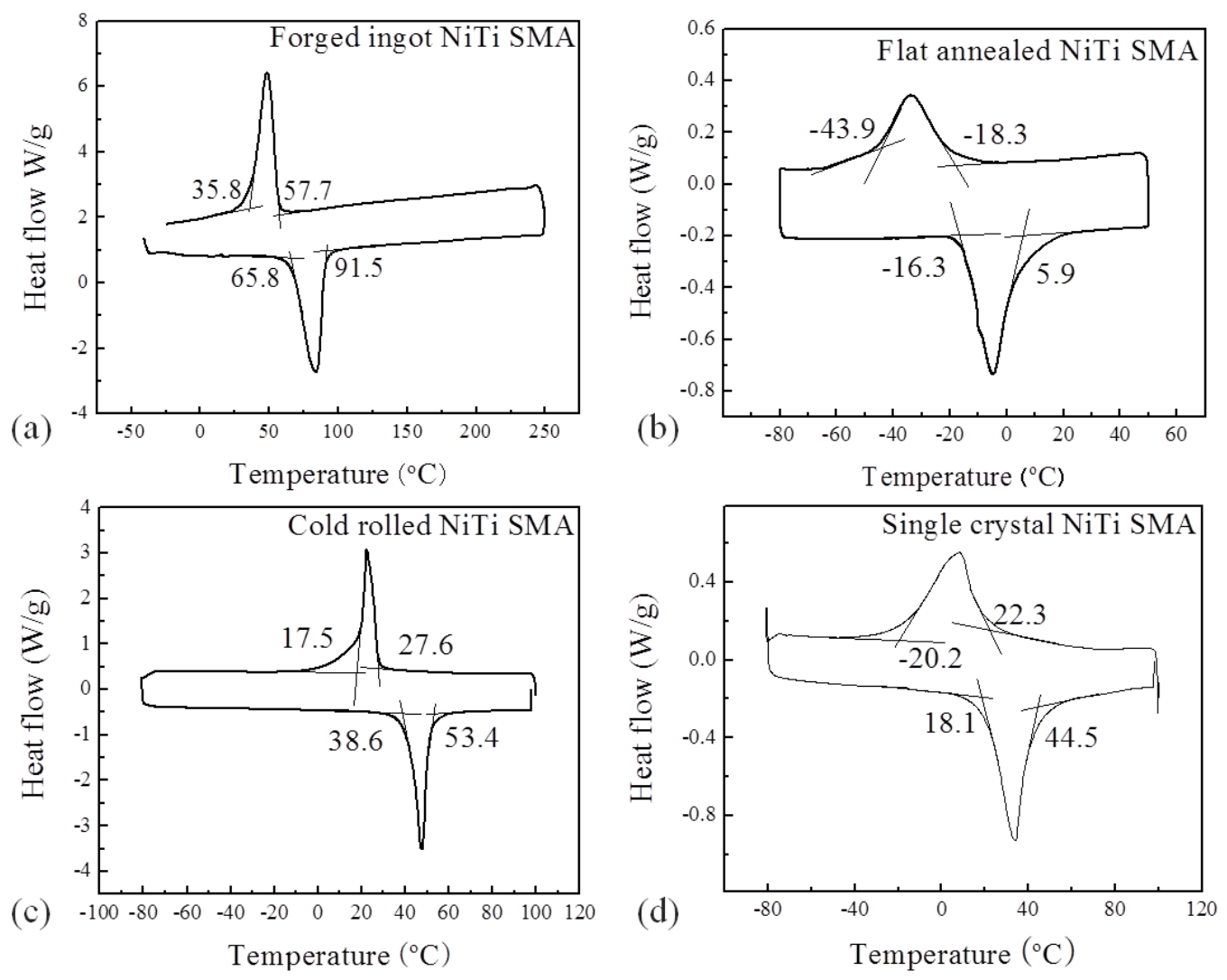

Figure 3-1: DSC curves of four samples with different transformation temperatures shown. (a) The forged ingot NiTi SMA; (b) the flat annealed NiTi SMA; (c) the cold rolled NiTi SMA and (d) the single crystal NiTi SMA. 


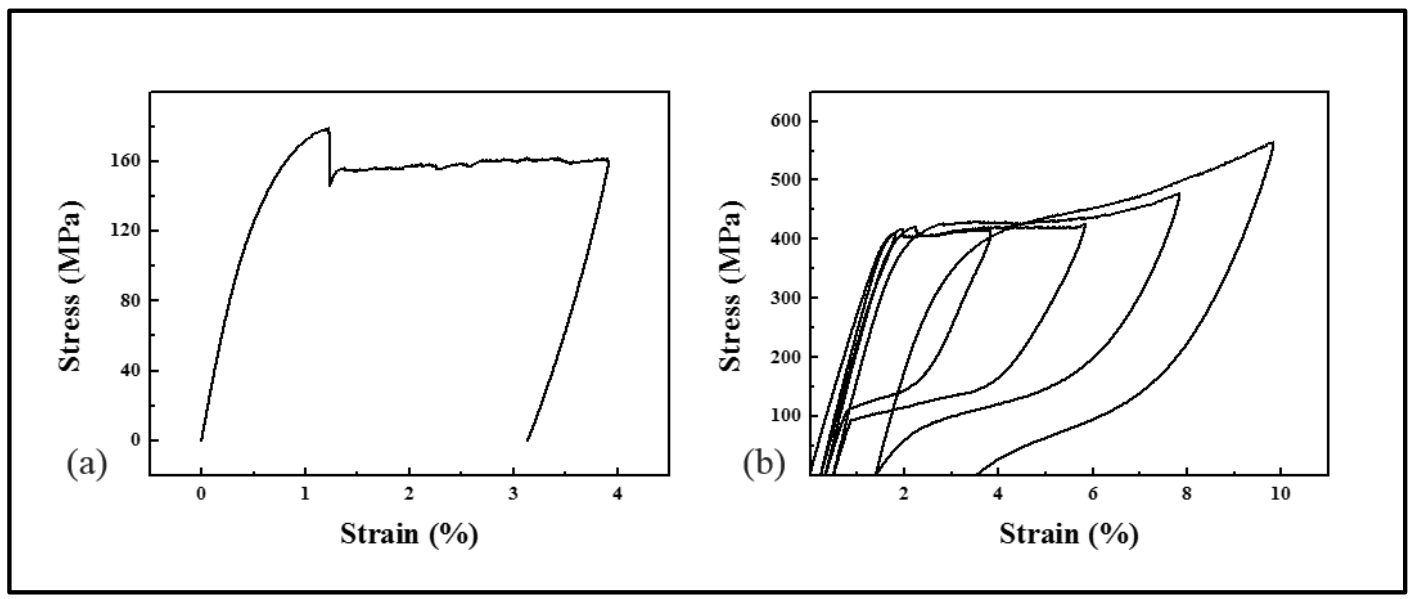

Figure 3-2: Tensile stress-strain curves when tested at $20{ }^{\circ} \mathrm{C}$. (a) The forged ingot NiTi SMA sample, and (b) the flat annealed NiTi SMA sample.

Instron equipped with a temperature chamber was used to examine the high temperature stress-strain curves. At $90{ }^{\circ} \mathrm{C}$ and $120{ }^{\circ} \mathrm{C}$, the forged ingot $\mathrm{Ni} 48.2$ at $\%$ Ti SMA was in the austenitic state. A stress-plateau was shown in the stress-strain curve. The critical stress for the stress-induced martensitic transformation (SIMT) at $90{ }^{\circ} \mathrm{C}$ and $120{ }^{\circ} \mathrm{C}$ were at about $320 \mathrm{MPa}$ and $530 \mathrm{MPa}$, respectively.

The flat annealed Ni 50.9 at $\%$ Ti SMA was in stable austenitic state at $20{ }^{\circ} \mathrm{C}$. In the tensile test, the strain was increased from $2 \%$ to $10 \%$. Figs. $3-2 \mathrm{~b}$ showed the tensile stress-strain curves of the flat annealed Ni 50.9 at\% Ti SMA. A nearly perfect loop, which represents the fully reversible stress-induced martensitic transformation, was observed for a strain up to $6 \%$ (Fig. 3-2b). With further increasing temperature, the critical stress for SIMT obeys a Clausius-Clapeyron type of equation, this will be discussed in chapter 5 .

\subsection{Sample preparation}

Different types of NiTi SMAs were cut into sizes of $10 \mathrm{~mm} \times 10 \mathrm{~mm} \times 1 \mathrm{~mm}$. Those samples were mounted onto an acrylic resin substrate for ease of handing. Surfaces were grinded and polished to remove the oxide layers [149]. Sand papers 
were used in grinding, with grits from 400 to 1200 . Then, the silicon carbide abrasive paper with grit of 4000 was used. Thereafter, the diamond paste and alcohol based lubricant, which were provided by Talon Technology, were used in polishing. After the grinding and polishing process, the acrylic resin substrate was mechanically removed. This process was illustrated in Fig. 3-3. After ultrasonic cleaning in the acetone and the ethanol for 3 minutes, the specimens were held at $150{ }^{\circ} \mathrm{C}$ for 10 minutes to release the surface strains.

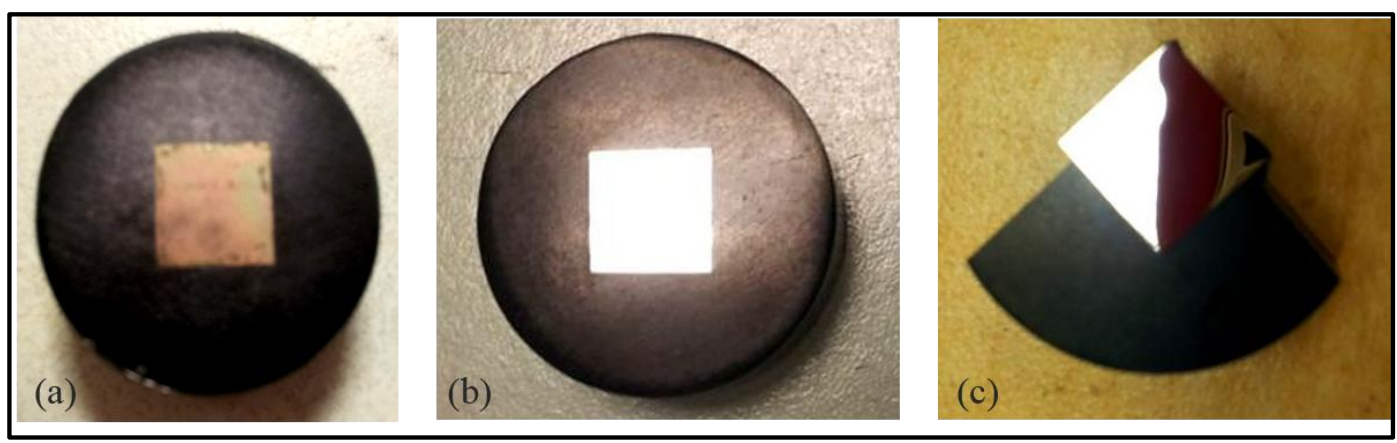

Figure 3-3: Sample preparation process. (a) Samples were mounted onto an acrylic resin substrate; (b) samples were grinded and polished; (c) the substrate was removed partially.

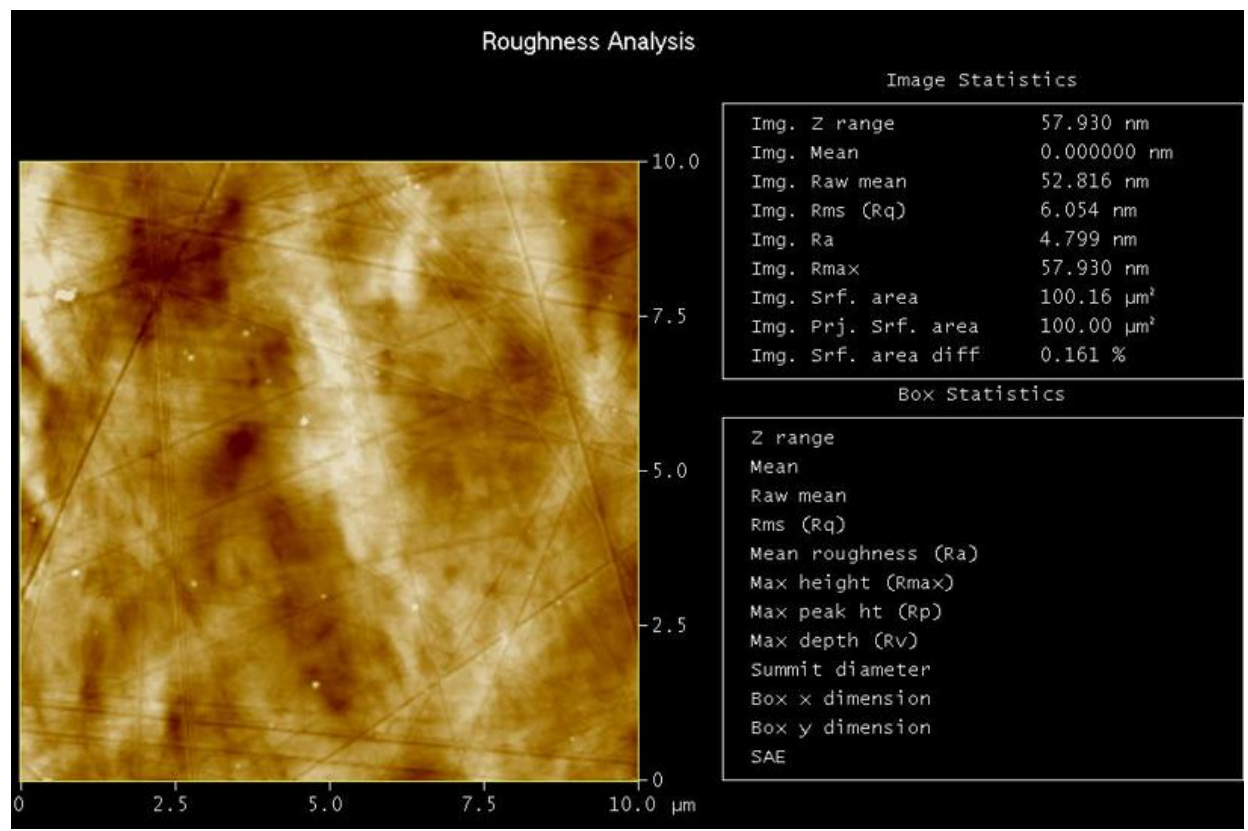

Figure 3-4: AFM image of a sample surface. 
The surface roughness of sample ( $\mathrm{Ra})$ was examined using a DI3000 Atomic Force Microscope (AFM) from Bruker. On each sample, three regions were arbitrarily selected for scanning, with an area of $10 \mu \mathrm{m} \times 10 \mu \mathrm{m}$. Only specimens with surface roughness values below $15 \mathrm{~nm}$ were kept for further wear studies. One example is shown in Fig. 3-4, the surface roughness was at about $4.8 \mathrm{~nm}$. However, some scratches were found on the surface.

\subsection{Wear testing}

\subsubsection{Equipment}

In the present study, small scale wear tests were conducted on three types of tribometer, that is, the Nano-tribometer, the CETR tribometer and the High temperature tribometer. Ball-on-disk contact mode was used. The coefficient of friction was recorded as a function of wear cycles. After each test, the surface wear features were examined using the Confocal Microscope, Atomic Force Microscope and Scanning Electron Microscope.

\section{(1) Nano-tribometer}

A Nano-tribometer from CSM instruments was used under ball-on-disk contact mode. The NiTi SMA has worn against an alumina counter-ball having a diameter of $2 \mathrm{~mm}$. Sliding and reciprocating wear tests were conducted under different applied loads and sliding speeds. The major difference between these two types of wear modes is that under sliding mode, the sliding alumina ball moves in the same direction on a circular wear track all the time; while in the reciprocating mode, the alumina ball moves back and forth in the opposite directions on a linear track. This has caused different wear features.

On the Nano tribometer, a high-load cantilever was used when the applied load 
ranging from $100 \mathrm{mN}$ to $1000 \mathrm{mN}$. A medium-load cantilever was used when the applied load ranging from $10 \mathrm{mN}$ to $100 \mathrm{mN}$. The closer the applied load to the upper limit of the cantilever, the higher the vibration in the wear tests. Furthermore, to protect the cantilever from being damaged, wear tests were manually stopped once an extreme large vibration occurred.

(2) High-temperature tribometer

A High-temperature tribometer from CSM instruments was used under ball-on-disk contact mode. An alumina counter-ball with a diameter of $6 \mathrm{~mm}$ was used. The test temperature was changed from $20^{\circ} \mathrm{C}$ to $110^{\circ} \mathrm{C}$, and the details were listed in Table 3-2.

\section{(3) CETR tribometer}

The CETR tribometer is equipped with a temperature chamber, which is used to study the effect of temperature on the wear behaviour of NiTi SMAs. The CETR tribometer is a high load and heavy duty tribometer, and it is equipped with the CETR UMT Multi-specimen test system from Dymek Asia. Alumina counter-ball with a diameter of $4 \mathrm{~mm}$ was used. The applied load was changed from $50 \mathrm{mN}$ to $500 \mathrm{mN}$ (see more details in table 3-2). In the wear test, once the force exceeds the abort level, which is $510 \mathrm{mN}$, the tests are stopped automatically.

(4) Summary of wear tests

In the present study, different parameters were used according to the specifications on each tribometer, they are summarized in Table 3-2. The term "S" and "R" represent the sliding and reciprocating wear mode. 
Table 3-2: Summary of the detailed parameters used in the wear study.

\begin{tabular}{|c|c|c|c|}
\hline Parameters & Nano & CETR & High-temp \\
\hline Temperature $\left({ }^{\circ} \mathrm{C}\right)$ & 20 & $20,35,50,90,120$ & $20,40,70,110$ \\
\hline \multirow[t]{2}{*}{ Wear mode } & Sliding (S) & Sliding & Sliding \\
\hline & Reciprocating (R) & & \\
\hline Sliding speed & $1.25 / 2.5(\mathrm{~S})$ & 4.71 & $10,20,30,40$ \\
\hline$(\mathrm{mm} / \mathrm{s})$ & $1.5 / 2.5(\mathrm{R})$ & & \\
\hline Applied Load & $25,50,75,100$ & $50,100,200,300$ & 1000 \\
\hline$(\mathrm{mN})$ & $200,300,400,500$ & 400 & \\
\hline Ball Radius (mm) & 1 & 2 & 3 \\
\hline Track radius (mm) & 0.25 & 1.5 & 1 \\
\hline \multirow[t]{2}{*}{ Track length (mm) } & $1.57(\mathrm{~S})$ & $9.42(\mathrm{~S})$ & $6.28(\mathrm{~S})$ \\
\hline & $0.25(\mathrm{R})$ & & \\
\hline Wear cycle (up to) & 1000 & 1000 & 3000 \\
\hline
\end{tabular}

In this study, different tribometers were used to investigate the effect of different influential factors on the wear behaviour of NiTi SMAs. For example, the effect of temperature on the wear resistance of NiTi SMA was investigated by using the CETR tribometer. However, this tribometer in our lab is only eligible for sliding wear test. In order to study the effect of deformation mode on the wear behaviour of NiTi SMA under sliding and reciprocating wear mode, the Nano-tribometer was used. Nevertheless, the Nano-tribometer is only eligible for room temperature test.

Different tribometer having different cantilevers, which are eligible for different sliding speeds. For each tribometer, several sliding speeds were tested initially. When under extreme high/low loads, the wear process was highly unstable and the results were not repeatable due to the vibrations in the cantilever. The intermediate sliding speed gave repeatable results was selected when tested under different applied loads and wear modes. 
In addition, different track radii were selected for different tribometers to ensure the final wear track is clear, uniform and repeatable, since the cantilever of each tribometer was coupled with counter-ball having different sizes.

The present study aims at providing a fundamental understanding on the wear behaviour of NiTi SMAs before severe wear occurs, thus 1000 wear cycles were tested. In the applications of NiTi SMA based implants and bio-medical devices, severe wear may cause a serious inflammation of the human body. Thus, surface degradation process prior to severe wear condition is of essential importance in monitoring the service life of devices.

In chapter 4 , we aim at understanding the wear behaviour of the stable martensitic NiTi SMA. The forged ingot Ni 48.2 at\% Ti SMA, which shows stable martensitic phase at $20{ }^{\circ} \mathrm{C}$, was tested on the Nano-tribometer. The detailed parameters are listed in Table 3-2.

Similarly, in chapter 5, the Nano-tribometer was used to examine the wear behaviour of the stable austenitic NiTi SMA. The flat annealed Ni 50.9 at\% Ti SMA sample was used, which shows stable austenitic phase at $20{ }^{\circ} \mathrm{C}$. Furthermore, the effect of temperature on the wear behaviour of the austenitic NiTi SMA was studied using the CETR tribometer. The temperature was changed from 20 to $120{ }^{\circ} \mathrm{C}$ (table 3-2).

In chapter 6, the CETR tribometer and the high-temperature tribometer were used to examine the effect of microstructure on the wear behaviour of the forged ingot Ni 48.2 at\% Ti SMA.

In chapter 7, the wear behaviour of the single crystal $\mathrm{Ni} 50$ at\% Ti SMA and polycrystal Ni 49.4 at\% Ti SMA were studied, where the martensitic phase coexisted with the austenitic phase. Wear tests were conducted on the 
Nano-tribometer, with alumina counter-ball having a diameter of $2 \mathrm{~mm}$.

In the present study, small scale wear tests were selected, using $\mathrm{Al}_{2} \mathrm{O}_{3}$ counter-ball with radius of 1, 2 and $3 \mathrm{~mm}$. Furthermore, the test was conducted under low load and low sliding speed. It is thus expected that temperature rise during the wear test should be negligible, taking into consideration the good thermal conductivity of NiTi SMAs.

Monitoring of temperature changes in the contact areas was attempted by using two methods, i.e., a thermo-couple and temperature sensitive color changing materials (change to black color at $43^{\circ} \mathrm{C}$ ). However, almost no temperature change was observed possibly due to the high thermal conductivity of NiTi alloy. A verification experiment was conducted by doubling the rotary speed and using the same ball against a plate of color changing material. During the wear process, the color changing material did not turn into black, indicates the temperature in the contact area may be lower than $43{ }^{\circ} \mathrm{C}$.

Thus, it was concluded that self-heating/flash temperature in the wear test might be insignificant in the present study.

\subsubsection{Data collection and evaluation}

After each wear test, the Nikon Eclipse L150 laser confocal microscope from Sensofar group was used to examine the surface wear features at a magnification of 200 times. An example is shown in Fig. 3-5a. A profile on the cross-section of the wear track was plotted using the 3D confocal microscopic imaging system. The position of the profile shown in Fig. 3-5b is indicated by a red color arrow in Fig. $3-5 a$. 


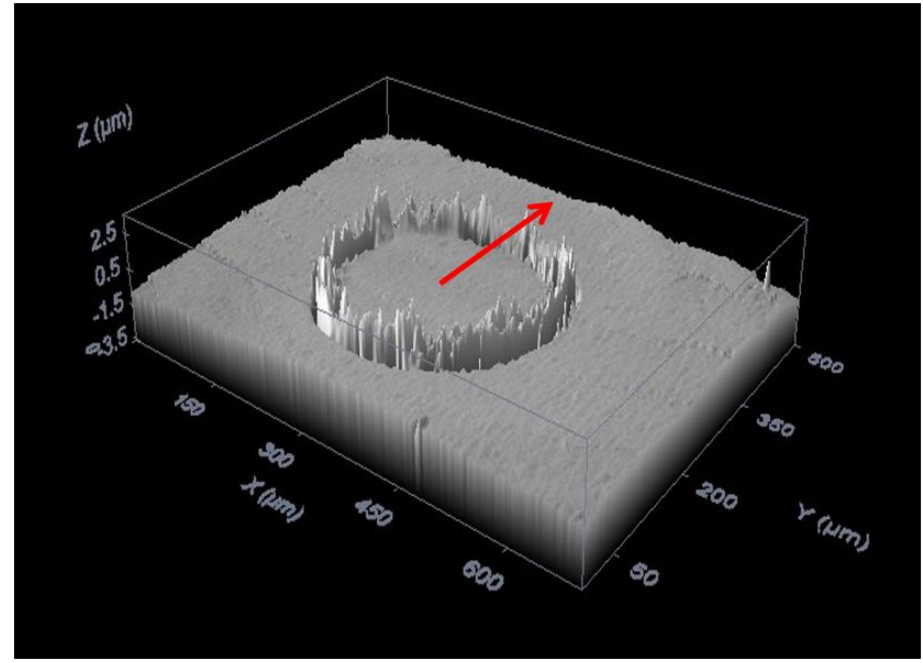

(a)

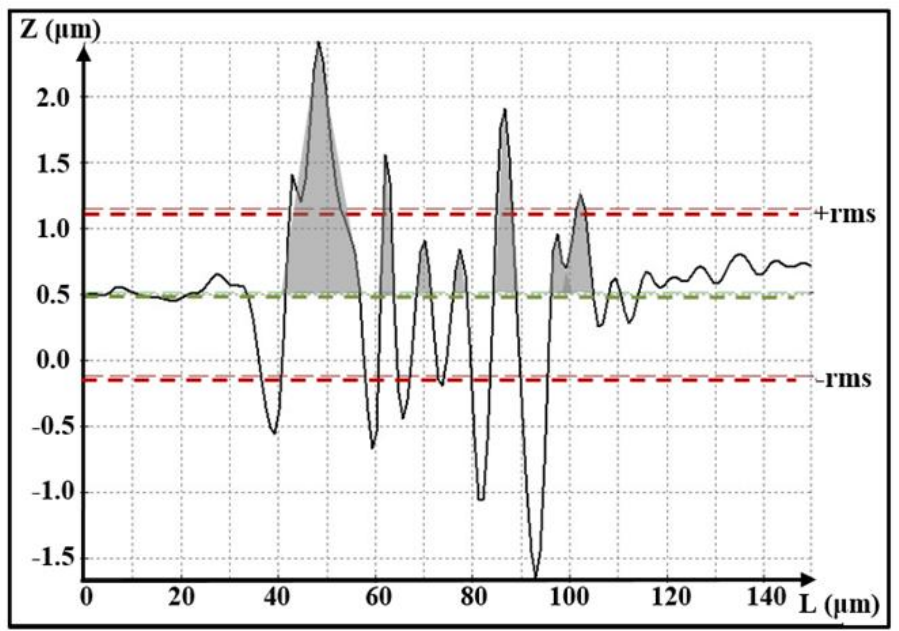

(b)

Figure 3-5: (a) Typical surface wear features imaged using the confocal microscope; (b) a profile on the cross-section of the wear track.

On Fig. 3-5b, the sum of the area indicated by grey color represents the cross-section area of the asperities on this track. Ten locations were randomly selected on each wear track. With reference to the bulk surface, the width and height of individual asperities were measured. Since those features were in triangular shape, the calculation method of the area of a triangular was employed. By summarizing the areas of asperities on each cross-section profile, the average cross-section area of worn track was obtained. Therefore, the wear volume was 
estimated by multiplying the length of the wear track and the average cross-section area of asperities:

$$
V=A_{a} \times L
$$

Here, $V$ is the total wear volume; $L$ is the length of wear track; $A_{a}$ is the average cross-section area of asperities.

It is worth noting that, the wear volume estimated using the asperities represents debris that piled up on surface. Meanwhile, the wear volume estimated using the wear tracks represents materials removal from the surface. Theoretically, the estimated wear volumes should equivalent. However, in the present study, tracks were blocked by large asperities. As a result, the estimated wear volume from tracks was insignificant as compared to the volume of asperities. Therefore, we have used the wear volume of surface asperities to analyze the wear behaviour.

In addition, the specific wear rate is commonly used to compare the wear volume per distance per load for conventional wear resistant materials. However, due to super-elasticity of NiTi SMA, the relation between wear volume, sliding distance and applied load is complicated. In the present study, the wear volume was used to define the surface degradation stages when tested under different applied load and wear cycles.

The surface wear features was further examined using the JSM 5600LV field emission Scanning Electron Microscope (SEM) from JEOL Ltd. A secondary electron image system was employed, with magnifications of 1000 to 4000 times. Clear features of worn tracks and debris were highlighted. A voltage of $10 \mathrm{kV}$ was applied, and some asperities were charged up since they were partially detached from the surface. In addition, the X-ray Photoelectron Spectroscopy (XPS) 
attached to the SEM was used to determine the composition of wear debris. Although different regions on the wear track were selected, no trace of aluminum suggests insignificant wear from the alumina counter-ball $\left(\mathrm{Al}_{2} \mathrm{O}_{3}\right)$.

The DI3000 Atomic Force Microscope (AFM) was used to further examine the surface wear features. When under the tapping mode, an area of $10 \mu \mathrm{m} \times 10 \mu \mathrm{m}$ was scanned at a rate of $1 \mathrm{~Hz}$. Clear features of surface asperities were revealed. The AFM tip can be damaged when debris was present, hence, only tracks with small asperities were tested using AFM. 


\section{Wear Behaviour of Stable Martensitic NiTi SMA}

In this chapter, a systematic wear study was conducted when tested under different applied loads, deformation modes and wear cycles. The dominant deformation mechanism involved in the wear process was analyzed, in consideration of the coefficient of friction, surface wear features, contact stress estimation, and the stress-strain curve of the martensitic NiTi SMA.

In Section 4.1, the coefficients of friction and surface wear features were explained. In Section 4.2, the contact stress was estimated, thereby the dominant deformation mechanisms involved in the wear process were discussed.

\subsection{Wear resistance of forged ingot Ni 48.2 at \% Ti SMA}

By using a Nano-tribometer, wear tests were conducted under sliding and reciprocating wear mode. The detailed parameters were listed in Table 3-2. When under sliding wear mode, deformation was repeated in the unique direction. When under reciprocating wear mode, forward and reversed deformation occurred in each of the wear cycle.

\subsubsection{Under ball-on-disk sliding wear mode}

(1) Coefficients of friction

When tested under sliding wear mode, the coefficient of friction was obtained as a function of wear cycles, applied loads and sliding speeds (Figs. 4-1). When tested at sliding speed of $1.25 \mathrm{~mm} / \mathrm{s}$, under $50 \mathrm{mN}$, the coefficient of friction stabilized at around 0.07 throughout the test. When tested under $100 \mathrm{mN}$, the coefficient of friction increased initially, and it stabilized at around 0.31 after about 500 wear cycles. The coefficient of friction remained stabilized for up to 1000 wear cycles. 

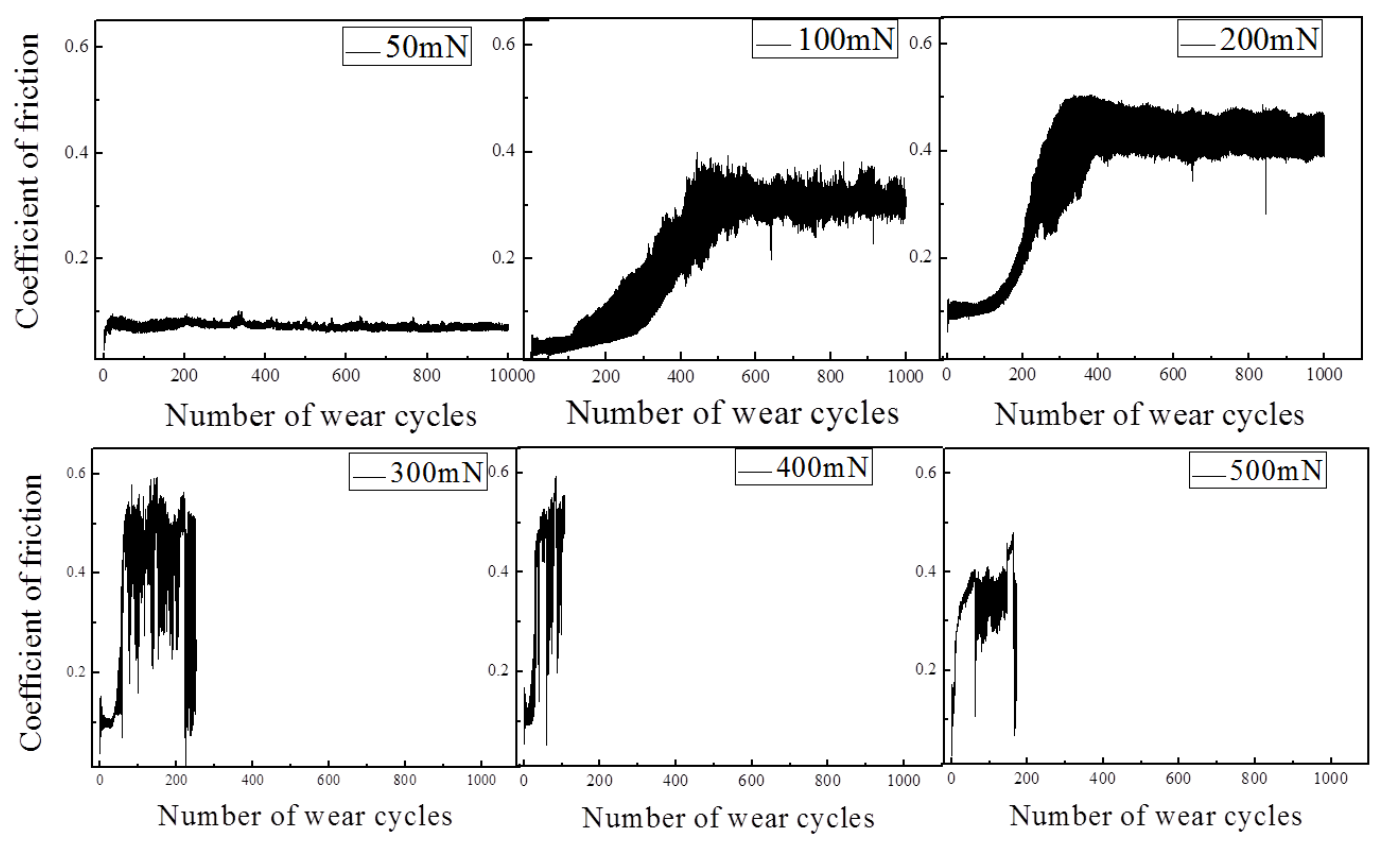

(a)
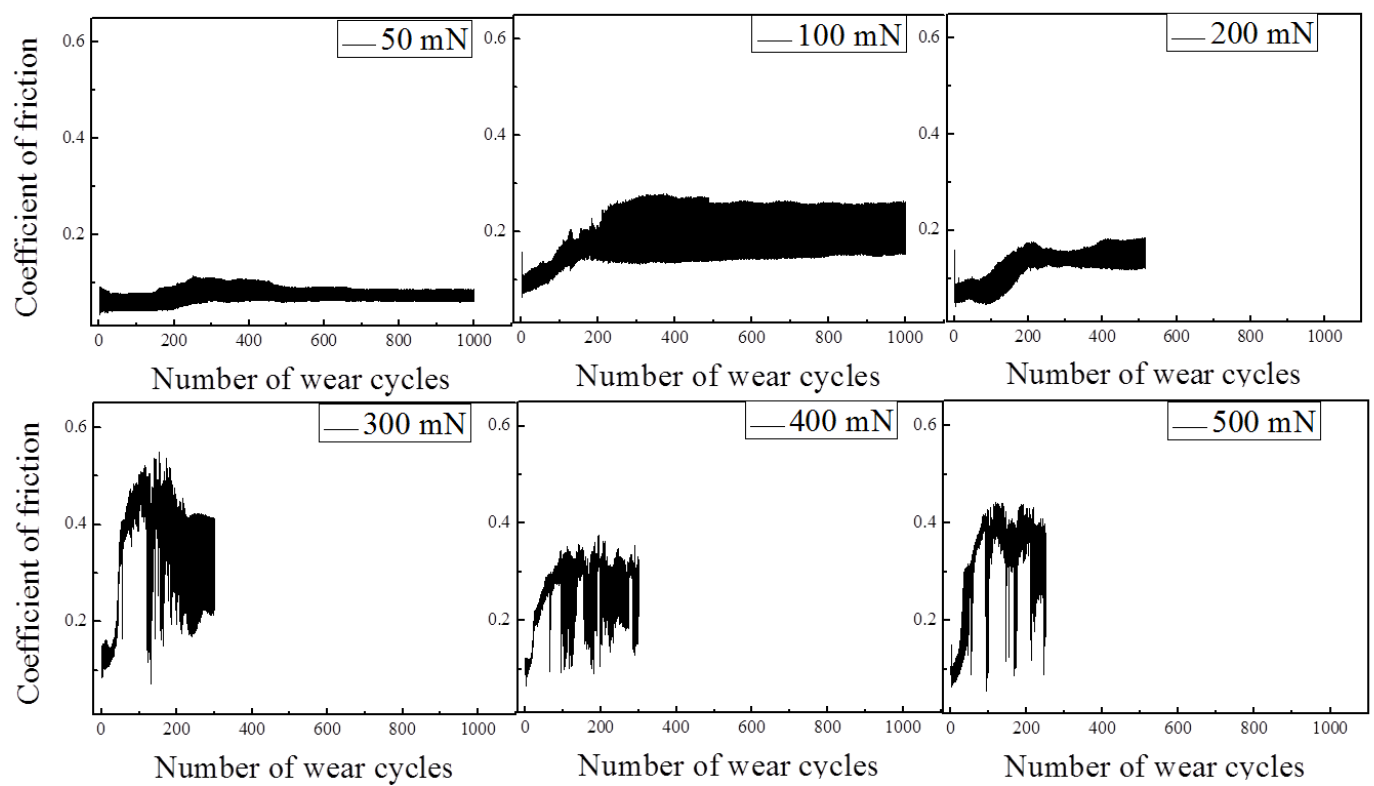

(b)

Figure 4-1: When under ball-on-disk sliding wear mode, the coefficients of friction were shown as a function of wear cycles and applied load. (a) With sliding speed of $1.25 \mathrm{~mm} / \mathrm{s}$; (b) with sliding speed of $2.5 \mathrm{~mm} / \mathrm{s}$.

When tested under a load of $200 \mathrm{mN}$, the trend of the coefficient of friction was similar to that under $100 \mathrm{mN}$. It increased initially and then stabilized at around 0.43 from about 400 wear cycles until the end of the test. When the load was increased to 
$300 \mathrm{mN}$ and above, the coefficients of friction were highly unstable, and large amount of debris was generated. Such instability in the wear process was likely due to the extremely high level of contact stress. Once such instability occurred, tests were stopped in order to protect the cantilever.

By increasing the sliding speed to $2.5 \mathrm{~mm} / \mathrm{s}$, the trends in the coefficients of friction were changed significantly (Fig. 4-1b). When tested under $50 \mathrm{mN}$ and $100 \mathrm{mN}$, from about 300 wear cycles until the end of the test, the coefficients of friction stabilized at around 0.07 and 0.2 , respectively. When tested under a load of $200 \mathrm{mN}$, the coefficient of friction stabilized at around 0.15 after approximately 200 wear cycles. However, at around 520 wear cycles, the coefficient of friction became highly unstable, the test was thereby stopped. When under $300 \mathrm{mN}, 400 \mathrm{mN}$ and $500 \mathrm{mN}$ (Fig. 4-1b), the tests were stopped before 1000 wear cycles and severe damage occurred at the very beginning of the test. When tested under such high applied loads, similar wear behaviour were found even under different sliding speeds.

In order to ensure the repeatability of results, three to five tests with exactly the same conditions were repeated. Although the obtained curves in coefficients of friction did not exactly overlap with each other, the trends were the same.

\section{(2) Surface wear features}

After each wear test mentioned in Figs. 4-1a and 4-1b, the corresponding surface wear features were studied by using a 3D confocal microscope, Atomic Force Microscope (AFM), and a Scanning Electron Microscope (SEM). Since the applied load was ranged from $50 \mathrm{mN}$ to $500 \mathrm{mN}$, the micro-scale wear occurred on surface. Due to the extremely low amount of materials removal from the surface, conventional method such as the weighting is not suitable for a quantitative wear measurement. The 3-D confocal microscopic images on surface wear features were used to estimate the wear volume, which will be further explained. 
When tested under the sliding speed of $1.25 \mathrm{~mm} / \mathrm{s}$, the typical wear features were shown in Fig. 4-2a. When under $50 \mathrm{mN}$, a crown-like wear track was formed on the sample surface after 1000 wear cycles. When the load was increased to $100 \mathrm{mN}$, the height of the crown-like structure was increased. By further increasing the load to $200 \mathrm{mN}$, some deep tracks cutting into the surface occurred at the bottom of the crown-like structure. This is in consistency with the increasing trend of the stabilized coefficient of friction under increased applied load.
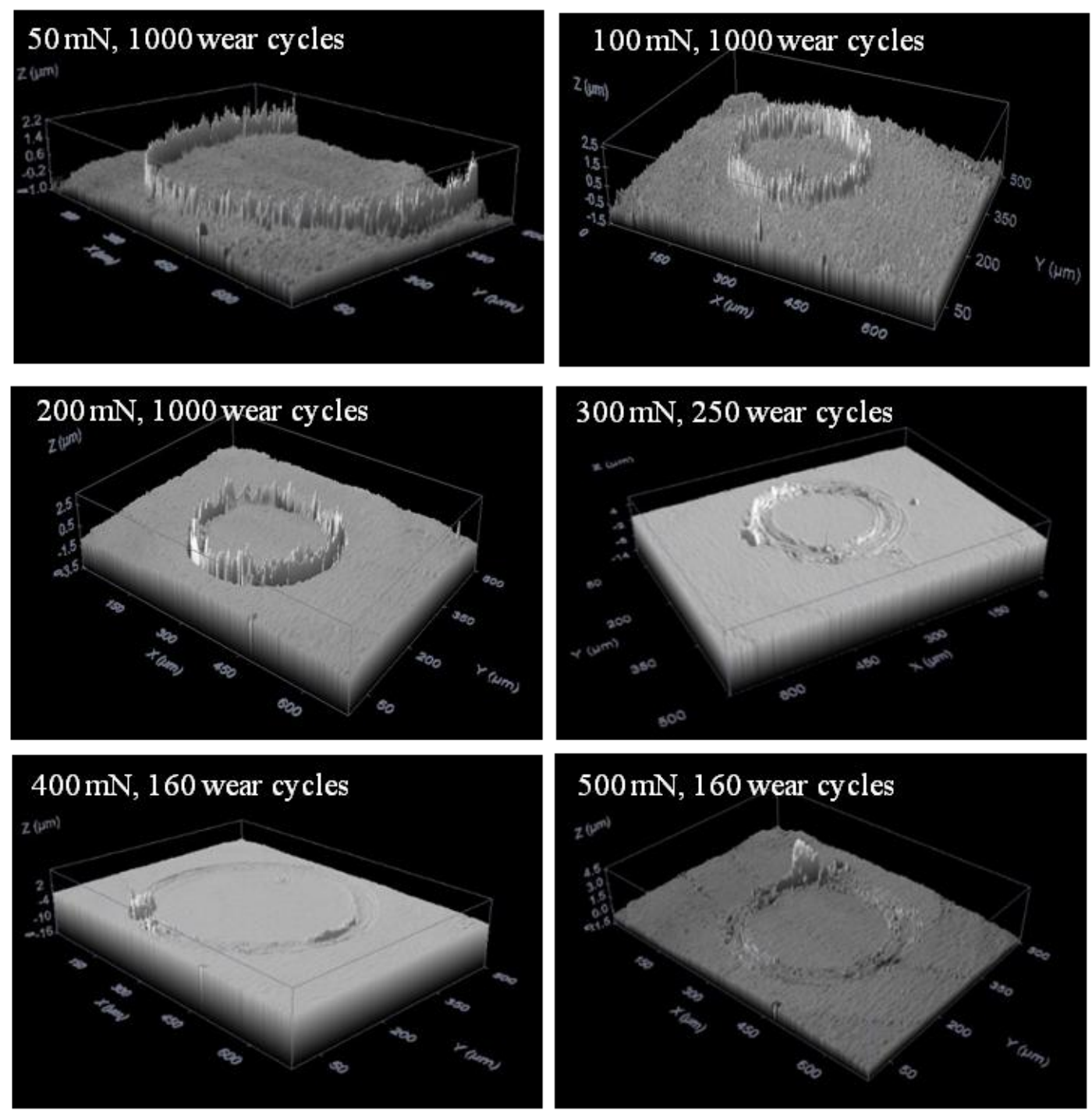

Figure 4-2a: 3D confocal microscopic images of worn surfaces of the martensitic NiTi SMA, with sliding speed of $1.25 \mathrm{~mm} / \mathrm{s}$. The test conditions were indicated. 

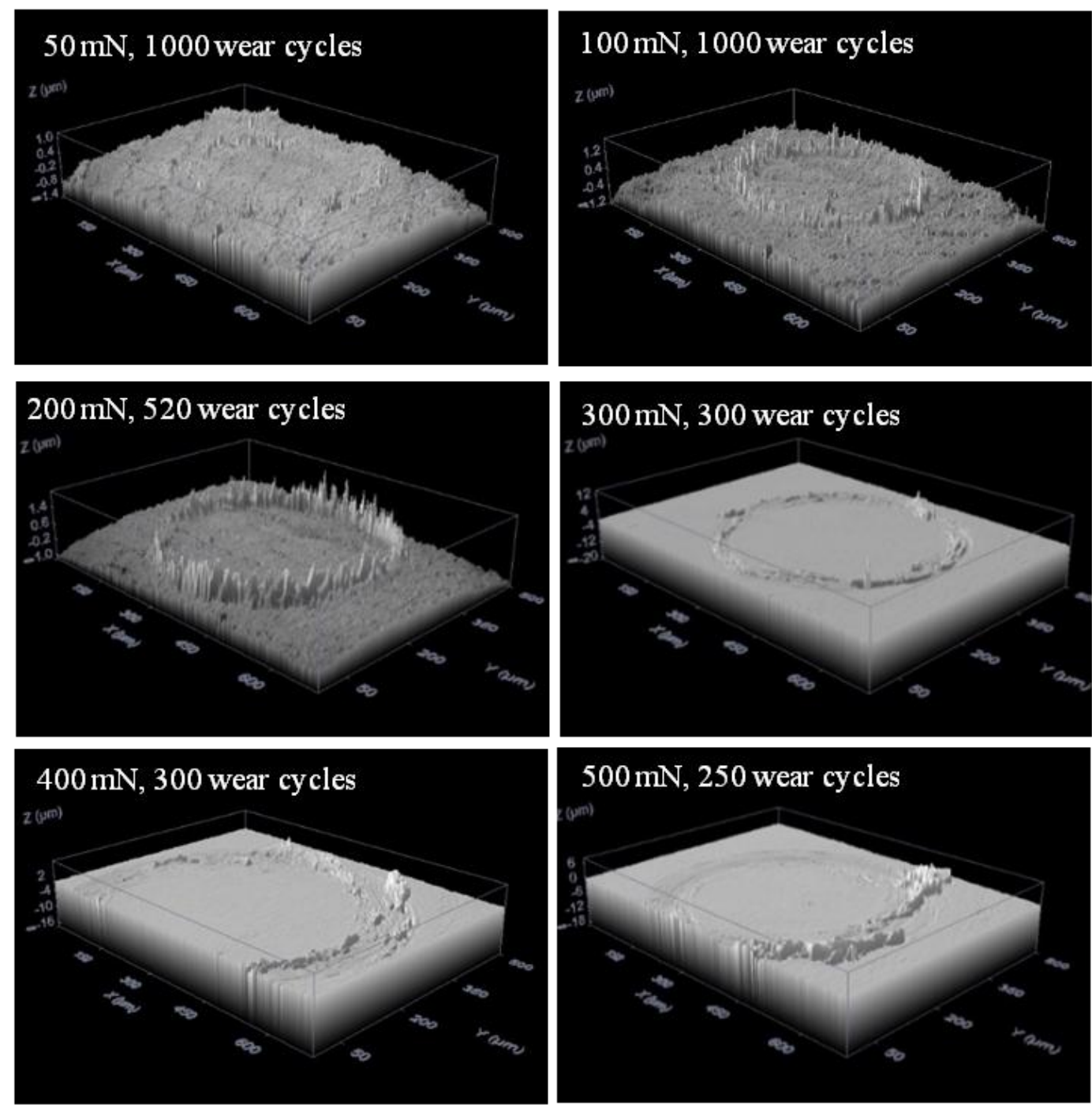

Figure 4-2b: 3D confocal microscopic images of worn surfaces of the martensitic NiTi SMA, with sliding speed of $2.5 \mathrm{~mm} / \mathrm{s}$.

In order to provide a better understanding of the crown-like structure, when under $200 \mathrm{mN}$, the wear test was repeated with different wear cycles. When tested after 10 wear cycles, no visible wear track was found. Meanwhile, when tested after 50 wear cycles, small amount of asperities that embossed on the surface was formed. The growth of crown-like structure with increased wear cycles is possibly correlated to the plastic strain accumulation process, which will be further discussed. The tests were stopped before 1000 wear cycles, when tested under $300 \mathrm{mN}, 400 \mathrm{mN}$ and 500 $\mathrm{mN}$, due to high instability in the coefficient of friction. However, a large amount of debris and tracks were found (Fig. 4-2a), suggests that severe wear occurred at the very beginning of the test. 
When tested under sliding speed of $2.5 \mathrm{~mm} / \mathrm{s}$ (Fig. 4-2b), the surface wear features were similar to that observed under $1.25 \mathrm{~mm} / \mathrm{s}$. Under $50 \mathrm{mN}, 100 \mathrm{mN}$ and $200 \mathrm{mN}$, the crown-like structures were observed and, the height of asperities was increased with an increase in the applied load. However, when tested under loads of $300 \mathrm{mN}$, $400 \mathrm{mN}$ and $500 \mathrm{mN}$, the surfaces were severely damaged, and a large amount of debris was formed. This observation is in consistency with the high instability in the coefficient of friction, which indicated changes in the deformation mechanism when tested under extremely high applied load.

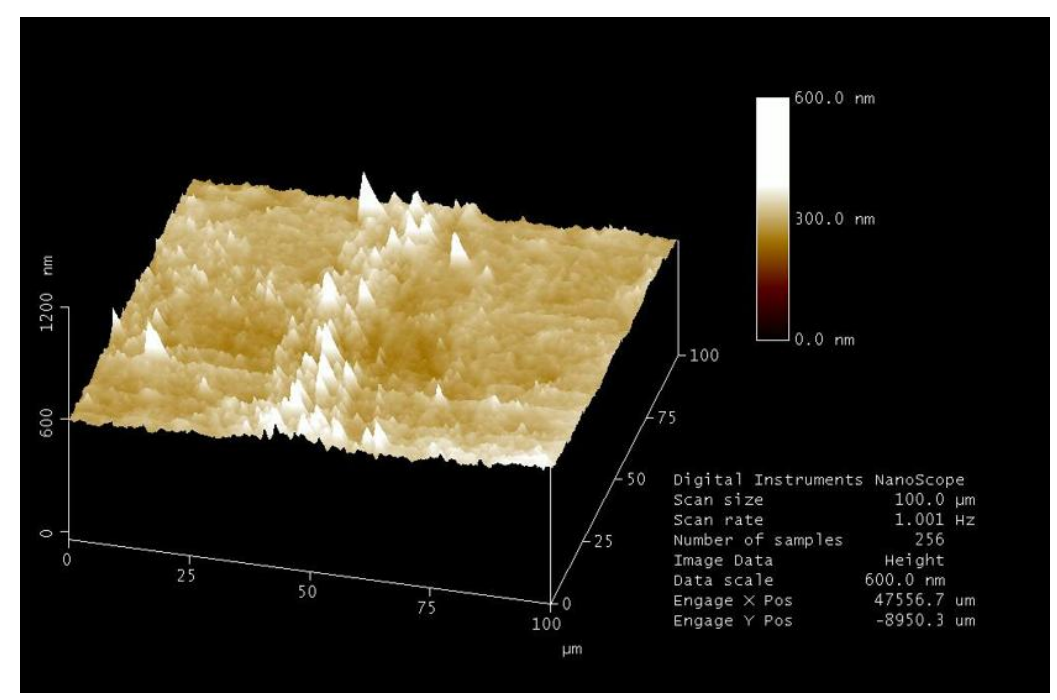

Figure 4-3: AFM image of a portion of the "crown-like" structure

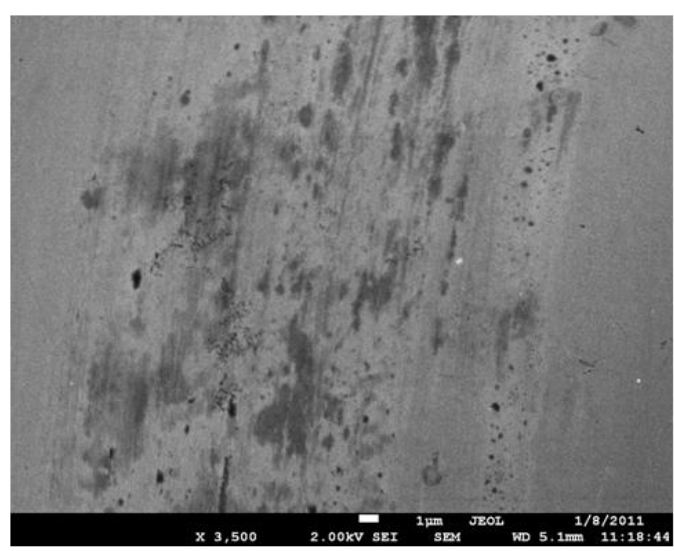

(a)

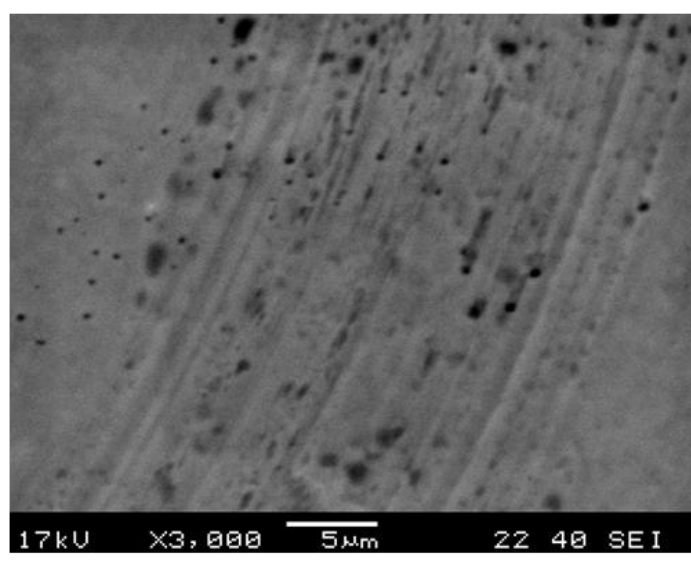

(b)

Figure 4-4: High magnification SEM images of surface wear features. (a) under 50 $\mathrm{mN}$; (b) under $100 \mathrm{mN}$. 
Since the crown-like structure has not been reported, the AFM and SEM images were used to reveal further details. A portion of the crown-like structure, which was shown in Fig. 4-2a, was imaged by using AFM with high magnification (Fig. 4-3). Furthermore, the surface wear features, that obtained when under $50 \mathrm{mN}$ and 100 $\mathrm{mN}$, were further examined by using SEM (Fig. 4-4). Comparing the high resolution AFM and SEM images, it was envisaged to propose that the crown-like structure observed on the confocal image consisted of large amount of wear asperities that embossed on the track area.

To determine the chemical composition of the crown-like structure, samples were ultrasonically cleaned in both acetone and ethanol for three minutes. The cleaned samples were examined again using confocal microscope. No visible change in the wear features were found, this observation suggests insignificant material removal in the wear process. Furthermore, by heating the samples to $150{ }^{\circ} \mathrm{C}$ (above the $A_{\mathrm{f}}$ ) for 10 minutes, no visible change in the wear features suggest no shape memory effect in the asperities that embossed on the surface. The chemical composition of the crown-like structure was analyzed using Energy Dispersive X-ray Spectroscopy (EDX), which is attached to a SEM.

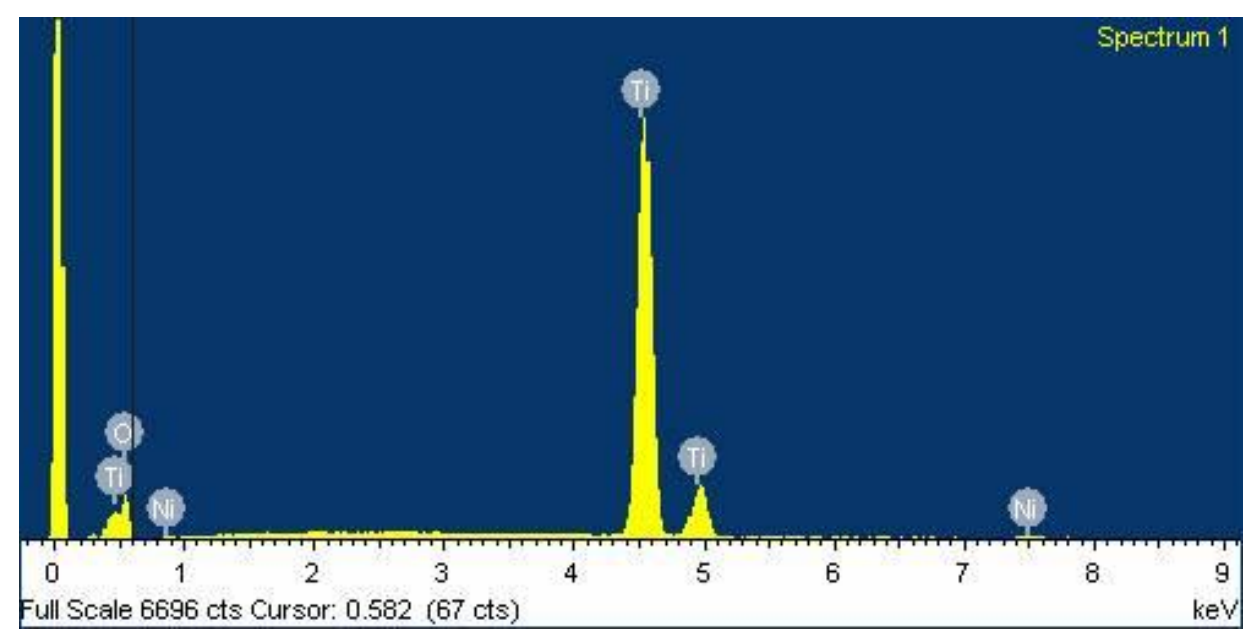

Figure 4-5: The EDX analysis highlighting the chemical composition of the crown-like structure shown. 
In the EDX analysis, no trace of $\mathrm{Al}$ indicated insignificant wear on the $\mathrm{Al}_{2} \mathrm{O}_{3}$ counter-ball. It was thus concluded that the crown-like structure was composed of large surface asperities, which originated from plastic strain accumulation.

When tested under $50 \mathrm{mN}$ and $100 \mathrm{mN}$, only asperities that embossed on the surface was observed in the confocal microscopic images (Fig. 4-2). The tracks shown in the SEM images (Fig. 4-4) were blocked by the asperities due to the low resolution of the confocal microscope. Due to the non-uniform distribution of the asperities and tracks, as well as the small-scale wear features, the precise measurement on the wear volume is difficult.

The width of track is closely related to the contact area, thus it is somehow related to the deformation mechanism. When tested under different applied loads and sliding speeds, the average width of track was summarized in Fig. 4-6. Ten measurements that transverse to the sliding direction were arbitrarily selected on each wear track.

When tested under $50 \mathrm{mN}, 100 \mathrm{mN}$ and $200 \mathrm{mN}$, the average width of track remained at around $40 \mu \mathrm{m}$. However, when tested under $300 \mathrm{mN}$, the width of track increased to around $70 \mu \mathrm{m}$ to $80 \mu \mathrm{m}$, although less wear cycles were tested.
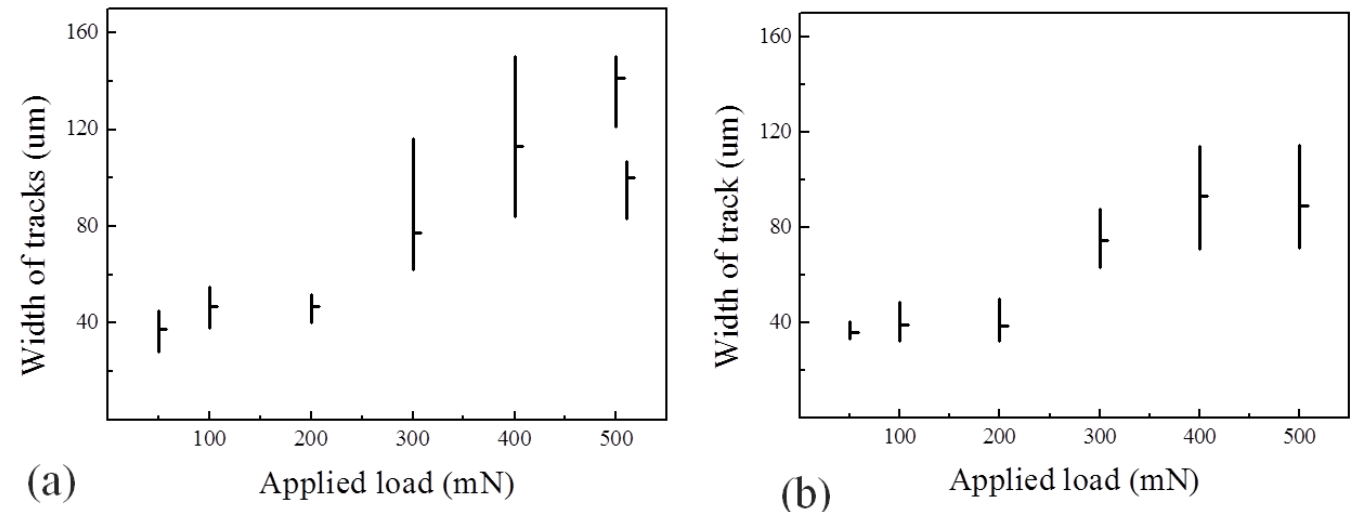

Figure 4-6: The width of wear tracks with respect to applied loads in ball-on-disk sliding wear tests. (a) At the sliding speed of $1.25 \mathrm{~mm} / \mathrm{s}$, (b) at the sliding speed of $2.5 \mathrm{~mm} / \mathrm{s}$. 
The significant increase in the width of track indicates the change in the deformation mechanism. This change is consistent with the tendency of the coefficient of friction. Under extreme high load (that is, $300 \mathrm{mN}, 400 \mathrm{mN}$ and 500 $\mathrm{mN}$ ), plastic deformation likely dominated the wear process which caused severe wear at the very beginning of test.

\subsubsection{Under ball-on-disk reciprocating wear mode}

\section{(1) Coefficients of friction}

Under the reciprocating wear mode, alumina $\left(\mathrm{Al}_{2} \mathrm{O}_{3}\right)$ counter-ball with a diameter of $2 \mathrm{~mm}$ was used, which is the same as that under the sliding wear mode. The half amplitude of the movement was at $0.25 \mathrm{~mm}$, and the sliding speed varied at 1.5 $\mathrm{mm} / \mathrm{s}$ and $2.5 \mathrm{~mm} / \mathrm{s}$. Figs. $4-7 \mathrm{a}$ and $4-7 \mathrm{~b}$ highlighted the coefficient of friction as a function of wear cycles and applied loads.

Under sliding speed of $1.5 \mathrm{~mm} / \mathrm{s}$, under $50 \mathrm{mN}$, the coefficients of friction increased from about 0.1 to 0.17 after 1000 wear cycles (Fig. 4-7a). When tested under $100 \mathrm{mN}$, the coefficient of friction stabilized at around 0.18 , with less scattering as compared with that under $50 \mathrm{mN}$. This is due to the change in the cantilever from a medium-load one to a high-load one. The coefficient of friction reached around 0.22 when tested under $200 \mathrm{mN}$ and after 1000 wear cycles. The test was stopped at around 850 wear cycles when tested under $300 \mathrm{mN}$. This is due to the large vibration in the cantilever. Under $400 \mathrm{mN}$ and $500 \mathrm{mN}$, the tests were stopped at around 400 wear cycles and 140 wear cycles.

Under sliding speed of $2.5 \mathrm{~mm} / \mathrm{s}$ (Fig. 4-7b), when under $50 \mathrm{mN}$, the coefficient of friction increased from around 0.06 to 0.08 after 1000 wear cycles. When tested under $100 \mathrm{mN}$, the coefficient of friction gradually increased with the increasing wear cycles. Thereby, it reached around 0.2 after 1000 wear cycles. 

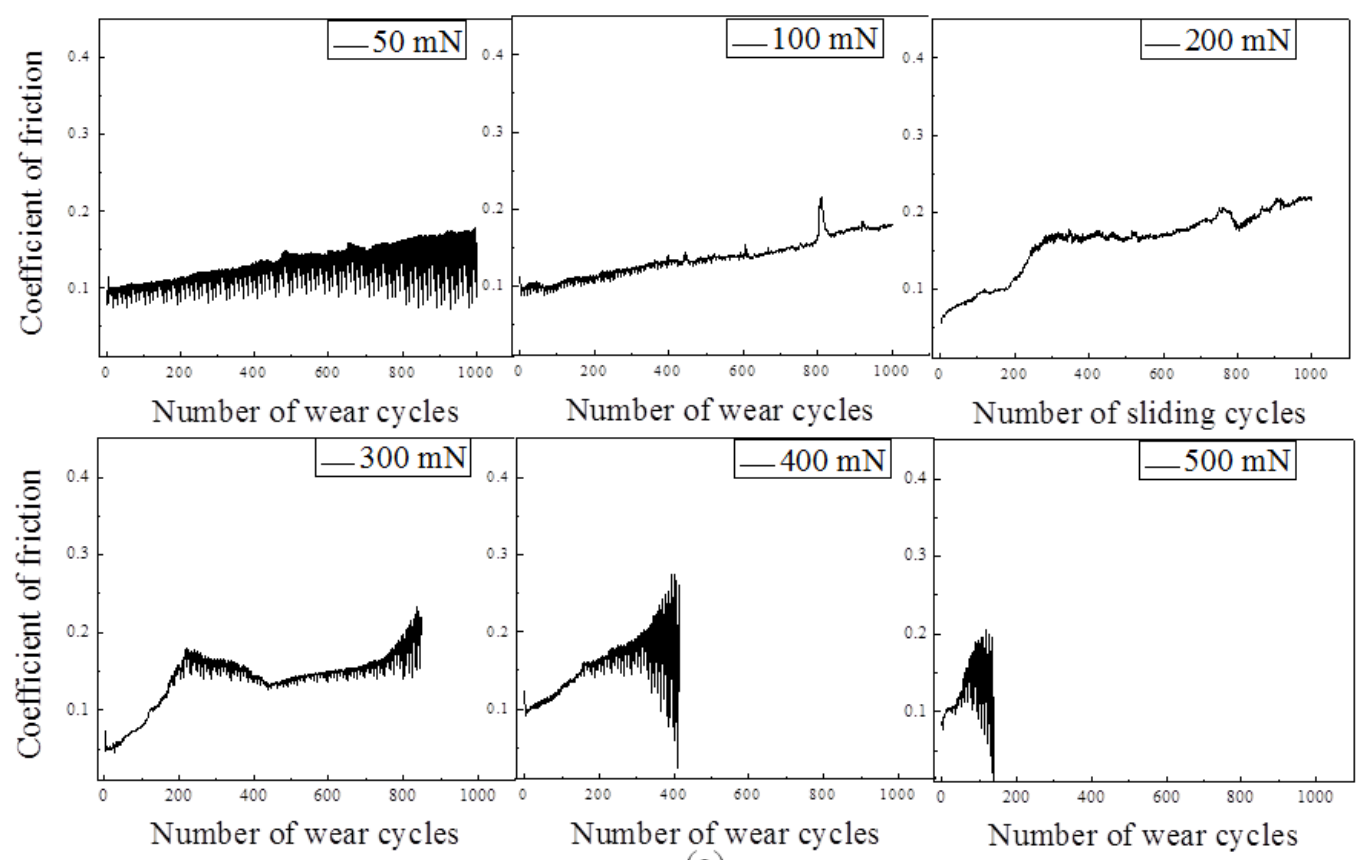

(a)
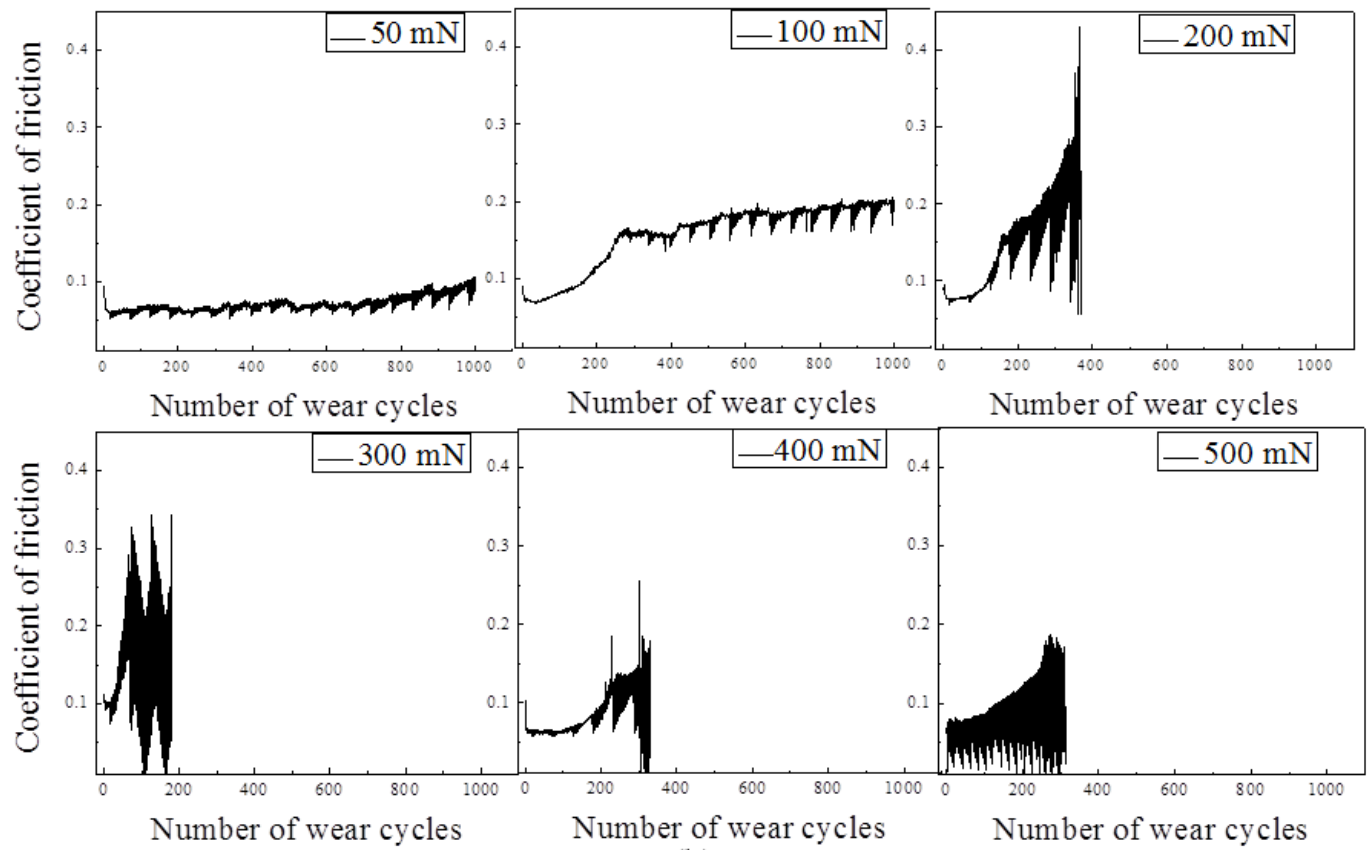

(b)

Figure 4-7: When tested under reciprocating wear mode, the coefficients of friction were shown as a function wear cycles and applied load, (a) with the sliding speed of $1.5 \mathrm{~mm} / \mathrm{s}$; (b) with the sliding speed of $2.5 \mathrm{~mm} / \mathrm{s}$.

In addition, under applied loads of $50 \mathrm{mN}$ and $100 \mathrm{mN}$, serrated coefficients of friction was observed. This is possibly related to the plastic strain accumulation and will be further discussed. When tested under $200 \mathrm{mN}$ and $300 \mathrm{mN}$, the tests 
were stopped after about 370 and 180 wear cycles, respectively. Nevertheless, when tested under $400 \mathrm{mN}$ and $500 \mathrm{mN}$, surfaces were severely damaged and the tests were stopped after around 320 wear cycles.

When under reciprocating wear mode, the cantilever has changed sliding direction in each wear cycle, which caused discontinuity in the movement. Therefore, the coefficient of friction was not stabilized. Furthermore, when under $50 \mathrm{mN}$, the medium-load cantilever was used, which is suitable for applied loads from 10 to $100 \mathrm{mN}$. The high sensitivity of the cantilever caused large scattering in the coefficient of friction when under $50 \mathrm{mN}$. When under $100 \mathrm{mN}$, high-load cantilever was used, which is less sensitive thus caused less scattering.

\section{(2) Surface wear features}

When tested under reciprocating wear mode, the surface wear features showed a linear pattern, since the forward and reversed movements were repeated on a linear track. The surface wear features, which correspond to the coefficients of friction shown in Figs. 4-7a and 4-7b, were illustrated in Figs. 4-8a and 4-8b, respectively.

Comparing the surface wear features obtained under the sliding and reciprocating wear mode, less surface damage was found when tested under the reciprocating wear mode. This is consistent with low values in the coefficients of friction under reciprocating wear mode. It is likely related to the cancelling of deformation strain due to forward and reversed movement, this will be discussed further.

The width of track was concluded as a function of applied load and sliding speed as shown in Fig. 4-9. Ten measurements were selected arbitrarily on each wear track. When tested at sliding speed of $1.5 \mathrm{~mm} / \mathrm{s}$, the width of track was distributed at around $30 \mu \mathrm{m}$ to $50 \mu \mathrm{m}$ when the load was increased from $50 \mathrm{mN}$ to $500 \mathrm{mN}$. When tested at $2.5 \mathrm{~mm} / \mathrm{s}$, the width of track was in increasing tendency with 
increasing the load from $50 \mathrm{mN}$ to $200 \mathrm{mN}$. However, with further increasing the applied load from $300 \mathrm{mN}$ to $500 \mathrm{mN}$, the width of track was decreased. This was attributed to the small number of wear cycles in the wear test. Trends in the width of track as a function of applied load and sliding speed agreed with the trends in the coefficient of friction.
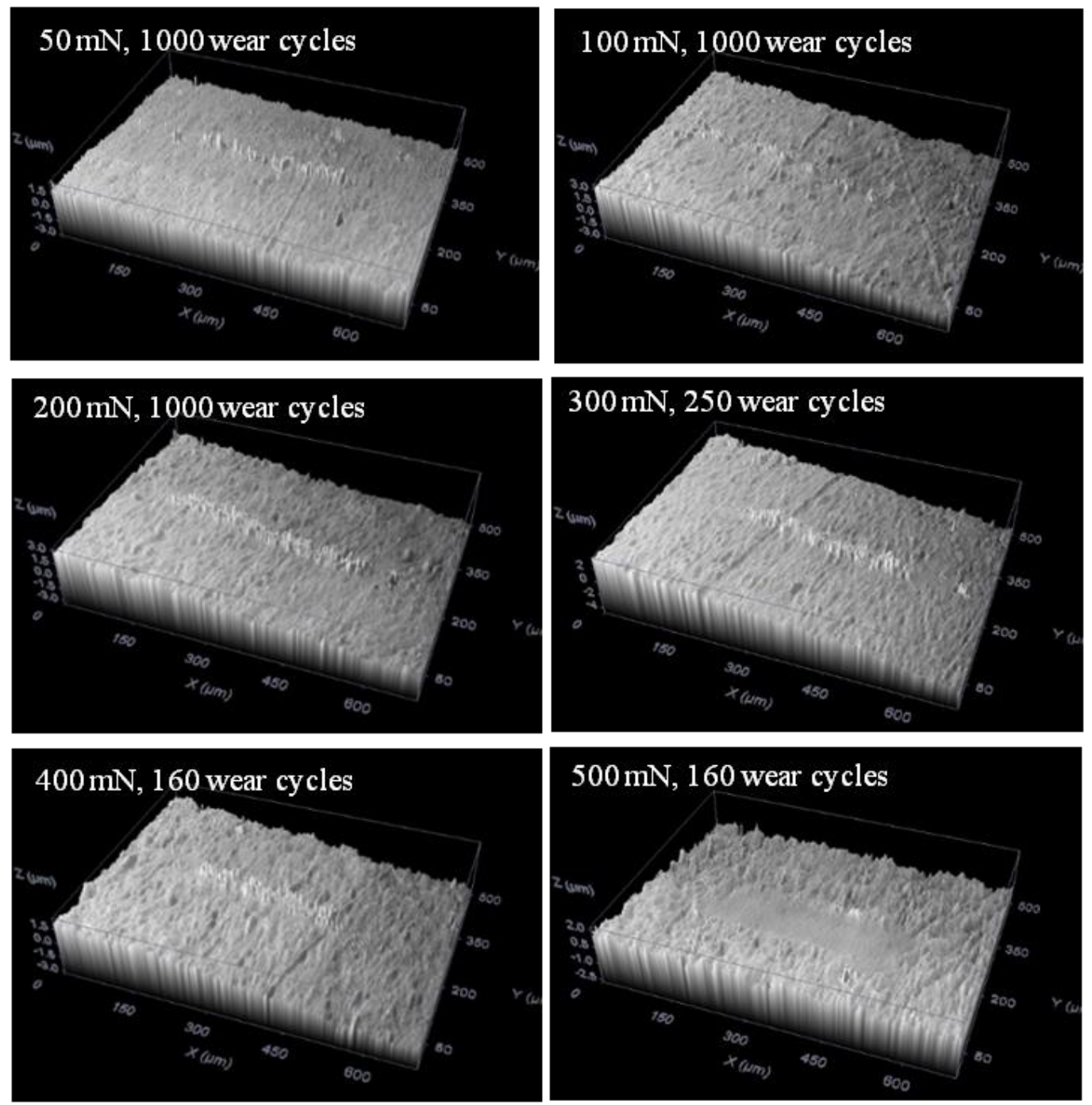

Figure 4-8a: 3D confocal microscopic images of worn surfaces of the martensitic NiTi samples when tested at the sliding speed of $1.5 \mathrm{~mm} / \mathrm{s}$. The applied load and wear cycles were indicated accordingly. 

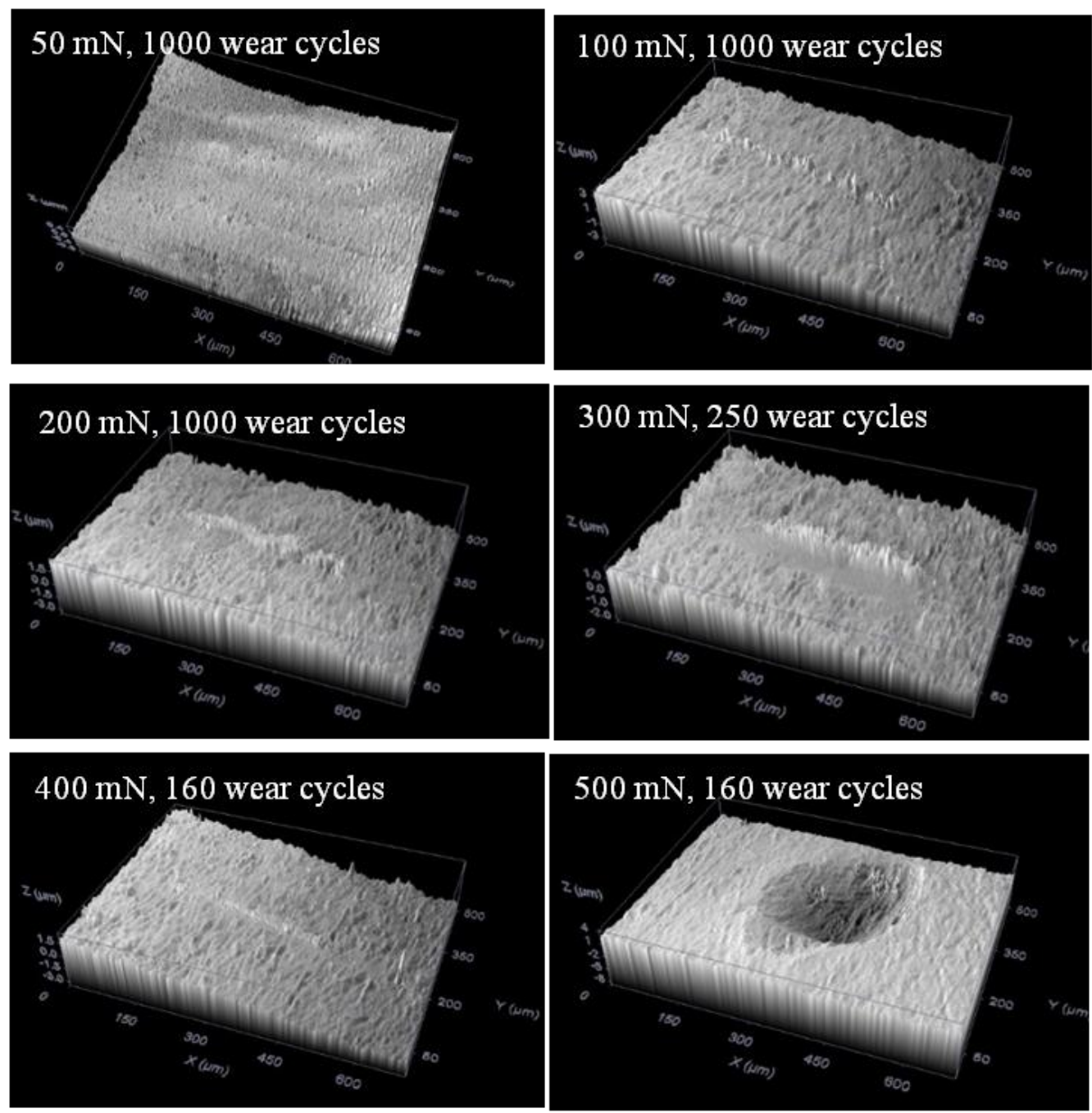

Figure 4-8b: 3D confocal microscopic images of worn surfaces of the martensitic NiTi samples when tested at the sliding speed of $2.5 \mathrm{~mm} / \mathrm{s}$.

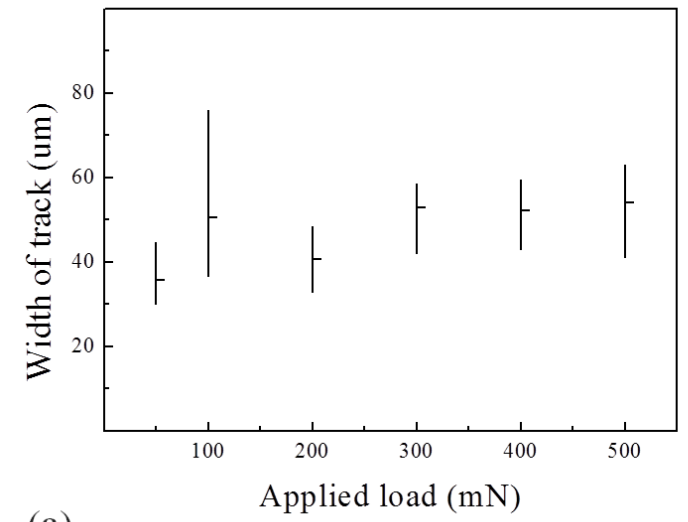

(a)

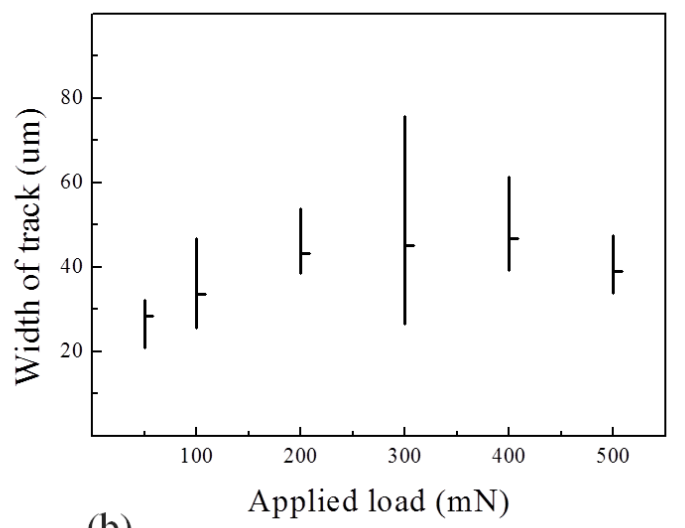

(b)

Figure 4-9: When tested under reciprocating wear mode, the width of wear track is shown as a function of applied load. (a) When tested at the sliding speed of 1.5 $\mathrm{mm} / \mathrm{s}$ and, (b) when tested at the sliding speed of $2.5 \mathrm{~mm} / \mathrm{s}$. 


\subsubsection{Summary on the coefficient of friction and wear volume}

(1) Summary on the coefficient of friction

To reveal the evolution of the deformation mechanisms in the wear process, the coefficients of friction after 100 wear cycles and 1000 wear cycles were compared in Fig. 4-10. After 100 wear cycles, the initial coefficient of friction is affected by the plastic deformation on the high asperities, since the surfaces adapted to each other at the beginning of the wear test. Meanwhile, after 1000 wear cycles, the stabilized coefficient of friction is dependent on the contact stress and deformation mechanisms of the martensitic NiTi SMA.

For ease of discussion, terms of the "initial coefficient of friction" and "stabilized coefficient of friction" were used, refer to the coefficient of friction after 100 wear cycles and 1000 wear cycles, respectively. The "S1" and "S2" were used to represent the low and high sliding speed.

Under sliding wear tests, two regions were found in the initial coefficients of friction as a function of applied load (Fig. 4-10a). The initial coefficients of friction kept below 0.1 at $\mathrm{S} 1$ and $\mathrm{S} 2$, when tested under $50 \mathrm{mN}, 100 \mathrm{mN}$ and $200 \mathrm{mN}$. However, the initial coefficients of friction scattered at around 0.3 to 0.5 , when tested under 300, 400 and $500 \mathrm{mN}$.

The Fig. 4-10b summarized the stabilized coefficients of friction as a function of applied load. When under $50 \mathrm{mN}$, at sliding speed of $\mathrm{S} 1$ and $\mathrm{S} 2$, the coefficient of friction stabilized at around 0.07 . When under $100 \mathrm{mN}$, at $\mathrm{S} 1$, the coefficient of friction stabilized at around 0.32 ; while at $\mathrm{S} 2$, it stabilized at around 0.2 . When under $300 \mathrm{mN}$, the stabilized coefficient of friction reached around 0.43 at $\mathrm{S} 1$. Meanwhile, due to severe instability, the test at S2 was stopped before 1000 wear cycles. 

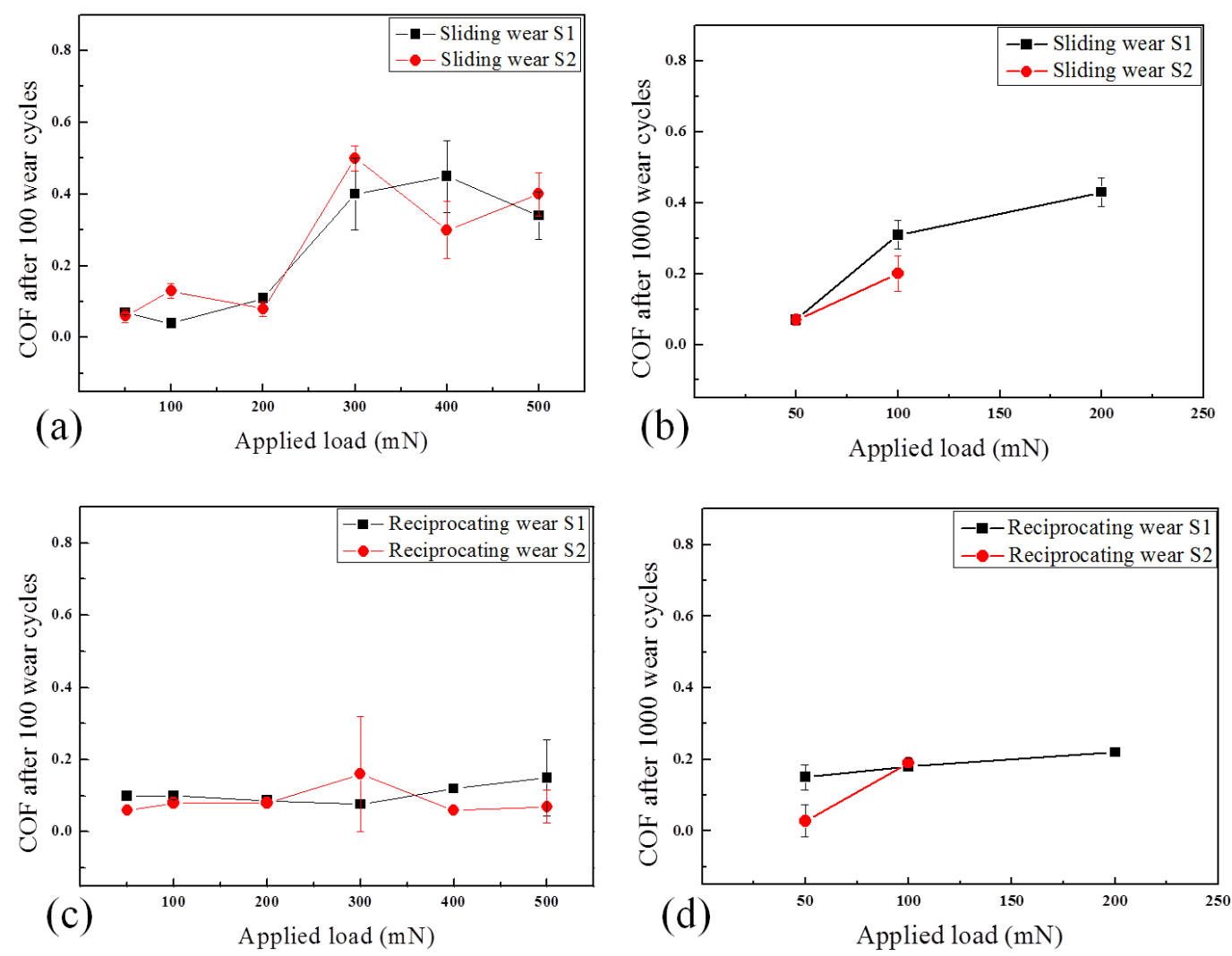

Figure 4-10: The coefficients of friction when tested under different applied load, wear mode and sliding speed. (a) When under the sliding wear mode after 100 wear cycles; (b) when under the sliding wear mode after 1000 wear cycles; (c) when under the reciprocating wear mode after 100 wear cycles; and (d) when under the reciprocating wear mode after 1000 wear cycles.

Under reciprocating wear mode, both the initial and stabilized coefficients of friction had kept at relative low values as compared to that under sliding wear mode (Fig. 4-10). The initial coefficients of friction scattered at around 0.1, when under different applied loads and sliding speeds (Fig. 4-10c). Nevertheless, the stabilized coefficient of friction varied at around $0.15,0.19$ and 0.22 , when under 50, 100 and $200 \mathrm{mN}$ and at S1, respectively (Fig. 4-10d). At S2, the stabilized coefficients of friction were at about 0.02 and 0.19 , when tested under applied loads of 50 and $100 \mathrm{mN}$. 
When under sliding wear mode, both the initial and stabilized coefficients of friction showed higher values than that under reciprocating wear mode. This is likely related to the deformation strain cancelling in the forward and reversed movement when tested under reciprocating wear mode. In addition, with increasing the sliding speed, high instability occurred, which is likely associated with the time restriction on the martensite variants reorientation process. It will be further discussed in section 4.2.3.

(2) Wear volume estimation

In order to provide a quantitative analysis on the surface damage, the surface wear volume was estimated. The detailed explains on the calculations were shown in Chapter 3 (section 3.3.2). It is worthy to note that, the wear volume estimated by using asperities was higher than the wear volume estimated by using tracks. This is due to the low resolution of $3 \mathrm{D}$ confocal microscopic images, since small tracks were blocked by surface asperities. Examples can be found when comparing Figs. 4-3a and 4-4. The wear volume of asperities embossed on the surface was used to represent the total wear volume, which is summarized in Fig. 4-11.

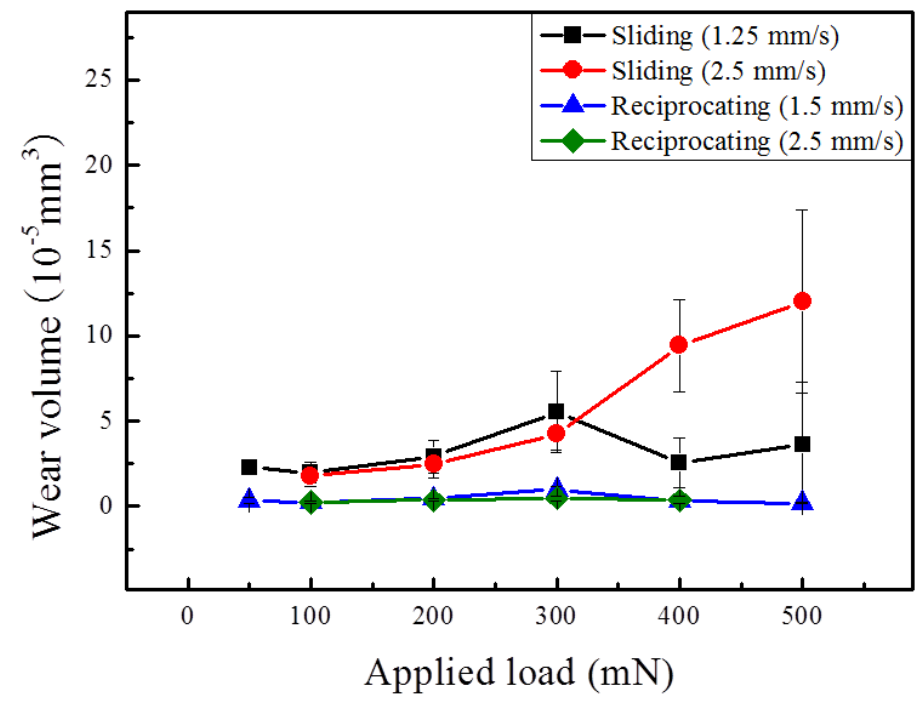

Figure 4-11: The estimated wear volume of the martensitic NiTi SMA when tested under different wear mode, sliding speed and applied load. 
Under the reciprocating wear mode, the wear volume kept at low value when the applied load was increased from $50 \mathrm{mN}$ to $500 \mathrm{mN}$ (Fig. 4-11). When under sliding wear mode, the wear volume increased when the load was increased from $50 \mathrm{mN}$ to $300 \mathrm{mN}$. This suggests increased amount of plastic strain accumulation, and it is likely caused by changing in the deformation mechanism. When the load exceeded $300 \mathrm{mN}$, the wear volume was scattered. This likely originates from severe wear dominated wear process, which occurred under an extreme high contact stress.

\subsection{Discussion}

\subsubsection{Deformation mechanisms and contact stress distributions}

The deformation of martensitic NiTi SMA proceeds as the following: elastic deformation of twinned martensite; detwinning of twinned martensite with occurrence of stress-plateau in the stress-strain curve; elastic deformation of detwinned martensite; and plastic deformation of detwinned martensite [150]. Same deformation sequences were reported when tested under tensile and compressive loading. Furthermore, under compressive loading, early strain-hardening can lead to asymmetric stress-strain curves between tension and compression. The resulted yield stress of the twinned martensite is slightly higher than that under tension $[82,83]$. Therefore, more dislocation can be generated under the compressive load as compared with that under the tensile load.

In the wear studies, the NiTi SMA surface was subjected to a compressive load, which was distributed non-uniformly. The area that is closest to the tip of counter-ball bearing the highest level of contact stress. With increasing the distance from this area, the contact stress was decreased. The deformation distribution beneath the contact area was illustrated schematically in Fig. 4-12. 


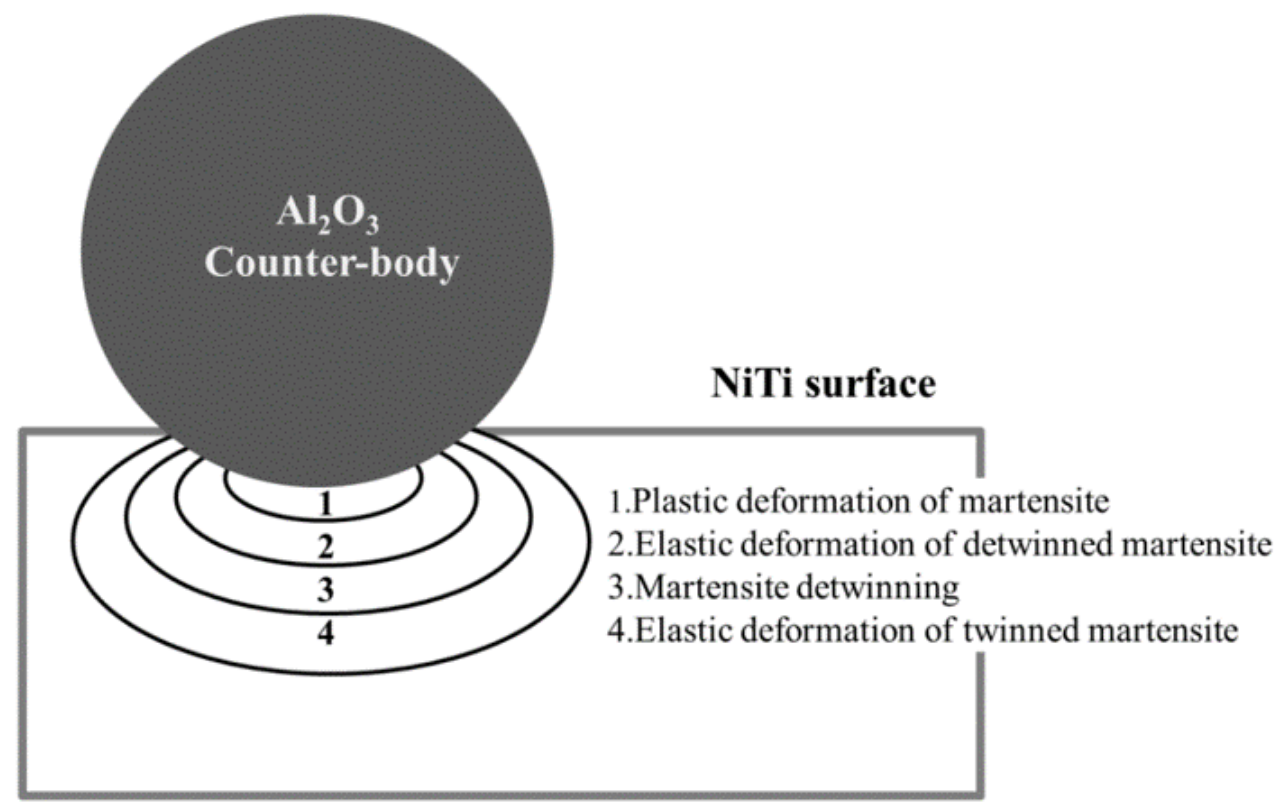

Figure 4-12: Schematic illustration of the deformation distribution in the vicinity of the contact area in the wear test of the martensitic forged ingot NiTi.

The 2-D mode showed a cross-sectional view near the deformed area, where four deformation zones were identified. Figure 4-12 is a refined model based on the one proposed by Qian et al [12, 109].

In Region 1, plastic deformation of martensite occurred at the tip of the counter-ball, the corresponding contact stress is the highest, which exceeded the yield stress of the detwinned martensite. With increasing distance from the Region 1, the contact stress was decreased below the yield stress of detwinned martensite. Elastic deformation of detwinned martensite dominated the Region 2, thereby the detwinning process dominated the Region 3.

By increasing the distance from the contact tip, the contact stress was decreased below the critical stress for detwinning. Elastic deformation of twinned martensite dominated the Region 4, which is fully reversible.

On the other hand, when tested under an extremely low load, only elastic 
deformation occurs. Deformation in Region 4 dominates the wear process, results in insignificiant plastic deformation, thus giving an insignificant wear. By increasing the applied load, the contact stress will be increased. Deformations in Region 2 and 3 will dominate the wear process, which result in plastic strain accumulation in repeated wear cycles. However, deformation in Region 4 occurs beneath the zone of Region 2 and 3, which will not contribute to the wear process due to insignificant formation of plastic strain. Under extreme high load, that the average contact stress exceeds the yield stress of detwinned martensite, plastic deformation dominates the wear process, which is associated with severe wear. In the region that is directly beneath the Region 1, elastic deforamtion of detwinned martensite and detwinning process are the dominant deformation mechanisms. However, less surface damage can be formed in this region as compared with the plastic deformation dominated Region 1. The deformation mechanism in the region that is nearest to the contact tip dominates the wear process, which will be paid particular attention in analyzing the wear behaviour of martensitic NiTi SMA in the present study.

Furthermore, the stress-strain curve can be affected by the strain rate, since the strain rate may lead to a change in the deformation mechanism. For the martensitic NiTi SMA, the stress-strain curve was insensitive to the strain rate that ranged from $0.002 \mathrm{~s}^{-1}$ to $300 \mathrm{~s}^{-1}$ [88]. We have controlled the sliding speed in wear tests so that the deformation is insensitive to the strain rate.

\subsubsection{Degradation stages of martensitic NiTi SMA}

The wear process of the martensitic NiTi SMA has rarely been discussed due to the difficulty in simulating the surface damage accumulation process. However, an understanding of the deformation mechanism in the wear process is essential in selecting the effective application conditions. In the present study, the degradation stages of the martensitic NiTi SMA surface were defined using the coefficient of friction and surface wear features. Three degradation stages are closely related to 
the plastic strain accumulation process, therefore they were further related to the dominant deformation mechanisms involved in the wear process. It is worthy to note that, the following discussion on the degradation stages was focused on the results obtained under the sliding wear mode. The results on the reciprocating wear will be discussed in next section.

The degradation stage I (the near-zero wear stage), is characterized by insignificant formation of surface damage in repeated wear cycles accompanied by low coefficient of friction. The coefficient of friction was not affected by such insignificant plastic strain accumulation. Therefore, the deformation mechanism has kept the same throughout the test. For example, when tested under low load (that is, $50 \mathrm{mN}$ ), the coefficient of friction, which was not affected by the formation of the crown-like structure, has kept at low values for up to 1000 wear cycles.

The degradation stage II, the transition wear stage, is characterized by significant plastic strain accumulation, which has led to the change in the dominant deformation mechanism in increasing wear cycles. At the beginning of the test, the coefficient of friction was low and near-zero wear occurred, which was accompanied by insignificant formation of surface damage. A crown-like structure was formed. With increasing the wear cycles, a drastic increase in the coefficient of friction indicated the change in the deformation mechanism. In this case, the height of the crown-like structure increased due to further plastic strain accumulation. Then, the coefficient of friction entered a steady state in further wear cycles, thereby the crown-like structure was stabilized.

The degradation stage III, the abrasive wear stage, is characterized by severe plastic deformation which has led to a high instability in the coefficient of friction. The occurrence of stage III is load-dependent, hence two situations are involved. Under low load, the wear remained in stage I for a large number of wear cycles, which is associated with insignificant plastic strain accumulation. A crown-like structure was 
formed and gradually destructed with further increased wear cycles. This is due to local plastic strain accumulation. This process is very slow, suggesting slow wear process when tested under low load. Once debris was formed, the wear rate can be increased suddenly, which is associated with change in the deformation mechanism. The presence of debris and tracks after a large number of wear cycles indicates the beginning of the abrasive wear stage. On the other hand, under high load, severe wear occurred at the very beginning of the test, and abrasive wear dominated the wear process. The surface can be quickly damaged due to significant formation of debris.

Based on the observations in the coefficient of friction and surface wear features, and by the understanding of the stress-strain curve and contact stress estimation, we have attempted to understand the deformation mechanisms of the martensitic NiTi SMA in the wear process. When tested under an extremely low load of $50 \mathrm{mN}$, insignificant surface damage was formed after 1000 wear cycles. Meanwhile, the coefficient of friction remained low, suggesting insignificant plastic strain accumulation over repeated wear cycles. To further understand the wear process, a wear test under $50 \mathrm{mN}$ was stopped after about 10 wear cycles. No visible wear track was found. However, after 1000 wear cycles, a crown-like structure was formed as shown in Fig. 4-2 and 4-3, suggests the near-zero wear stage.

The Hertzian elastic contact theory is commonly used in wear studies for contact stress estimation $[12,109,151]$. However, this contact model is only suitable for elastic deformation problems. When tested under extreme low load, the contact stress likely below the critical stress for detwinning. To estimate the elastic contact stress, the Hertzian elastic model was applied using the following equations [12, $151]$.

$$
\sigma^{3}=\frac{6 F_{n}\left(E^{*}\right)^{2}}{\pi^{3} R^{2}}
$$




$$
\frac{1}{E^{*}}=\frac{1-v_{1}^{2}}{E_{1}}+\frac{1-v_{2}^{2}}{E_{2}}
$$

Here, $F_{\mathrm{n}}$ is the applied load; $E^{*}$ is the combined modulus, which is related to the Young's modulus of two materials involved; $\sigma$ is the contact stress; $R$ is the radius of sphere (1 mm); $E_{1}, E_{2}, v_{1}$ and $v_{2}$ are the elastic moduli and Poisson's ratio of the martensitic NiTi SMA and alumina counter-ball, with values of $26 \mathrm{GPa}, 375 \mathrm{GPa}$, 0.33 and 0.23 , respectively.

From the tensile test, the Young's modulus of our sample was $26 \mathrm{GPa}$, and the critical stress for detwinning was $157 \mathrm{MPa}$. Those values are comparable with the reported values [152]. By substituting the values in Eqs. 4.1 and 4.2, when tested under $50 \mathrm{mN}$, the calculated contact stress was at $193 \mathrm{MPa}$. This value is slightly higher than the critical stress for detwinning (157 MPa), but it is much less than the reported yield stress of the detwinned martensite which is at around $630 \mathrm{MPa}$ to $800 \mathrm{MPa}[152,153]$. Hence, this calculation further supports the wear in the near-zero wear stage. In addition, the estimated elastic contact radius was 0.011 $\mathrm{mm}$ when under $50 \mathrm{mN}$, further suggesting insignificant surface wear. Using the Hertzian elastic contact theory (Eqs. 2.11 and 2.12), under $50 \mathrm{mN}$, the calculated contact radius is $0.011 \mathrm{~mm}$. This extreme small contact area further suggest insignificant wear and insignificant temperature rise in this study.

The near-zero wear occurred when tested under $50 \mathrm{mN}$. The overall contact stress approached the critical stress for detwinning, but it was below the yield stress of detwinned martensite. When the contact stress was in this range, elastic deformation of twinned martensite and detwinning of twinned martensite (Regions 3 and 4 of Fig. 4-12) will play a major role in the wear process. Inelastic detwinning process is likely involved at the contact tip, which is not reversible at present testing temperature. Hence, the irreversible detwinning process leads to a small amount of plastic strain accumulation. The formation of the crown-like 
structure after 1000 wear cycles has confirmed this mechanism, examples are shown in Figs. 4-2 and 4-3. In addition, the coefficient of friction remained low throughout the test (Fig. 4-1a), this further supports the insignificant amount of surface wear. In addition, the value in the coefficient of friction is comparable to the reported value at near-zero wear conditions [154].

Transition wear occurs when the contact stress is above the critical stress for detwinning but below the yield stress of detwinned martensite. Detwinning of twinned martensite as well as elastic deformation of detwinned martensite (Region 2 and 3 in Fig. 4-12) will play a major role in the transition wear stage. Furthermore, plastic deformation in Region 1 will also contribute to the wear, which only occurs at the contact tip area thus being less significant. Since the detwinning process is irreversible at the test temperature, plastic strain can be accumulated in repeated wear cycles. This is in consistency with our observations when tested under $100 \mathrm{mN}$ and $200 \mathrm{mN}$. The coefficient of friction stabilized after 440 wear cycles when tested under $100 \mathrm{mN}$, while it stabilized after 310 wear cycles under $200 \mathrm{mN}$. The change in the coefficient of friction indicates the transition in the deformation mechanism caused by plastic strain accumulation. Furthermore, the plastic strain accumulation process was accelerated when under higher load, this is further confirmed by the early stage transition behaviour under $200 \mathrm{mN}$. In addition, small variations in the radius of wear cycles was found in different tests, which had insignificant effect on the wear process.

When the load is extremely high, the contact stress exceeds the yield stress of detwinned martensite. The plastic deformation shown in the Region 1 on Fig. 4-12 dominates the wear process, and the abrasive wear (stage III) occurs. The wear process is highly unstable at the very beginning of the test due to the presence of a large amount of debris. This can be supported by our observations when tested under $300 \mathrm{mN}, 400 \mathrm{mN}$ and $500 \mathrm{mN}$. High instability in the coefficient of friction was observed, and a large amount of debris was found even after 100 wear cycles. 
Once such severe wear occurs, the wear resistance of the martensitic NiTi SMA can be deteriorated. We should avoid sharp contact in the application of the martensitic NiTi SMA, since the surface is relatively soft as compared with the conventional wear resistant materials.

\subsubsection{Effect of deformation mode on the wear behaviour of martensitic NiTi SMA}

In both sliding and reciprocating wear test, at different sliding speeds, similar wear behaviour was observed in the near-zero wear stage. However, when the transition wear (stage II) occurred at different sliding speeds, some discrepancy in the wear behaviour was observed. When under sliding wear mode, the stabilized coefficient of friction was lower when tested at higher sliding speed. Meanwhile, when under reciprocating wear mode, opposite trend was found. In the abrasive wear stage, tests were stopped due to large vibrations of cantilever caused by severe wear.

In the near-zero wear stage, elastic deformation dominated the wear process. Hence, similar insignificant surface wear occurred when tested under sliding and reciprocating wear mode.

In the transition wear stage, martensite variants reorientation dominated the wear process. The transition wear behavior is sensitive to the deformation mode. Under sliding wear mode, in the beginning of wear process, the single martensite variant in the most favourable orientation grows in each grain [150]. The elastic energy stored in the self-accommodated martensite can be released in the detwinning process. Due to mismatch in the orientations, dislocations can also be generated [155]. Thereby, internal stress field can be introduced due to dislocation generation, which further contributes to the martensitic stabilization effect $[156,157]$. When the contact stress is further increased but below the yield stress of detwinned martensite, deformation can be accommodated through further reorientation of 
martensite variants that in the unfavourably oriented directions [156, 158]. Therefore, majority of self-accommodated twinned martensite changes to a reoriented configuration.

In the beginning of transition wear, deformation can be effectively accommodated through martensite variants reorientation process. Therefore, plastic strain accumulation can be retarded, results in insignificant surface damage. With increasing wear cycles, the detwinning of twinned martensite can be completed. Hence, elastic and plastic deformation of twinned martensite occurs in further increasing wear cycles, accompanying by significant plastic strain accumulation. For example, when tested under sliding wear mode, the coefficient of friction increased significantly with increasing wear cycles when transition wear occurred under 100 and $200 \mathrm{mN}$. After 100 wear cycles, the coefficients of friction remained below 0.12 . This relative low value is comparable with that under $50 \mathrm{mN}$, suggests insignificant plastic strain accumulation. After 1000 wear cycles, the coefficient of friction stabilized at about 0.3 and 0.4 , suggests significant plastic strain accumulation in repeated wear cycles. The significant increase in the coefficient of friction further supports transition wear behaviour.

When tested under reciprocating wear mode, the internal stress field developed by deformation in opposite direction can cancel with each other. As a result, the plastic strain accumulation process can be retarded, thus the surface degradation process can be delayed. This can be supported by the near-zero wear when the applied load was increased from $50 \mathrm{mN}$ to $200 \mathrm{mN}$. The coefficient of friction remained at low values, while insignificant amount of surface asperities were formed after 1000 wear cycles. These values are much lower than those under sliding wear mode.

In the abrasive wear stage, similar severe wear occurred in both sliding and reciprocating wear mode. Plastic deformation dominated the wear process. 


\subsection{Summary}

The wear behaviour of the martensitic NiTi SMA was investigated systematically through varying of several influential factors. Those factors include the wear mode, sliding speed, wear cycles and applied load. Three degradation stages, namely, near-zero wear stage, transition wear stage and abrasive wear stage were defined according to the observations in the coefficient of friction and surface wear features.

1. Near-zero wear stage, which is characterized by low coefficient of friction which does not affected by the formation of surface asperities in increasing wear cycles. Elastic deformation dominated the near-zero wear process, which caused insignificant plastic strain accumulation in repeated wear cycles.

2. Transition wear stage, which is characterized by significant formation of surface damage in the wear process, is thereby accompanied with transition in the deformation mechanism. The coefficient of friction stabilized at high values as compared to that in the near-zero wear stage. The detwinning as well as elastic deformation of detwinned martensite dominated the transition wear stage. By further increasing the wear cycles, the abrasive wear is likely to set in due to the significant formation of surface damage.

3. Abrasive wear stage is characterized by severely damaged surface, as well as high instability in the coefficient of friction. Plastic deformation dominated the abrasive wear stage since the contact stress has exceeded the yield stress of detwinned martensite.

Furthermore, results obtained under sliding and reciprocating wear modes were 
compared under low load and high load conditions. When tested under low load condition, the wear process was not sensitive to the deformation mode. However, when tested under high load condition, the sliding wear mode caused more surface damage as compared to reciprocating wear mode. This was tentatively explained due to the inversed direction of contact stress in the reciprocating wear mode that promotes the reversibility of martensite variant reorientation process. This retarded the plastic strain accumulation hence caused less surface damage. 


\section{Wear Behaviour of Stable Austenitic NiTi SMA}

Several wear studies have reported superior wear resistance of austenitic NiTi SMA, which was attributed to their super-elasticity. The super-elasticity of austenitic NiTi SMA is temperature-dependent [16, 18, 19, 109]. However, understanding of deformation mechanism in the wear process as a function of temperature has rarely being discussed. In our previous study, the deformation mechanism involved in the wear process of martensitic NiTi SMA was systematically revealed [159]. In this chapter, the wear behaviour of austenitic NiTi SMA was studied as a function of temperature and load. The deformation mechanism was revealed through the understanding of the temperature-dependent stress-strain curves and load-dependent deformation regions.

\subsection{Wear resistance of flat annealed Ni 50.9 at \% Ti SMA}

\subsubsection{Under ball-on-disk sliding wear mode}

(1) Coefficients of friction as a function of applied load and wear cycles

Ball-on-disk sliding wear tests were conducted on a Nano-tribometer with an alumina counter-ball having a diameter of $2 \mathrm{~mm}$ (see more details in table 3-2). Three tests with exactly the same experimental parameters were repeated on a new specimen to ensure the repeatability of results. When tested at different sliding speeds, the coefficients of friction as a function of wear cycles and applied load were shown in Figs. 5-1a and 5-1b, respectively.

As shown in Fig. 5-1a, when tested under $25 \mathrm{mN}$ at sliding speed of $1.25 \mathrm{~mm} / \mathrm{s}$, the coefficient of friction increased slightly from around 0.05 to 0.1 after 1000 wear cycles. 

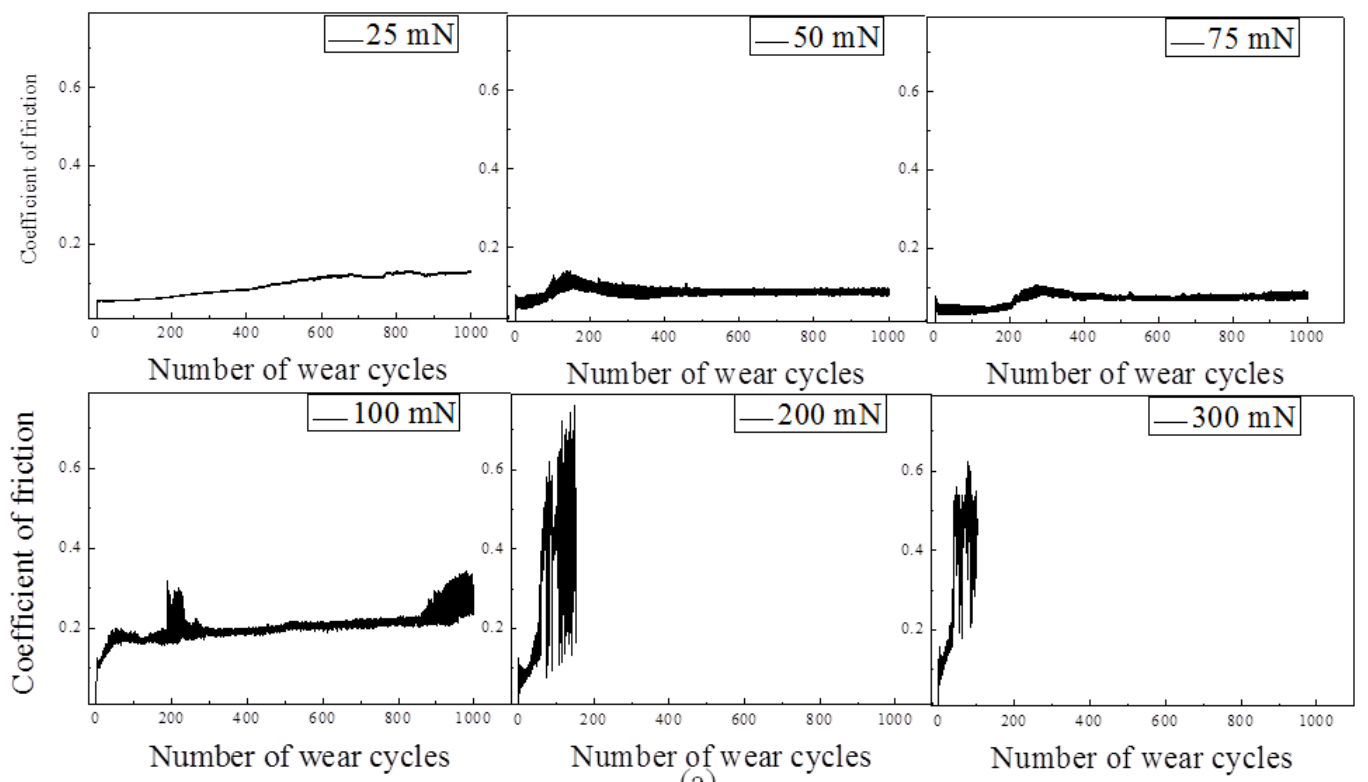

(a)

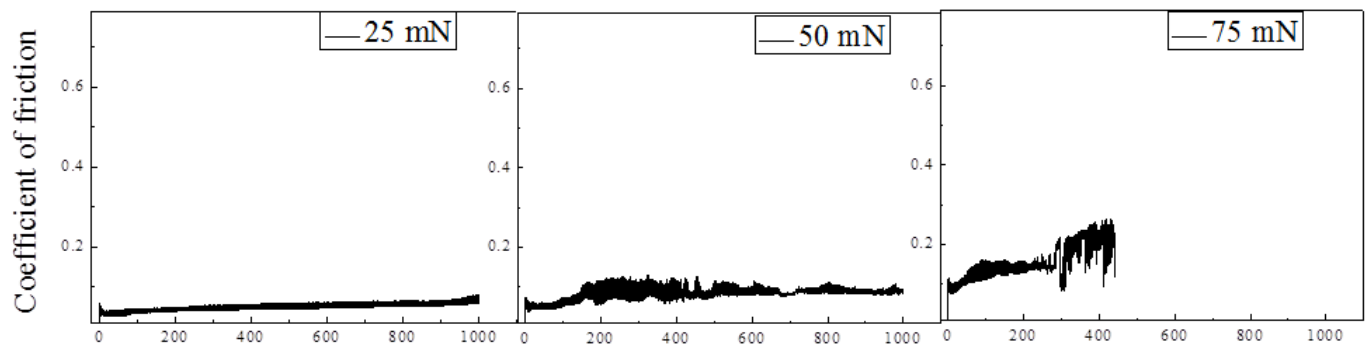

Number of wear cycles

Number of wear cycles

Number of wear cycles

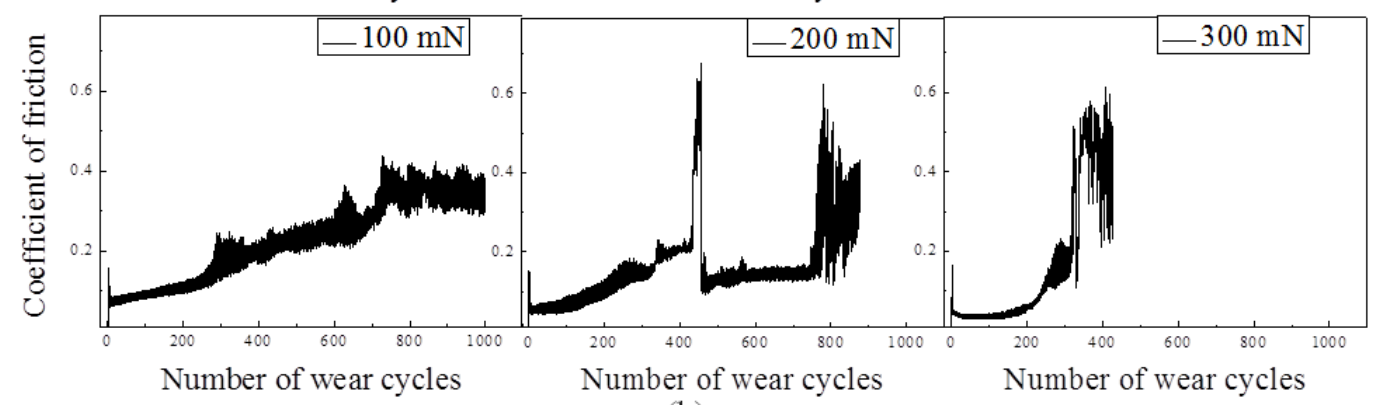

(b)

Figure 5-1: Coefficients of friction as a function of wear cycles and applied load when tested under sliding wear mode. (a) With sliding speed of $1.25 \mathrm{~mm} / \mathrm{s}$; (b) with sliding speed of $2.5 \mathrm{~mm} / \mathrm{s}$.

When tested under $50 \mathrm{mN}$ and $75 \mathrm{mN}$, the coefficients of friction remained about 0.09 after 1000 wear cycles. Same trends in the coefficient of friction suggest similar deformation mechanisms dominated the wear process. When the applied load was increased to $100 \mathrm{mN}$, after 700 wear cycles, the coefficient of friction stabilized at about 0.2. By further increasing the wear cycles, a large scattering was 
observed. When tested under $200 \mathrm{mN}$ and $300 \mathrm{mN}$, high instabilities in the coefficients of friction were observed, thus wear tests were stopped at around 160 and 100 wear cycles, respectively.

When tested at sliding speed of $2.5 \mathrm{~mm} / \mathrm{s}$, higher scatterings in coefficient of friction were observed as compared with that at $1.25 \mathrm{~mm} / \mathrm{s}$ (Fig. 5-1b). Under 25 $\mathrm{mN}$ and $50 \mathrm{mN}$, the coefficients of friction remained at around 0.03 and 0.07 for up to 1000 wear cycles. Under $75 \mathrm{mN}$, the coefficient of friction increased to about 0.13 after approximately 100 wear cycles. The test under $75 \mathrm{mN}$ was stopped after around 450 wear cycles due to large vibrations of the cantilever. When tested under $100 \mathrm{mN}$, the coefficient of friction stabilized at about 0.35 after around 700 wear cycles. When tested under $200 \mathrm{mN}$, the coefficient of friction was highly unstable, and the test was stopped at about 880 wear cycles. When the applied load was further increased to $300 \mathrm{mN}$, the test was stopped after 430 wear cycles due to high instability in the wear process.

When tested under $50 \mathrm{mN}$, similar insignificant wear was observed when the sliding speed was increased from $1.25 \mathrm{~mm} / \mathrm{s}$ to $2.5 \mathrm{~mm} / \mathrm{s}$. When under $75 \mathrm{mN}$ and $100 \mathrm{mN}$, higher instability occurred at higher sliding speed. Furthermore, the wear observations under $200 \mathrm{mN}$ and $300 \mathrm{mN}$ were similar when tested at different sliding speeds, this results suggest that similar severe wear occurred. This will be further explained by deformation mechanisms involved in the wear process.

\section{(2) Surface wear features}

Confocal microscopic images of surface wear features correspond to the coefficients of friction in Figs. 5-1a and 5-1b were shown in Figs. 5-2a and 5-2b, respectively. When tested under $25 \mathrm{mN}$ at a sliding speed of $1.25 \mathrm{~mm} / \mathrm{s}$, small amount of asperities that embossed on the surface was observed (Fig. 5-2a). When tested under $50 \mathrm{mN}, 75 \mathrm{mN}$ and $100 \mathrm{mN}$, increased amount of asperities were 
found, which formed a crown-like structure after 1000 wear cycles. Furthermore, by increasing the applied load, the height and width of the crown-like structure had increased significantly (Figs. 5-2a). This is consistent with the trends in the coefficient of friction as a function of applied load. However, under $200 \mathrm{mN}$ and $300 \mathrm{mN}$, the surfaces were severely damaged. Deep tracks and large amount of debris were observed after around 150 wear cycles. Meanwhile, the coefficient of friction was highly unstable, suggests plastic deformation, which is caused by extreme high contact stress.
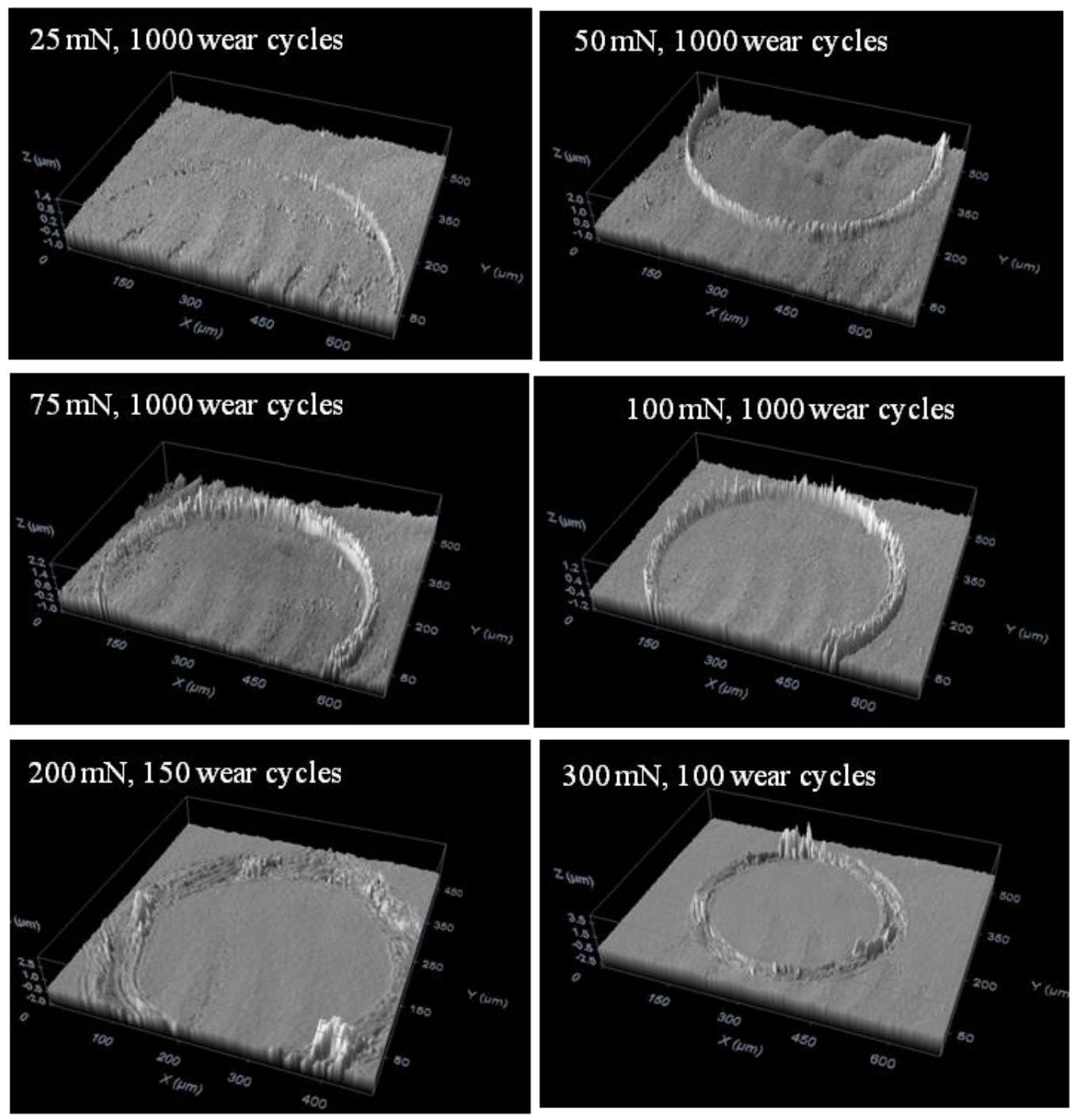

Figure 5-2a: 3D confocal microscopic images of worn surfaces of austenitic NiTi SMA under sliding wear mode and at sliding speed of $1.25 \mathrm{~mm} / \mathrm{s}$. The applied load and number of wear cycles were indicated accordingly. 

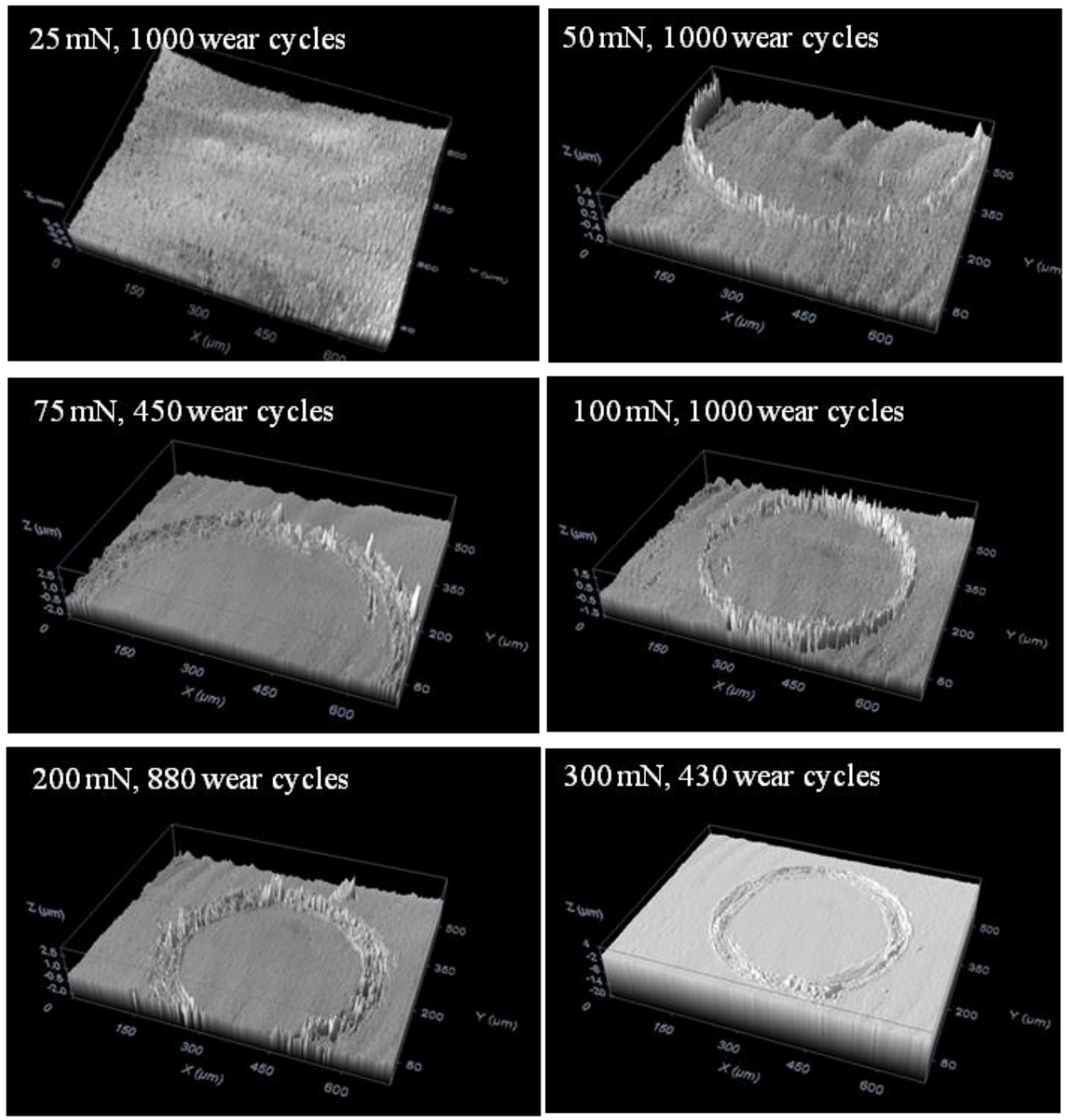

Figure 5-2b: 3D confocal microscopic images of worn surfaces of austenitic NiTi SMA under sliding wear mode and at sliding speed of $2.5 \mathrm{~mm} / \mathrm{s}$.

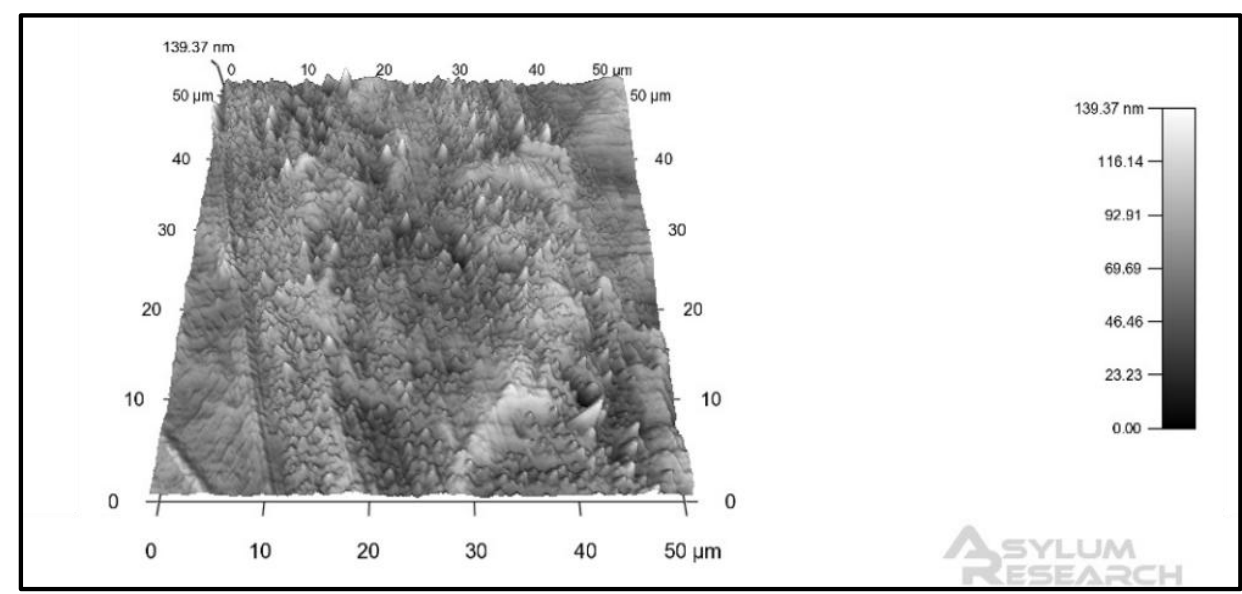

Figure 5-3: High resolution atomic force microscopic image of the surface wear features obtained when tested under $100 \mathrm{mN}$ at $20^{\circ} \mathrm{C}$. 


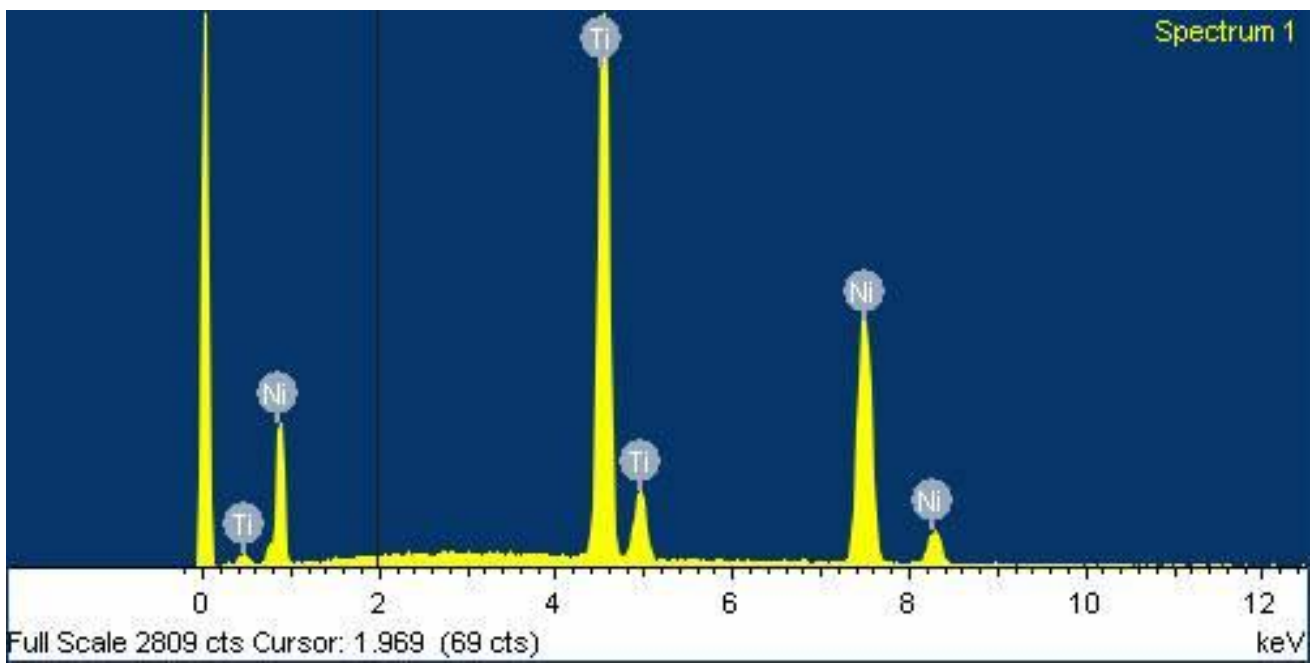

Figure 5-4: Energy dispersive X-ray analysis on the composition of surface asperities obtained when tested under $100 \mathrm{mN}$ at $20^{\circ} \mathrm{C}$.

When the sliding speed was increased to $2.5 \mathrm{~mm} / \mathrm{s}$ (Fig. $5-2 \mathrm{~b}$ ), under $25 \mathrm{mN}$, no visible wear feature was found after 1000 wear cycles. By increasing the load to 50 $\mathrm{mN}, 75 \mathrm{mN}$ and $100 \mathrm{mN}$, crown-like structures were found. When the applied load was further increased to $200 \mathrm{mN}$, a significant amount of surface damage was found after 880 wear cycles. Under $300 \mathrm{mN}$, deep tracks and debris were observed after 430 wear cycles. When tested at higher sliding speed, higher instability in the wear process occurred.

After ultrasonic cleaning in the acetone and the ethanol for 3 mins, the wear features remained. A high resolution AFM image of a part of a crown-like structure is shown in Fig. 5-3. The EDX image of the same region is shown in Fig. 5-4, which suggests no trace of wear debris from alumina counter-ball $\left(\mathrm{Al}_{2} \mathrm{O}_{3}\right)$.

Worn track profiles that transverse to the sliding direction were further examined using the confocal microscope. Ten measurements that transverse to the sliding direction were conducted at random locations on each worn track. The average width of track was obtained by averaging ten readings (Figs. 5-5a and 5-5b). 

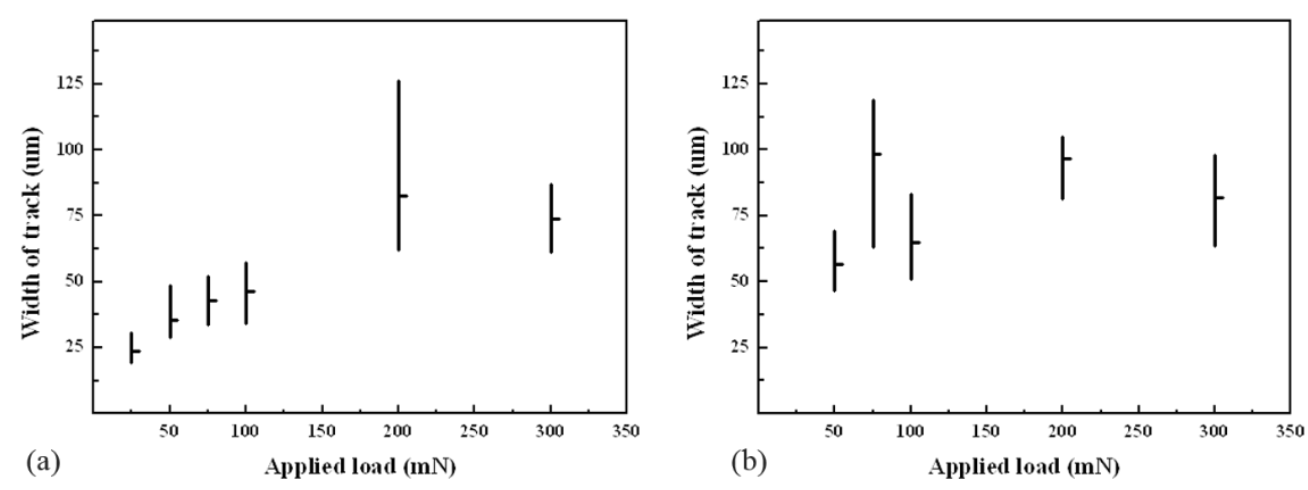

Figure 5-5: The width of wear track with respect to the applied load in ball-on-disk sliding wear test. (a) At sliding speed of $1.25 \mathrm{~mm} / \mathrm{s}$, (b) at sliding speed of 2.5 $\mathrm{mm} / \mathrm{s}$.

When tested at sliding speed of $1.25 \mathrm{~mm} / \mathrm{s}$ (Fig. 5-5a), the width of track was in increasing tendency with increasing the applied load. In addition, when tested under $200 \mathrm{mN}$ and above, the width of track has increased significantly although less wear cycles were tested.

Nevertheless, at sliding speed of $2.5 \mathrm{~mm} / \mathrm{s}$ (Fig. 5-5b), no visible wear was observed when tested under $25 \mathrm{mN}$ after 1000 wear cycles. Furthermore, no clear trend in the width of track was observed as a function of applied load. This originated from high instability in the wear process at high sliding speed. When tested at different sliding speeds, trends on the width of track as a function of applied load were in consistency with the trends in the stabilized coefficient of friction.

\subsubsection{Under ball-on-disk reciprocating wear mode}

(1) Coefficients of friction as a function of applied load and wear cycles

In Fig. 5-6, coefficients of friction were depicted as a function of wear cycles and applied load when tested at different sliding speeds. Medium-load cantilever was 
used when the applied load was at $75 \mathrm{mN}$ or below, while high-load cantilever was used when the applied load was above $100 \mathrm{mN}$. In the reciprocating wear test at sliding speed of $1.5 \mathrm{~mm} / \mathrm{s}$ (Fig. 5-6a), with increasing the applied load from $25 \mathrm{mN}$ to $200 \mathrm{mN}$, trends in the coefficient of friction were quite similar but the values were different.
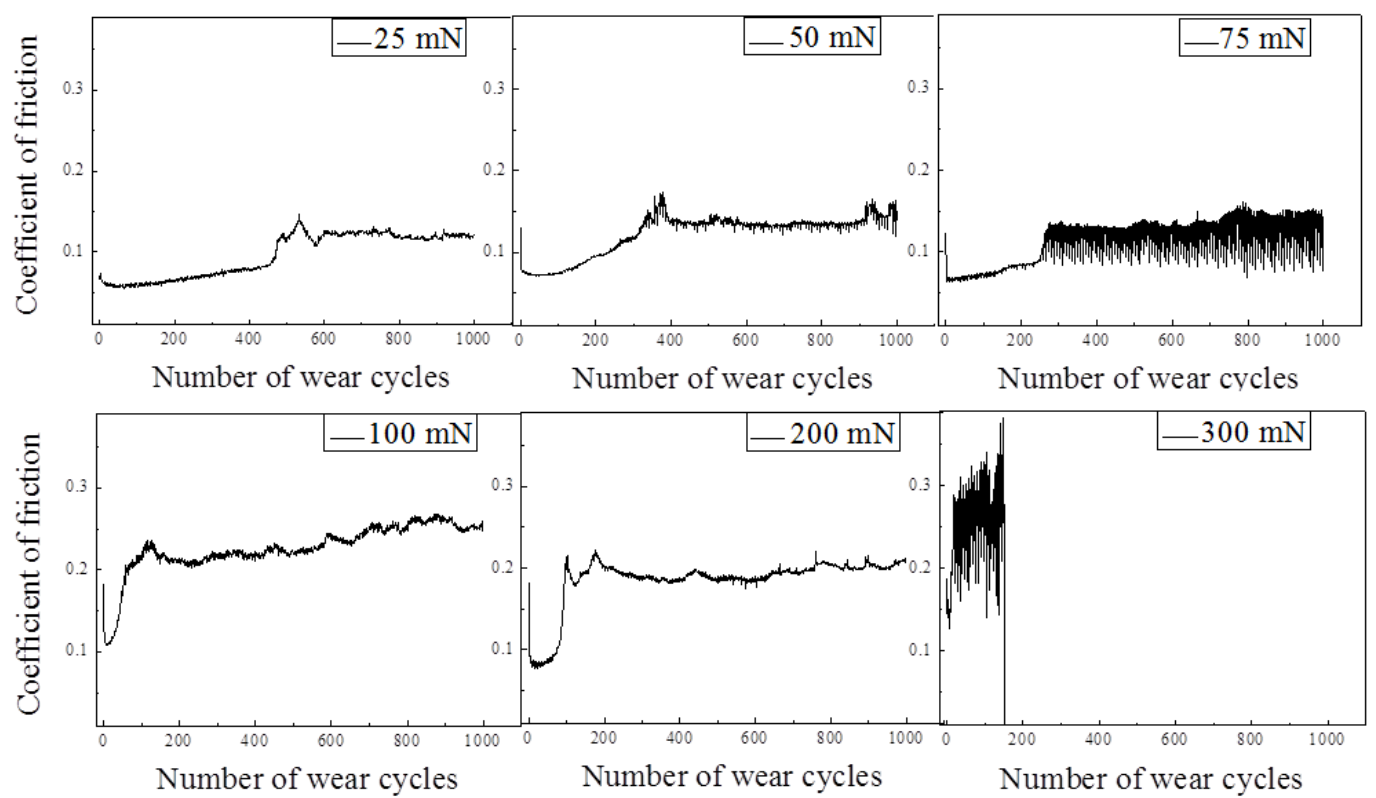

(a)
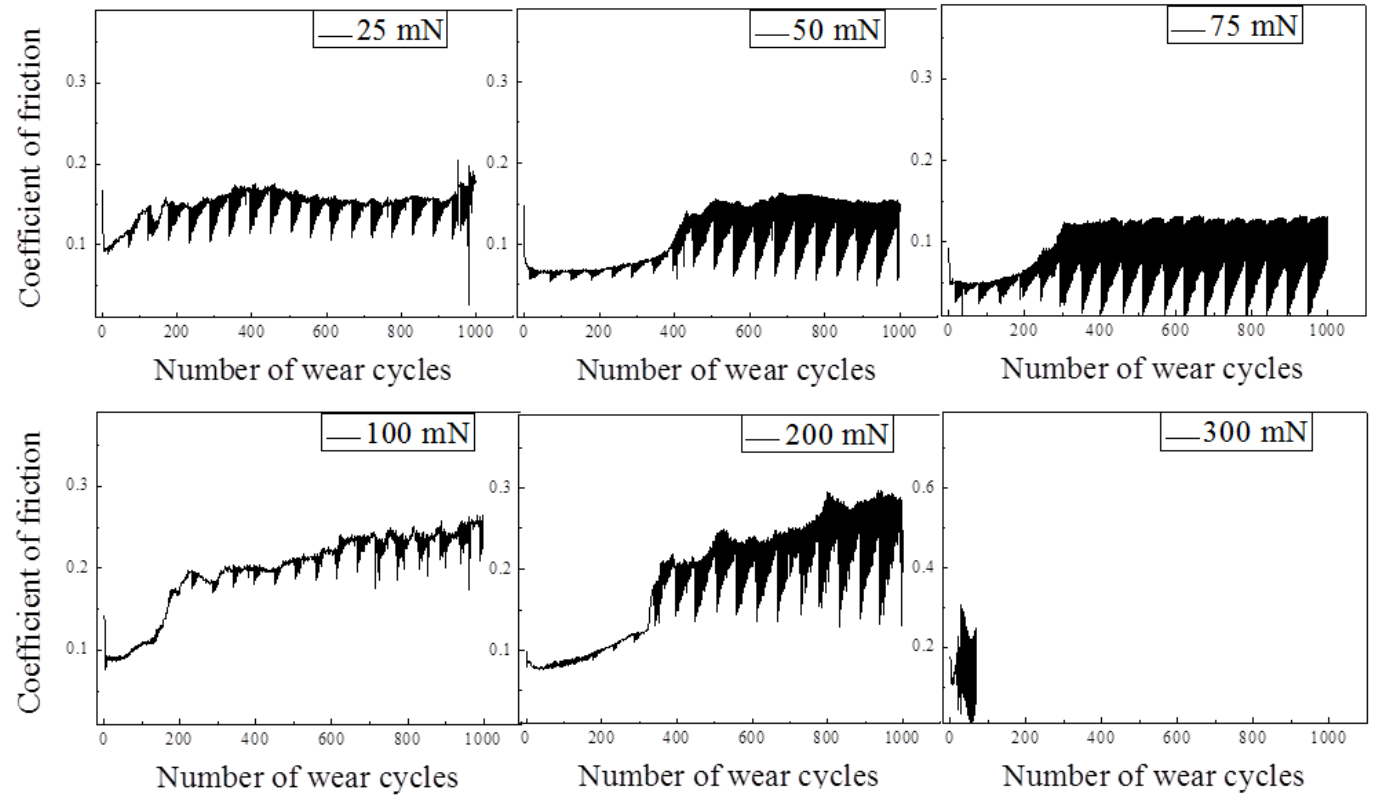

(b)

Figure 5-6: Coefficients of friction as a function of wear cycles and applied load when tested under reciprocating wear mode. (a) At sliding speed of $1.5 \mathrm{~mm} / \mathrm{s}$; (b) at sliding speed of $2.5 \mathrm{~mm} / \mathrm{s}$. 
Under $25 \mathrm{mN}$ and $50 \mathrm{mN}$, the coefficients of friction reached to around 0.12 after 1000 wear cycles. Under $75 \mathrm{mN}$, the coefficient of friction scattered from about 0.07 to 0.13 for up to 1000 wear cycles. Under $100 \mathrm{mN}$ and $200 \mathrm{mN}$, the coefficient of friction had stabilized at about 0.26 and 0.18 after 1000 wear cycles. Under $300 \mathrm{mN}$, the test was stopped after around 160 wear cycles due to high instability in the coefficient of friction.

When tested at sliding speed of $2.5 \mathrm{~mm} / \mathrm{s}$, large scatterings in the coefficients of friction were observed as compared with that at sliding speed of $1.5 \mathrm{~mm} / \mathrm{s}$. By increasing the load from 25 to $75 \mathrm{mN}$, the scattering in the coefficient of friction was increased, while the values remained about 0.15 (Fig. 5-6). The medium-load cantilever, which is sensitive to the applied load ranging from $10 \mathrm{mN}$ to $100 \mathrm{mN}$, was used when tested under $75 \mathrm{mN}$. Due to the high sensitive, the scattering in the coefficient of friction was high when the applied load approaches the upper limit. When tested under $100 \mathrm{mN}$, after 1000 wear cycles, the coefficient of friction reached to around 0.25 . When the applied load was further increased to $200 \mathrm{mN}$, after 1000 wear cycles, the coefficient of friction scattered from about 0.1 to 0.3 . Under $300 \mathrm{mN}$, the test was stopped after about 60 wear cycles.

\section{(2) Surface wear features}

Corresponding to the coefficients of friction shown in Fig. 5-6, surface wear features after each test were imaged using confocal microscope, which are shown in Fig. 5-7.

Similar asperities that embossed on the surface were observed in tests conducted at different sliding speeds under various applied loads (Figs. 5-7a and 5-7b). The average width of track was summarized as a function of applied load, which are shown Fig. 5-8. 
The average width of track is related to the contact area during the wear process. The profiles of asperities on the cross-section that transverse to the sliding direction are used to quantitatively estimate the wear volume.

When tested at sliding speed of $1.5 \mathrm{~mm} / \mathrm{s}$, the width of track was in increasing tendency with increasing applied loads (Fig. 5-8a). When tested at sliding speed of $2.5 \mathrm{~mm} / \mathrm{s}$, high instability in the width of track occurred, which was in agreement with the high instability in the coefficient of friction (Fig. 5-8b).
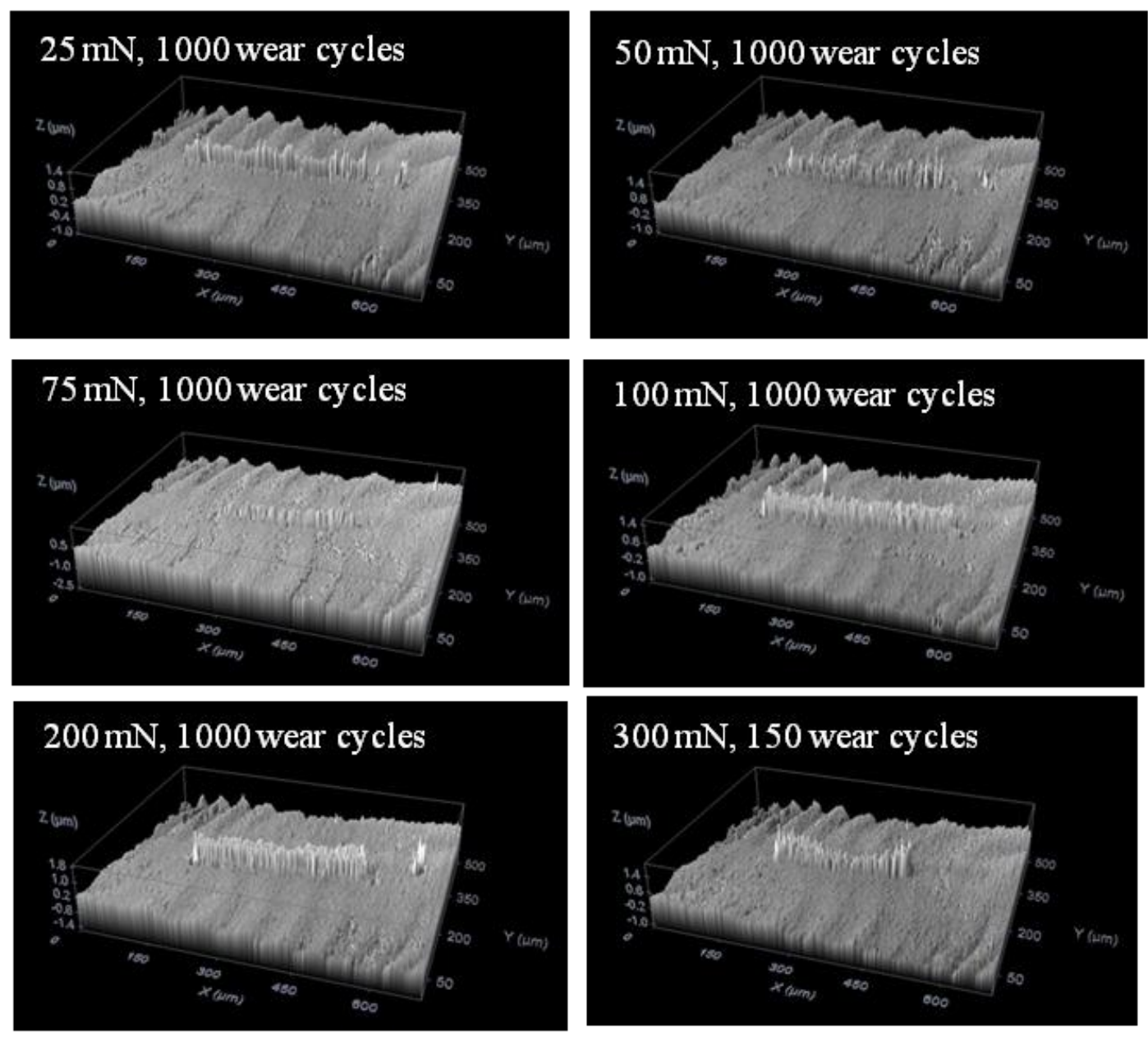

Figure 5-7a: 3D confocal microscopic images of worn surfaces of austenitic NiTi SMA when under reciprocating wear mode and at sliding speed of $1.5 \mathrm{~mm} / \mathrm{s}$. The applied loads and number of wear cycles were indicated accordingly. 

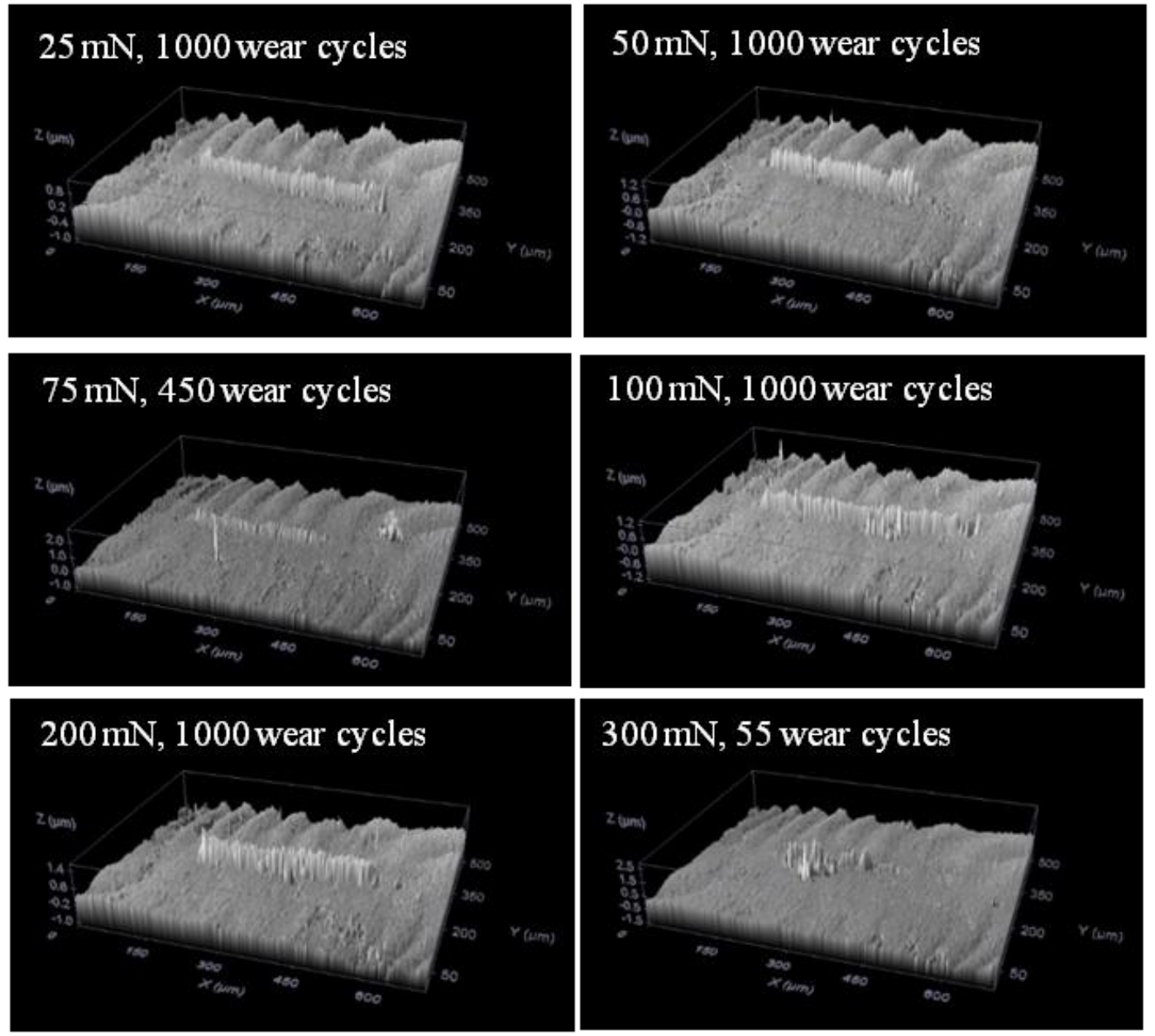

Figure 5-7b: 3D confocal microscopic images of worn surfaces of austenitic NiTi SMA when under reciprocating wear mode and at sliding speed of $2.5 \mathrm{~mm} / \mathrm{s}$.
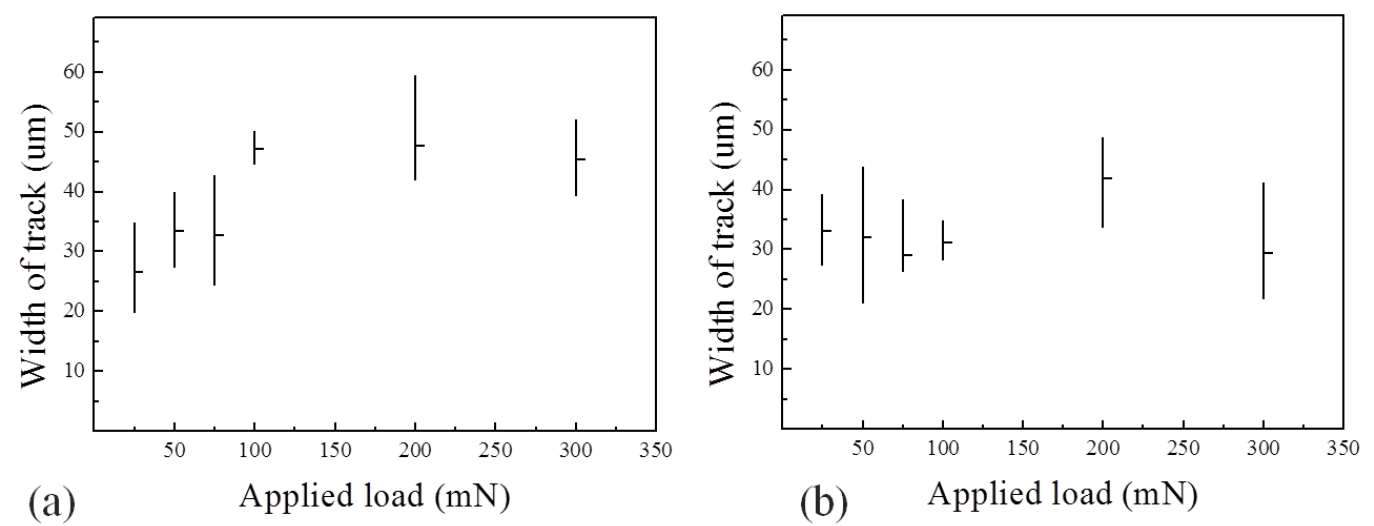

Figure 5-8: Average widths of wear track with respect to applied load in reciprocating wear tests. (a) At sliding speed of $1.5 \mathrm{~mm} / \mathrm{s}$; (b) at sliding speed of $2.5 \mathrm{~mm} / \mathrm{s}$. 


\subsubsection{Summary on the coefficient of friction and wear volume}

In order to compare the trends in coefficient of friction with respect to the wear mode, applied load and sliding speed, the coefficients of friction at $100^{\text {th }}$ and $1000^{\text {th }}$ wear cycles were summarized in Figs. 5-9a and 5-9b, respectively.

In Fig. 5-9, the coefficient of friction was load-sensitive when tested under sliding wear mode. When tested under $25 \mathrm{mN}, 50 \mathrm{mN}$ and $75 \mathrm{mN}$, the coefficients of friction had kept at low values. However, a clear increase in the coefficient of friction was observed when the load was increased to $100 \mathrm{mN}$ and above, this observation suggests significant change in the deformation mechanism.
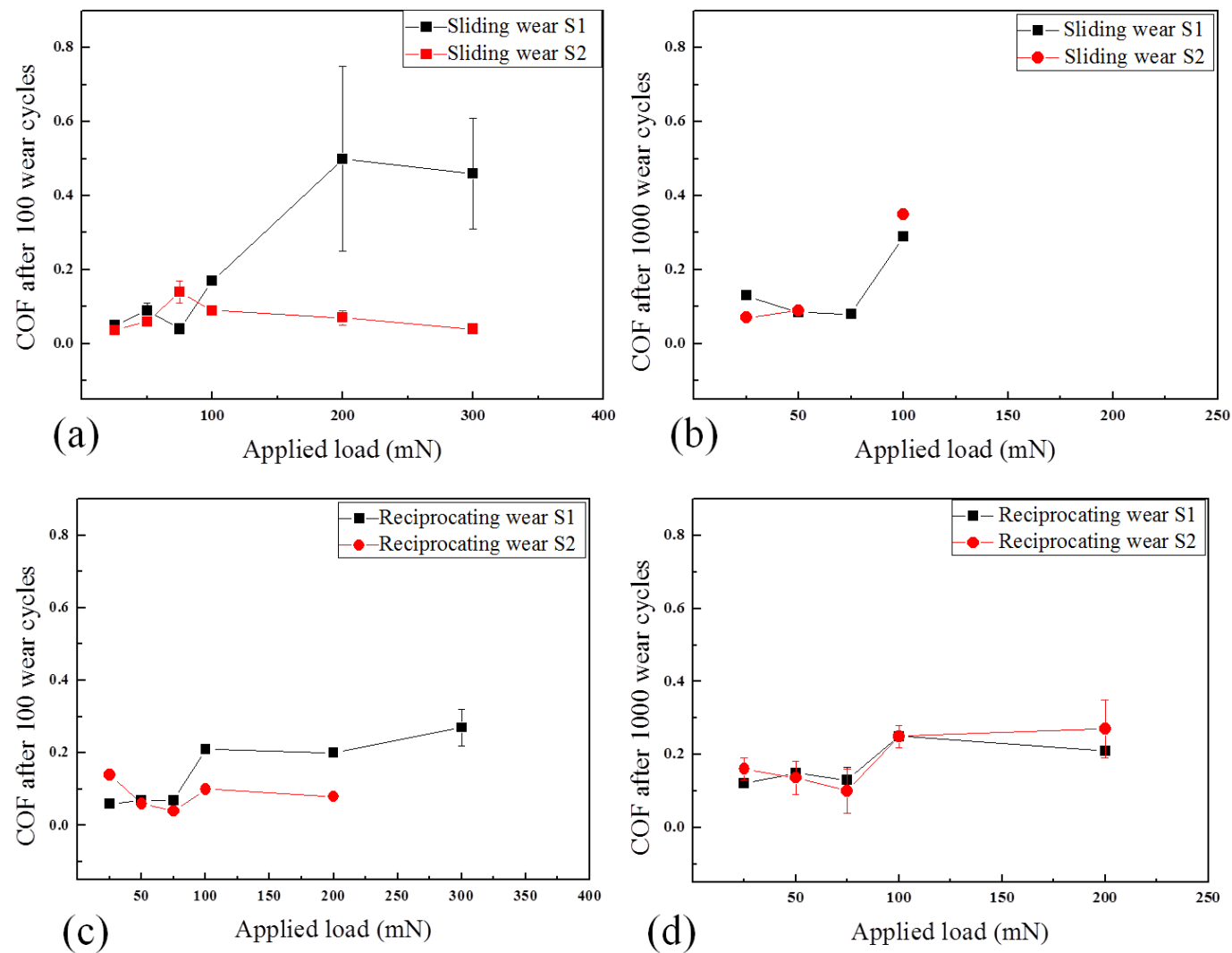

Figure 5-9: Summary of coefficients of friction when tested under different applied load, wear mode and sliding speed. (a) When tested under sliding wear mode after 100 wear cycles; (b) when tested under sliding wear mode after 1000 wear cycles;

(c) when tested under reciprocating wear mode after 100 wear cycles; (d) when tested under reciprocating wear mode after 1000 wear cycles. 


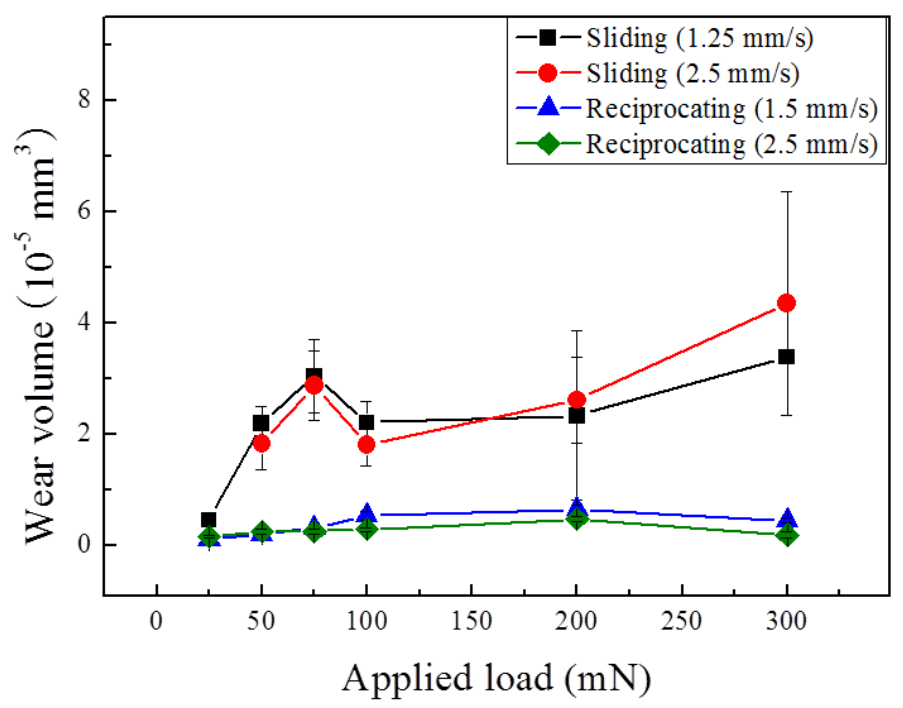

Figure 5-10: Estimated wear volume as a function of wear mode, applied load and sliding speed.

The quantitative measurement on the wear volume was introduced in Chapter 3 (section 3.3.2). From Fig. 5-10, when tested under sliding wear mode, the wear volume was increased by increasing the applied load. When under $75 \mathrm{mN}$, the wear volume was even higher than that under $200 \mathrm{mN}$. This is likely due to the high vibration in the medium-load cantilever, which has enhanced plastic deformation. When tested under reciprocating wear mode, the wear volume remained at low values with increasing the applied load from $25 \mathrm{mN}$ to $300 \mathrm{mN}$. Different wear behaviour was likely caused by different deformation modes, which will be further discussed.

\subsection{Wear resistance of austenitic Ni 50.9 at \% Ti SMA when tested at different temperatures}

When tested above $A_{\mathrm{f}}$, the critical stress for stress-induced sartensitic transformation (SIMT) increases with increasing temperature and obeys the Clausius-Clapeyron type of equation [20, 21]. By further increasing the temperature to the $M_{\mathrm{d}}$ which is the highest temperature for SIMT, dislocation can be generated prior to the occurrence of the SIMT [1]. Since the stress-strain curve 
of austenitic NiTi is temperature-sensitive, the deformation mechanism is load and temperature-sensitive. The effect of temperature and load on the wear behaviour of austenitic NiTi SMA can be understood through understanding of the temperature-dependent stress-strain curves, load-dependent deformation region, and contact stress estimations.

\subsubsection{Stress-strain curves at different temperatures}

The DSC curve of the present sample is shown in Fig. 5-11a, which indicates stable austenitic phase when the temperature ranges from $20{ }^{\circ} \mathrm{C}$ to $120{ }^{\circ} \mathrm{C}$. The temperature-dependent stress-strain curve is shown in Fig. 5-11b.

When tested at $20{ }^{\circ} \mathrm{C}$, clear stress-induced martensitic transformation occurred, accompanied with a stress plateau on the stress-strain curve. Strain up to $6 \%$ was nearly fully reversible. By increasing the temperature to $35{ }^{\circ} \mathrm{C}$ and $50{ }^{\circ} \mathrm{C}$, the increase in the critical stress for SIMT was in agreement with the Clausius-Clapeyron type of equation. Meanwhile, the shape recovery ratio has decreased. The stress plateau associated with SIMT disappeared when the temperature was further increased to $90{ }^{\circ} \mathrm{C}$ and $120{ }^{\circ} \mathrm{C}$. A conventional strain-hardening process occurred accompanied by large percentage of residue strain. This observation further confirmed that the $M_{\mathrm{d}}$ temperature of the present sample is above $50{ }^{\circ} \mathrm{C}$ but below $90{ }^{\circ} \mathrm{C}$. Furthermore, the calculated elastic modulus was in between 70 and $80 \mathrm{GPa}$, which falls within the reported range [1].

The shape recovery ratio was calculated using Eq. 5.1:

$$
R=\frac{\left(\varepsilon_{\max }-\varepsilon_{\text {res }}\right)}{\varepsilon_{\max }}
$$

Here, $\varepsilon_{\max }$ is the maximum strain and $\varepsilon_{\text {res }}$ is the residual strain. 
As shown in Fig. 5-11b, with increasing temperature, the critical stress for SIMT showed an increasing tendency while the shape recovery ratio (R) showed a decreasing tendency. Table 5-1 has summarized the critical stress for SIMT (when tested at $20{ }^{\circ} \mathrm{C}, 35{ }^{\circ} \mathrm{C}$ and $50{ }^{\circ} \mathrm{C}$ ), the yield stress of austenite (when tested at $90{ }^{\circ} \mathrm{C}$ and $120^{\circ} \mathrm{C}$ ), and the corresponding shape recovery ratio.
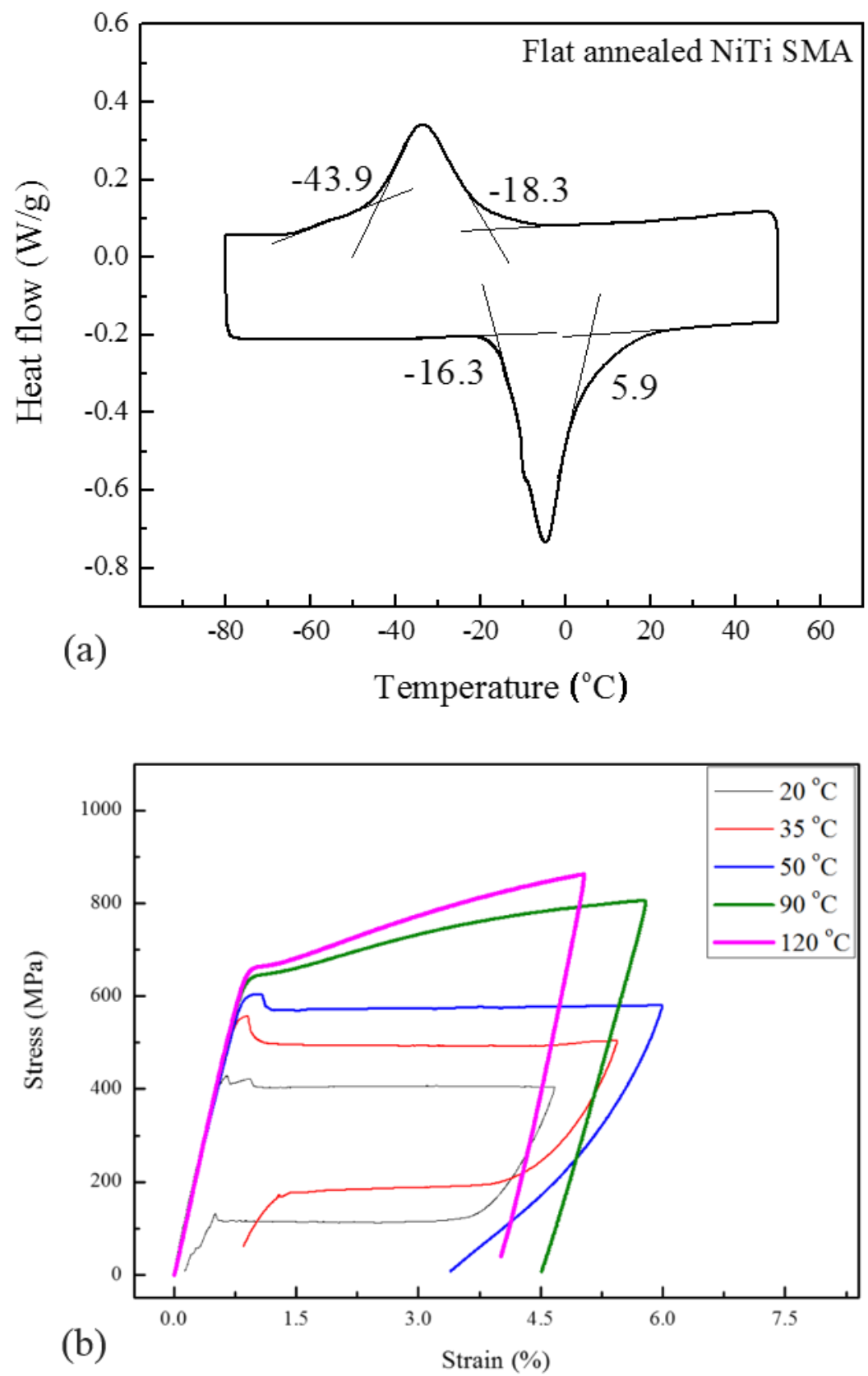

Figure 5-11: (a) Transformation temperature of austenitic NiTi SMA obtained by using differential scanning calorimeter (DSC); (b) stress-strain curves of austenitic NiTi SMA obtained at temperatures ranged from 20 to $120{ }^{\circ} \mathrm{C}$. 
Table 5-1: Summary of the critical stress for stress-induced martensitic transformation, the yield stress of austenite and the recovery ratio at different temperatures.

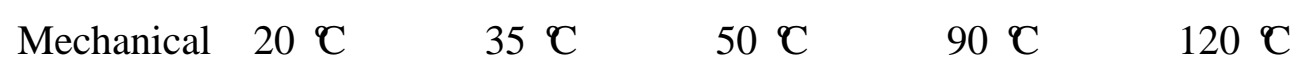

properties

\begin{tabular}{llllll}
\hline$\sigma_{c r i}(\mathrm{MPa})$ & 404 & 495 & 572 & 646 & 668 \\
$R$ & 0.95 & 0.86 & 0.44 & 0.22 & 0.22 \\
\hline
\end{tabular}

In order to further validate the stress-strain curves shown in Fig. 5-11b, the Clausius-Clapeyron type of equation was used to examine the critical stress for SIMT. The general relation between critical stress for SIMT and temperature can be expressed by the Eq. 5.2 [160]:

$$
\frac{d \sigma}{d T}=\frac{-\Delta H}{\left(T \cdot \varepsilon_{0}\right)}
$$

Here, $\sigma$ is the stress; $\Delta H$ is the transformation latent heat (or enthalpy of the transformation per unit volume); $T$ is the temperature and $\varepsilon_{0}$ is the amount of strain due to stress-induced martensitic transformation.

The Eq. 5.2 was further developed to the Eqs. 5.3 and 5.4 [161]:

$$
\begin{gathered}
\frac{d \sigma^{T}}{d T}=\frac{-\left(\Delta h \cdot \rho_{A}\right)}{\left(T \cdot \varepsilon^{T}\right)} \\
\sigma^{T}-\sigma_{0}=\frac{-\left(\Delta h \cdot \rho_{A}\right)}{\varepsilon^{T}} \cdot \ln \left(\frac{T}{T_{0}}\right)
\end{gathered}
$$

Where, $\Delta h$ is the enthalpy of transformation; while $\rho_{A}$ is the density of austenitic NiTi SMA. 
We have applied Eqs. 5.3 and 5.4 to calculate the critical stress for SIMT at $35^{\circ} \mathrm{C}$ and $50{ }^{\circ} \mathrm{C}$. By using the critical stress at $20^{\circ} \mathrm{C}$ as a reference, the calculated values are very close to our experimental observations. Furthermore, the reported values of $(\mathrm{d} \sigma / \mathrm{d} T)$ were at around $5 \mathrm{MPa} \mathrm{K}^{-1}$ to $8 \mathrm{MPa} \mathrm{K}^{-1}$ [160-162], which are comparable to our experimental value of around 5.6 $\mathrm{MPa} \mathrm{K}^{-1}$.

\subsubsection{Coefficients of friction}

In order to understand the wear behaviour of austenitic NiTi SMA, wear tests were conducted as a function of applied load, wear cycles and temperature. Fig. 5-12 has summarized the coefficients of friction. The horizontal axis represents the applied load while the vertical axis represents the temperature.

In Fig. 5-12a, the coefficient of friction was shown as a function of applied load when tested at $20^{\circ} \mathrm{C}$. Under $50 \mathrm{mN}$, the coefficient of friction remained at around 0.2 to 0.3 for up to 1000 wear cycles. By increasing the load to $100 \mathrm{mN}$, the coefficient of friction had reached about 0.75 after 100 wear cycles, and then, it decreased to about 0.43 after 1000 wear cycles. Under $200 \mathrm{mN}$, the coefficient of friction increased to about 0.8 after 100 wear cycles. Thereafter, it decreased and stabilized at about 0.53 in the reminder of the test. When tested under $300 \mathrm{mN}$, the coefficient of friction increased to about 0.7 after around 200 wear cycles, and then it stabilized at about 0.51 for up to 1000 wear cycles. When tested under $100 \mathrm{mN}$, $200 \mathrm{mN}$ and $300 \mathrm{mN}$, similar trends in the coefficient of friction suggest similar dominant deformation mechanisms were involved in the wear process.

By increasing the temperature to $35^{\circ} \mathrm{C}$, the critical stress for SIMT was increased while the shape recovery ratio was decreased as compared with that at $20{ }^{\circ} \mathrm{C}$. The change in the stress-strain curve likely results in change in the dominant deformation mechanism in the wear process. Under $50 \mathrm{mN}$ (Fig. 5-11b), the coefficient of friction remained at around 0.07 for up to 1000 wear cycles. 


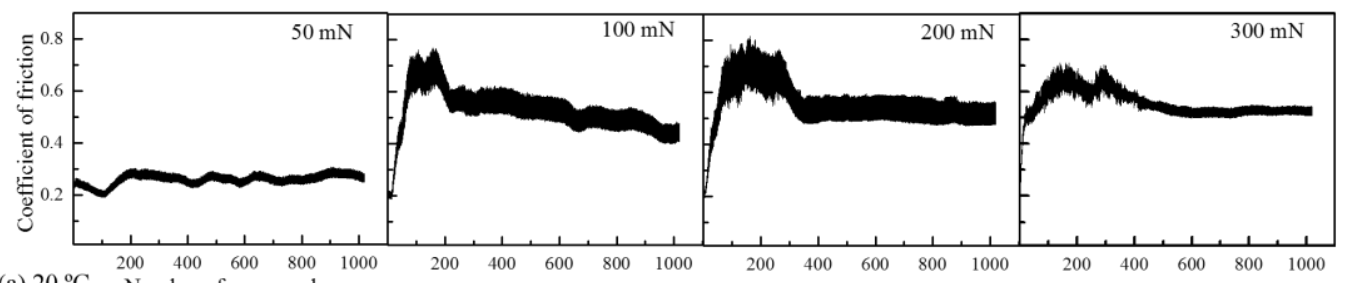

(a) $20^{\circ} \mathrm{C} \quad$ Number of wear cycles
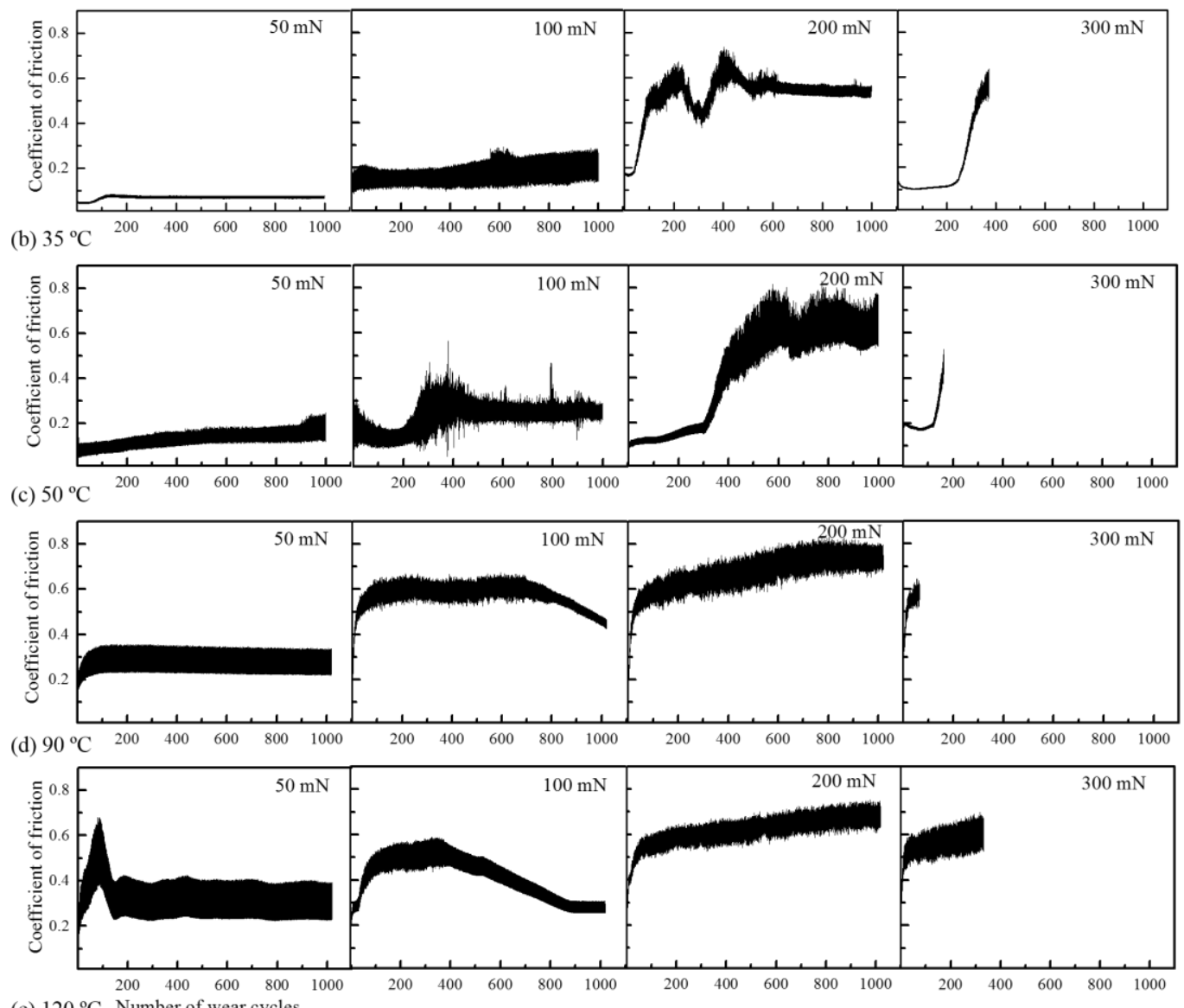

(e) $120^{\circ} \mathrm{C}$ Number of wear cycles

Figure 5-12: Coefficient of friction as a function of applied load and temperature.

(a) When tested at $20^{\circ} \mathrm{C}$ under various loads; (b) when tested at $35^{\circ} \mathrm{C}$ under various loads; (c) when tested at $50{ }^{\circ} \mathrm{C}$ under various loads; (d) when tested at 90 ${ }^{\circ} \mathrm{C}$ under various loads and, (e) when tested at $120{ }^{\circ} \mathrm{C}$ under various loads.

Under $100 \mathrm{mN}$, the coefficient of friction had increased from about 0.15 to 0.23 after 1000 wear cycles, this value is relatively low when compared with that tested at $20{ }^{\circ} \mathrm{C}$. When the load was increased to $200 \mathrm{mN}$, the coefficient of friction reached about 0.65 after 250 wear cycles, then it had decreased and stabilized at about 0.55 until 1000 wear cycles. This trend is somehow similar to the result 
obtained at $20{ }^{\circ} \mathrm{C}$ under $300 \mathrm{mN}$. However, when tested at $35^{\circ} \mathrm{C}$, under $300 \mathrm{mN}$, the wear process was highly unstable. Thus, the wear test was stopped after 380 wear cycles. Comparing with the results obtained at $20{ }^{\circ} \mathrm{C}$, the wear process at $35{ }^{\circ} \mathrm{C}$ was retarded when tested under $50 \mathrm{mN}$ and $100 \mathrm{mN}$. This is likely contributed by the higher critical stress for SIMT at $35{ }^{\circ} \mathrm{C}$. On the other hand, under high load (that is, $300 \mathrm{mN}$ ), the wear process was more stable when tested at $20{ }^{\circ} \mathrm{C}$, which corresponds to higher shape recovery ratio and will be discussed further.

Fig. 5-12c showed the trends in the coefficient of friction as a function of wear cycles and applied load when tested at $50{ }^{\circ} \mathrm{C}$, which is somehow similar to the trends observed at $35{ }^{\circ} \mathrm{C}$. Under $50 \mathrm{mN}$, the coefficient of friction remained at around 0.18 throughout the test. Under $100 \mathrm{mN}$, the coefficient of friction had reached to about 0.29 in a short period after about 200 wear cycles. Then it had stabilized at about 0.25 for up to 1000 wear cycles. Under $200 \mathrm{mN}$, the coefficient of friction had increased to about 0.7 after 600 wear cycles, thereby it stabilized at this value in further wear cycles. When the load was increased to $300 \mathrm{mN}$, the test was stopped after 180 wear cycles since severe wear occurred. Similar trends observed when tested at $35{ }^{\circ} \mathrm{C}$ and $50{ }^{\circ} \mathrm{C}$ further suggest that similar deformation mechanism was involved in the wear process.

Since the $M_{\mathrm{d}}$ temperature of the present sample is below $90{ }^{\circ} \mathrm{C}$, no stress-induced martensitic transformation was involved when tested at $90{ }^{\circ} \mathrm{C}$. Trends in the coefficients of friction at $90{ }^{\circ} \mathrm{C}$ were obviously different from that observed at lower temperatures (Fig. 5-12d). Under $50 \mathrm{mN}$, the coefficient of friction had maintained at about 0.3 for up to 1000 wear cycles. Under $100 \mathrm{mN}$, the coefficient of friction had reached to about 0.6 after 100 wear cycles, and the value remained in repeated wear cycles. Starting from 700 wear cycles, the coefficient of friction had decreased and finally reached about 0.4 after 1000 wear cycles. Under $200 \mathrm{mN}$, the coefficient of friction increased quickly in the very beginning of test. Then it 
stabilized at around 0.72 for up to 1000 wear cycles. The stabilized coefficient of friction is relatively high as compared with that when tested at lower temperatures $\left(20{ }^{\circ} \mathrm{C}, 35^{\circ} \mathrm{C}\right.$ and $\left.50{ }^{\circ} \mathrm{C}\right)$. This result further suggests that the change in the dominant deformation mechanism has deteriorated the wear resistance. When the load was increased to $300 \mathrm{mN}$, the wear test was stopped after 70 wear cycles. When tested at $90{ }^{\circ} \mathrm{C}$, plastic deformation dominated the wear process, which caused significant plastic strain accumulation.

By further increasing the temperature to $120{ }^{\circ} \mathrm{C}$ (Fig. 5-12e), the deformation mechanism is similar to that of $90{ }^{\circ} \mathrm{C}$. Thus, similar wear behaviour was expected. Under $50 \mathrm{mN}$, the coefficient of friction had suddenly increased to about 0.68 after around 100 wear cycles and then quickly decreased. Thereafter, it remained at around 0.3 for up to 1000 wear cycles. Under $100 \mathrm{mN}$, the coefficient of friction reached about 0.5 after 120 wear cycles. Then it had gradually decreased to about 0.3 after 1000 wear cycles. Under $200 \mathrm{mN}$, the trend in the coefficient of friction as a function of wear cycles is similar to that observed at $90{ }^{\circ} \mathrm{C}$. Under $300 \mathrm{mN}$, the test was stopped after 350 wear cycles due to high instability in the coefficient of friction.

When two surfaces are approaching each other, high asperities are getting into contact thus being deformed first $[159,163]$. Surfaces adapt to each other through plastic deformation of high asperities associated with quick increase in the coefficient of friction. This period is defined as the run-in period. The wear process can be stabilized in further increased wear cycles, and the mechanical properties of the counter-wear materials will determine the stabilized wear process. To understand the deformation mechanisms involved in the wear process, the stabilized values of the coefficient of friction were summarized in Fig. 5-13. We have not plotted the values when under $300 \mathrm{mN}$ since the tests were stopped before 1000 wear cycles. 


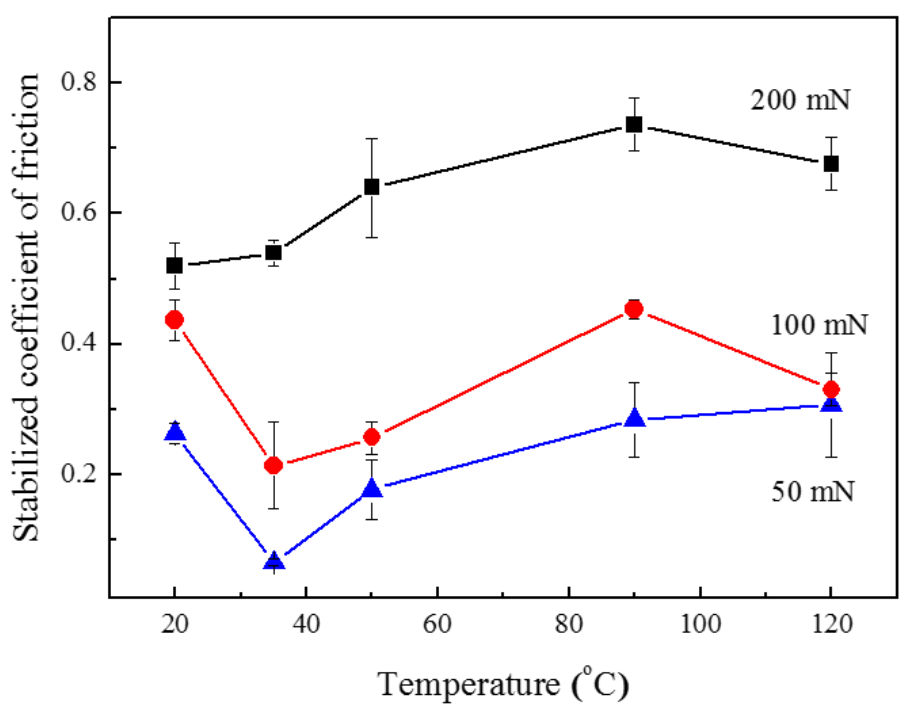

Figure 5-13: The values of stabilized coefficient of friction when tested under different loads and temperatures shown.

Since the temperature-dependent stress-strain curve of austenitic NiTi SMA determines the deformation mechanism in the stabilized wear process, we have analyzed the stabilized coefficient of friction after 1000 wear cycles as a function of temperature and load (Fig. 5-13). When tested under $50 \mathrm{mN}$ and $100 \mathrm{mN}$, the stabilized coefficients of friction decreased when the temperature was increased from $20{ }^{\circ} \mathrm{C}$ to $50{ }^{\circ} \mathrm{C}$. This was attributed to the increased critical stress for SIMT, which has retarded plastic strain accumulation. It will be further explained by contact stress estimations. When tested at $90{ }^{\circ} \mathrm{C}$ and $120{ }^{\circ} \mathrm{C}$, the coefficient of friction stabilized at high values associated with plastic deformation dominated wear process.

By further increasing the load to $200 \mathrm{mN}$, the coefficient of friction had shown increasing tendency with increasing temperature. This was attributed to decreased strain accommodation through the reversible SIMT process, which was caused by decreased shape recovery ratio with increasing temperature. 


\subsubsection{Surface wear features}

The surface wear features corresponding to coefficients of friction shown in Fig. 5-12 were illustrated in Fig. 5-14. Confocal images were shown, and each sample was scanned on an area of $0.7 \mathrm{~mm} \times 0.5 \mathrm{~mm}$. The height and width of surface wear features showed clear increasing tendency with increasing load. We have plotted the cross-section profile of each track to quantitatively examine the wear features.

When tested at $20^{\circ} \mathrm{C}$ under $50 \mathrm{mN}$, the crown-like structure was found, which consisted of large amount of asperities that embossed on the track area [159]. By increasing the load to $100 \mathrm{mN}$, a large amount of tracks appeared and the crown-like structure was destructed (Fig. 5-14a). When the load was increased to $200 \mathrm{mN}$ and $300 \mathrm{mN}$, severe wear occurred. When tested at $35{ }^{\circ} \mathrm{C}$ and $50{ }^{\circ} \mathrm{C}$, similar surface wear features were observed. Under $50 \mathrm{mN}$, no visible wear feature appeared on the surface, indicating zero wear condition. Under $100 \mathrm{mN}$, the crown-like structure was found. This further confirmed that the wear process was retarded at increased temperature (that is, $35^{\circ} \mathrm{C}$ and $50{ }^{\circ} \mathrm{C}$ ). When tested at $90{ }^{\circ} \mathrm{C}$ and $120^{\circ} \mathrm{C}$, a large amount of surface damage was formed when tested under 50 $\mathrm{mN}$ and $100 \mathrm{mN}$. This observation further confirmed the plastic deformation dominated wear process when the temperature exceeded the $M_{\mathrm{d}}$.

When tested at different temperatures and loads, the wear volume was estimated and summarized in Fig. 5-15. The detailed wear volume estimation method is introduced in Chapter 3 (section 3.3.2).

Fig. 5-15 summarized the estimated wear volume as a function of temperature and load, which showed nearly the same trend as that of the corresponding coefficient of friction. This further confirmed that the change in the deformation mechanism is related to the temperature-dependent stress-strain curves and the load-dependent contact stresses. 

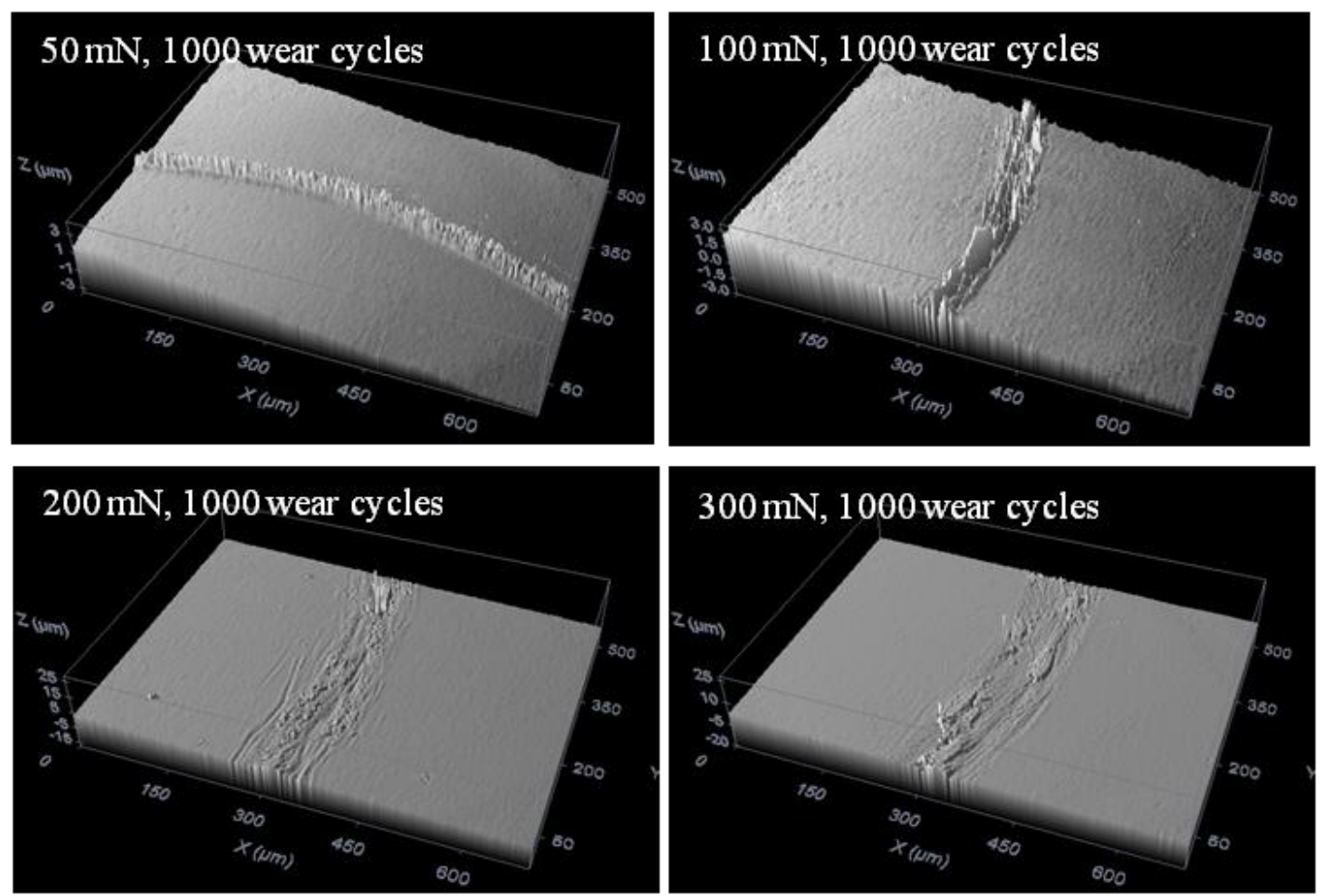

Figure 5-14a: The 3-D confocal microscopic images of the surface wear features when tested at $20^{\circ} \mathrm{C}$, with the applied loads and wear cycles indicated individually.
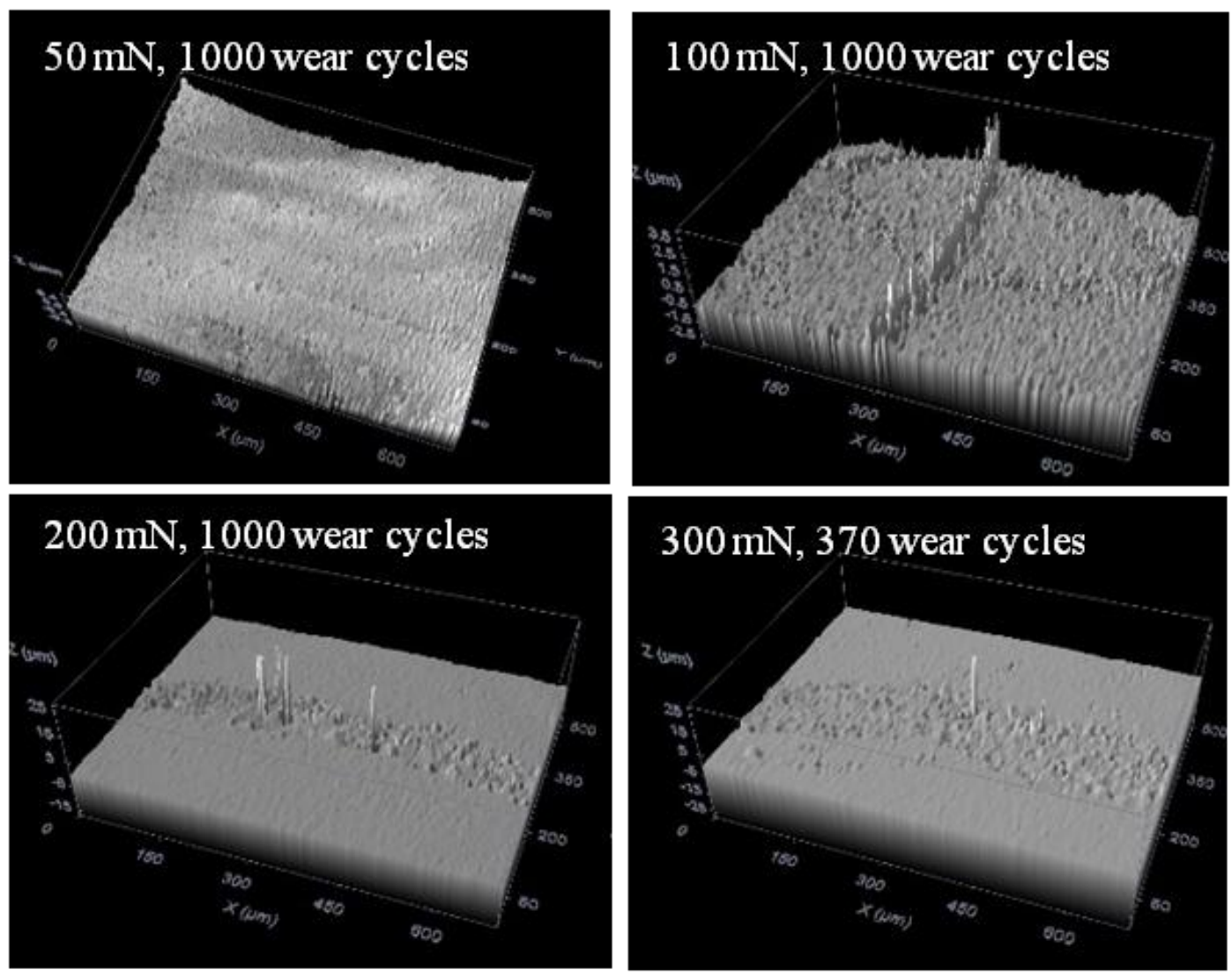

Figure 5-14b: The 3-D confocal microscopic images of the surface wear features when tested at $35^{\circ} \mathrm{C}$, with the applied loads and wear cycles indicated individually. 

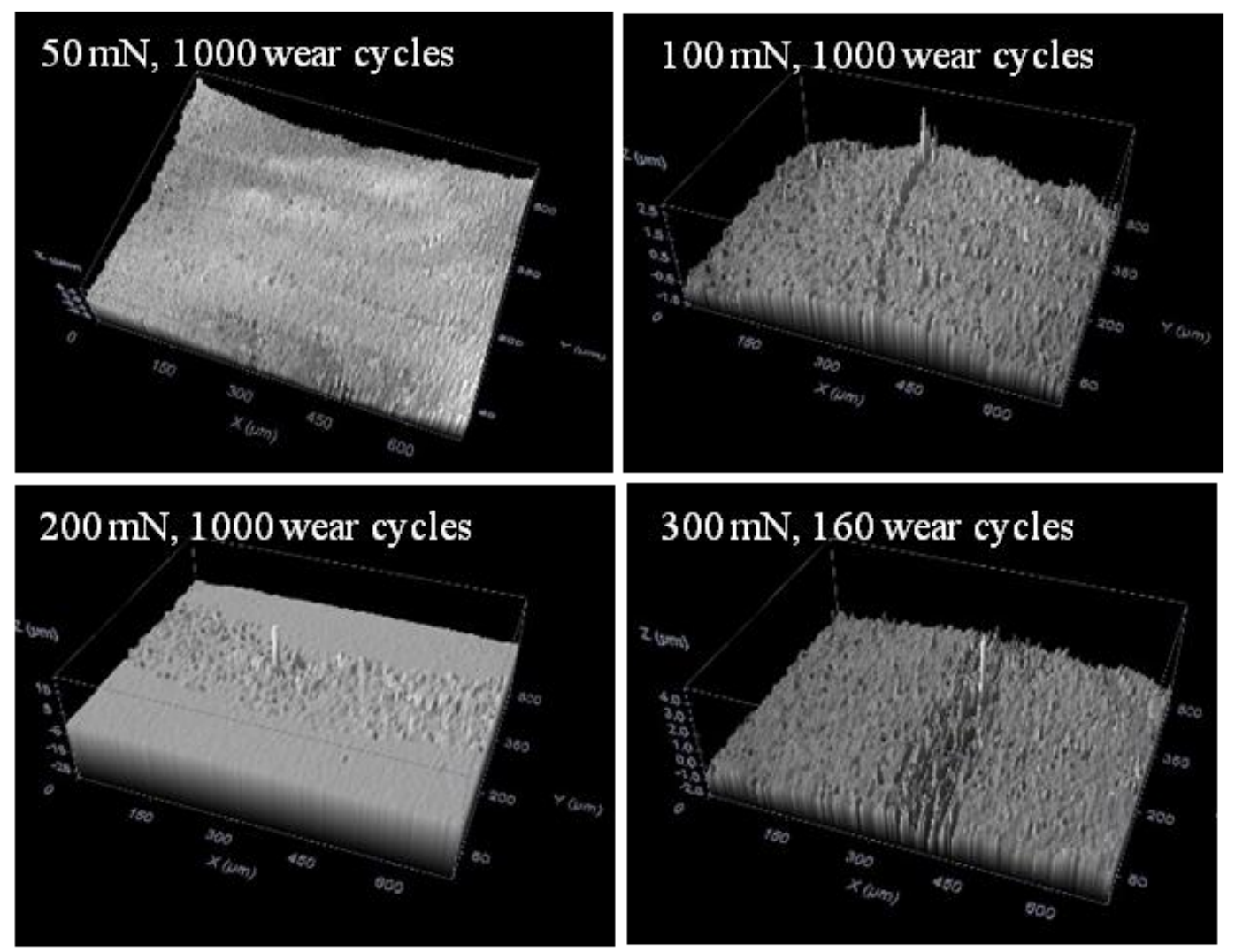

Figure 5-14c: The 3-D confocal microscopic images of the surface wear features when tested at $50{ }^{\circ} \mathrm{C}$, with the applied loads and wear cycles indicated individually.
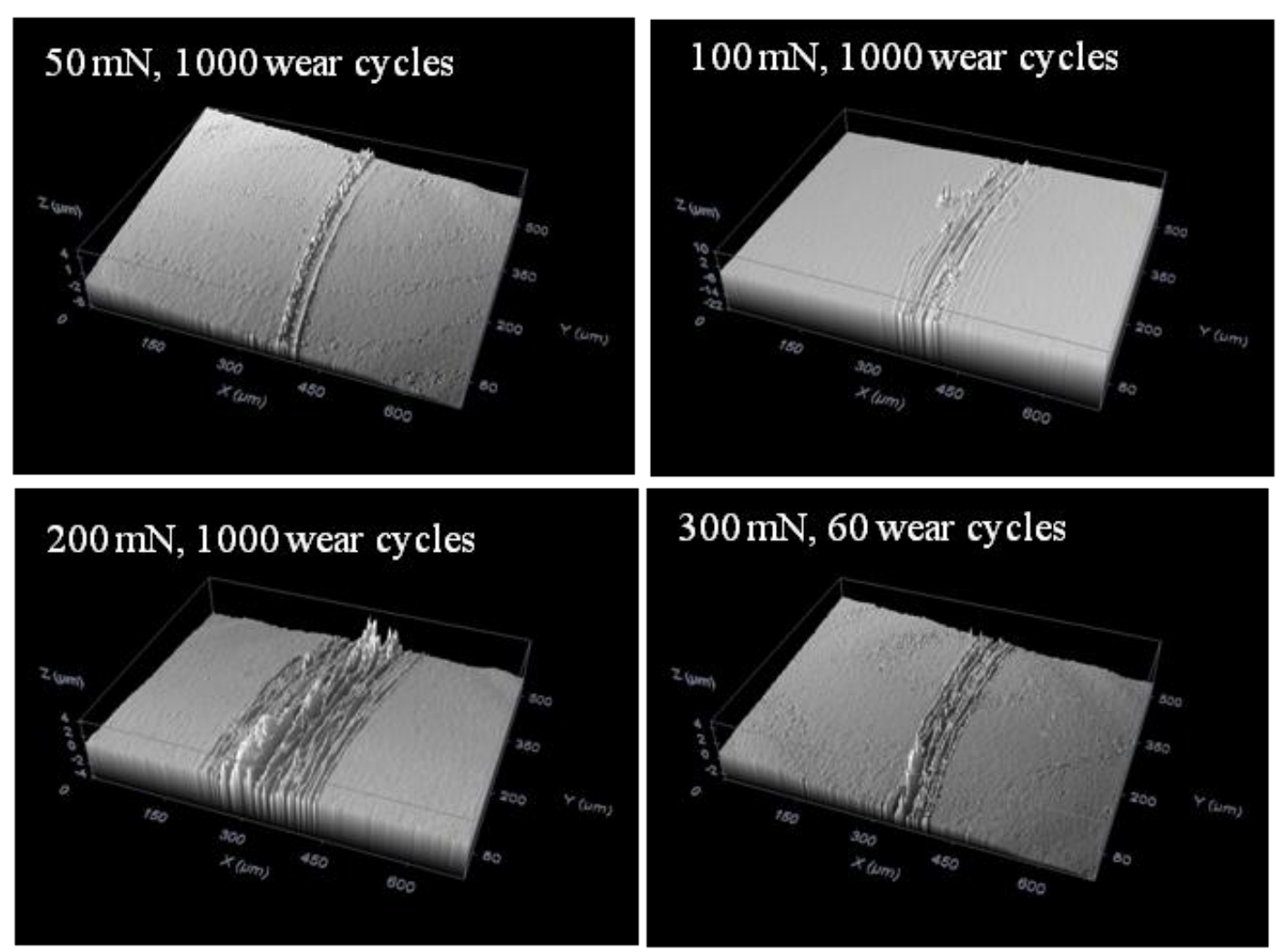

Figure 5-14d: The 3-D confocal microscopic images of the surface wear features when tested at $90{ }^{\circ} \mathrm{C}$, with the applied loads and wear cycles indicated individually. 

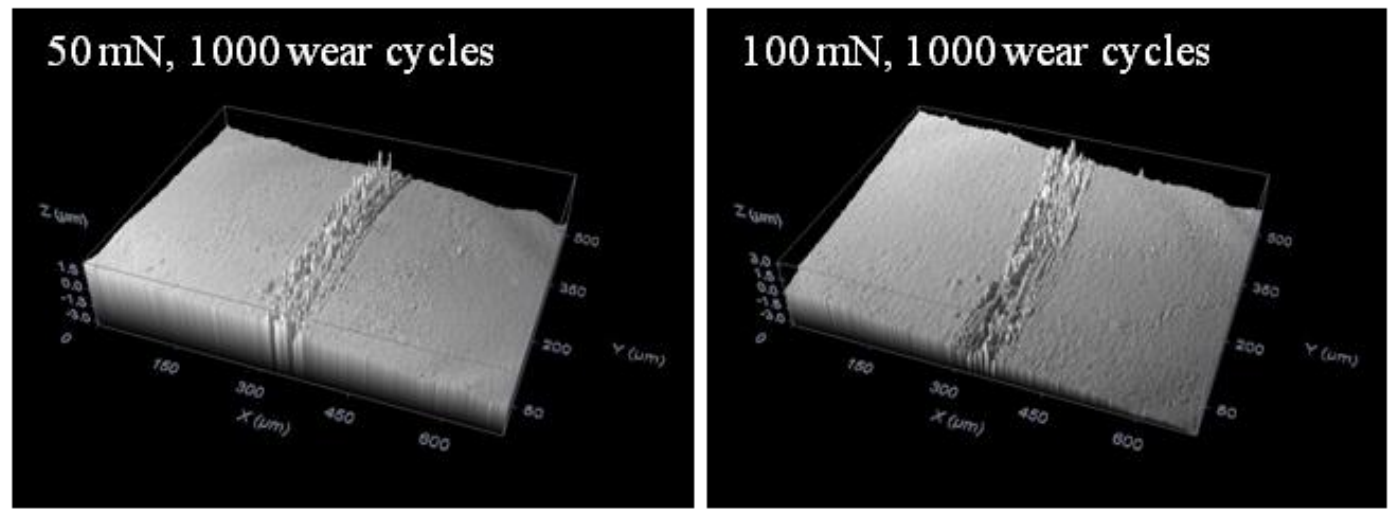

\section{$200 \mathrm{mN}, 1000$ wear cycles}
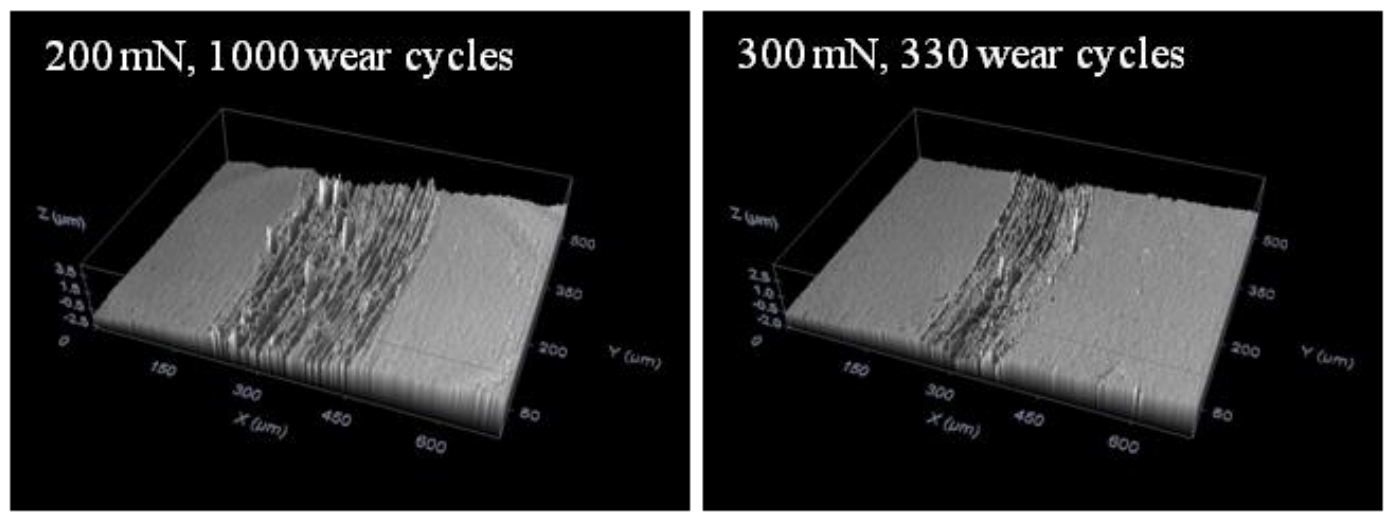

Figure 5-14e: The 3-D confocal microscopic images of the surface wear features when tested at $120{ }^{\circ} \mathrm{C}$, with the applied loads and wear cycles indicated individually.

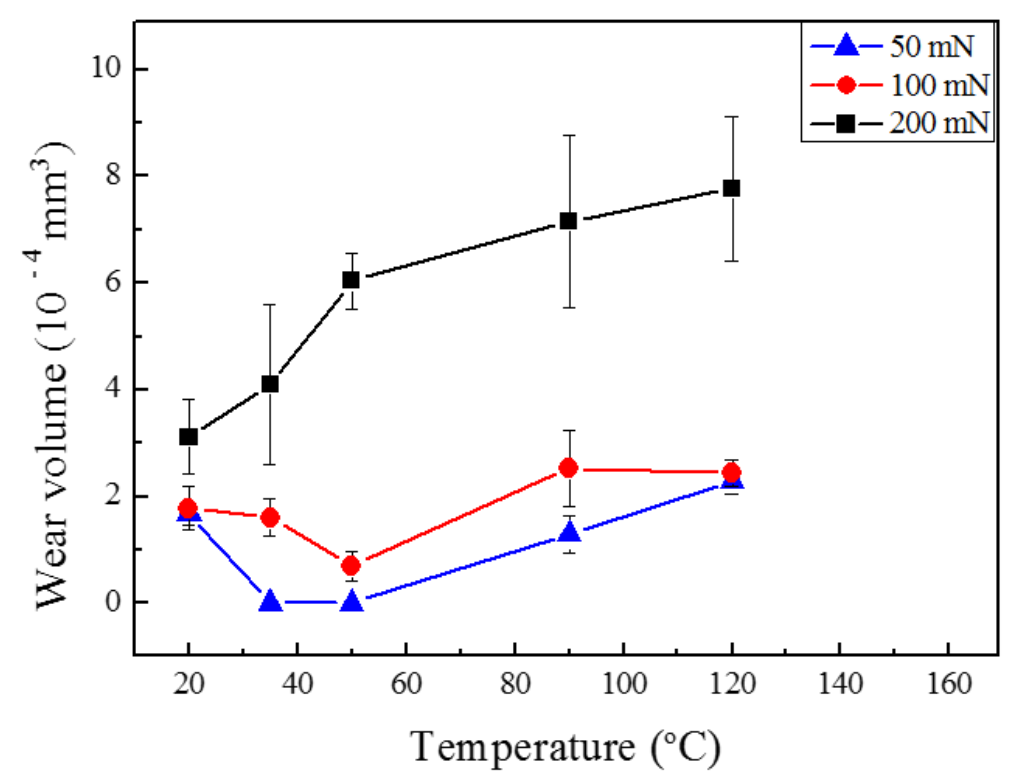

Figure 5-15: The estimated surface wear volume as a function of load and temperature. 


\subsection{Discussion}

\subsubsection{Deformation mechanisms of austenitic NiTi SMA}

By increasing temperature above the $A_{\mathrm{f}}$, the critical stress for SIMT increases, which obeys the Clausius-Clapeyron type of equation. Meanwhile, the shape recovery ratio decreases, and results in an increased percentage of plastic deformation. When the temperature is increased to the $M_{\mathrm{d}}$ which is the highest temperature for stress-induced martensitic transformation, strain hardening occurs, accompanied with dislocation generation and motion.

When $A_{\mathrm{f}}<T<M_{\mathrm{d}}$, the austenitic NiTi SMA can be deformed in the sequence of: (I) elastic deformation of austenite; (II) stress-induced martensitic transformation accompanying with a stress-plateau on the stress-strain curve; (III) elastic deformation of stress-induced martensite and (IV) plastic deformation of stress-induced martensite. When $T>M_{\mathrm{d}}$, elastic deformation of austenite occurs and followed by plastic deformation associated with dislocation motion. Under tensile and compressive load, the deformation sequences are the same but higher yield stress occurs under compressive load associated with more dislocation generation [99, 110, 164, 165]. Furthermore, increase in the dislocation density might hinder the forward and reversed stress-induced martensitic transformation, thereby reduce the shape recovery ratio $[164,166]$. In the wear process, compressive stress is involved, which is associated with larger amount of dislocation generation as compared to the tensile test.

According to the tensile tress-strain curve shown in Fig. 5-11, the contact stress determines the strain region on the stress-strain curve, hence it further determines the deformation mechanism that was involved in the wear process. Nevertheless, the contact stress is dependent on the applied load. Hence, the wear behaviour was discussed with respect to the stress distribution beneath the contact area when 
tested under different magnitude of applied load. Based on our previous study [159, 166], the highest contact stress occurs at the mostly deformed area which is closest to the tip of counter-ball. The deformation mechanism in the mostly deformed region dominates the wear process, since majority of plastic deformation occurs in this region.

When the applied load is extremely low, elastic deformation dominates the contact region. In this case, the Hertzian elastic contact model can be used to estimate the average contact stress $[12,151]$ :

$$
\begin{gathered}
\sigma^{3}=\frac{6 F_{n}\left(E^{*}\right)^{2}}{\left(\pi^{3} r^{2}\right)} \\
\frac{1}{E^{*}}=\frac{\left(1-v_{1}^{2}\right)}{E_{1}}+\frac{\left(1-v_{2}^{2}\right)}{E_{2}}
\end{gathered}
$$

Here, $\sigma$ is the contact stress; $F_{\mathrm{n}}$ is the applied load; $r$ is the radius of the sphere; $E_{1}$ and $E_{2}$ are the elastic moduli of the austenitic NiTi SMA and the alumina ball $\left(\mathrm{Al}_{2} \mathrm{O}_{3}\right)$, with values of 75 and $375 \mathrm{GPa}$, respectively. In addition, $v_{1}$ and $v_{2}$ are the Poisson's ratio of the austenitic NiTi SMA and alumina, with values of 0.33 and 0.23, respectively. It is worthwhile to mention that, the Hertzian elastic contact model is only suitable for the elastic deformation dominated contact problem. In this study, we have used counter-ball with diameters of $2 \mathrm{~mm}$ and $4 \mathrm{~mm}$ on the Nano-tribometer and CETR tribometer, accordingly.

\subsubsection{Effect of deformation mode on the wear behaviour of austenitic NiTi SMA}

This section is based on the results obtained from wear tests on Nano-tribometer (section 5.1), detailed parameters are listed in table 3-2. 
When the contact stress is below the critical stress for SIMT (I), elastic deformation dominates the wear process. Thus no significant plastic strain accumulation occurs in repeated wear cycles. For example, when under applied loads of $25 \mathrm{mN}, 50 \mathrm{mN}$ and $75 \mathrm{mN}$, for both sliding and reciprocating wear modes, the coefficient of friction had kept at low values (below 0.15) for up to 1000 wear cycles.

The contact stress was further examined using Hertzian elastic contact theory. Under $25 \mathrm{mN}, 50 \mathrm{mN}$ and $75 \mathrm{mN}$, the estimated average contact stresses were at $286 \mathrm{MPa}, 360 \mathrm{MPa}$, and $412 \mathrm{MPa}$, respectively. Those estimated values are below or approaches the critical stress for SIMT at $20{ }^{\circ} \mathrm{C}$, which is about $400 \mathrm{MPa}$. This calculation further supports the elastic deformation dominated wear process.

It is worthy to note that, when the contact stress exceeds the critical stress for SIMT, the Hertzian elastic contact theory is not suitable for contact stress estimation. When the load was further increased to $100 \mathrm{mN}$, the contact stress likely exceeded the critical stress for SIMT.

When the contact stress approaches the critical stress for SIMT (II), in the early stage of wear, stress-induced martensite is formed from austenite grains that in the most preferential orientation to the stress [39]. With further increasing wear cycles, unfavourably oriented grains begin to reorient, which requires higher stress in inducing phase transformation. Furthermore, orientation mismatch among the grains that in different orientations causes internal stress field [167]. Defects such as dislocations and vacancies can be generated in compensate to the grain reorientation. As a result, partial of stress-induced martensite variants can be "locked" or "pinned" by internal stress field [168]. Nevertheless, in the reversed SIMT process, movement of phase boundaries can be hindered by dislocations/defects that induced by deformation [169]. 
With further increasing the contact stress to stage III, elastic deformation of SIM dominates the wear process. Upon unloading, critical stress for reversed SIMT decreases due to the stabilization of martensite by internal stress field [170].

When the SIMT and elastic deformation of SIM dominate the wear process, in the early stage of wear, deformation can be accommodated through the SIMT in the most favourably oriented grains. Thus insignificant surface wear can be formed. With increasing wear cycles, due to reorientation of unfavourably oriented grains, increased internal stress field can cause further plastic strain accumulation. For example, when tested under $100 \mathrm{mN}$, the coefficient of friction increased with increasing wear cycles. Under sliding wear mode, the coefficient of friction was at around 0.17 (S1) and 0.09 (S2) after 100 wear cycles; while it had stabilized at about $0.29(\mathrm{~S} 1)$ and $0.36(\mathrm{~S} 2)$ after 1000 wear cycles.

On the other hand, in the reciprocating wear test, the internal stress field developed by mismatching of reoriented grains can be effectively relieved, since the external stress is applied in the opposite direction. As a result, the stabilized SIM by internal stress field can also be released. Thereby, the released SIM will further contribute to the deformation accommodation process. This can further reduce plastic strain accumulation. For example, when tested under applied load of 100 $\mathrm{mN}$, under reciprocating wear mode, the increase in the coefficient of friction with increasing wear cycles is not significant as compared with the sliding wear mode. The coefficients of friction were about 0.2 (S1) and 0.1 (S2) after 100 wear cycles; while they reached about 0.26 at different sliding speeds after 1000 wear cycles. This further suggests that, less plastic strain accumulation occurred due to relieve of internal stress field when under reciprocating wear mode.

When the contact stress exceeds the yield stress of SIM, plastic deformation of SIM occurs (IV). A large number of dislocations can be generated. However, some shape recovery can be induced by reciprocating stress, hence the wear can be 
reduced. For example, when tested under 200 and $300 \mathrm{mN}$ at low sliding speed, under sliding wear mode, the coefficient of friction after 100 wear cycles was about 0.5 . However, under reciprocating wear mode, it was about 0.27 . This significant difference further supports less surface damage when under reciprocating wear mode than sliding wear mode. This is attributed to a relief of internal stress field which promotes the reversibility of stress-induced phase transformation in the reciprocating wear test.

\subsubsection{Wear behaviour of austenitic NiTi SMA when tested under different temperature regimes}

(1) Wear behaviour when $A_{\mathrm{f}}<T<M_{\mathrm{d}}$

By increasing the temperature in this regime, the critical stress for SIMT increases while the shape recovery ratio decreases, accordingly. Three temperatures were selected to examine the effect of temperature-dependent stress-strain curve on the wear behaviour of austenitic NiTi SMA. The deformation mechanism involved in the wear process was discussed according to the wear observations, stress-strain curves and contact stress estimations.

For austenitic NiTi SMA, elastic deformation occurs when the contact stress is below the critical stress for SIMT. Insignificant wear can be formed when reversible elastic deformation dominates the wear process. This can be supported by our observations in the coefficient of friction and surface wear features. When tested at $20^{\circ} \mathrm{C}$ and under $50 \mathrm{mN}$, the coefficient of friction remained below 0.3 and insignificant wear occurred. The formation of crown-like structure on the surface did not affect the coefficient of friction (Figs. 5-12a and 5-14a). After 1000 wear cycles, the estimated wear volume was about $1.7 \times 10^{-4} \mathrm{~mm}^{3}$, which is relatively low as compared with the tests under higher loads (Fig. 5-15). The average contact stress was estimated using Hertzian elastic contact model illustrated in Eqs. 5.5 
and 5.6. When under $50 \mathrm{mN}$, the calculated contact stress was $230 \mathrm{MPa}$, which is lower than the critical stress for SIMT at $20^{\circ} \mathrm{C}$ (that is, $404 \mathrm{MPa}$ ). This calculation further confirms the elastic deformation dominated wear process when under 50 $\mathrm{mN}$.

By increasing the temperature to 35 and $50^{\circ} \mathrm{C}$, the critical stress for SIMT was increased to $495 \mathrm{MPa}$ and $572 \mathrm{MPa}$ as shown in Fig. 5-11. As a result, elastic deformation region on the stress-strain curve can be prolonged, while further super-elastic/plastic deformation can be retarded, accordingly. The increase in the critical stress for SIMT may lead to retardation of the wear process. This can be further supported by comparing results obtained when tested at $20^{\circ} \mathrm{C}, 35^{\circ} \mathrm{C}$ and 50 ${ }^{\circ} \mathrm{C}$. When tested at $35^{\circ} \mathrm{C}$ and $50{ }^{\circ} \mathrm{C}$, under $50 \mathrm{mN}$, no visible surface damage was found after 1000 wear cycles. Under $100 \mathrm{mN}$, the coefficient of friction was stabilized at about 0.3, while the crown-like wear feature was formed after 1000 wear cycles. The corresponding wear volume was around $1.6 \times 10^{-4} \mathrm{~mm}^{3}\left(35^{\circ} \mathrm{C}\right)$ and $0.69 \times 10^{-4} \mathrm{~mm}^{3}\left(50{ }^{\circ} \mathrm{C}\right)$, which were lower than that observed under $50 \mathrm{mN}$ and $100 \mathrm{mN}$ when tested at $20^{\circ} \mathrm{C}$. By increasing the temperature, the low value in the coefficient of friction and wear volume further suggests better wear resistance, which is originated from increased critical stress for SIMT.

When the average contact stress is increased above the yield stress of stress-induced martensite, the deformation mechanism can be changed from super-elastic deformation to plastic deformation. Deformation strain accommodation through the reversible SIMT process can effectively reduce the amount of plastic strain. Hence, the shape recovery ratio will become the predominant factor in determining the wear resistance. Results have confirmed that, by increasing the shape recovery ratio, less plastic strain can be accumulated, thus results in better wear resistance. For example, when tested under $200 \mathrm{mN}$, the coefficients of friction stabilized at about 0.53 at $20{ }^{\circ} \mathrm{C}, 0.55$ at $35{ }^{\circ} \mathrm{C}$, and 0.64 at $50{ }^{\circ} \mathrm{C}$, respectively (Figs. 5-12 and 5-13b). Meanwhile, the estimated wear volume 
showed an increased tendency with increasing temperature, which was at $3.1 \times$ $10^{-4} \mathrm{~mm}^{3}\left(20^{\circ} \mathrm{C}\right), 4 \times 10^{-4} \mathrm{~mm}^{3}\left(35^{\circ} \mathrm{C}\right)$ and $6.1 \times 10^{-4} \mathrm{~mm}^{3}\left(50{ }^{\circ} \mathrm{C}\right)$, respectively. Under high load condition (that is, $200 \mathrm{mN}$ ), with an increase in the temperature, the wear resistance can be degraded. The decrease in the wear resistance is corresponding to the decreased shape recovery ratio, being 0.95 at $20{ }^{\circ} \mathrm{C}, 0.86$ at $35^{\circ} \mathrm{C}$ and 0.44 at $50{ }^{\circ} \mathrm{C}$, respectively.

Under extremely high load, the contact stress is far beyond the yield stress of stress-induced martensite. Hence, severe wear occurs at the early stage of test. Our observations of high instability when tested under $300 \mathrm{mN}$ further support this type of wear (Fig. 5-12). Meanwhile, large amount of debris was found after 100 wear cycles or even at less wear cycles (Fig. 5-14). Specifically, when tested under extreme high load, the wear test at $20^{\circ} \mathrm{C}$ showed different trend when compared with that at 35 and $50{ }^{\circ} \mathrm{C}$ (Fig. 5-12a). When tested at $20^{\circ} \mathrm{C}$ under $300 \mathrm{mN}$, the coefficient of friction remained stabilized for up to 1000 wear cycles. This is similar to the wear process that dominated by plastic deformation, which is associated with effective strain accommodation through the SIMT process. The nearly perfect stress-strain curve with shape recovery ratio of 0.95 at $20{ }^{\circ} \mathrm{C}$ is responsible for the good wear resistance. Therefore, in the plastic deformation dominated wear process, the shape recovery property plays a major role in the wear resistance.

When $A_{\mathrm{f}}<T<M_{\mathrm{d}}$, the wear resistance of austenitic NiTi SMA is closely related to the critical stress for SIMT and shape recovery properties. By increasing the critical stress through metallurgical means such as precipitation, refining the grain size, alloying, and manipulation of the transformation temperature, the wear resistance of austenitic NiTi SMA can be improved. On the other hand, by improving the shape recovery properties through altering the textures, better strain accommodation through the reversible SIMT process can improve the wear resistance. 
(2) Wear behaviour when $T>M_{\mathrm{d}}$

From the stress-strain curve shown in Fig. 5-11, strain hardening occurred when tested at $90{ }^{\circ} \mathrm{C}$ and $120{ }^{\circ} \mathrm{C}$. Different deformation mechanisms were activated as compared with the tests at $20{ }^{\circ} \mathrm{C}, 35^{\circ} \mathrm{C}$ and $50{ }^{\circ} \mathrm{C}$, and the corresponding wear behaviour was explained accordingly.

When the contact stress is below the yield stress of austenite, elastic deformation dominates the wear process. However, the contact stress in the region that is closest to the tip of counter-ball may exceeds the yield stress. Therefore, the region near to the contact tip may experience plastic deformation. This can be confirmed by wear observations when tested at $90{ }^{\circ} \mathrm{C}$ and $120^{\circ} \mathrm{C}$. For example, under $50 \mathrm{mN}$, the coefficient of friction remained at around 0.3, which is comparable with values that observed at lower temperatures. Meanwhile, the wear volumes have risen to $1.3 \times 10^{-4} \mathrm{~mm}^{3}\left(90{ }^{\circ} \mathrm{C}\right)$ and $2.3 \times 10^{-4} \mathrm{~mm}^{3}\left(120{ }^{\circ} \mathrm{C}\right)$, which are higher than that tested at $T<M_{\mathrm{d}}$. Similar value in the stabilized coefficient of friction has further confirmed the elastic deformation dominated wear process. Furthermore, the slight increase in the wear volume when tested at high temperature $\left(\mathrm{T}>M_{\mathrm{d}}\right)$ was attributed to increased plastic strain accumulation, since the deformation strain accommodation through the SIMT process has been prohibited.

By further increasing the load to $100 \mathrm{mN}$, the contact stress was below the critical stress for SIMT at $35^{\circ} \mathrm{C}$ and $50{ }^{\circ} \mathrm{C}$ (495 MPa and $572 \mathrm{MPa}$ ), hence it was below the yield stress of austenite, which was at $646 \mathrm{MPa}\left(90^{\circ} \mathrm{C}\right)$ and $668 \mathrm{MPa}\left(120^{\circ} \mathrm{C}\right)$. Therefore, elastic deformation has dominated the wear process; while plastic strain was accumulated in the region that is close to the contact tip. At $90{ }^{\circ} \mathrm{C}$ and $120{ }^{\circ} \mathrm{C}$, under $100 \mathrm{mN}$, the stabilized coefficient of friction after 1000 wear cycles remained at around 0.3 to 0.4 . This is consistent with the elastic deformation dominated wear process when $A_{\mathrm{f}}<T<M_{\mathrm{d}}$. The wear volume has been further increased by plastic strain accumulation at $90{ }^{\circ} \mathrm{C}$ and $120{ }^{\circ} \mathrm{C}$. In this case, the 
strain accommodation associated with shape recovery property was not involved, and the wear mechanism is similar to that of conventional materials.

When the contact stress exceeds the yield stress of austenite, plastic deformation dominates the wear process. Significant amount of plastic strain can be accumulated in the wear process. This can be supported by tests conducted under $200 \mathrm{mN}$ and $300 \mathrm{mN}$ (Figs. 5-12d, 5-12e and 5-15). At $90{ }^{\circ} \mathrm{C}$ and $120{ }^{\circ} \mathrm{C}$, under $200 \mathrm{mN}$, the coefficient of friction reached about 0.72 and 0.65 ; while the wear volume reached about $7.2 \times 10^{-4} \mathrm{~mm}^{3}$ and $7.8 \times 10^{-4} \mathrm{~mm}^{3}$, respectively. Those values in the stabilized coefficient of friction and wear volume were much higher than those observed at lower temperatures. Furthermore, when tested under 300 $\mathrm{mN}$, the surface was severely damaged at the very beginning of the test, which is similar to that observed at $35^{\circ} \mathrm{C}$ and $50{ }^{\circ} \mathrm{C}$.

Since the wear resistance of austenitic NiTi SMA was deteriorated when the temperature was increased to $M_{\mathrm{d}}$, applications for wear-resistant purpose should be kept below this temperature. Furthermore, the $M_{\mathrm{d}}$ temperature can be manipulated by altering the composition of NiTi SMA.

\section{(3) Summary}

The results show that, less surface damage was formed when under reciprocating wear mode than under sliding wear mode. This was attributed to the release of internal stress field in the reciprocating stress cycles, which has reduced further plastic strain accumulation.

Since the stress-strain curve of austenitic NiTi SMA is temperature-dependent, the wear behaviour of austenitic NiTi SMA was classified into two modes according to the deformation mechanisms in the sliding wear test. Mode I occurs when $A_{\mathrm{f}}<T<$ $M_{\mathrm{d}}$ while Mode II occurs when $T>M_{\mathrm{d}}$. In Mode I, the wear behaviour is 
determined by the interplay among contact stress, critical stress for SIMT, and the shape recovery ratio. A trend of increased wear resistance with increasing temperature was observed. This can be understood based on the fact that the critical stress for the SIMT increases with increasing temperature, thus it retards the plastic deformation. Nevertheless, the shape recovery ratio also played an important role in this process. In Mode II, the SMA lost its super-elasticity and the deformation sequences were similar to other structural materials, namely, elastic and plastic deformation. In this mode, the wear resistance has been deteriorated due to significant plastic deformation that dominated the wear process. Metallurgical means, heat treatment and metal forming process can be applied to improve the shape recovery ratio and critical stress for SIMT, therefore to improve the wear resistance. 


\section{Effect of microstructure on the Wear Behaviour of NiTi SMA associated with temperature changes}

In the present chapter, we have focused on the effect of temperature on the wear behaviour of forged ingot $\mathrm{Ni} 48.2$ at\% Ti SMA. Three temperature regimes were selected, namely, $T\left(20^{\circ} C\right)<M_{\mathrm{f}}, M_{\mathrm{f}}<T\left(90^{\circ} C\right)<A_{\mathrm{f}}$ and $A_{\mathrm{f}}<T\left(120^{\circ} C\right)<M_{\mathrm{d}}$, where martensitic phase, martensitic phase coexists with austenitic phase, and austenitic phase were presented, respectively. For the forged ingot $\mathrm{Ni} 48.2$ at $\% \mathrm{Ti}$ SMA, at $20{ }^{\circ} \mathrm{C}, 90{ }^{\circ} \mathrm{C}$ and $120{ }^{\circ} \mathrm{C}$, the critical stress for the detwinning/SIMT were at 157, 320 and $530 \mathrm{MPa}$. Those values were obtained from tensile tests introduced in Chapter 3, and they are comparable to the reported values. In addition, the effect of temperature on the abrasive wear behaviour of NiTi SMA was studied under extreme high load to examine the plastic deformation dominated wear process.

\subsection{Wear resistance of forged ingot $\mathrm{Ni} 48.2$ at $\%$ Ti SMA when under different temperature regimes}

\subsubsection{Micro-scale wear behaviour of NiTi SMA}

(1) Coefficients of friction

The micro-scale wear behaviour of forged ingot NiTi SMA was studied under ball-on-disk sliding wear mode. A CETR tribometer was used, which was introduced in Chapter 3. In Fig. 6-1, the coefficients of friction were shown as a function of temperature and applied load.

\section{$T<M_{\mathrm{f}}$ - Martensitic NiTi}

Martensitic phase was present when tested at $20{ }^{\circ} \mathrm{C}$, the coefficient of friction was shown as a function of wear cycles and applied load in Fig. 6-1a. 


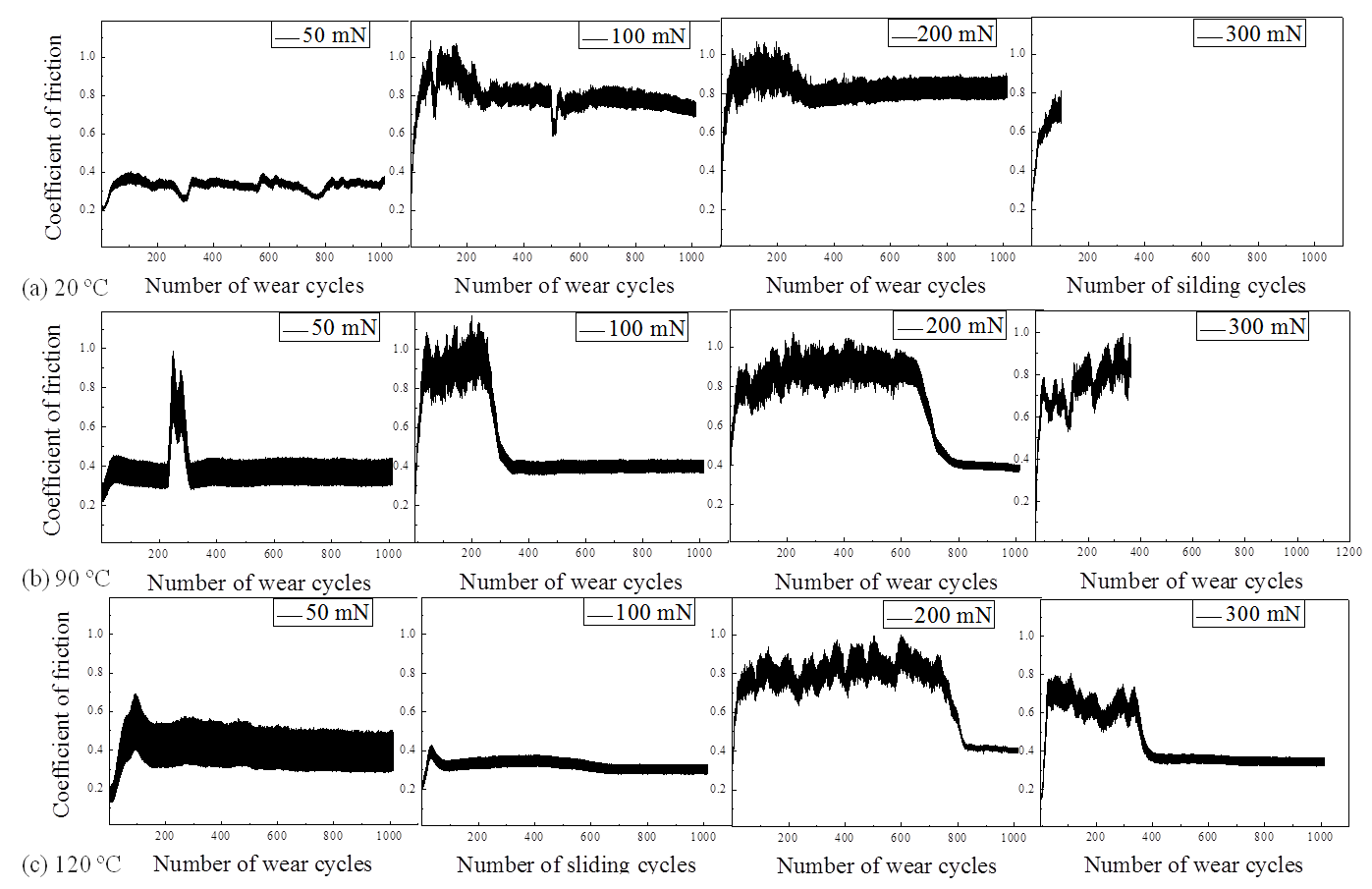

Figure 6-1: The coefficients of friction as a function of temperature, wear cycles and applied load shown. (a) When tested at $20{ }^{\circ} \mathrm{C}$ under various applied loads; (b) when tested at $90{ }^{\circ} \mathrm{C}$ under various applied loads; (c) when tested at $120{ }^{\circ} \mathrm{C}$ under various applied loads.

At $20{ }^{\circ} \mathrm{C}$, when under $50 \mathrm{mN}$, the coefficient of friction scattered at around 0.37 throughout the test. When under $100 \mathrm{mN}$, the coefficient of friction increased to around 1.0 after about 100 sliding cycles. Interestingly, it thereby decreased with further increasing wear cycles. After around 280 wear cycles, the coefficient of friction stabilized at a value of around 0.8. When the load was increased to 200 $\mathrm{mN}$, the coefficient of friction reached about 1.0 and then decreased to around 0.8 after about 300 wear cycles. Same trends in the coefficient of friction were observed when tested under $100 \mathrm{mN}$ and $200 \mathrm{mN}$. It was likely caused by similar deformation mechanisms involved in the wear process. Furthermore, under 300 $\mathrm{mN}$, the coefficient of friction was highly unstable and the test was stopped after around 100 wear cycles. 


\section{$M_{\mathrm{f}}<T<A_{\mathrm{f}}-$ Martensitic phase coexisted with austenitic phase}

When tested at $90{ }^{\circ} \mathrm{C}$ which approaches the $A_{f}\left(92{ }^{\circ} \mathrm{C}\right)$ temperature, martensitic phase coexisted with austenitic phase. Furthermore, the majority of austenitic phase dominates the sample. Different trends of the coefficient of friction as a function of wear cycles and applied load were observed when tested at $20{ }^{\circ} \mathrm{C}$ and $90{ }^{\circ} \mathrm{C}$. This suggests that different deformation mechanisms were involved in the wear process. Under $90{ }^{\circ} \mathrm{C}$, when tested under $50 \mathrm{mN}$ (Fig. 6-1b), the coefficient of friction remained at about 0.35 . From around 220 wear cycles to 320 wear cycles, the coefficient of friction reached to about 0.7 , and then decreased within a short period. Such instability in the wear process was attributed to the random error when the signal was extremely low under low load (that is, $50 \mathrm{mN}$ ). When tested under $100 \mathrm{mN}$, the coefficient of friction quickly increased to around 0.9 at the beginning of wear test. After about 250 wear cycles, it has decreased suddenly, and then stabilized at around 0.38 from 300 wear cycles onwards. By increasing the load to $200 \mathrm{mN}$, the coefficient of friction reached about 0.9 , and it then started to decrease after about 680 wear cycles. Thereby, the coefficient of friction has stabilized at about 0.4 from 800 wear cycles onwards. Under $300 \mathrm{mN}$, the test was stopped after about 400 wear cycles due to high instability in the wear process. It is worthy to mention that, the coefficient of friction has dropped by nearly $50 \%$ in tests under $100 \mathrm{mN}$ and $200 \mathrm{mN}$, this drop is much higher than the decrease in the coefficient of friction that has been reported [109, 110, 114, 115].

\section{$A_{\mathrm{f}}<T<M_{\mathrm{d}}-$ Austenitic NiTi}

When tested at $120{ }^{\circ} \mathrm{C}$, fully austenitic phase is present, accompanied with reversible stress-induced martensitic transformation process. When tested under a load of $50 \mathrm{mN}$ (Fig. 6-1c), the coefficient of friction reached about 0.65 within a short period; and then it stabilized at a value of about 0.4 (scattered between 0.3 and 0.53 ) from 150 wear cycles onwards. When tested under $100 \mathrm{mN}$, the coefficient of friction stabilized at about 0.3 for up to 1000 wear cycles. When the load was increased from $50 \mathrm{mN}$ to $100 \mathrm{mN}$, scattering in the coefficient of friction 
was reduced. This was attributed to a significant background noise when the signal was extremely low under the load of $50 \mathrm{mN}$. By further increasing the load to 200 $\mathrm{mN}$, the coefficient of friction remained at about 0.8 until 700 wear cycles. Then, it decreased and re-stabilized at about 0.4 in the remaining wear cycles. When tested under $300 \mathrm{mN}$, the coefficient of friction reached about 0.7 initially; and then it decreased and stabilized at about 0.35 after around 400 wear cycles. This observation under $300 \mathrm{mN}$ was different from previous tests under lower temperatures, suggesting better wear resistance at $120{ }^{\circ} \mathrm{C}$. Furthermore, when tested under $200 \mathrm{mN}$, the stabilized coefficient of friction at $120^{\circ} \mathrm{C}$ was nearly the same as that observed at $90^{\circ} \mathrm{C}$.

In repeated wear tests, similar trends in the coefficient of friction were observed as a function of wear cycles, applied load and temperature.

Fig. 6-2 summarized the coefficient of friction after 100 and 1000 wear cycles. The coefficient of friction after 100 wear cycles is related to the plastic deformation of high asperities when surfaces adapting to each other in the beginning of wear process. Meanwhile, the coefficient of friction after 1000 wear cycles is dependent on the contact stress and deformation mechanisms involved in the stabilized wear process. Therefore, the terms of "initial coefficient of friction" and "stabilized coefficient of friction" were used to differentiate the coefficient of friction after 100 wear cycles and 1000 wear cycles, respectively.

It is worth noting that, the wear process has shown different run-in stage when tested at different temperatures and loads. The coefficients of friction after 100 wear cycles were compared to assist the understanding of initial wear process, not the run-in stage.

When tested under $50 \mathrm{mN}$, the initial coefficient of friction has kept at relative low values (Fig. 6-2a). This was attributed to the low contact stress, which caused 
insignificant surface damage. Under $50 \mathrm{mN}$, the initial coefficient of friction at 120 ${ }^{\circ} \mathrm{C}$ was high when compared to $20{ }^{\circ} \mathrm{C}$ and $90{ }^{\circ} \mathrm{C}$. This can be attributed to different run-in stage when tested at different temperatures. At $120{ }^{\circ} \mathrm{C}$, the coefficient of friction was not stabilized after 100 wear cycles. Meanwhile, at $20{ }^{\circ} \mathrm{C}$ and $90{ }^{\circ} \mathrm{C}$, the coefficients of friction have stabilized before 100 wear cycles. This is likely due to the super-elastic deformation of austenite, which has retarded plastic deformation in the run-in stage.

When tested under applied load of $100 \mathrm{mN}$, at $20{ }^{\circ} \mathrm{C}, 90{ }^{\circ} \mathrm{C}$ and $120{ }^{\circ} \mathrm{C}$, the initial coefficients of friction reached about $0.95,0.87$ and 0.3 , respectively. This is likely due to better deformation accommodation through the SIMT process at $120{ }^{\circ} \mathrm{C}$ than the detwinning process at $20^{\circ} \mathrm{C}$.

When under $200 \mathrm{mN}$, the initial coefficient of friction was at about $0.88,0.8$ and 0.8 ; while under $300 \mathrm{mN}$, the initial coefficients of friction were at about 0.7 . No significant temperature-dependence in the coefficient of friction further suggests that, similar plastic deformation dominated wear process when tested under high contact stress.
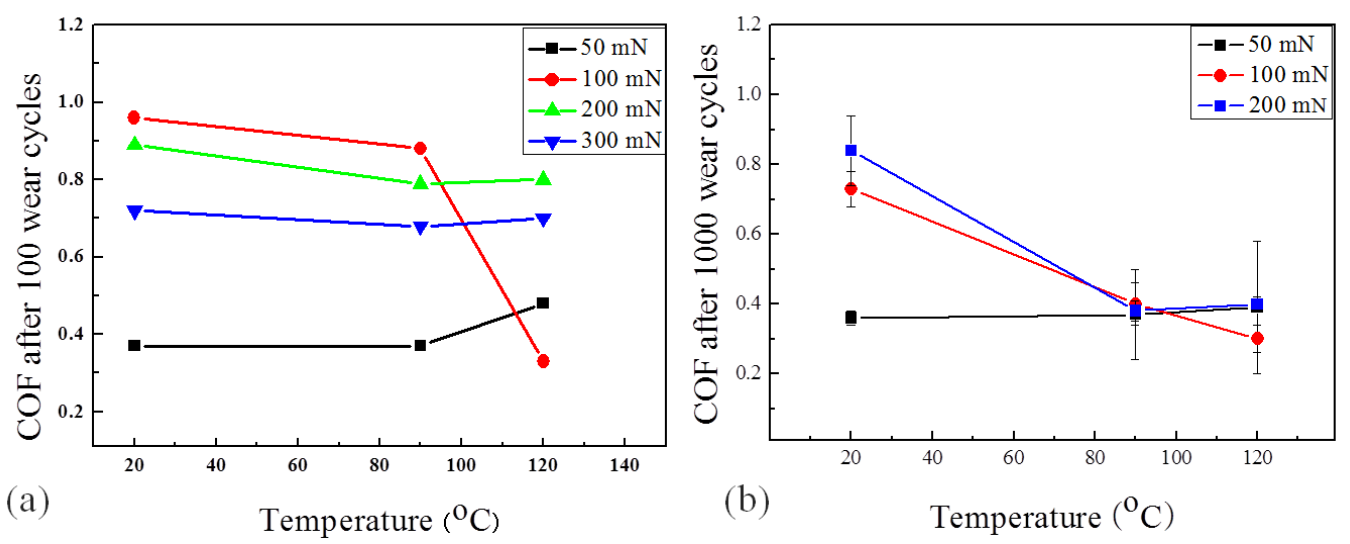

Figure 6-2: The coefficient of friction as a function of applied load and temperature. (a) After 100 wear cycles, and (b) after 1000 wear cycles. 
In the stabilized wear stage, similar stabilized coefficients of friction were observed when tested under $50 \mathrm{mN}$. This originated from similar elastic deformation dominated wear process. When under $100 \mathrm{mN}$ and $200 \mathrm{mN}$, the stabilized coefficients of friction decreased with increasing temperature (Fig. 6-2b). This was attributed to better wear resistance of austenitic phase. Coefficients of friction under $300 \mathrm{mN}$ were not plotted in Fig. 6-2b since tests were stopped before 1000 sliding cycles due to high instability in the wear process.

(2) Surface wear features and degradation stages

After each test shown in Fig. 6-1, the corresponding surface wear features were shown in Fig. 6-3. When tested at $20{ }^{\circ} \mathrm{C}, 90{ }^{\circ} \mathrm{C}$ and $120{ }^{\circ} \mathrm{C}$, under $50 \mathrm{mN}$, asperities that embossed on the surface were observed after 1000 wear cycles (Fig. 6-3). This special surface wear feature was named as "crown-like structure" in our previous report [159]. When tested at $20^{\circ} \mathrm{C}$ and $90{ }^{\circ} \mathrm{C}$, under $100 \mathrm{mN}$ and above, tracks and large amount of debris were found (Fig. 6-3a and 6-3b). However, when tested at $120{ }^{\circ} \mathrm{C}$, the crown-like structure was found under $100 \mathrm{mN}$, which was similar to the wear features under $50 \mathrm{mN}$. By further increasing the applied load to $200 \mathrm{mN}$ and $300 \mathrm{mN}$, tracks and debris were found (Figs. 6-3c).

In order to quantitatively analyze the wear behaviour, the widths of track and wear volume were shown as a function of load and temperature (Fig. 6-4). When tested at $120^{\circ} \mathrm{C}$ under several loads, widths of track and wear volume obtained after 1000 sliding cycles were lower than that observed at $20^{\circ} \mathrm{C}$ and $90^{\circ} \mathrm{C}$. Less surface wear at $120^{\circ} \mathrm{C}$ was attributed to the super-elasticity of the austenitic phase, which will be discussed further. When tested at $90{ }^{\circ} \mathrm{C}$, widths of track and surface wear volumes reached the maximum value. This was originated from the coexistence of martensitic phase and austenitic phase at $90{ }^{\circ} \mathrm{C}$. Furthermore, under $200 \mathrm{mN}$, the wear process was stabilized after about 700 wear cycles. Plastic deformation dominated the wear process, resulted in significant amount of surface wear. 

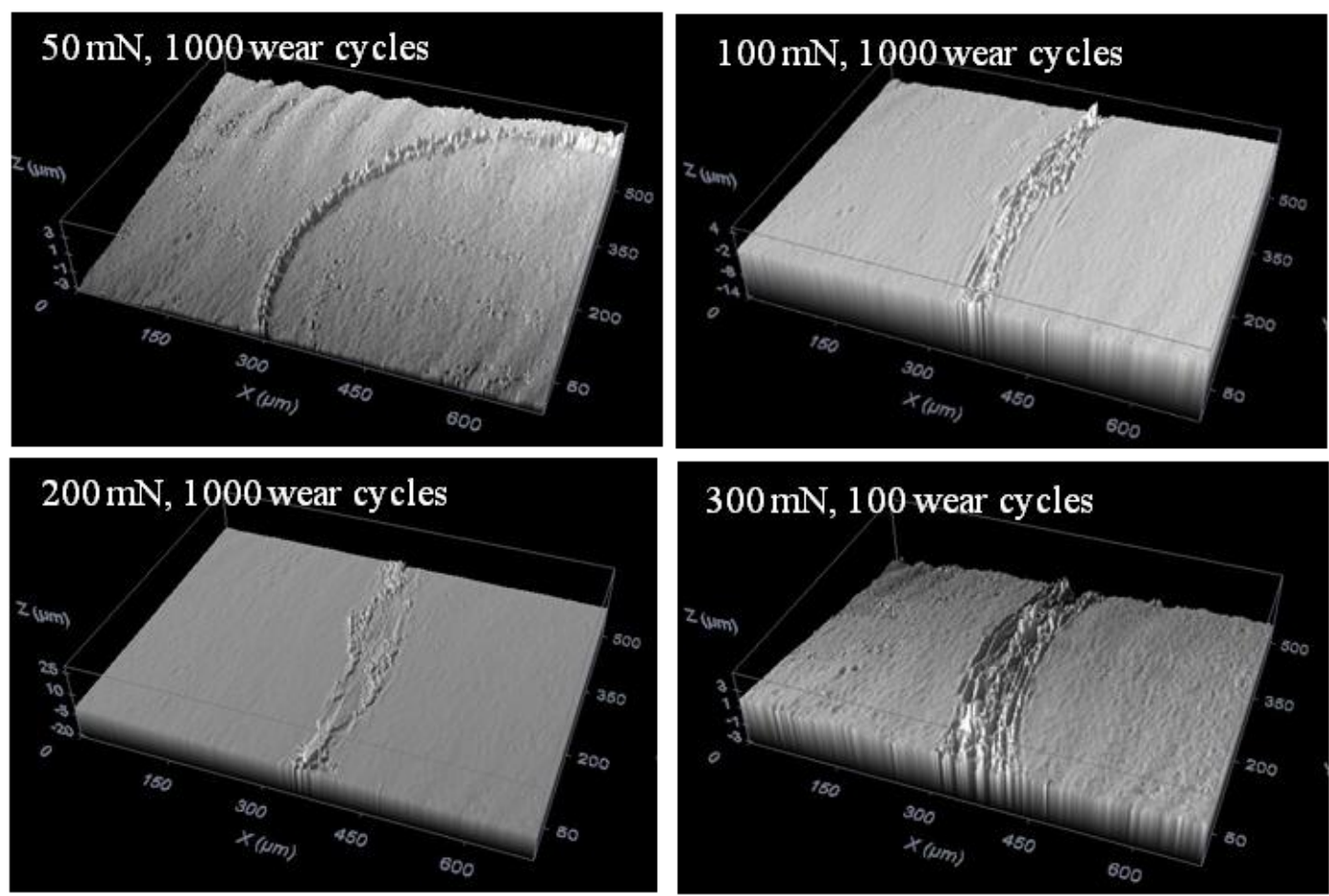

Figure 6-3a: 3D confocal microscopic images of worn surfaces when tested at $20{ }^{\circ} \mathrm{C}$, with applied loads and wear cycles indicated individually.
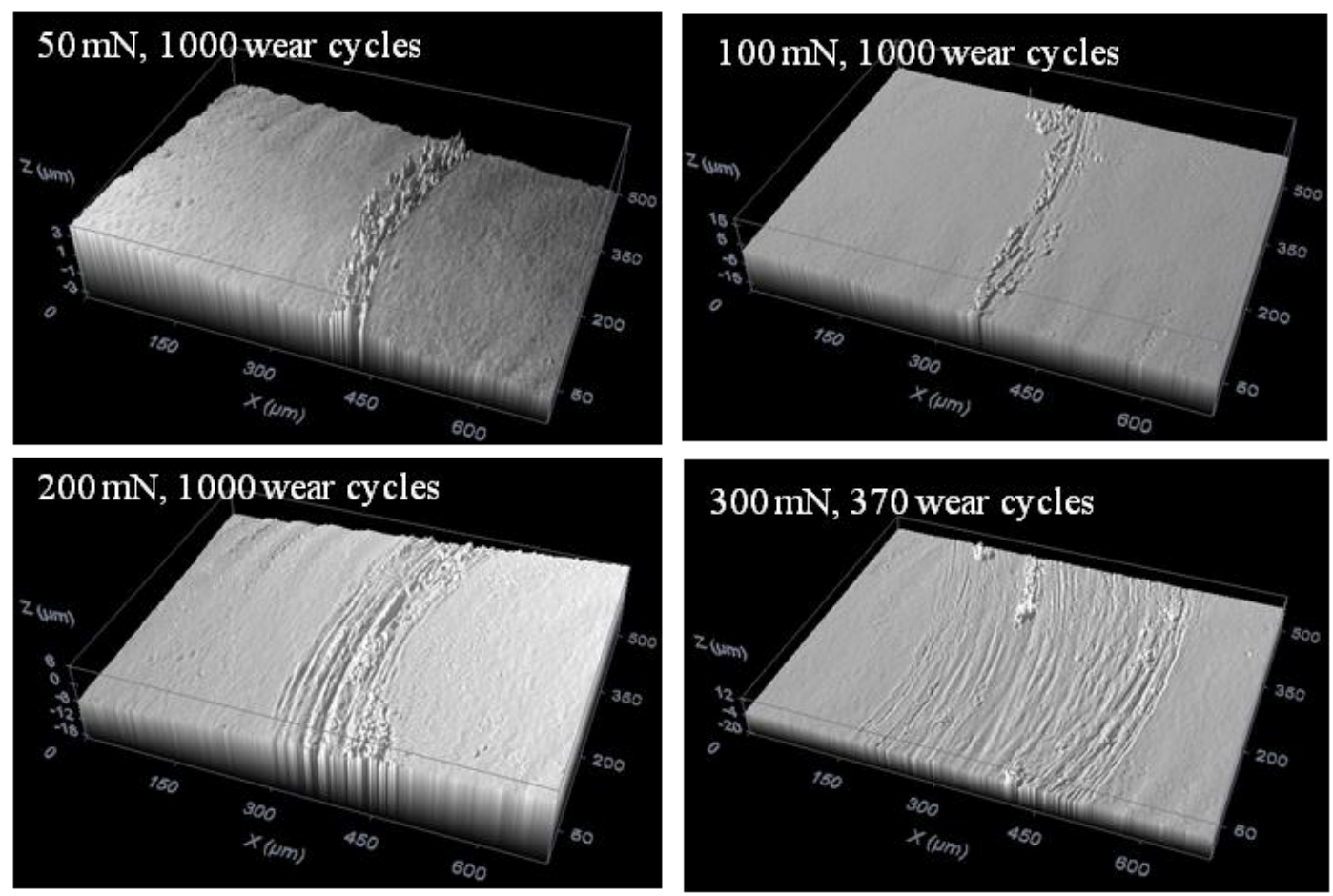

Figure 6-3b: 3D confocal microscopic images of worn surfaces when tested at $90{ }^{\circ} \mathrm{C}$, with applied loads and wear cycles indicated individually. 

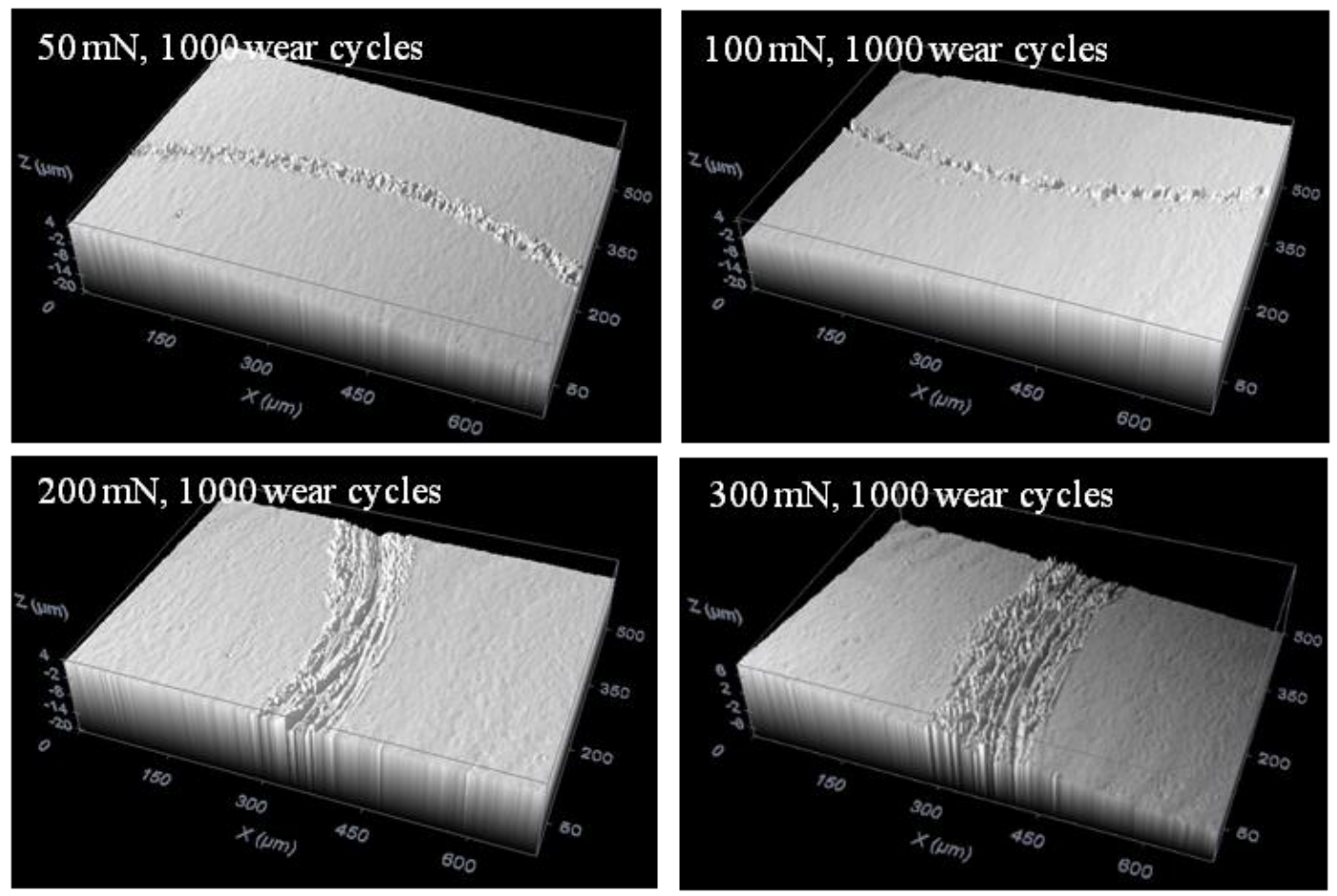

Figure 6-3c: 3D confocal microscopic images of worn surfaces when tested at $120{ }^{\circ} \mathrm{C}$, with applied loads and wear cycles indicated individually.
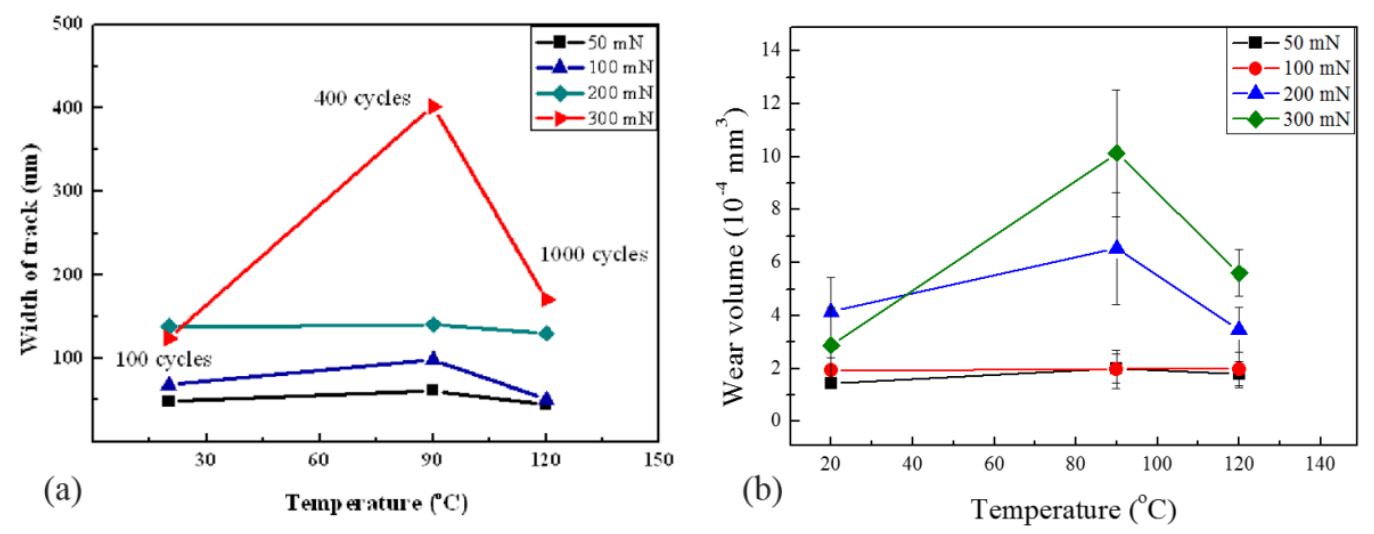

Figure 6-4: (a) The average width of track as a function of temperature and load; (b) the estimated wear volume as a function of temperature and load.

\subsubsection{Macro-scale wear behaviour of NiTi SMA}

Under extreme high load, plastic deformation dominates the wear process. Tests shown in section 6.1.1 were stopped once the wear entered the abrasive wear stage. The effect of temperature-dependent phase on the abrasive wear behaviour was 
studied through wear tests that were conducted on a high-temperature tribometer, a load of $1000 \mathrm{mN}$ was applied.

(1) Coefficients of friction as a function of temperature and sliding speed

When tested under $1000 \mathrm{mN}$, the coefficient of friction remained around 0.7 to 0.8 for up to 3000 wear cycles. An example was shown in Fig. 6-5a, the test was conducted at $20{ }^{\circ} \mathrm{C}$ with sliding speed of $30 \mathrm{~mm} / \mathrm{s}$. The coefficient of friction increased to around 0.75 after 10 wear cycles, indicating abrasive wear at the very beginning of the test. All tests were conducted at different temperatures and sliding speeds, however similar trends in the coefficient of friction were observed for up to 3000 wear cycles. Fig. 6-5b summarized the average values in the coefficient of friction as a function of temperature and applied load after 3000 wear cycles.

From Fig. 6-5b, the coefficients of friction were not strongly dependent on the temperature and sliding speed when under abrasive wear condition. It is likely due to the high contact stress, which exceeded the yield stress of the detwinned martensite, therefore plastic deformation dominated the wear process.
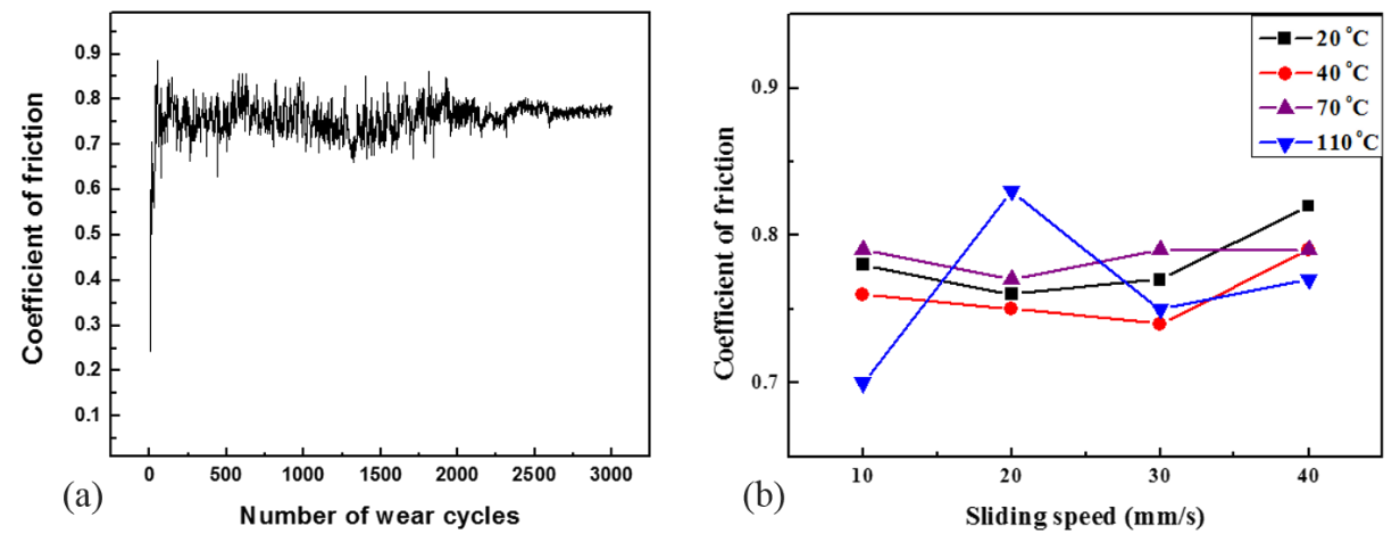

Figure 6-5: (a) The coefficient of friction as a function of wear cycles in test conducted at sliding speed of $30 \mathrm{~mm} / \mathrm{s}$ at $20{ }^{\circ} \mathrm{C}$; (b) the average coefficients of friction obtained when tested at various sliding speeds and temperatures. 
(2) Surface wear features

When tested under $1000 \mathrm{mN}$ at sliding speed of $30 \mathrm{~mm} / \mathrm{s}$, surface wear features were imaged after different number of wear cycles. Figs. 6-6a to 6-6e have highlighted the surface wear features after 10, 100, 500, 1000 and 3000 wear cycles when tested at $20{ }^{\circ} \mathrm{C}$. Similar tests were conducted at $110{ }^{\circ} \mathrm{C}$ when the specimen was in the austenitic phase, and similar abrasive wear occurred.
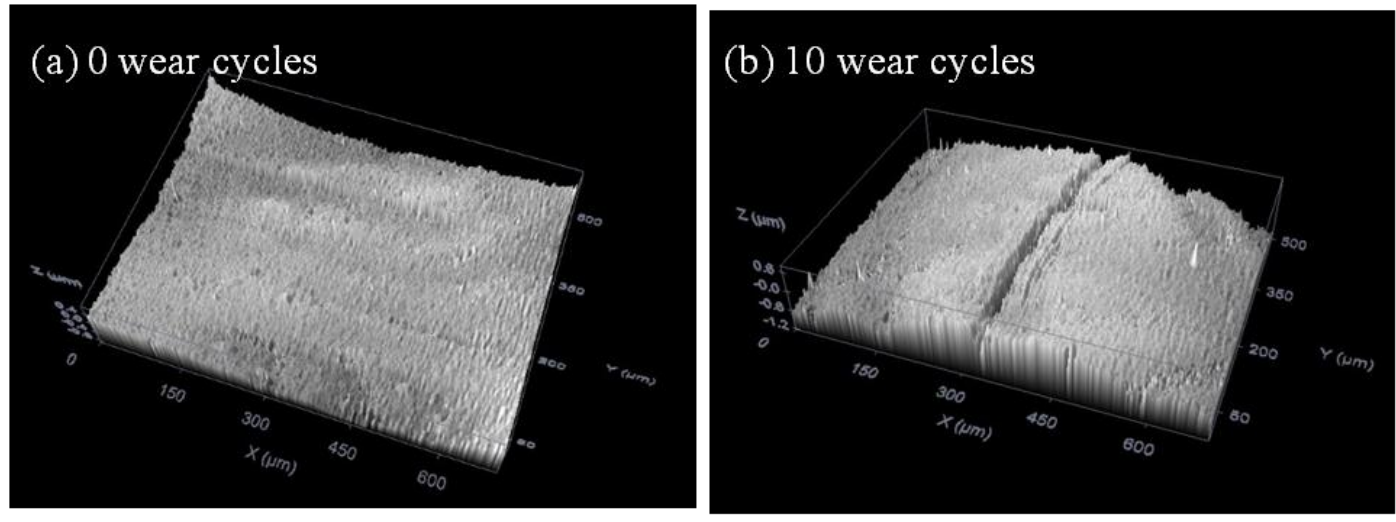

(c) 100 wear cycles

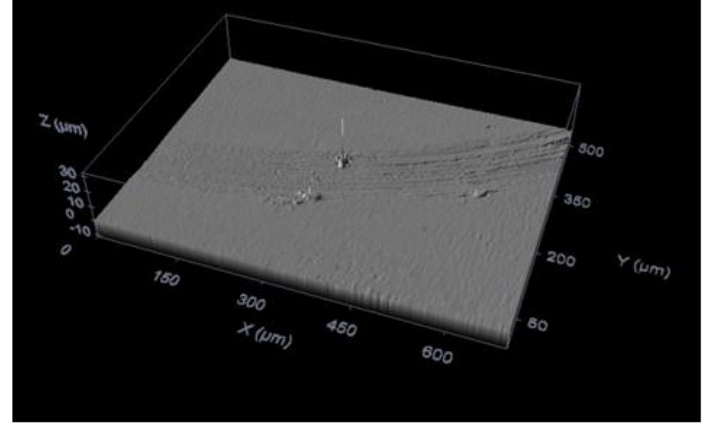

(e) 1000 wear cycles

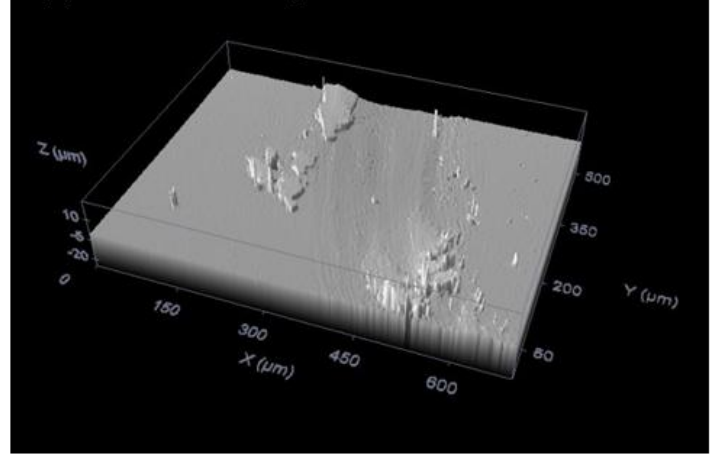

Figure 6-6: The surface wear features of martensitic NiTi SMA when tested under $1000 \mathrm{mN}$ at sliding speed of $30 \mathrm{~mm} / \mathrm{s}$, with wear cycles indicated in each image. 
When tested under $1000 \mathrm{mN}$, deep tracks were formed after 10 wear cycles, meanwhile debris was formed after 100 wear cycles (Fig. 6-6a, 6-6b). By further increasing the wear cycles, an increased amount of debris was found. Due to the non-uniform distribution of wear debris, the wear volume estimation was of large scattering, and thus, was not shown here.

\subsection{Discussion}

\subsubsection{Wear behaviour of NiTi SMA when under different temperature regimes}

Since the deformation mechanism in the wear process is dependent on the phase presents associated with different stress-strain curves, the wear behaviour of NiTi SMA is temperature- and stress-dependent. In this chapter, the wear behaviour of NiTi SMA was explained with the understanding of microstructure, deformation region in the stress-strain curves, and the estimated contact stresses.

(1) Fully martensitic phase at $20{ }^{\circ} \mathrm{C}\left(T<M_{f}\right)$

As known, the deformation of martensitic NiTi SMA proceeds in the following sequences: elastic deformation of twinned martensite; detwinning of twinned martensite with occurrence of stress-plateau on the stress-strain curve; elastic deformation of detwinned martensite; and plastic deformation of detwinned martensite. Due to strain accommodation through the detwinning process, plastic deformation can be retarded, which results in improved wear resistance.

Under ball-on-disk contact mode, the contact stress distribution beneath the counter-ball is non-uniform, which results in different deformation mechanism in different contact regions. The largest deformation occurs in the region that is closest to the tip of the counter-ball (contact tip). With increasing the distance from 
the contact tip, the contact stress can be reduced, thus causing less surface damage. The deformation mechanism on the contact tip is the predominant deformation mechanism in the wear process, since majority of surface damage occurs in this region. Furthermore, the contact stress reaches maximum at the contact tip region, and it decreases with increased distance from the contact tip.

When the contact stress is below the critical stress for detwinning, elastic deformation of twinned martensite dominates the wear process. Due to insignificant formation of plastic strain, the surface wear is insignificant. Examples can be found when tested under extreme low load of $50 \mathrm{mN}$ at $20{ }^{\circ} \mathrm{C}$. The coefficient of friction remained below 0.4 for up to 1000 wear cycles (Fig. 6-1a). Meanwhile, insignificant surface wear was formed, with estimated volume of $1.5 \times$ $10^{-4} \mathrm{~mm}^{3}$.

To further confirm the contact stress involved in the wear process, the Hertzian elastic contact model was used to estimate the average contact stress when tested under $50 \mathrm{mN}$. The following equations were applied [1, 2]:

$$
\begin{gathered}
\sigma^{3}=\frac{6 F_{n}\left(E^{*}\right)^{2}}{\pi^{3} R^{2}} \\
\frac{1}{E^{*}}=\frac{1-v_{1}^{2}}{E_{1}}+\frac{1-v_{2}^{2}}{E_{2}}
\end{gathered}
$$

Here, $\sigma$ is the contact stress; $F_{\mathrm{n}}$ is the applied load; $R$ is the radius of the sphere ( 2 $\mathrm{mm}) ; E_{1}$ and $E_{2}$ are the elastic moduli of the martensitic NiTi and the alumina counter-ball, which have values of $26 \mathrm{GPa}$ and $375 \mathrm{GPa}$, respectively. In addition, $v_{1}$ and $v_{2}$ are the Poisson's ratio for the martensitic NiTi SMA and alumina counter-ball, with values of 0.33 and 0.23 , respectively.

By substituting those values to Eqs. 6.1 and 6.2, the calculated contact stress under 
$50 \mathrm{mN}$ was $122 \mathrm{MPa}$. From tensile stress-strain test, the critical stress for the detwinning at $20{ }^{\circ} \mathrm{C}$ was $157 \mathrm{MPa}$ (Fig. 3-2), which is comparable to the reported values [110]. The calculated contact stress under $50 \mathrm{mN}$ is lower than the critical stress for detwinning. This further suggests that, the elastic deformation dominated the wear process.

By increasing the contact stress above the critical stress for detwinning but below the yield stress of detwinned martensite, detwinning and elastic deformation of detwinned martensite dominate the wear process. Since the detwinning process is not reversible at $20{ }^{\circ} \mathrm{C}$, increased amount of martensite will become detwinned, followed by plastic strain accumulation. Meanwhile, strain accommodation through the detwinning process can retard further plastic deformation. This can be supported by wear observations when tested under $100 \mathrm{mN}$ and $200 \mathrm{mN}$ at $20{ }^{\circ} \mathrm{C}$ (Fig. 6-1a). The coefficients of friction had decreased from around 1.0 to 0.8 , and then stabilized at low values after 1000 wear cycles. The decrease in the coefficient of friction was attributed to the strain accommodation through the detwinning process. Furthermore, under $100 \mathrm{mN}$ and $200 \mathrm{mN}$, the wear volume was around $1.9 \times 10^{-4} \mathrm{~mm}^{3}$ and $4 \times 10^{-4} \mathrm{~mm}^{3}$, which were higher than that observed under 50 $\mathrm{mN}\left(1.5 \times 10^{-4} \mathrm{~mm}^{3}\right)$.

When tested under $100 \mathrm{mN}$, the contact stress was likely around the critical stress for detwinning. We have calculated the contact stress using Hertzian elastic contact model to further confirm our discussion. The calculated contact stress under 100 $\mathrm{mN}$ was at $153 \mathrm{MPa}$, which is very close to the critical-stress for detwinning at 157 MPa. This further confirms the contact stress analysis. The Hertzian elastic contact model is applicable for elastic deformation dominated contact problems. In the presence of non-elastic deformation (detwinning), the calculated results will be of low accuracy. Therefore, when tested under $200 \mathrm{mN}$, due to the further increased contact stress which exceeded the critical stress for detwinning, no calculation was considered [159]. 
By further increasing the contact stress above the yield stress of detwinned martensite, plastic deformation dominates the wear process. Severe wear occurs at the very beginning of test, thus causing high instability in the coefficient of friction. This can be supported by the wear observations when tested under $300 \mathrm{mN}$ (Fig. 6-1a). The coefficient of friction was highly unstable at the very beginning of the test, and the wear volume was increased to around $3 \times 10^{-4} \mathrm{~mm}^{3}$ after only 100 wear cycles.

(2) Fully austenitic phase at $120{ }^{\circ} \mathrm{C}\left(T>A_{f}\right)$

Deformation of fully austenitic NiTi SMA proceeds in the sequence of: elastic deformation of austenite; stress-induced martensitic transformation (SIMT) with occurrence of stress-plateau in the stress-strain curve; elastic deformation of stress-induced martensite, and plastic deformation of stress-induced martensite. Deformation strain up to $13 \%$ can be fully recovered through a reversed stress-induced martensitic transformation process. Therefore, plastic deformation might be retarded by strain accommodation through the reversible SIMT process.

The critical stress for stress-induced martensitic transformation increases with increasing temperature, which obeys the Clausius-Clapeyron type of equation [160, 161]:

$$
\begin{gathered}
\frac{d\left(\sigma^{T}\right)}{d T}=-\frac{\Delta h \times \rho_{A}}{T \times \varepsilon_{O}} \\
\sigma^{T}-\sigma^{O}=\left(-\frac{\Delta h \times \rho_{A}}{\varepsilon^{T}}\right) \ln \left(\frac{T}{T_{o}}\right)
\end{gathered}
$$

Here, $\sigma$ is the contact stress, and $\varepsilon_{0}$ is the amount of strain due to stress induced martensitic transformation. By applying Eqs. 6.3 and 6.4, the calculated critical stress for stress-induced martensitic transformation was around $400 \mathrm{MPa}$ and 608 
$\mathrm{MPa}$ when tested at $90{ }^{\circ} \mathrm{C}$ and $120{ }^{\circ} \mathrm{C}$, respectively. These values are in good agreement with the reported range $[160,161]$. Since the reported yield stress of austenite was around $650 \mathrm{MPa}$ to $900 \mathrm{MPa}$, the austenitic NiTi behaves super-elastically at $120^{\circ} \mathrm{C}$. The deformation mechanism in the wear process was discussed with respect to the contact stress and the corresponding stress-strain curve of the austenitic NiTi SMA.

When the contact stress is below or approaches the critical stress for SIMT, elastic deformation or stress-induced martensitic transformation dominates the contact area. Such deformation process is fully reversible, hence insignificant plastic strain can be accumulated, which results in insignificant surface damage after large number of wear cycles. Examples are illustrated in Figs. 6-1c, 6-3c and 6-4. When tested at $120{ }^{\circ} \mathrm{C}$, under $50 \mathrm{mN}$ and $100 \mathrm{mN}$, the coefficient of friction remained around 0.4 throughout the test. Meanwhile, insignificant surface damage was found with estimated wear volume of around $1.7 \times 10^{-4} \mathrm{~mm}^{3}(50 \mathrm{mN})$ and $1.9 \times$ $10^{-4} \mathrm{~mm}^{3}(100 \mathrm{mN})$.

In comparison, when tested at $20{ }^{\circ} \mathrm{C}$ under $100 \mathrm{mN}$, the coefficient of friction reached around 0.7, while significant amount of surface damage was found. The result further suggests that, when tested at $20^{\circ} \mathrm{C}$ and $120{ }^{\circ} \mathrm{C}$, different deformation mechanisms were involved in the wear process. Since the critical stress for detwinning at $20{ }^{\circ} \mathrm{C}$ was much lower than the critical stress for SIMT at $120{ }^{\circ} \mathrm{C}$, the wear process was retarded when the temperature was increased.

When the contact stress exceeds the critical stress for SIMT but is below the yield stress of stress-induced martensite, elastic deformation of stress-induced martensite dominates the wear process. Significant amount of plastic strain can be accumulated in this process, which leads to significant surface wear. For example, when tested under $200 \mathrm{mN}$ and $300 \mathrm{mN}$, the coefficient of friction reached around 0.8 at the beginning of test, indicates that significant plastic deformation occurred. 
However, the coefficient of friction had decreased and stabilized at about 0.4 in further wear cycles. The change in the coefficient of friction can be understood by the change in the deformation mechanism. The initial wear process under high load was dominated by adaption of high asperities, which is accompanied with significant plastic deformation. Thereafter, high asperities were plastically deformed and, the SIMT dominated the stabilized wear process. Furthermore, the plastic deformation was effectively reduced due to deformation strain accommodation through the reversible SIMT process.

It is worth noting that, when tested under $300 \mathrm{mN}$, plastic deformation dominated the wear process at $20^{\circ} \mathrm{C}$, which is associated with severe surface wear. However, by increasing the temperature to $120{ }^{\circ} \mathrm{C}$, the wear process remained stabilized for up to 1000 wear cycles. This further confirmed the important role of strain accommodation through the SIMT process in retarding plastic strain accumulation, thereby, resisting wear.

(3) Martensite coexists with austenite at $90{ }^{\circ} \mathrm{C}\left(M_{f}<T<A_{f}\right)$

When tested at $90{ }^{\circ} \mathrm{C}$, which was above the $M_{f}$ but below the $A_{f}$, martensite coexisted with austenite. Deformation mechanisms of both phases were involved in the wear process, and the dominant deformation mechanism was dependent on the proportion of each phase. When tested at $90{ }^{\circ} \mathrm{C}$ which is close to the $A_{f}$ temperature $\left(92{ }^{\circ} \mathrm{C}\right)$, majority of austenitic phase were presented in the sample. We would expect the wear behaviour of NiTi SMA to be similar to that of the austenitic phase dominated samples.

When the contact stress is below the critical stress for SIMT at $90{ }^{\circ} \mathrm{C}(400 \mathrm{MPa})$, majority of austenitic phase will be deformed elastically. While minority of martensitic phase will be detwinned. According to our previous analysis on the contact stress, when tested under $50 \mathrm{mN}$, the contact stress approached the critical 
stress for detwinning (157 MPa), but it was below the critical stress for SIMT at $90{ }^{\circ} \mathrm{C}(400 \mathrm{MPa})$. Therefore, elastic deformation of austenite dominated the wear process at $90{ }^{\circ} \mathrm{C}$, accompanied with insignificant surface wear. This can be supported by the results shown in Fig. 6-1b and 6-4. When tested at $90{ }^{\circ} \mathrm{C}$ under 50 $\mathrm{mN}$, the coefficient of friction remained around 0.4 , while the wear volume was at about $2 \times 10^{-4} \mathrm{~mm}^{3}$. Those values were comparable to the elastic deformation dominated wear process at $20^{\circ} \mathrm{C}$ and $120{ }^{\circ} \mathrm{C}$.

When the contact stress is above the critical stress for SIMT but below the yield stress of stress-induced martensite, stress-induced martensitic transformation dominates the wear process. In addition, a small portion of the detwinned martensite will be deformed elastically or plastically, further contributing to the plastic strain accumulation. Since the test temperature is close to the $A_{\mathrm{f}}$ temperature, part of the stress-induced martensite will be restricted from reversed transformation, which causes an increased plastic strain accumulation [166]. For example, when tested under $100 \mathrm{mN}$ (Fig. 6-1b), the clear stabilization process in the coefficient of friction further supported changes in the deformation mechanism. When the load was increased to $200 \mathrm{mN}$, elastic deformation of stress-induced martensite dominated the wear process, which caused significant surface damage. When tested at $90{ }^{\circ} \mathrm{C}$ and $120^{\circ} \mathrm{C}$, under $200 \mathrm{mN}$, the coefficient of friction showed the same trend. This further confirmed the same elastic deformation of stress-induced martensite dominated wear process.

When the contact stress exceeds the yield stress of stress-induced martensite/ detwinned martensite, plastic deformation dominates the wear process. For example, when tested under $300 \mathrm{mN}$, due to superior strain accommodation through fully reversible SIMT process at $120{ }^{\circ} \mathrm{C}$, the abrasive wear process was retarded. However, the SIMT process was only partially reversible at $90{ }^{\circ} \mathrm{C}$, hence abrasive wear occurred and the wear process was highly unstable at the very beginning of the test. 
(4) Summary

The effect of temperature on the wear behaviour of NiTi SMA was summarized in Fig. 6-7. The dominant deformation mechanism involved in the wear process was highlighted in three temperature regimes, which are corresponding to different phases. Three wear stages were defined according to observations in the coefficient of friction and surface wear features, namely, near-zero wear stage, transition wear stage and abrasive wear stage [159]. The near-zero wear stage is characterized by insignificant formation of surface damage and low value in the coefficient of friction. In the transition wear stage, significant formation of surface damage can cause transition in the deformation mechanism in wear process. In the abrasive wear stage, severe wear occurs in the very beginning of test.

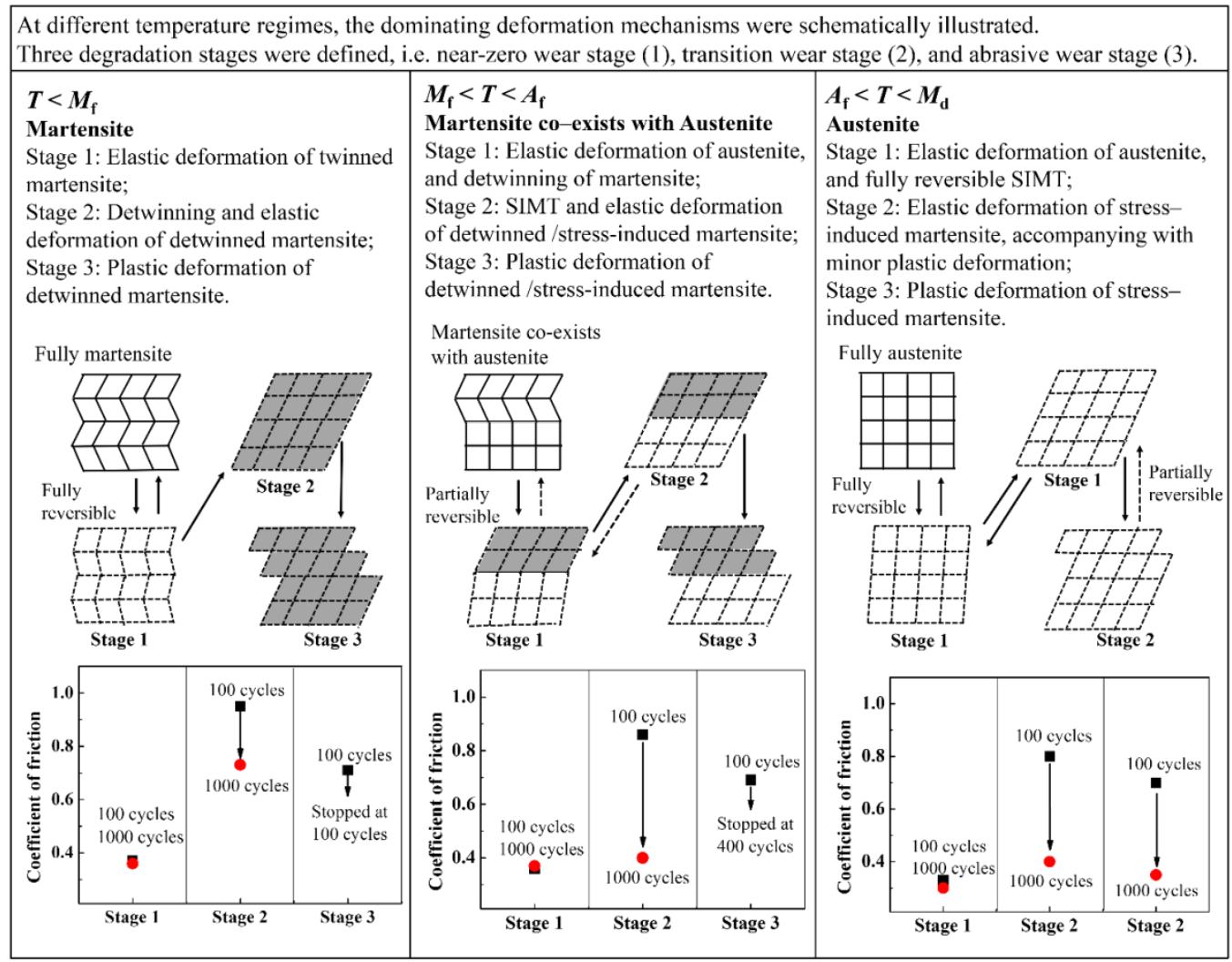

Figure 6-7: Summary of the effect of temperature on the wear behaviour of NiTi SMA. 
When tested below the $M_{\mathrm{f}}$, the reversible elastic deformation of twinned martensite dominated the near-zero wear stage, which caused insignificant surface damage. By increasing the contact stress, detwinning process dominated the wear process. Deformation was accommodated through the detwinning process, thus the plastic strain accumulation was reduced. Transition in the dominant deformation mechanism occurred by increasing the wear cycles, and it was indicated by a decrease in the coefficient of friction for up to $20 \%$. When plastic deformation dominated the wear process, the test was stopped after 100 wear cycles due to high instability in the wear process.

By increasing the temperature $\left(M_{\mathrm{f}}<T<A_{\mathrm{f}}\right)$, majority of austenite coexisted with martensite phase. In this case, the near-zero wear stage was dominated by elastic deformation of austenite, while the transition wear stage was dominated by stress-induced martensitic transformation process. Due to the better strain accommodation through the SIMT process when compared to the detwinning process, the decrease in the coefficient of friction reached about $50 \%$. When the contact stress exceeded the yield stress of stress-induced martensite, abrasive wear occurred and plastic deformation dominated the wear process.

When the temperature was increased above the $A_{\mathrm{f}}$, both the critical stress for SIMT and the recovery ratio in the reversed SIMT were increased. This causes further strain accommodation through the reversible SIMT process. The near-zero wear stage was prolonged, therefore wear process associated with plastic strain accumulation was retarded. The transition wear behaviour at this temperature was characterized by a decrease in the coefficient of friction for up to $50 \%$, which occurred under higher magnitude of applied load than that tested at lower temperatures. In addition, tests were stopped once the abrasive wear (stage 3) occurred. Further study on the abrasive wear behaviour was discussed in the following section. 
The NiTi SMA showed better wear resistance in the austenitic phase than the martensitic phase. Hence, one can improve the wear performance of NiTi SMA through decreasing the transformation temperature or increasing the application temperature to above $A_{\mathrm{f}}$ but below $M_{\mathrm{d}}$.

\subsubsection{Abrasive wear behaviour of NiTi SMA}

When tested under $1000 \mathrm{mN}$, the contact stress exceeded the yield stress of stress-induced/detwinned martensite, hence plastic deformation dominated the wear process. This can be supported by deep tracks that were observed after 10 wear cycles as shown in Fig. 6-6. When tested at different temperatures and sliding speeds, the average coefficients of friction remained at around 0.7 to 0.8 in 3000 wear cycles. Meanwhile, large amount of wear debris was found (Figs. 6-5 and 6-6). Plastic deformation had dominated the abrasive wear process when tested under an applied load of $1000 \mathrm{mN}$. Therefore, similar severe wear was observed when different phases were present at different temperatures. This conclusion is consistent with the conclusion from section 6.2.1. We should avoid sharp contact in the application of NiTi SMA, since the wear resistance can be deteriorated in the abrasive wear stage.

In addition, as reported by Totten et al [86], in the dry sliding test of steel, high sliding speed which was greater than $1000 \mathrm{~mm} / \mathrm{s}$ has introduced local heating. Local surface was likely modified by oxidation or even melting. In the present study, the highest sliding speed of $40 \mathrm{~mm} / \mathrm{s}$ was applied. Furthermore, small scale wear test was selected with counter-ball having diameter of $6 \mathrm{~mm}$. Therefore, the effect of local heating on altering the local phase was not significant. 


\section{Wear Behaviour of Single Crystal and Polycrystal NiTi SMAs When Martensite Coexists with Austenite}

Single crystal and polycrystal NiTi SMAs may show different wear behaviour due

to different mechanical properties associated with different plastic strain accumulation process. In this section, the wear behaviour of single crystal and polycrystal NiTi SMAs were compared when martensitic phase coexisted with austenitic phase.

\subsection{Wear resistance of single crystal Ni 50 at \% Ti SMA and polycrystal Ni 49.4 at\% Ti SMA}

\subsubsection{Phase transformation temperatures}

The DSC curves of the single crystal and polycrystal NiTi SMA samples are shown in Fig. 7-1. For the single crystal NiTi SMA, the starting and finishing temperatures of martensitic transformation are $22.3{ }^{\circ} \mathrm{C}$ and $-20.2{ }^{\circ} \mathrm{C}$; while the starting and finishing temperatures of austenitic transformation are $18.1{ }^{\circ} \mathrm{C}$ and $44.5{ }^{\circ} \mathrm{C}$, respectively. For the polycrystal NiTi SMA, the $M_{\mathrm{s}}, M_{\mathrm{f}}, A_{\mathrm{s}}$ and $A_{\mathrm{f}}$ temperatures are $27.6{ }^{\circ} \mathrm{C}, 17.5{ }^{\circ} \mathrm{C}, 38.6{ }^{\circ} \mathrm{C}$, and $53.4{ }^{\circ} \mathrm{C}$, respectively.

The pre-heating and pre-cooling processes are highlighted on the DSC curves, and the transformation directions are indicated (Fig. 7-1). By pre-heating samples in hot water $\left(100{ }^{\circ} \mathrm{C}\right)$ for 30 minutes and air-cooling to $20^{\circ} \mathrm{C}$, majority of austenitic phase presents. Similarly, by pre-cooling samples in liquid nitrogen for 30 minutes and expose them to air at $20^{\circ} \mathrm{C}$, majority of martensitic phase presents.

For ease of comparison, single crystal samples with majority of martensitic/ austenitic phase are defined as SC1/ SC2; while polycrystal samples with majority of martensitic/austenitic phase are defined as PC1/ PC2, respectively. 

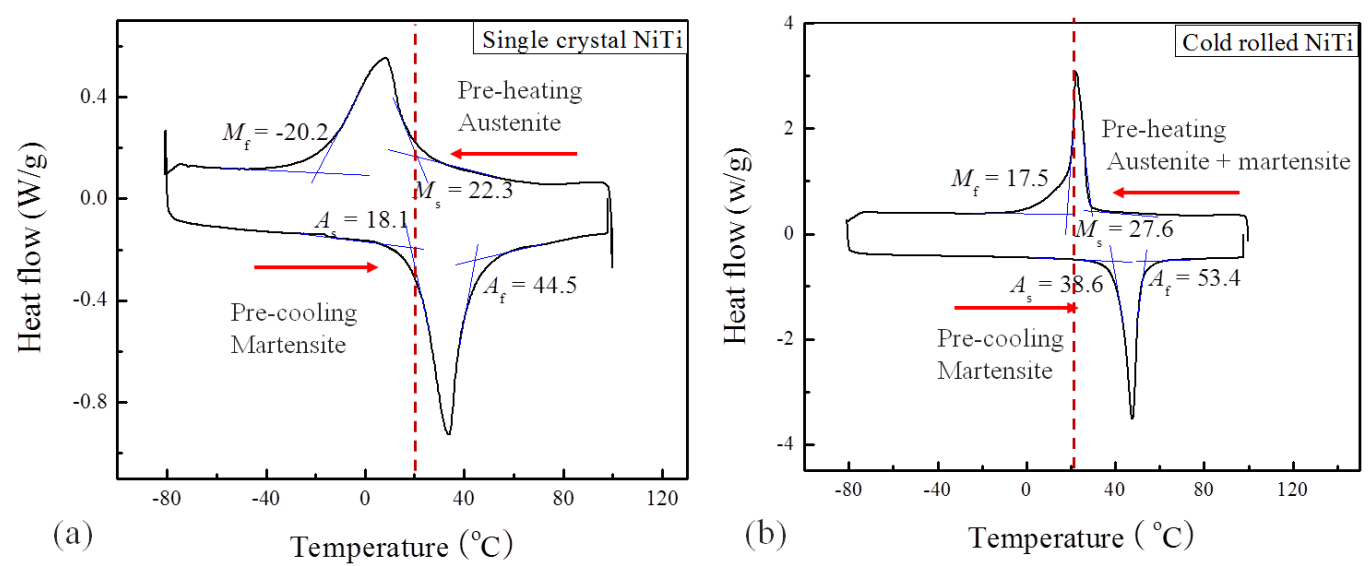

Figure 7-1: The schematic illustration of phase transformations in pre-heating and pre-cooling processes. (a) Single crystal NiTi SMA (SC samples), and (b) polycrystal NiTi SMA (PC samples).

\subsubsection{Coefficients of friction}

Wear tests were conducted at a sliding speed of $1.25 \mathrm{~mm} / \mathrm{s}$. The coefficients of friction were shown as a function of applied load and wear cycles in Fig. 7-2.

For sample SC1, pre-cooling was applied before the wear test, hence majority of martensitic phase was present (Fig. 7-2a). When tested under $100 \mathrm{mN}$, the coefficient of friction kept increasing with increased wear cycles. After about 700 wear cycles, it stabilized at around 0.41 . When tested under $200 \mathrm{mN}$, the coefficient of friction reached about 0.25 after about 1000 wear cycles. When tested under $300 \mathrm{mN}$, the coefficient of friction was highly unstable, hence the test was stopped after 280 wear cycles. However, by further increasing the load to 400 $\mathrm{mN}$, the coefficient of friction stabilized at about 0.3 from 300 wear cycles onwards. The stabilized coefficient of friction under $400 \mathrm{mN}$ is likely associated with strain hardening mechanism. Tests were repeated under $400 \mathrm{mN}$ to confirm this observation. Two groups of tests showed high instability in the coefficient of friction; while other two groups showed stabilized coefficient of friction, which are similar to the results shown in Fig. 7-2a. 

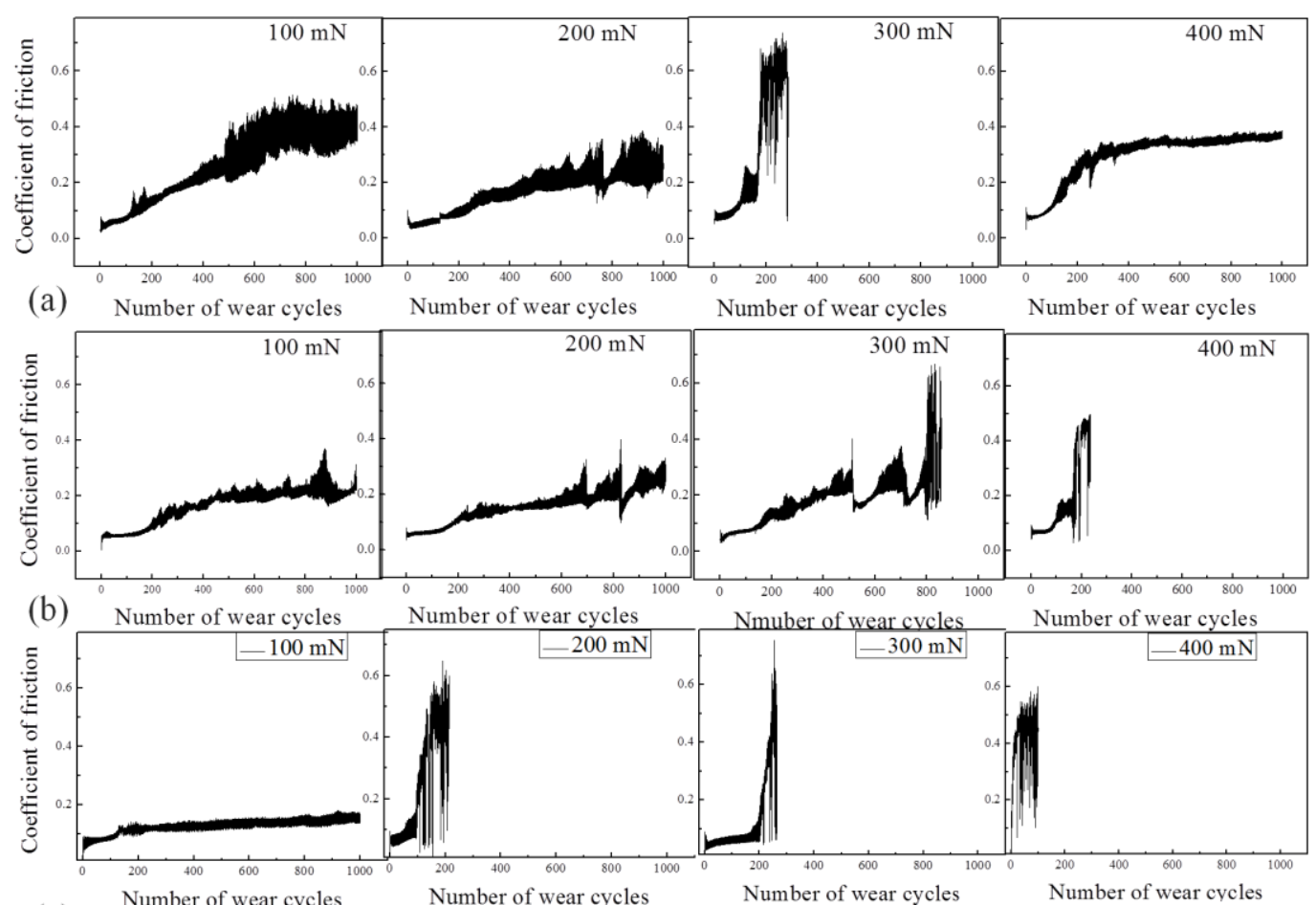

(c)

Number of wear cycles

Number of wear cycles

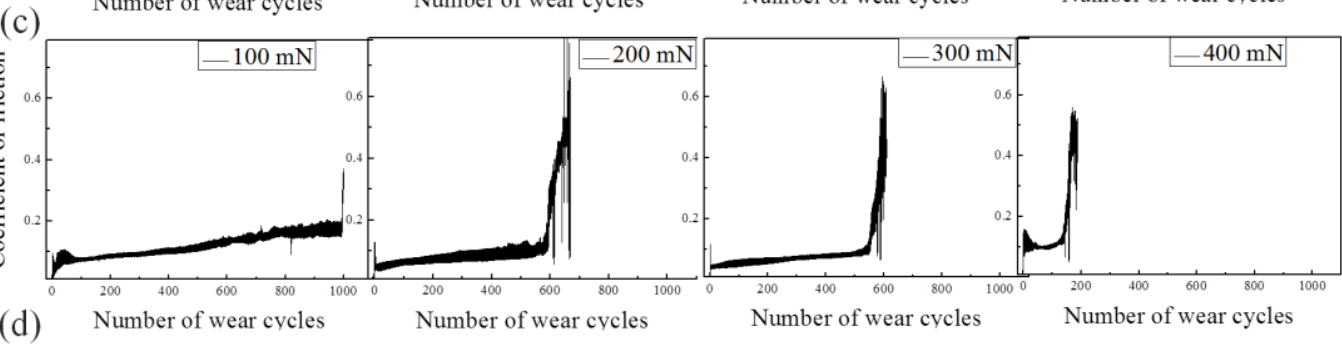

(d)

Figure 7-2: Coefficients of friction as a function of applied load when tested on, (a) sample SC1; (b) sample SC2; (c) sample PC1, and (d) sample PC2.

For sample SC2, majority of austenitic phase was present after pre-heating. When tested under $100 \mathrm{mN}$ and $200 \mathrm{mN}$, the coefficients of friction showed the same trend as a function of wear cycles. They increased with increasing wear cycles, and reached about 0.23 and 0.25 after 1000 wear cycles (Fig. 7-2b). When tested under $300 \mathrm{mN}$, the test was stopped after 860 wear cycles due to large scattering that occurred with increasing wear cycles. By further increasing the load to $400 \mathrm{mN}$, the test was stopped after about 240 wear cycles due to high instability in the wear process. 
When tested on the sample of SC1 and SC2, the coefficients of friction showed increasing tendencies with increasing wear cycles. This is likely associated with significant dislocation/ plastic strain accumulation process. In addition, the coefficient of friction showed lower values as a function of applied load when tested on the SC2 as compared with SC1. This can be attributed to the majority of austenitic phase in SC2, which has better strain accommodation ability than the martensitic phase in SC1. Furthermore, pre-heating may release the residual strain, thus further contribute to the wear resistance. This will be discussed further.

When tested on PC1 and PC2, trends in the coefficient of friction as a function of applied load have changed significantly as compared to the SC1 and SC2. When tested on PC1 (martensitic phase), under $100 \mathrm{mN}$, the coefficient of friction remained at about 0.15 for up to 1000 wear cycles (Fig. 7-2c). When tested under $200 \mathrm{mN}$ and $300 \mathrm{mN}$, similar trends in the coefficients of friction were observed. The coefficient of friction remained about 0.1 in the beginning of the test, then it became highly unstable within a short time period. When under $200 \mathrm{mN}$ and 300 $\mathrm{mN}$, tests were stopped after 213 and 265 wear cycles, respectively. When the load was further increased to $400 \mathrm{mN}$, the coefficient of friction was highly unstable at the very beginning of the test, this was likely caused by plastic deformation dominated wear process.

When tested on PC2 which is dominated by austenitic phase, more wear cycles were conducted before getting into a highly unstable wear stage as compared to the PC1 (7-2d). When tested under $100 \mathrm{mN}$, the coefficient of friction remained around 0.16 for up to 1000 wear cycles. When tested under $200 \mathrm{mN}$, the coefficient of friction remained about 0.1 for 590 wear cycles. Then it became highly unstable, and the test was stopped at 680 wear cycles. When tested under $300 \mathrm{mN}$, the coefficient of friction remained around 0.09 for 550 wear cycles, then it became highly unstable. The test was stopped after 610 wear cycles. By increasing the load further to $400 \mathrm{mN}$, the test was stopped after 200 wear cycles. 
When tested on the PC1 and PC2 (Fig. 7-2c and 7-2d), the coefficient of friction remained extremely low under low load. By increasing the applied load, the coefficient of friction remained low at the beginning of the wear test; and then it became highly unstable with further increasing wear cycles. This special wear process was likely related to the strain hardening mechanism, which will be discussed further.

\subsubsection{Surface wear features}

Different surface wear features obtained from different wear tests were shown in Fig. 7-3, which are corresponding to the coefficients of friction shown in Fig. 7-2.

When tested on SC1 and under $100 \mathrm{mN}$, a "crown-like" structure was observed after 1000 wear cycles (Figure 7-3a). When tested under $200 \mathrm{mN}$, deep tracks appeared at the bottom of the crown-like structure, indicating further surface damage. By further increasing the applied load to $300 \mathrm{mN}$ and $400 \mathrm{mN}$, surfaces were severely damaged as shown in Figure 7-3a.

When tested on SC2, under $100 \mathrm{mN}$ and $200 \mathrm{mN}$, less surface asperities were formed as compared with the SC1 (Figure 7-3b). However, deep tracks were formed when tested under $300 \mathrm{mN}$ and $400 \mathrm{mN}$, indicating change in the deformation mechanism. This is in agreement with the trends in the coefficient of friction as a function of applied load.

When tested on the PC1 and PC2, relatively small amount of surface wear was found when compared to the SC1 and SC2. Furthermore, when tested under different magnitude of applied load, no crown-like structure was found on the PC1 and PC2, indicates that different wear mechanisms were involved. 

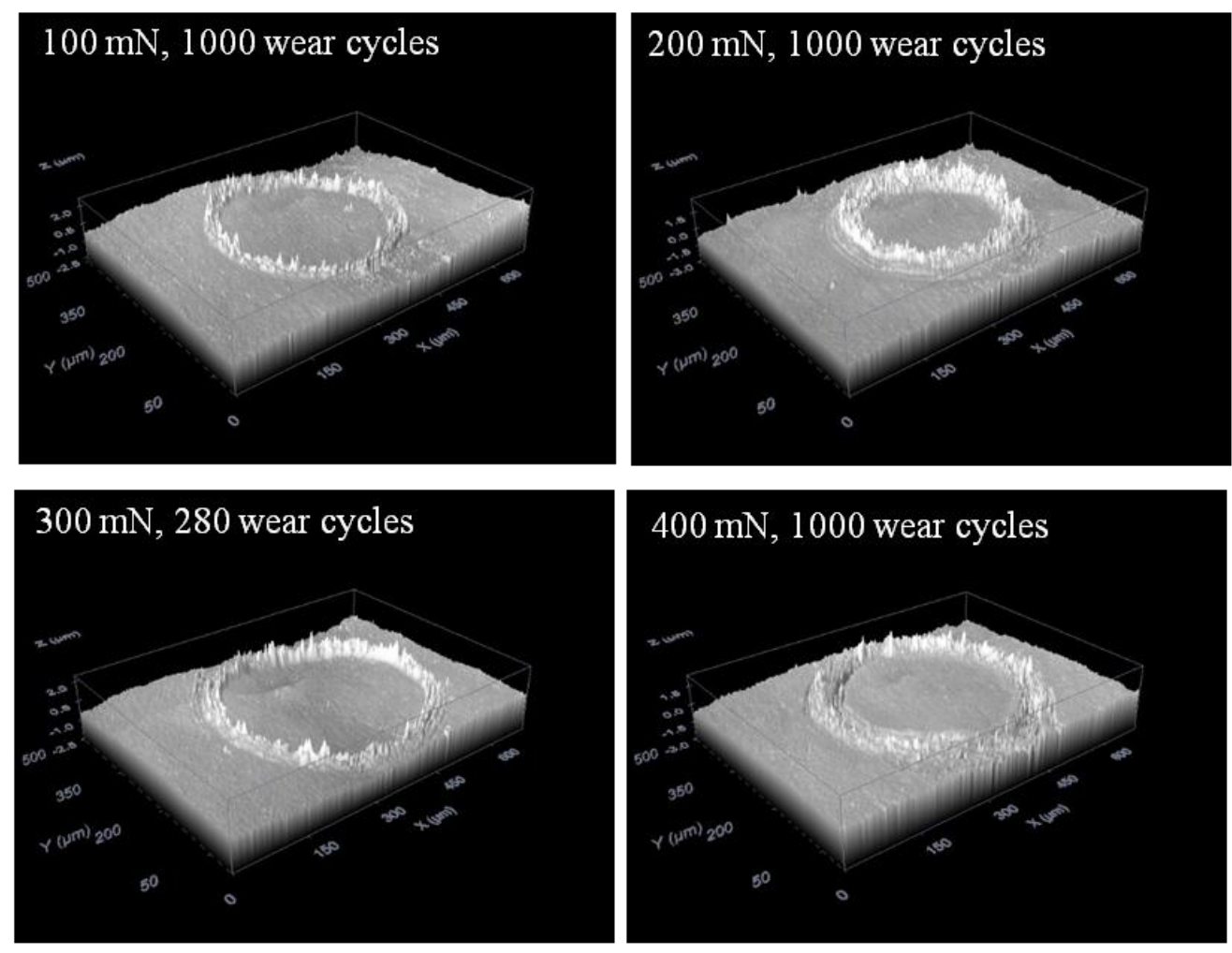

Figure 7-3a: 3D confocal microscopic images of worn surfaces on sample SC1, with wear conditions indicated in each image.
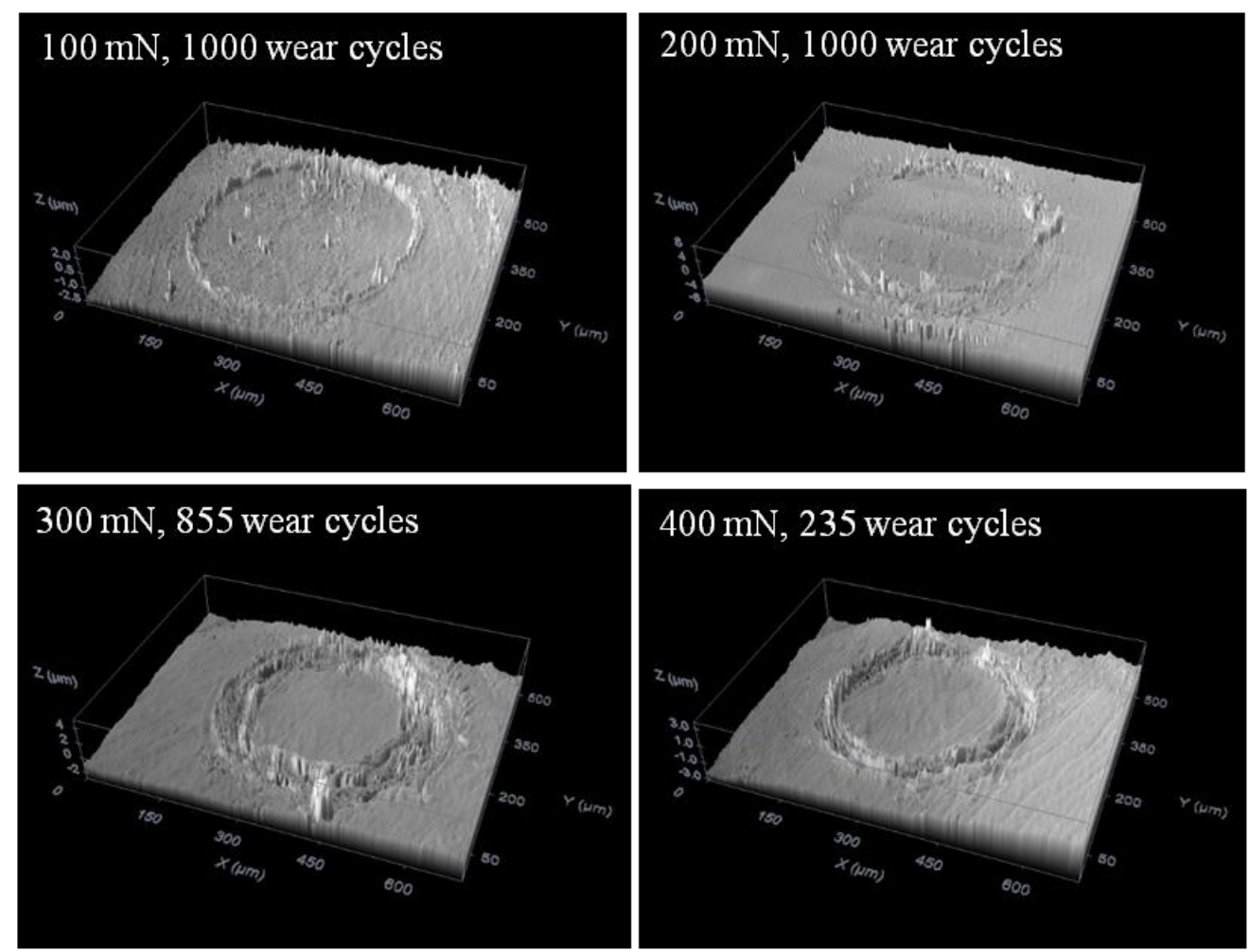

Figure 7-3b: 3D confocal microscopic images of worn surfaces on sample SC2, with wear conditions indicated in each image. 

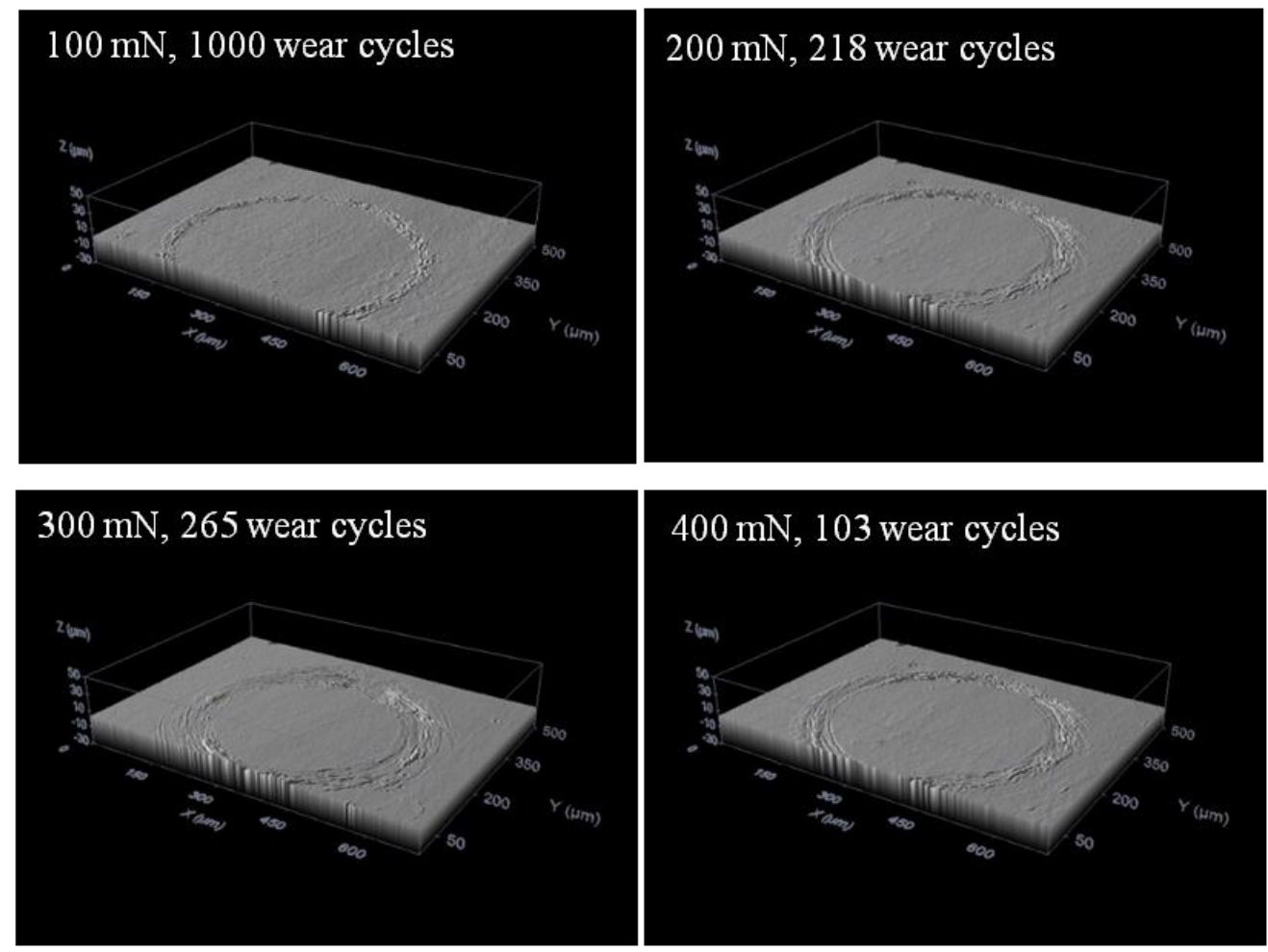

Figure 7-3c: 3D confocal microscopic images of worn surfaces on sample PC1, with wear conditions indicated in each image.
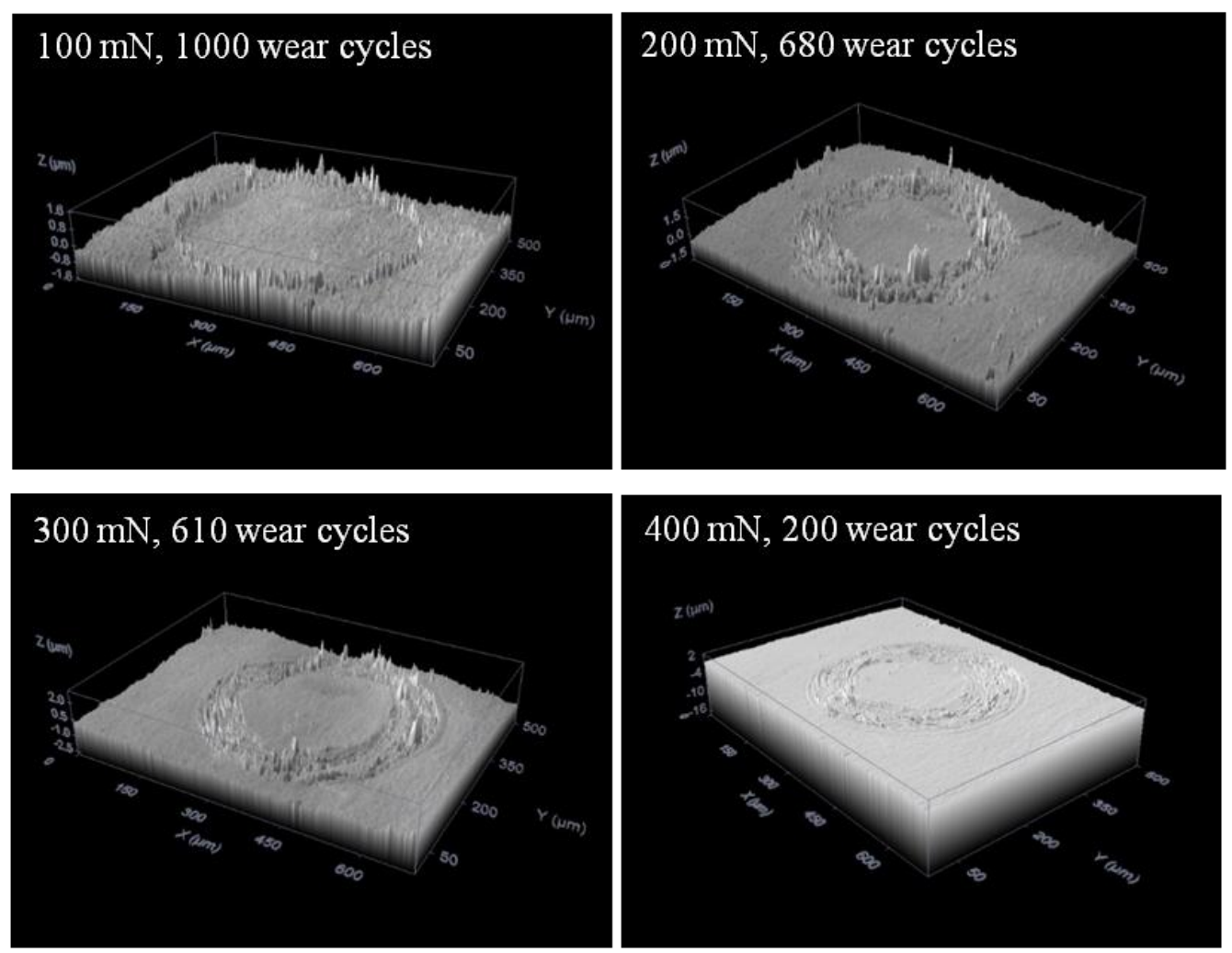

Figure 7-3d: 3D confocal microscopic images of worn surfaces on sample PC2, with wear conditions indicated in each image. 
The detailed surface wear features were further studied using SEM. Fig. 4 showed high magnification SEM images of damaged area when tested under 100 mN, 200 $\mathrm{mN}$ and $300 \mathrm{mN}$ on the $\mathrm{SC} 1$. When under $100 \mathrm{mN}$, no clear surface charging occurred. The track area showed a slightly different color from nearby surface; while the center of track was in a darker color, which represents more surface damage. When under $200 \mathrm{mN}$ and $300 \mathrm{mN}$, significant charging areas were found. The higher the applied load, the larger the surface area that was charged up. The large debris, which has been partially separated from the surface, likely contributed to the charging area on the track region.

The high magnification SEM images show that, the crown-like structure observed on the confocal microscopic images consisted of plastically deformed tracks when under low load $(100 \mathrm{mN})$. Furthermore, insignificant surface crack/ debris were formed. When deep tracks that cut into the surface appeared on the confocal microscopic image, a large number of debris was formed in the track region. When under $200 \mathrm{mN}$ and $300 \mathrm{mN}$, the large asperities originated from wear flakes, which were partially removed from the surface. Furthermore, a small number of debris was removed from the track area, which was present in the nearby region as shown in Fig. 7-4c. This indicates the start of the three-body abrasive wear stage.

To quantitatively analyze the surface wear, the wear volume was estimated by plotting the cross-section profile on each track shown in the confocal microscopic images (Fig. 7-5). Detailed calculation method was illustrated in Section 3.3.2.

When tested under $50 \mathrm{mN}$ and $100 \mathrm{mN}$, the wear volumes on the SC1 and SC2 were identical, suggesting that a similar deformation mechanism was involved in the wear process. However, in the test performed under $200 \mathrm{mN}$ and higher forces, higher wear volume was observed on the SC2 than SC1, mostly likely due to a greater number of wear cycles employed in the tests. 
In addition, the PC1 exhibited a higher wear volume than the PC2, even though the latter was subjected to a greater number of wear cycles. This is likely related to the residual strain being released in the pre-heating process in $\mathrm{PC} 1$. The results also revealed that, the estimated wear volume in SC samples was higher than that noted in the PC samples. This finding is consistent with the values in the coefficient of friction.

(a)
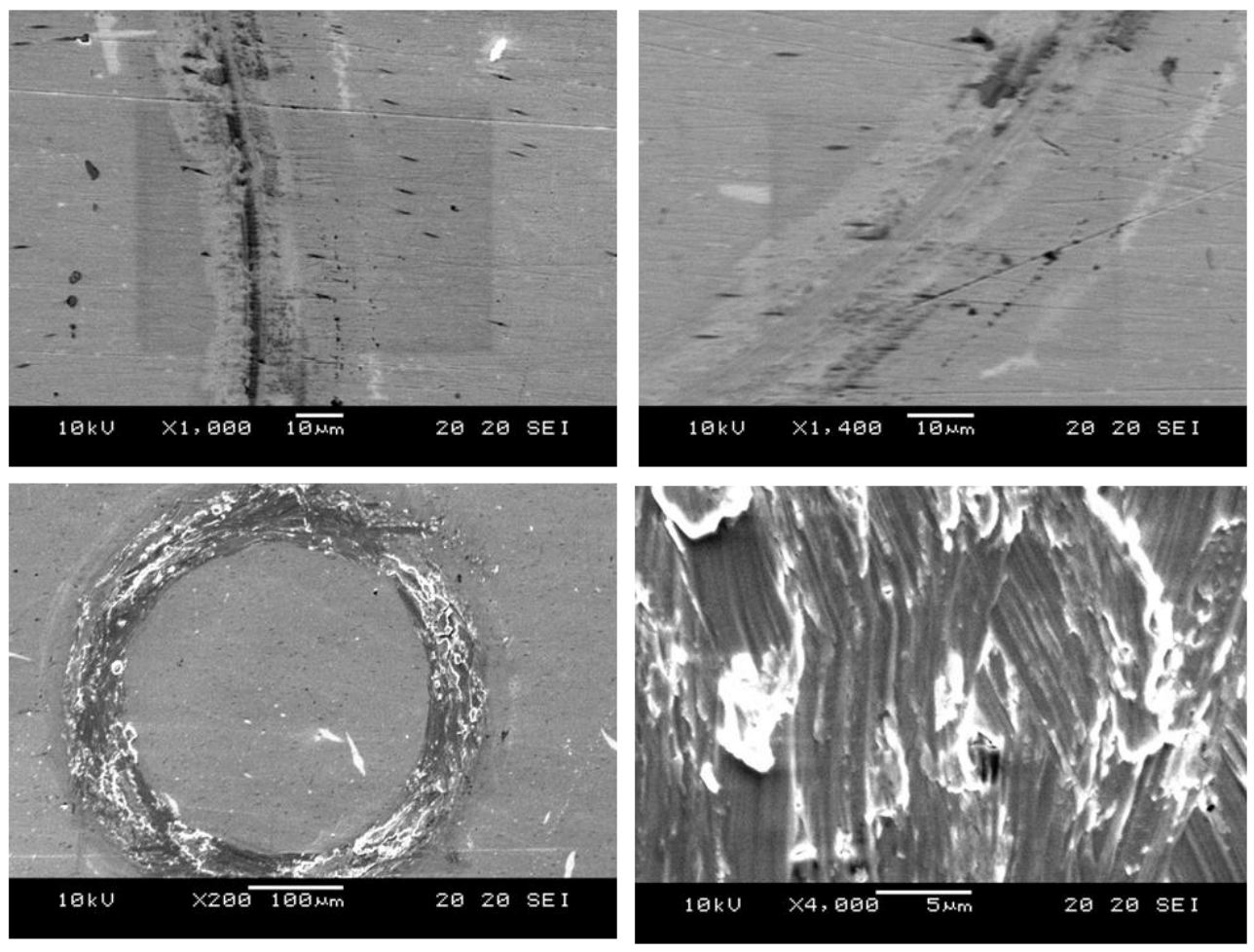

(b)
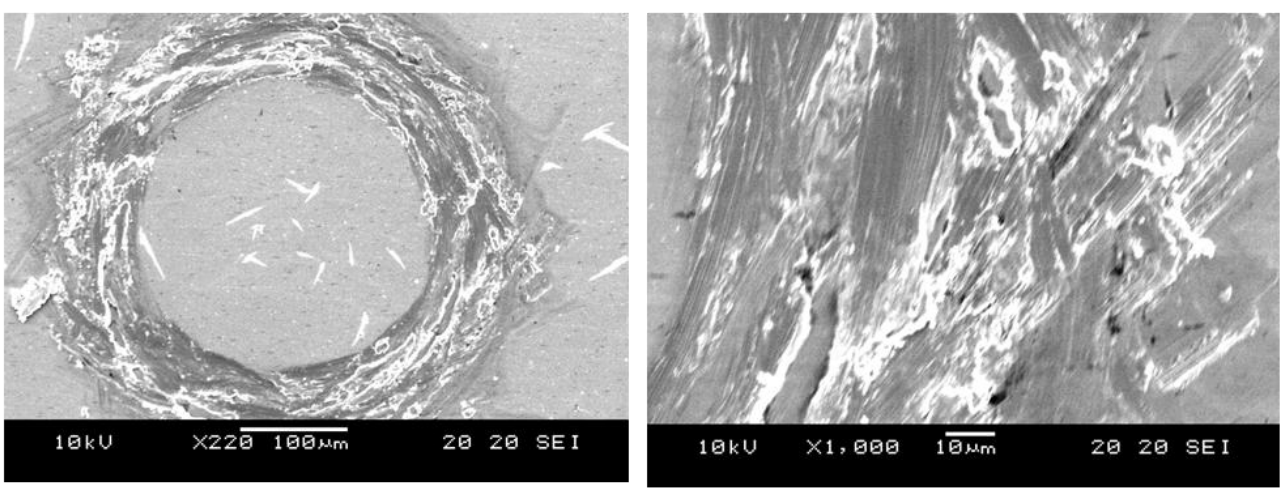

Figure 7-4: The SEM image of the wear features on the surface of SC1, (a) when tested under $100 \mathrm{mN}$ after 1000 cycles; (b) when tested under $200 \mathrm{mN}$ after 1000 cycles; (c) when tested under $300 \mathrm{mN}$ after 280 cycles. 


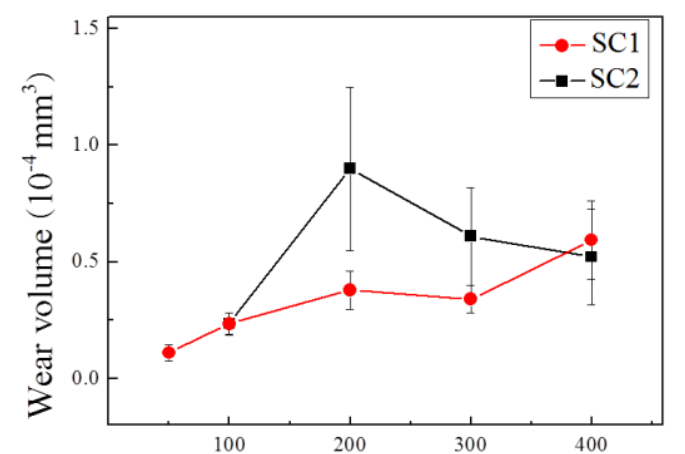

(a)

$$
\text { Applied load (mN) }
$$

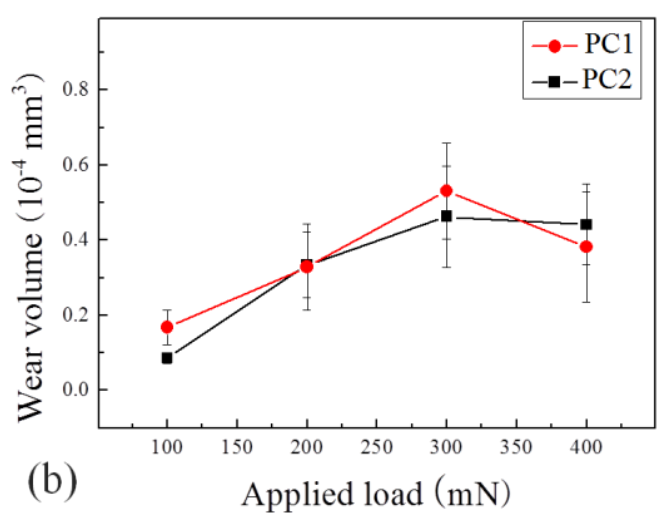

Figure 7-5: The estimated wear volume as a function of applied load, (a) for the SC samples and, (b) for the PC samples.

A comparison of the wear behaviour of the SC and PC samples revealed different trends in both coefficient of friction and surface wear features. This result suggests that, different deformation mechanisms were likely involved in the wear process, which are associated with different plastic strain accumulation processes.

\subsection{Discussion}

\subsubsection{Deformation mechanisms}

When the martensitic phase coexisted with the austenitic phase, the deformation mechanism is likely different from that of stable martensitic or austenitic phase dominated samples. When tested at $M_{\mathrm{f}}<T<A_{\mathrm{f}}$, the martensitic phase follows the deformation sequences of: elastic deformation of martensite; detwinning; elastic deformation of detwinned martensite, and plastic deformation of detwinned martensite. The detwinning process is partially reversible in this temperature regime, leading to slightly improved strain accommodation ability. Nevertheless, in this temperature regime, the austenitic phase deforms in the sequences of: elastic deformation of austenite; stress-induced martensitic transformation (SIMT); elastic deformation of stress induced martensite and plastic deformation of stress induced 
martensite. The SIMT process is partially reversible, therefore the strain accommodation ability is slightly degraded as compared with that at $T>A_{\mathrm{f}}$. Therefore, when at $M_{\mathrm{f}}<T<A_{\mathrm{f}}$, the plastic strain accumulation process associated with deformation strain accommodation through the detwinning/ SIMT process will be different from samples that are fully dominated by martensitic or austenitic phases.

When the contact stress is below the yield stress of detwinned/ stress-induced martensite, detwinning or SIMT occurs in the samples that are dominated by martensite or austenite phases. Due to the special temperature regime, strain accommodation in the detwinning process was enhanced, while it was degraded in the SIMT process. When tested under low load, similar wear behaviour was observed in the samples that are dominated by martensite and austenite phase. This further supports the similar plastic strain accumulation process. For example, when tested on the single crystal NiTi SMA, the samples were dominated by the martensitic phase (SC1) and austenitic phase (SC2). Tests conducted under 100 $\mathrm{mN}$ and $200 \mathrm{mN}$ revealed similar incremental trends in the coefficient of friction as a function of wear cycles (Fig. 7-2); while the estimated surface wear volumes remained unchanged (Fig. 7-3).

On the other hand, tests performed under $100 \mathrm{mN}$ on PC1 and PC2 revealed similar wear behaviour. This finding further suggests that similar plastic strain accumulation process was involved when $M_{\mathrm{f}}<T<A_{\mathrm{f}}$, although the samples were dominated by different phases. On the other hand, wear processes on pre-heated samples were slightly more stable than those of pre-cooled samples. This was attributed to residual strain being released in the pre-heating process.

As the applied load further increases, the contact stress exceeds the yield stress of detwinned/ stress-induced martensite. For example, when tested under 300 and 400 $\mathrm{mN}$, plastic deformation dominates the wear process, which results in a similar 
wear behaviour as shown in Fig. 7-2 and 7-3.

By controlling the presence of martensite/ austenite phase in the NiTi SMA samples through pre-cooling and pre-heating processes, different deformation mechanisms were involved in the wear process. However, similar wear behaviour was observed, suggests similar plastic strain accumulation process in samples dominated by different phases. Therefore, the wear behaviour of NiTi SMA is strongly temperature-dependent, and pre-heating or pre-cooling process has no significant effect on the wear process. Furthermore, the release of residual strain in the pre-heating process can improve the stability of the wear process.

In addition, the observations in the coefficient of friction and surface wear features revealed markedly different trends when tested on the SC and PC samples, which can be attributed to the dislocation motion mechanisms.

\subsubsection{Wear mechanisms}

In this work, the wear behaviour of the single crystal NiTi SMA having large grain size was compared to the polycrystal NiTi SMA obtained via cold rolling process. Samples with significantly different surface properties were chosen to illustrate the effect of grain size on the wear behaviour.

\section{(1) Single crystal NiTi SMA}

When a single crystal is deformed under a tensile stress, plastic deformation occurs through slip of well-defined parallel crystal planes. A particular set of crystallographic planes along which slip occurs are known as slip planes, and the combination of slip plane and slip direction comprises a slip system. Slip occurs by dislocation motion. The yield stress of a material is equivalent to the contact stress 
required for dislocation motion $\left(\tau_{\mathrm{R}}\right)$, and can be represented by the Schmid's law [64]:

$$
\tau_{R}=\frac{\text { resolved force acting on slip plane }}{\text { area of slip plane }}=\frac{F \cos \lambda}{A / \cos \phi}=\sigma \cos \phi \cos \lambda
$$

Here, $\varphi$ is the angle between the normal vector of slip plane (n) and loading direction; $\lambda$ is the angle between the slip plane (S) and loading direction, as shown in Fig. 7-9 below; and the $\sigma$ is the normal stress. The product $(\cos \varphi \cos \lambda)$ is known as the Schmid Factor (M).

Experimental measurements revealed that, at room temperature, the dislocation motion through the crystal lattice is the main source of plastic deformation [171]. Moreover, dislocations move along fixed crystal planes in fixed crystallographic directions corresponding to the Burgers vector.

For the single crystal NiTi, defects such as vacancies, dislocations and inclusions are insignificant relative to those in polycrystalline NiTi. Therefore, the energy barrier for dislocation generation can be estimated based on the knowledge of bond breaking strength [153]. A slip system will start exhibiting yield when the shear stress applied on this system first reaches a critical value, which is independent of the tensile stress or any other normal stress exerted on the lattice plane [172].

Furthermore, due to the nearly perfect single crystal, only a small amount of grain boundary is present. In the wear process, marked changes in the dislocation position has likely caused significant plastic strain accumulation [153]. 


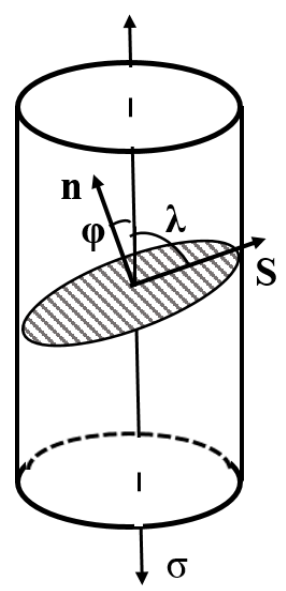

Figure 7-6: The slip plane and slip direction in a single crystal material.

It is known that, dislocations are easily introduced by thermal cycling, which is associated with the martensitic and reversed transformation process [173]. Furthermore, for single crystal NiTi SMA, dislocations move easily at low stress at about $150 \mathrm{MPa}$ [38]. This phenomenon explains the early dislocation generation which has caused large number of asperities on the single crystal NiTi SMA surface (Fig. 7-3).

The wear of single crystal samples has proceeded in the sequence of: (1) formation of crown-like structure associated with surface asperities; (2) growth of asperities and tracks; and (3) formation of debris (Figure 7-3). A clear trend of growing surface asperities was observed by increasing the applied load and wear cycles, which was originated from dislocation/ plastic strain accumulation in the repeated wear cycles. The increasing trend in the coefficient of friction has further supported the plastic strain accumulation process. Furthermore, the low dislocation density on the single crystal sample surface has favored plastic strain accumulation. In addition, in the detwinning or SIMT process, sharp twin boundary or phase boundary can be formed; and continued loading results in changing of strains in the region separated by those boundaries [171]. This results in higher free energy in boundary regions thus the reversed transformation process may be pinned. 
According to our previous study [174], larger amount of deformation strain can be accommodated through the SIMT process than the detwinning process, which results in better wear resistance of austenitic phase (Chapter 6). However, when tested on the single crystal NiTi at $M_{\mathrm{f}}<T<A_{\mathrm{f}}$, the wear process on the austenitic samples (SC2) was slightly more stable than the martensitic samples (SC1). This was attributed to the strong temperature-dependence of the deformation mechanism of NiTi SMA.

\section{(2) Polycrystal NiTi SMA}

On a polycrystal NiTi SMA, deformation on only one slip system is not possible, because various grains have to be compatible. Polycrystal is inherently inhomogeneous, thus the crystal orientation varies from grain to grain. Slip occurs in the well-defined crystallographic planes within each grain, but more than one slip plane is possible. In different grains, slip planes have different orientations because of the random nature of crystal orientations. Dislocations tend to pile-up at grain boundaries, thus forming asperities or even cracks. A schematic illustration of the dislocation motion plane is shown in Fig. 7-10 below.

Since plastic deformation of a single grain is restrained by its neighbouring grains, polycrystal materials will have intrinsically greater resistance to dislocation motion than the single crystal. This is the basis of the strain hardening mechanism.

The surface degradation process of the polycrystal NiTi (PC) was different from that of the single crystal NiTi (SC). No clear trace of crown-like structure was observed. Insignificant formation of surface damage was found when tested under $100 \mathrm{mN}$, while the coefficient of friction remained at around 0.15 for up to 1000 wear cycles. However, when the load was increased to $200 \mathrm{mN}$ and above, all the wear process started with low coefficient of friction (around 0.1); thereby the coefficient of friction became highly unstable within a short time period. No 
tendency of stable increase in the coefficient of friction was found, indicating sudden failure of surface. This type of wear behaviour can be understood by the dislocation mechanism. On the polycrystal NiTi surface, large number of dislocations exist, which were introduced by cold rolling process. Under low load of $100 \mathrm{mN}$, insignificant amount of plastic strain was accumulated, since the dislocation motion was strongly restricted by grain boundaries. By increasing the load, the initial coefficient of friction remained low since the surface was strain hardened in the cold rolling process. However, in repeated wear cycles, internal stress field can be developed through further dislocation generation. Therefore, once a critical number of dislocation was generated, cracks can be formed within a short period, causes severe damages.

In addition, results show that the pre-heated sample (PC2) remained stable for more wear cycles than the pre-cooled sample (PC1), although the wear process was similar. Furthermore, lower wear volume was found on the pre-heated samples than the pre-cooled samples. This was attributed to the effective releasing of the internal stress field in the pre-heating process.

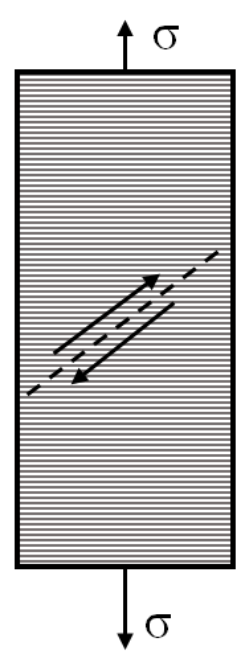

Single crystal

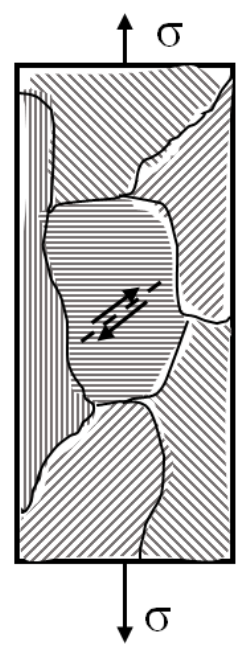

Polycrystalline

Figure 7-7: The schematic representation of dislocation motion in the single crystal and polycrystal materials. 


\subsubsection{Summary}

Different wear processes were observed when tested on the single crystal and polycrystal NiTi SMAs, which were attributed to the different plastic strain accumulation process. When tested on the single crystal NiTi, surface asperities was increased gradually by increasing the applied load and wear cycles. This originated from dislocation/ plastic strain accumulation. Nevertheless, when tested on the polycrystal $\mathrm{NiTi}$, under low load, the coefficient of friction remained low and an insignificant amount of asperities was formed. This was attributed to strain hardening due to significant amount of dislocation on the surface. Since the wear process was affected by the strain hardening mechanism, moderate amount of dislocation on the surface may enhance the wear resistance. 


\section{Conclusion}

Experiments on martensitic NiTi SMA have shown three clear surface degradation stages, namely, near-zero wear stage, transition wear stage and abrasive wear stage. In the near-zero wear stage, elastic deformation dominated the wear process. Insignificant wear occurred when tested under different conditions. In the transition wear stage, detwinning and elastic deformation of detwinned martensite dominated the wear process. Strain accommodation through the detwinning process has retarded further plastic strain accumulation. In the abrasive wear stage, severe wear occurred at the very beginning of the test, and plastic deformation has dominated the wear process.

When the austenitic phase dominated the surface, the wear resistance was found to be closely related to the stress-strain curve as a function of temperature. Two wear modes were identified, accordingly. Mode I is temperature-sensitive and occurred when $A_{\mathrm{f}}<T<M_{\mathrm{d}}$. In this mode, wear process was dominated by the interplay among contact stress, temperature and shape recovery property. Results show that, when the elastic deformation of austenite or stress-induced martensitic transformation dominated the wear process, the wear resistance was improved by increasing temperature. This was originated from increased critical stress for stress-induced martensitic transformation, which has retarded plastic deformation. However, when the contact stress is higher than the yield stress of stress-induced martensite, plastic deformation dominated the wear process, hence, the wear resistance was deteriorated. Mode II occurs when $T>M_{\mathrm{d}}$ and it is less temperature-sensitive within the testing range. In this mode, the austenitic NiTi lost its super-elasticity and obeyed a conventional deformation sequence, that is, elastic and plastic deformation. The wear resistance of austenitic NiTi SMA can be improved through metallurgical means and heat treatment by altering the transformation temperature. 
Furthermore, when the martensite coexisted with austenite phase, deformation mechanism was dependent on the percentage of each phase. When $T<M_{\mathrm{f}}$, with increasing wear cycles, the coefficient of friction had decreased quickly and thereafter stabilized at a lower value. More significant decrease was found when the temperature was near $A_{\mathrm{s}}$. Furthermore, when tested above $A_{\mathrm{f}}$, the coefficient of friction had decreased more significantly when under higher load. Difference in the trend of coefficient of friction at different temperature originated from the different deformation mechanism involved in the wear process, particularly, the martensite detwinning process, the stress-induced phase transformation process, and the plastic deformation of martensite/ austenite. Wear resistance of NiTi SMA was deteriorated when tested under extremely high load, which is associated with severe materials removal.

In addition, the surface wear process of single crystal NiTi SMA was compared with the polycrystal NiTi SMA. For the single crystal NiTi SMA, significant growth of asperities was observed with increasing applied load. It was attributed to the significant plastic strain accumulation process. For the polycrystal NiTi SMA, insignificant wear occurred under low load. However, by increasing the applied load, sudden change in the coefficient of friction led to high instability. This was originated from high dislocation density that caused strain hardening. With increased applied load, cracks were initiated which caused wear tracks and debris, thus the wear process became highly unstable. 


\section{Future work}

Although we have systematically revealed the deformation mechanisms involved in the wear process of NiTi SMAs, the following studies are important and should be performed in the future.

1. Effect of grain size on the wear behaviour of NiTi SMAs.

The surface degradation process of NiTi SMA is closely related to the grain size, which is further associated with martensite variants reorientation process in each grain. The grain size of NiTi SMA can be modified through cold working or annealing, which may affect the degradation process.

2. Systematic estimation of contact stress involved in the wear process of NiTi SMAs.

Due to the complex deformation mechanisms involved in the wear process of NiTi SMAs, the estimation of contact stress is extremely difficult. Through studying the wear behaviour of NiTi SMA with a series of counter-ball possessing different radius and hardness, the corresponding contact stress can be systematically estimated. This can provide further guideline in applications of NiTi SMAs. 


\section{References}

1. Otsuka, K. and Wayman, C.M., Shape Memory Materials. 1998, UK: Cambridge University Press.

2. Otsuka, K. and Ren, X., Recent developments in the research of shape memory alloys. Intermetallics, 1999. 7(5): p. 511-528.

3. Gandhi, M.V. and Thompson, B.S., Smart Materials and Structures. 1992, New York: Chapman \& Hall.

4. Miyazaki, S., Fukutsuji, S., and Taira, M., Application of Ti-Ni Shape Memory Alloys to Partial Dentures. Proceedings of the International Conference on Martensitic Transformations (Icomat-92), 1993: p. 1235-1240.

5. El Feninat, F., et al., Shape memory materials for biomedical applications. Advanced Engineering Materials, 2002. 4(3): p. 91.

6. Miyazaki, S., Medical and dental applications of shape memory alloys, ed. Otsuka K, W.C. 1998, Cambridge: Cambridge University Press.

7. Michiardi, A., et al., The influence of surface energy on competitive protein adsorption on oxidized NiTi surfaces. Biomaterials, 2007. 28(4): p. 586-594.

8. Pandit, H., et al., Pseudotumours associated with metal-onmetal hip resurfacings. Journal of Bone and Joint Surgery-British Volume, 2008. 90B(7): p. 847-851.

9. Michiardi, A., et al., New oxidation treatment of NiTi shape memory alloys to obtain Ni-free surfaces and to improve biocompatibility. Journal of Biomedical Materials Research Part B, 2005. 77: p. 43.

10. Geetha, M., et al., Ti based biomaterials, the ultimate choice for orthopaedic implants - A review. Progress in Materials Science, 2009. 54(3): p. 397-425.

11. Pan, Q. and Cho, C., The investigation of a shape memory alloy micro-damper for MEMS applications. Sensors, 2007. 7(9): p. 1887-1900. 
12. Qian, L.M., Sun, Q.P., and Zhou, Z.R., The role of martensite reorientation in the fretting behaviour of nickel titanium shape memory alloy. Proceedings of the Institution of Mechanical Engineers Part J-Journal of Engineering Tribology, 2008. 222(J7): p. 887-897.

13. Liang, Y.N., et al., Wear behavior of a TiNi alloy. Wear, 1996. 198(1-2): p. 236-241.

14. Li, D.Y., Wear behaviour of TiNi shape memory alloys. Scripta Materialia, 1996. 34(2): p. 195-200.

15. Clayton, P., Tribological Behavior of a Titanium Nickel-Alloy. Wear, 1993. 162: p. 202-210.

16. Gialanella, S., Ischia, G., and Straffelini, G., Phase composition and wear behavior of NiTi alloys. Journal of Materials Science, 2008. 43(5): p. 1701-1710.

17. Liu, R., et al., Indentation behavior of pseudoelastic TiNi alloy. Scripta Materialia, 1999. 41(7): p. 691-696.

18. Abedini, M., Ghasemi, H.M., and Ahmadabadi, M.N., Tribological behavior of NiTi alloy in martensitic and austenitic states. Materials \& Design, 2009. 30(10): p. 4493-4497.

19. Li, D.Y., Exploration of TiNi shape memory alloy for potential application in a new area: tribological engineering. Smart Materials \& Structures, 2000. 9(5): p. 717-726.

20. Otsuka, K. and Shimize, K., Pseudoelasticity and shape memory effects in alloys. International Materials Review, 1986. 31: p. 21.

21. Ortin, J. and Planes, A., Thermodynamics of Thermoelastic Martensitic Transformations. Acta Metallurgica, 1989. 37(5): p. 1433-1441.

22. Ölander, A., An electrochemical investigation of solid cadmium-gold alloys. Journal of the American Chemical Society, 1932. 54(10): p. 3819-3833.

23. Chang, L.C. and Read, T.A., Plastic deformation and diffusionless phase changes in metals-The gold-cadmium beta-phase. Transactions of the 
American Institute of Mining and Metallurgical Engineers, 1951. 191(1): p. 47-52.

24. Buehler, W.J., Gilfrich, J.V., and Wiley, R.C., Effect of low-temperature phase changes on the mechanical properties of alloys near composition TiNi. Journal of applied physics, 1963. 34(5): p. 1475-1477.

25. Liu, Y., et al., Some aspects of the properties of NiTi shape memory alloy. Journal of Alloys and Compounds, 1997. 247(1): p. 115-121.

26. San Juan, J., Nó, M.L., and Schuh, C.A., Nanoscale shape-memory alloys for ultrahigh mechanical damping. Nature Nanotechnology, 2009. 4(7): p. 415-419.

27. Hartl, D.J. and Lagoudas, D.C., Aerospace applications of shape memory alloys. Proceedings of the Institution of Mechanical Engineers, Part G: Journal of Aerospace Engineering, 2007. 221(4): p. 535-552.

28. Willey, C.E., Huettl, B., and Hill, S.W. Design and development of a miniature mechanisms tool-kit for micro spacecraft. in 35 th Aerospace Mechanisms Symposium. 2001.

29. Liu, C., Foundations of MEMS. 2006: Pearson Education India.

30. Porter, D.A., Easterling, K.E., and Sherif, M., Phase Transformations in Metals and Alloys, (Revised Reprint). 2009: CRC press.

31. Gilbert, A. and Owen, W., Diffusionless transformation in iron-nickel, iron-chromium and iron-silicon alloys. Acta Metallurgica, 1962. 10(1): p. $45-54$

32. Zerwekh, R. and Wayman, C., On the nature of the $\alpha \rightarrow \gamma$ transformation in iron: A study of whiskers. Acta Metallurgica, 1965. 13(2): p. 99-107.

33. DeHoff, R., Thermodynamics in materials science. 2006: CRC Press.

34. Olson, G. and Cohen, M., Stress-assisted isothermal martensitic transformation: application to TRIP steels. Metallurgical Transactions A, 1982. 13(11): p. 1907-1914.

35. Salzbrenner, R.J. and Cohen, M., On the thermodynamics of thermoelastic 
martensitic transformations. Acta Metallurgica, 1979. 27(5): p. 739-748.

36. Shaw, J.A. and Kyriakides, S., Thermomechanical aspects of NiTi. Journal of the Mechanics and Physics of Solids, 1995. 43(8): p. 1243-1281.

37. Meyrick, G. and Powell, G.W., Phase transformations in metals and alloys. Annual Review of Materials Science, 1973. 3(1): p. 327-362.

38. Takei, F., et al., Stress-induced martensitic transformation in a Ti-Ni single crystal. Scripta metallurgica, 1983. 17(8): p. 987-992.

39. Miyazaki, S., Otsuka, K., and Suzuki, Y., Transformation pseudoelasticity and deformation behavior in a Ti-50.6 at\% Ni alloy. Scripta Metallurgica, 1981. 15(3): p. 287-292.

40. Zheng, Q.S. and Liu, Y., Prediction of the detwinning anisotropy in textured NiTi shape memory alloy. Philosophical Magazine A, 2002. 82(4): p. 665-683.

41. Liu, Y., Li, Y.L., and Ramesh, K.T., Rate dependence of deformation mechanisms in a shape memory alloy. Philosophical Magazine a-Physics of Condensed Matter Structure Defects and Mechanical Properties, 2002. 82(12): p. 2461-2473.

42. Miyazaki, S., Otsuka, K., and Wayman, C., The shape memory mechanism associated with the martensitic transformation in $\mathrm{Ti} N \mathrm{Ni}$ alloys-I. Self-accommodation. Acta Metallurgica, 1989. 37(7): p. 1873-1884.

43. Miyazaki, S., Otsuka, K., and Wayman, C., The shape memory mechanism associated with the martensitic transformation in $\mathrm{Ti} \quad \mathrm{Ni}$ alloys-II. Variant coalescence and shape recovery. Acta Metallurgica, 1989. 37(7): p. 1885-1890.

44. Knowles, K. and Smith, D., The crystallography of the martensitic transformation in equiatomic nickel-titanium. Acta Metallurgica, 1981. 29(1): p. 101-110.

45. Miyazaki, S., et al., Shape memory effect and pseudoelasticity in a $\mathrm{Ti} \quad \mathrm{Ni}$ single crystal. Scripta metallurgica, 1983. 17(9): p. 1057-1062. 
46. Perkins, J. and Hodgson, D., The two-way shape memory effect. Engineering aspects of shape memory alloys, 1989: p. 195-206.

47. Contardo, L. and Guenin, G., Training and two way memory effect in $\mathrm{Cu}$ Zn Al alloy. Acta Metallurgica et Materialia, 1990. 38(7): p. 1267-1272.

48. Miller, D.A. and Lagoudas, D.C., Thermomechanical characterization of NiTiCu and NiTi SMA actuators: influence of plastic strains. Smart Materials and Structures, 2000. 9(5): p. 640.

49. Liu, Y.N., Liu, Y., and Van Humbeeck, J., Two-way shape memory effect developed by martensite deformation in NiTi. Acta materialia, 1998. 47(1): p. 199-209.

50. Zhang, Y., Cheng, Y.-T., and Grummon, D.S., Two-way indent depth recovery in a NiTi shape memory alloy. Applied Physics Letters, 2006. 88(13): p. 131904.

51. Van Humbeeck, J. and Stalmans, R., Shape memory alloys, types and functionalities. Encyclopedia of Smart Materials, 2002.

52. Miyazaki, S. and Otsuka, K., Deformation and transition behavior associated with theR-phase in Ti-Ni alloys. Metallurgical Transactions A, 1986. 17(1): p. 53-63.

53. Lexcellent, C., et al., Deformation behaviour associated with the stress-induced martensitic transformation in Ti-Ni thin films and their thermodynamical modelling. Thin Solid Films, 1998. 324(1): p. 184-189.

54. Miyazaki, S., et al, Characteristics of deformation and transformation pseudoelasticity in Ti-Ni alloys. Journal de Physique, 1982. 43(C4): p. 6.

55. Van Humbeeck, J., Non-medical applications of shape memory alloys. Materials Science and Engineering: A, 1999. 273: p. 134-148.

56. Yin, Y., et al. Fretting behavior of NiTi shape memory alloy against long bone in the imitated human physiological solution. in International Conference on Smart Materials and Nanotechnology in Engineering. 2007. International Society for Optics and Photonics. 
57. Perkins, J., Shape memory effects in alloys. 1975: Plenum Publishing Corporation.

58. $\mathrm{Hu}, \mathrm{T}$., et al., Corrosion behavior on orthopedic NiTi alloy with nanocrystalline/amorphous surface. Materials Chemistry and Physics, 2011. 126(1-2): p. 102-107.

59. Chen, K.C. NiTi-Magic or Phase Transformation? in Proceedings of the ASEE Annual Conference \& Exposition: Nashville, TN. 2003.

60. Schetky, L.M., Shape-Memory Alloys. Kirk-Othmer Encyclopedia of Chemical Technology, 1982.

61. Melton, K.N. and Mercier, O., The mechanical properties of NiTi-based shape memory alloys. Acta Metallurgica, 1981. 29(2): p. 393-398.

62. Drennen, D.C., Jackson, C.M., and Wagner, H.J., DEVELOPMENT OF MELTING AND CASTING PROCEDURES FOR NITINOL NICKEL-BASE ALLOYS. 1968, Battelle Memorial Inst., Columbus, Ohio.

63. Hanlon, J.E., Butler, S.R., and Wasilewski, R.J., Effect of martensitic transformation on the electrical and magnetic properties of NiTi. AIME MET SOC TRANS, 1967. 239(9): p. 1323-1326.

64. Buehler, W.J. and Wang, F.E., A summary of recent research on the Nitinol alloys and their potential application in ocean engineering. Ocean Engineering, 1968. 1(1): p. 105-120.

65. Wang, F.E., Buehler, W.J., and Pickart, S.J., Crystal Structure and a Unique "Martensitic"Transition of TiNi. Journal of Applied Physics, 1965. 36(10): p. 3232-3239.

66. Eckelmeyer, K.H., The effect of alloying on the shape memory phenomenon in nitinol. Scripta Metallurgica, 1976. 10(8): p. 667-672.

67. Frenzel, J., et al., Influence of Ni on martensitic phase transformations in NiTi shape memory alloys. Acta Materialia, 2010. 58(9): p. 3444-3458.

68. Duerig, T.W., Melton, K.N., and Stöckel, D., Engineering aspects of shape memory alloys. 2013: Butterworth-Heinemann. 
69. Bührer, W., Zolliker, M., and Gotthardt, R., Crystal structures of the shape memory alloy NiTi: Comments on recent publications in Acta metall. mater. Scripta metallurgica et materialia, 1992. 26(7): p. 1149-1151.

70. Buhrer, W., et al., Powder neutron diffraction study of nickel-titanium martensite. Journal of Physics F: Metal Physics, 1983. 13(5): p. L77.

71. Miyazaki, S. and Wayman, C., The R-phase transition and associated shape memory mechanism in Ti-Ni single crystals. Acta metallurgica, 1988. 36(1): p. 181-192.

72. Hara, T., et al., Structural study of R-phase in Ti-50.23 at.\% Ni and Ti-47.75 at.\% Ni-1.50 at.\% Fe alloys. Materials Transactions, JIM, 1997. 38(1): p. 11-17.

73. Miyazaki, S., et al., The habit plane and transformation strains associated with the martensitic transformation in Ti-Ni single crystals. Scripta metallurgica, 1984. 18(9): p. 883-888.

74. Miller, D.A. and Lagoudas, D.C., Influence of cold work and heat treatment on the shape memory effect and plastic strain development of NiTi. Materials Science and Engineering: A, 2001. 308(1): p. 161-175.

75. Frick, C.P., et al., Thermal processing of polycrystalline NiTi shape memory alloys. Materials Science and Engineering: A, 2005. 405(1): p. 34-49.

76. Nishida, M., Wayman, C.M., and Honma, T., Precipitation processes in near-equiatomic TiNi shape memory alloys. Metallurgical Transactions A, 1986. 17(9): p. 1505-1515.

77. Pelton, A.R., Dicello, J., and Miyazaki, S., Optimisation of processing and properties of medical grade Nitinol wire. Minimally Invasive Therapy \& Allied Technologies, 2000. 9(2): p. 107-118.

78. Treppmann, D. and Hornbogen, E., The effect of dislocation substructure and decomposition on the course of diffusionless transformations. Le Journal de Physique IV, 1995. 5(C2): p. C2-211-C2-216.

79. Gall, K., et al., Instrumented micro-indentation of NiTi shape-memory 
alloys. Acta Materialia, 2001. 49(16): p. 3205-3217.

80. Motemani, Y., et al., Effect of cooling rate on the phase transformation behavior and mechanical properties of Ni-rich NiTi shape memory alloy. Journal of Alloys and Compounds, 2009. 469(1-2): p. 164-168.

81. He, Y.J. and Sun, Q.P., On non-monotonic rate dependence of stress hysteresis of superelastic shape memory alloy bars. International Journal of Solids and Structures, 2011. 48(11): p. 1688-1695.

82. Liu, Y., et al., Asymmetry of stress-strain curves under tension and compression for NiTi shape memory alloys. Acta Materialia, 1998. 46(12): p. $4325-4338$.

83. Xie, Z.L., Liu, Y., and Van Humbeeck, J., Microstructure of NiTi shape memory alloy due to tension-compression cyclic deformation. Acta Materialia, 1998. 46(6): p. 1989-2000.

84. Liu, Y., et al., Effect of texture orientation on the martensite deformation of NiTi shape memory alloy sheet. Acta materialia, 1999. 47(2): p. 645-660.

85. Gao, S. and Yi, S., Experimental study on the anisotropic behavior of textured NiTi pseudoelastic shape memory alloys. Materials Science and Engineering: A, 2003. 362(1): p. 107-111.

86. Totten, G.E. and Liang, H., Mechanical tribology: materials, characterization, and applications. 2004: CRC Press.

87. Jialing, J., Wear resistance of Ni-Ti alloy. Acta Metall Sin, 2009. 24(1): p. 66-70.

88. Liu, R. and Li, D.Y., A finite element model study on wear resistance of pseudoelastic TiNi alloy. Materials Science and Engineering: A, 2000. 277(1): p. 169-175.

89. Arnell, R.D., et al., Tribology: principles and design applications. New York, Springer-Verlag, 1991, 266 p., 1991. 1.

90. Yan, W.Y., Theoretical investigation of wear-resistance mechanism of superelastic shape memory alloy NiTi. Materials Science and Engineering: 

A, 2006. 427(1-2): p. 348-355.

91. Hibbeler, R.C., Engineering mechanics. 2001: Pearson education.

92. Bhushan, B., Introduction to tribology. 2013: John Wiley \& Sons.

93. Merwin, J.E. and Johnson, K.L., An analysis of plastic deformation in rolling contact. Proceedings of the Institution of Mechanical Engineers, 1963. 177(1): p. 676-690.

94. François, D., Pineau, A., and Zaoui, A., Mechanical Behaviour of Materials, Vol II: Viscoplasticity, Damage, Fracture and Contact Mechanics. 1998.

95. Marukawa, K., Dislocation motion in copper single crystals. Journal of the Physical Society of Japan, 1967. 22(2): p. 499-510.

96. Stachowiak, G.W., Wear: materials, mechanisms and practice. 2006: John Wiley \& Sons.

97. Hiratani, M., Zbib, H.M., and Khaleel, M.A., Modeling of thermally activated dislocation glide and plastic flow through local obstacles. international Journal of Plasticity, 2003. 19(9): p. 1271-1296.

98. Foreman, A.J.E. and Makin, M.J., Dislocation movement through random arrays of obstacles. Philosophical magazine, 1966. 14(131): p. 911-924.

99. Gall, K., et al., Tension-compression asymmetry of the stress-strain response in aged single crystal and polycrystalline NiTi. Acta Materialia, 1999. 47(4): p. 1203-1217.

100. Aifantis, E.C., The physics of plastic deformation. International Journal of Plasticity, 1987. 3(3): p. 211-247.

101. Suzuki, T., Yoshinaga, H., and Takeuchi, S., Dislocation dynamics and plasticity. 1991: Springer.

102. Standard terminology relating to wear and erosion, in Annual Book of Standards A. S. T. M. 03.02. 1987. p. 7.

103. Wang, Y. and Rodkiewicz, C.M., Temperature maps for pin-on-disk configuration in dry sliding. Tribology international, 1994. 27(4): p. 259-266. 
104. Archard, J.F., The temperature of rubbing surfaces. wear, 1959. 2(6): p. $438-455$.

105. Chuang, M.-H., et al., Microstructure and wear behavior of AlxCo1.5CrFeNi1.5Tiy high-entropy alloys. Acta Materialia, 2011. 59(16): p. 6308-6317.

106. Lin, C.X., et al., Analysis of wear resistance and its mechanism in an $\mathrm{Fe}-\mathrm{Mn}-\mathrm{Si}-\mathrm{Cr}-\mathrm{Ni}$ shape memory alloy. Materials Science and Engineering: A, 2006. 438-440: p. 804-807.

107. Weinert, K. and Petzoldt, V., Machining of NiTi based shape memory alloys. Materials Science and Engineering: A, 2004. 378(1): p. 180-184.

108. Kang, G., et al., Ratchetting deformation of super-elastic and shape-memory NiTi alloys. Mechanics of Materials, 2009. 41(2): p. 139-153.

109. Qian, L.M., Zhou, Z.R., and Sun, Q.P., The role of phase transition in the fretting behavior of NiTi shape memory alloy. Wear, 2005. 259(1-6): p. 309-318.

110. Yan, W.Y., et al., Analysis of spherical indentation of superelastic shape memory alloys. International Journal of Solids and Structures, 2007. 44(1): p. 1-17.

111. Li, D.Y. and Liu, R., The mechanism responsible for high wear resistance of pseudo-elastic TiNi alloy-a novel tribo-material. Wear, 1999. 225: p. 777-783.

112. Abedini, M., Ghasemi, H.M., and Ahmadabadi, M.N., Self-healing effect on worn surface of NiTi shape memory alloy. Materials Science and Technology, 2010. 26(3): p. 285-288.

113. Arciniegas, M., et al., Study of hardness and wear behaviour of NiTi shape memory alloys. Journal of Alloys and Compounds, 2008. 460(1-2): p. 213-219.

114. Qian, L.M., Sun, Q.P., and Xiao, X.D., Role of phase transition in the 
unusual microwear behavior of superelastic NiTi shape memory alloy. Wear, 2006. 260(4-5): p. 509-522.

115. Qian, L.M., Sun, Q.P., and Zhou, Z.R., Fretting wear behavior of superelastic nickel titanium shape memory alloy. Tribology Letters, 2005. 18(4): p. 463-475.

116. Feng, X.-Q., et al., Wearless scratch on NiTi shape memory alloy due to phase transformational shakedown. Applied Physics Letters, 2008. 92(12): p. 121909.

117. Imbeni, V., et al., Preliminary study of micro-scale abrasive wear of a NiTi shape memory alloy. Wear, 2003. 254(12): p. 1299-1306.

118. Ravikiran, A. and Jahanmir, S., Effect of contact pressure and load on wear of alumina. Wear, 2001. 251(1): p. 980-984.

119. Kapoor, A. and Johnson, K., Plastic ratchetting as a mechanism of erosive wear. Wear, 1995. 186: p. 86-91.

120. Qian, L.M., et al., Spherical indentation for determining the phase transition properties of shape memory alloys. Journal of Materials Research, 2009. 24(03): p. 1082-1086.

121. Feng, X.X. and Sun, Q.P., Shakedown analysis of shape memory alloy structures. International Journal of Plasticity, 2007. 23(2): p. 183-206.

122. Yan, W. and O'Dowd, N.P. A micromechanics investigation of sliding wear in coated components. in Proceedings of the Royal Society of London A: Mathematical, Physical and Engineering Sciences. 2000. The Royal Society.

123. Liu, R., et al., Indentation behavior of pseudoelastic TiNi alloy. Scripta Materialia, 1999. 41(7): p. 691-696.

124. Amini, A., He, Y.J., and Sun, Q.P., Loading rate dependency of maximum nanoindentation depth in nano-grained NiTi shape memory alloy. Materials Letters, 2011. 65(3): p. 464-466.

125. Amini, A., Yan, W.Y., and Sun, Q.P., Depth dependency of indentation 
hardness during solid-state phase transition of shape memory alloys. Applied physics letters, 2011.99(2): p. 021901.

126. Qian, L.m., et al., Anomalous relationship between hardness and wear properties of a superelastic nickel-titanium alloy. Applied Physics Letters, 2004. 84(7): p. 1076.

127. Huang, X., et al., Nanoindentation of NiTi shape memory thin films at elevated temperatures. International Journal of Smart and Nano Materials, 2011. 2(1): p. 39-49.

128. Shaw, G.A., et al., Shape memory effect in nanoindentation of nickel-titanium thin films. Applied Physics Letters, 2003. 83(2): p. 257.

129. Tillmann, W. and Momeni, S., Tribological performance of near equiatomic and Ti-rich NiTi shape memory alloy thin films. Acta Materialia, 2015. 92: p. 189-196.

130. Ng, K.L., et al., Wear Behavior of Niti Thin Film at Micro-Scale. International Journal of Modern Physics B, 2010. 24(01n02): p. 85-93.

131. Ni, W., Cheng, Y.-T., and Grummon, D.S., Wear resistant self-healing tribological surfaces by using hard coatings on NiTi shape memory alloys. Surface and Coatings Technology, 2006. 201(3-4): p. 1053-1057.

132. Cheng, Y. and Zheng, Y.F., Deposition of TiN coatings on shape memory NiTi alloy by plasma immersion ion implantation and deposition. Thin Solid Films, 2006. 515(4): p. 1358-1363.

133. Cheng, Y. and Zheng, Y.F., Effect of N2/Ar gas flow ratio on the deposition of TiN/Ti coatings on NiTi shape memory alloy by PIIID. Materials Letters, 2006. 60(17-18): p. 2243-2247.

134. Kumar, A., et al., Effect of crystallographic orientation of nanocrystalline TiN on structural, electrical and mechanical properties of TiN/NiTi thin films. Journal of Alloys and Compounds, 2009. 479(1-2): p. 166-172.

135. Zhang, Y., Cheng, Y.-T., and Grummom, D.S., Novel tribological systems using shape memory alloys and thin films. Surface and Coatings 
Technology, 2007. 202(4-7): p. 998-1002.

136. Wu, S.K., Lin, H.C., and Lee, C.Y., Gas nitriding of an equiatomic TiNi shape-memory alloy: Part I: Nitriding parameters and microstructure characterization. Surface and Coatings Technology, 1999. 113(1): p. 17-24.

137. Wu, S.K., Chu, C.L., and Lin, H.C., Ion nitriding of TiNi shape memory alloys I. Nitriding parameters and microstructure characterization. Surface and Coatings Technology, 1997. 92(3): p. 197-205.

138. Lin, H.C., et al., Wear characteristics of ion-nitrided Ti $50 \mathrm{Ni} 50$ shape memory alloys. Surface and Coatings Technology, 1997. 92(3): p. 178-189.

139. Tan, L., et al., Effects of oxygen ion implantation on wear behavior of NiTi shape memory alloy. Mechanics of Materials, 2005. 37(10): p. 1059-1068.

140. Levintant-Zayonts, N. and Kucharski, S., Surface characterization and wear behavior of ion implanted NiTi shape memory alloy. Vacuum, 2009. 83: p. S220-S223.

141. Swiatek, Z., et al., Creation of wear-resistant near-surface-layers with inhomogeneous structure on NiTi alloy by ion implantation technology. Physics Procedia, 2010. 10: p. 69-76.

142. Mändl, S., et al., Wear behaviour of NiTi shape memory alloy after oxygen-PIII treatment. Surface and Coatings Technology, 2006. 200(22-23): p. $6225-6229$.

143. Moine, P., Popoola, O., and Villain, J.P., Wear behaviour of N+ implanted NiTi alloys. Scripta metallurgica, 1986. 20(3): p. 305-310.

144. Ye, H.Z., et al., Development of a new wear-resistant material: TiC/TiNi composite. Scripta materialia, 1999. 41(10): p. 1039-1045.

145. Fernandez, J., et al., Wear and corrosion of metal-matrix (stainless steel or NiTi)-TiC coatings. Physics Procedia, 2010. 10: p. 77-80.

146. Sun, T., et al. Fabrication, Nanomechanical Properties and In Vitro Evaluation of (Ti, O)/Ti Composite Coating on NiTi Shape Memory Alloy. in 6th World Congress of Biomechanics (WCB 2010). August 1-6, 2010 
Singapore. 2010. Springer.

147. Sun, T., Wang, L.P., and Wang, M., $(T i, O) / T i$ and $(T i, O, N) / T i$ composite coatings fabricated via PIIID for the medical application of NiTi shape memory alloy. J Biomed Mater Res B Appl Biomater, 2011. 96(2): p. 249-60.

148. $\mathrm{Hu}, \mathrm{T}$., et al., Wear resistance of NiTi alloy after surface mechanical attrition treatment. Surface and Coatings Technology, 2010. 205(2): p. 506-510.

149. Firstov, G.S., et al., Surface oxidation of NiTi shape memory alloy. Biomaterials, 2002. 23(24): p. 4863-4871.

150. Liu, Y., et al., On the deformation of the twinned domain in NiTi shape memory alloys. Philosophical Magazine A, 2000. 80(8): p. 1935-1953.

151. Johnson, K.L., Contact mechanics. 1985, Cambridge: Cambridge university press.

152. Otsuka, K. and Ren, X., Physical metallurgy of Ti-Ni-based shape memory alloys. Progress in materials science, 2005. 50(5): p. 511-678.

153. Brinson, L.C., Schmidt, I., and Lammering, R., Micro and macromechanical investigations of CuAlNi single crystal and CuAlMnZn polycrystalline shape memory alloys. Journal of intelligent material systems and structures, 2002. 13(12): p. 761-772.

154. Hattori, S. and Tainaka, A., Cavitation erosion of Ti-Ni base shape memory alloys. Wear, 2007. 262(1-2): p. 191-197.

155. Tan, G. and Liu, Y., Comparative study of deformation-induced martensite stabilisation via martensite reorientation and stress-induced martensitic transformation in NiTi. Intermetallics, 2004. 12(4): p. 373-381.

156. Liu, Y., Tan, G., and Miyazaki, S., Deformation-induced martensite stabilisation in [100] single-crystalline $\mathrm{Ni}-\mathrm{Ti}$. Materials Science and Engineering: A, 2006. 438: p. 612-616.

157. Piao, M., et al., Mechanism of the A s temperature increase by 
pre-deformation in thermoelastic alloys. Materials Transactions, JIM, 1993. 34(10): p. 919-929.

158. Liu, Y., Mechanistic simulation of deformation-induced martensite stabilisation. Materials Science and Engineering: A, 2004. 378(1): p. 459-464.

159. Yan, L., Liu, Y., and Liu, E.J., Wear behaviour of martensitic NiTi shape memory alloy under ball-on-disk sliding tests. Tribology International, 2013. 66: p. 219-224.

160. Plietsch, R. and Ehrlich, K., Strength differential effect in pseudoelastic NiTi shape memory alloys. Acta Materialia, 1997. 45(6): p. 2417-2424.

161. McKelvey, A.L. and Ritchie, R.O., On the temperature dependence of the superelastic strength and the prediction of the theoretical uniaxial transformation strain in Nitinol. Philosophical Magazine a-Physics of Condensed Matter Structure Defects and Mechanical Properties, 2000. 80(8): p. 1759-1768.

162. Liu, Y.N. and Yang, H., Strain dependence of the Clausius-Clapeyron relation for thermoelastic martensitic transformations in NiTi. Smart Materials \& Structures, 2007. 16(1): p. S22-S27.

163. Bhushan, B., Introduction to tribology. 2010, USA: John wiley \& sons.

164. Orgeas, L. and Favier, D., Stress-induced martensitic transformation of a NiTi alloy in isothermal shear, tension and compression. Acta Materialia, 1998. 46(15): p. 5579-5591.

165. Rebelo, N., Gong, X.Y., and Connally, M., Finite element analysis of nitinol's plastic behaviour. Proceedings of the International Conference on Shape Memory and Superelastic Technologies SPIE, 2003: p. 6.

166. Wood, A.J.M. and Clyne, T.W., Measurement and modelling of the nanoindentation response of shape memory alloys. Acta Materialia, 2006. 54(20): p. 5607-5615.

167. Liu, Y. and Favier, D., Stabilisation of martensite due to shear deformation 
via variant reorientation in polycrystalline NiTi. Acta materialia, 2000. 48(13): p. 3489-3499.

168. Brinson, L.C., Schmidt, I., and Lammering, R., Stress-induced transformation behavior of a polycrystalline NiTi shape memory alloy: micro and macromechanical investigations via in situ optical microscopy. Journal of the Mechanics and Physics of Solids, 2004. 52(7): p. 1549-1571.

169. Lin, H., et al., The effects of cold rolling on the martensitic transformation of an equiatomic TiNi alloy. Acta metallurgica et materialia, 1991. 39(9): p. 2069-2080.

170. Lin, H. and Wu, S., Determination of heat of transformation in a cold-rolled martensitic TiNi alloy. Metallurgical Transactions A, 1993. 24(2): p. 293-299.

171. Vainchtein, A. and Rosakis, P., Hysteresis and stick-slip motion of phase boundaries in dynamic models of phase transitions. Journal of nonlinear science, 1999. 9(6): p. 697-719.

172. Schmid, E. and Boas, W., Plasticity of crystals. 1950.

173. Miyazaki, S., Igo, Y., and Otsuka, K., Effect of thermal cycling on the transformation temperatures of Ti Ni alloys. Acta Metallurgica, 1986. 34(10): p. 2045-2051.

174. Yan, L. and Liu, Y., Effect of temperature on the wear behavior of NiTi shape memory alloy. Journal of Materials Research, 2014: p. 1-11. 